MURILO ZUBIOLI MIELLI

\title{
SENSOR DE VAZÃO PARA APLICAÇÃO EM SISTEMAS MICROFLUÍDICOS
}

Dissertação apresentada à Escola Politécnica da Universidade de São Paulo para obtenção do título de Mestre em Engenharia 
MURILO ZUBIOLI MIELLI

\section{SENSOR DE VAZÃO PARA APLICAÇÃO EM SISTEMAS MICROFLUÍDICOS}

Dissertação apresentada à Escola Politécnica da Universidade de São Paulo para obtenção do título de Mestre em Engenharia

Área de Concentração:

Engenharia Elétrica - Microeletrônica

Orientador:

Prof. Dr. Marcelo Nelson Páez Carreño 
Este exemplar foi revisado e alterado em relação à versão original, sob responsabilidade única do autor e com a anuência de seu orientador.

São Paulo, de setembro de 2012.

Assinatura do autor

Assinatura do orientador

FICHA CATALOGRÁFICA

Mielli, Murilo Zubioli

Sensor de vazão para aplicação em sistemas microfluídicos /

M.Z. Mielli. -- ed.rev. -- São Paulo, 2012.

$191 \mathrm{p}$.

Dissertação (Mestrado) - Escola Politécnica da Universidade de São Paulo. Departamento de Engenharia de Sistemas Eletrônicos.

1. Sensor de vazão 2. Fabricação (Microeletrônicos) 3. Sistemas microeletrônicos I. Universidade de São Paulo. Escola Politécnica. Departamento de Engenharia de Sistemas Eletronicos II. t. 


\section{AGRADECIMENTOS}

Ao Prof. Dr. Marcelo Nelson Páez Carreño, meu orientador e amigo, por todo o apoio e toda a confiança depositada em mim durante este e outros trabalhos.

Aos meus pais, Hélio de Carvalho Mielli e Sebastiana Aparecida Zubioli Mielli, e também a minha irmã Paula Zubioli Mielli por todo carinho e apoio dados não só durante este trabalho mas em toda a minha vida.

Aos colegas do Grupo de Novos Materiais e Dispositivos, pela convivência sempre prazerosa e pelas inúmeras contribuições para este trabalho.

Aos técnicos da Sala Limpa, em especial à Rita e à Tereza, sem os quais esse trabalho não poderia ter sido realizado.

Aos amigos Fernando Gonçalves de Almeida Neto, Wilder Bezerra Lopes e Amanda Souza de Paula, pelo apoio e por todos os momentos de discussão e descontração que fizeram parte do meu dia-a-dia durante a execução deste trabalho.

Aos amigos Thiago Kurimori Garcia da Silveira, Rafael Peciauskas, Henrique Ferrarese, Yuri Felipe Pasqualin, Karen Yuri Akamini e Camila Soares de Sousa por todo incentivo e anos de amizade.

Ao Laboratório de Sistemas Integráveis pelas imagens de microscopia eletrônica de varredura.

À FAPESP e ao CNPq pelo suporte financeiro. 


\section{RESUMO}

Este trabalho apresenta o desenvolvimento de um sensor térmico de vazão integrado a um microcanal. Todo o ciclo de desenvolvimento é abordado: conceito, modelagem e simulação, fabricação e caracterização. O sensor é composto por um filamento de níquel fabricado sobre uma lâmina de vidro que é soldada a um bloco de polidimetilsiloxano (PDMS) contendo microcanais. A aferição da vazão no interior do microcanal é feita indiretamente através da medida da troca de calor entre o filamento e o fluido. As simulações por elementos finitos mostraram que o sensor apresenta três faixas de operação, sendo que em duas delas (fluxos menores do que $20 \mu \mathrm{L} /$ min ou maiores do que $130 \mu \mathrm{L} / \mathrm{min}$ ) a resposta elétrica do sensor varia linearmente com a vazão. Diversos sensores foram fabricados seguindo o processo de fabricação proposto e alguns dispositivos foram caracterizados eletricamente, tendo sido levantadas as curvas da tensão elétrica sobre o filamento em função da vazão no microcanal. Os resultados experimentais mostraram que os sensores fabricados são capazes de medir vazões da ordem de dezenas de microlitros por minuto na faixa de operação de menor sensibilidade. Métodos de fabricação alternativos foram propostos com o intuito de aumentar a sensibilidade do sensor, produzindo filamentos auto-sustentados no interior dos microcanais. Foi proposto um modelo para simulação comportamental dos sensores otimizados por elementos concentrados e os resultados preliminares tanto de simulação quanto de fabricação desses sensores foram apresetandos.

Palavras-chave: Sensor de vazão, Microfluídica, MEMS. 


\begin{abstract}
This project presents the development of a thermal flow sensor integrated into a microchannel. The whole design cycle is discussed: concept, modeling and simulation, fabrication and characterization. The sensor consists of a nickel filament fabricated on a glass substrate which is bonded to a polydimethylsiloxane (PDMS) block containing the microchannels. The flow inside the microchannel is indirectly measured through the heat exchange between the filament and the fluid. Finite methods analysis revealed that the sensor has three operating ranges and in two of them (flows below $20 \mu \mathrm{L} / \mathrm{min}$ or higher than $130 \mu \mathrm{L} / \mathrm{min}$ ) the electric response of the sensor varies linearly with respect to the flow. Several flow sensors were fabricated according to the fabrication method presented in this project and some of them were characterized electrically. The response of the voltage on the filament as a function of the flow inside the microchannel was obtained. The experimental results demonstrated that the flow sensors could measure flow rates as small as tens of microliters per minute even when working on the less sensitive operating range. Alternative fabrication methods were proposed in order to improve the sensor sensitivity, leaving the filaments self-sustained inside the microchannels. A lumped element model was introduced in order to simulate the behavior of the optimized flow sensors. Some preliminary results of these simulations and of the fabrication processes were presented.
\end{abstract}

Keywords: Flow sensor, Microfludics, MEMS. 


\section{LISTA DE ILUSTRAÇÕES}

Figura 1 - Desenho esquemático de um sensor de vazão térmico. .22

Figura 2 - Desenho esquemático de um sensor de vazão por diferença de pressão utilizando sensores de pressão capacitivos.

Figura 3 - Desenho esquemático de um sensor de vazão por transferência de força. .26

Figura 4 - Desenho esquemático de um sensor de vazão óptico. .28

Figura 5 - Representação das tensões mecânicas agindo na partícula fluida. 31

Figura 6 - Preparo do PDMS. 36

Figura 7 - Etapas do processo de fabricação dos microcanais em vidro: (a) sobre as lâminas de vidro Corning 7059, (b) é depositado um filme de cromo. (c) O filme passa por um processo de fotogravação e (d) é usado como material de mascaramento durante a corrosão das lâminas em solução da HF. Após a corrosão, (e) o filme de cromo é removido. (f) A lâmina de tampa passa ainda por uma etapa de furação. Por fim, (g) as lâminas são soldadas pela técnica de soldagem direta e os scalps são presos à estrutura 39

Figura 8 - Representação esquemática do sensor de vazão térmico proposto. 40

Figura 9 - Desenho esquemático do dispositivo. (a) Vista em perspectiva; (b) Vista no corte $\mathrm{AA}^{\prime}$; (c) Vista no corte BB'.

Figura 10 - Imagens do software de simulação por elementos finitos utilizado para simulação do sensor proposto. (a,b) Domínio de simulação; (c,d) Malha de elementos finitos gerada pelo programa. 46

Figura 11 - Fotomáscara empregada na fabricação dos filamentos. .51

Figura 12 - Fotos da montagem experimental para realização da eletrodeposição. (a) Porta-amostras utilizado; (b) Montagem experimental. .52

Figura 13 - Etapas do processo de fabricação do sensor de vazão proposto. (a) Partindo de uma lâmina de vidro limpa, deposita-se (b) um filme de titânio e (c) outro de cobre por Sputtering. Em seguida é feita (d) a aplicação e (e) a fotogravação do fotorresiste com o padrão dos filamentos. Através das aberturas no fotorresiste é feita (f) a eletrodeposição do filme de níquel. (g) $\mathrm{O}$ fotorresiste então é removido, 
bem como os filmes (h) de cobre e (i) de titânio, obtendo-se assim a lâmina com os sensores fabricados.

Figura 14 - Fotomáscara empregada na fabricação dos microcanais em PDMS......58 Figura 15 - Processo de fabricação do microcanal na tampa de PDMS e soldagem no sensor de vazão.

Figura 16 - Curva normalizada da tensão x vazão obtida da simulação por elementos finitos para o sensor de vazão proposto com corrente de polarização de $20 \mathrm{~mA}$. ...62 Figura 17 - Curva diferença de tensão $x$ vazão obtida da simulação por elementos finitos para o sensor de vazão proposto com corrente de polarização de $20 \mathrm{~mA}$. ...64 Figura 18 - Campo de temperaturas no sensor de vazão proposto para corrente de polarização igual a $20 \mathrm{~mA}$. (a,b) Vazão igual a $10 \mu \mathrm{L} / \mathrm{min}$. (c,d) Vazão igual a 175 $\mu \mathrm{L} / \mathrm{min}$. .65

Figura 19 - Curvas isotermas na região do filamento para corrente de polarização igual a $20 \mathrm{~mA}$. (a) Vazão igual a $10 \mu \mathrm{L} / \mathrm{min}$; (b) Vazão igual a $175 \mu \mathrm{L} / \mathrm{min}$. Microcanal indicado em linha tracejada.

Figura 20 - Curva temperatura $x$ vazão obtida da simulação por elementos finitos para o sensor de vazão proposto com corrente de polarização de $20 \mathrm{~mA}$. (a) Temperatura máxima; (b) Temperatura média.

Figura 21 - Curvas da diferença de tensão $x$ vazão para quatro valores de corrente de polarização.

Figura 22 - Curvas da sensibilidade $x$ corrente de polarização para as duas regiões lineares da resposta do sensor: (a) Baixas vazões; (b) Altas vazões. 69 Figura 23 - Curvas da temperatura $x$ vazão para quatro valores de corrente de polarização. (a) Temperatura máxima; (b) Temperatura média. .71 Figura 24 - Curvas da temperatura máxima e temperatura média $x$ corrente de polarização para vazão igual a zero. .72

Figura 25 - Sensor de vazão proposto. (a) Visão geral do dispositivo; Detalhes dos filamentos nos microcanais com largura igual a (b) $600 \mu \mathrm{m}$, (c) $900 \mu \mathrm{m}$ e (d) $1,4 \mathrm{~mm}$. (e) Detalhe do filamento no formato de serpentina. Margens do microcanal indicadas em linha tracejada vermelha.

Figura 26 - Fotos da bomba de seringas montada no laboratório. (a) Suporte para seringas e atuadores; (b) Circuito eletrônico de interface com o computador. .76 Figura 27 - Montagem do dispositivo na placa de circuito impresso para garantir bom contato elétrico. 
Figura 28 - Fotos da montagem experimental. (a) Visão geral da montagem; (b) Detalhe do dispositivo medido; (c) Microscópio e a bomba de seringas empregada; (d) Multímetros e .78

Figura 29 - Curva da tensão $\mathrm{x}$ tempo para o sensor 1 para uma vazão de 180 $\mu \mathrm{L} / \mathrm{min}$.

Figura 30 - Curva da tensão $x$ tempo para o sensor 1 com corrente de polarização de $10 \mathrm{~mA}$ para quatro valores de vazão.

Figura 31 - Curvas da tensão $x$ tempo normalizadas em relação ao valor de tensão sem escoamento para quatro valores de vazão. (a) Sensor 1; (b) Sensor 2; (c) Sensor 3.

Figura 32 - Curvas da diferença de tensão x vazão obtidas da caracterização dos sensores.

Figura 33 - Curvas da diferença de tensão x vazão obtidas da simulação por elementos finitos dos três sensores. .85

Figura 34 - Desenho esquemático do dispositivo com filamento auto-sustentado. (a) Vista em perspectiva; (b) Vista no corte AA'; (c) Vista no corte BB' 90 Figura 35 - Imagens do software de simulação por elementos finitos utilizado para simulação do sensor otimizado. (a,b) Domínio de simulação; (c,d) Malha de elementos finitos gerada pelo programa. ..........................................................92

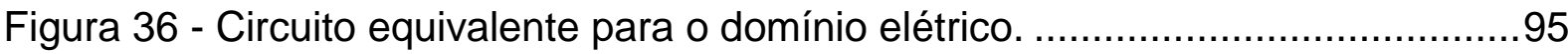
Figura 37 - Diagrama mostrando as resistências térmicas de condução consideradas.

Figura 38 - Diagrama ilustrando o modelo de condução do filamento e suas condições de contorno. 100

Figura 39 - Circuito equivalente do filamento. 101

Figura 40 - Escoamento ao redor de uma placa plana 103

Figura 41 - Circuito equivalente para o domínio térmico. 109

Figura 42 - Circuito equivalente para o domínio fluídico. 111

Figura 43 - Fotomáscara empregada na fabricação dos microcanais em vidro. .....114 Figura 44 - Processo de fabricação do sensor de vazão seguindo o método 1. .....118 Figura 45 - Fotomáscara empregada na corrosão de carbeto de silício para posterior corrosão dos microcanais em vidro 121

Figura 46 - Processo de fabricação do sensor de vazão segundo o método 2 . ......125 Figura 47 - Processo de fabricação do sensor de vazão segundo o método 3 
Figura 48 - Curva da diferença de tensão x vazão obtida da simulação por elementos finitos para o caso do filamento em contato com o substrato e auto-sustentado. ...133 Figura 49 - Curva da temperatura média x vazão obtida da simulação por elementos finitos para o caso do filamento em contato com o substrato e auto-sustentado. ...134 Figura 50 - Representação do sensor de vazão extraído da literatura (47) para validação do modelo a parâmetros concentrados. (a) Configuração do sensor \#2; (b) Configuração do sensor \#3; (c) Características construtivas das três configurações de sensor. 136

Figura 51 - Circuito equivalente utilizado para validação do modelo a parâmetros concentrados.

Figura 52 - Gráfico da diferença de temperatura $\Delta T$ em função da vazão $\phi$ referente à simulação para verificação do modelo a parâmetros concentrados. 140 Figura 53 - Gráfico da diferença de tensão $\Delta V$ em função da vazão $\phi$ referente à simulação para verificação do modelo a parâmetros concentrados. 140 Figura 54 - Circuito equivalente utilizado para determinar a resposta estática do sensor projetado.

Figura 55 - Gráfico da diferença de temperatura $\Delta T$ em função da vazão $\phi$ referente ao sensor projetado. 146

Figura 56 - Gráfico da diferença de tensão $\Delta V$ em função da vazão $\phi$ referente ao sensor projetado. 146

Figura 57 - Gráfico da diferença de temperatura $\Delta T$ em função da vazão $\phi$ referente ao sensor projetado polarizado para dissipar a mesma densidade de potência do sensor de referência do item 4.1.1. 148

Figura 58 - Gráfico da diferença de tensão $\Delta \mathrm{V}$ em função da vazão $\phi$ referente ao sensor projetado polarizado para dissipar a mesma densidade de potência do sensor de referência do item 4.1.1. 148

Figura 59 - Circuito equivalente utilizado para determinar a resposta dinâmica do sensor projetado.

Figura 60 - Resposta temporal da diferença de temperatura $\Delta T$ à aplicação de um pulso de vazão para o sensor projetado. 152

Figura 61 - Resposta temporal da diferença de tensão $\Delta V$ à aplicação de um pulso de vazão para o sensor projetado. 153

Figura 62 - Circuito equivalente utilizado para determinar a resposta dinâmica do sensor de referência. 
Figura 63 - Resposta temporal da diferença de temperatura $\Delta T$ à aplicação de um pulso de vazão para o sensor de referência. 155

Figura 64 - Resposta temporal da diferença de tensão $\Delta V$ à aplicação de um pulso de vazão para o sensor de referência. 155

Figura 65 - Desenho esquemático mostrando o procedimento usado para determinar a taxa de corrosão do vidro Corning 7059 em solução de HF 157 Figura 66 - Gráfico da espessura corroída em função do tempo para determinação da taxa de corrosão do vidro Corning 7059 em solução de HF. 158 Figura 67 - Lâmina de vidro Corning 7059 com microcanais fabricados em diferentes pontos da etapa de planarização do fotorresiste. (a) Microcanais preenchidos com fotorresiste antes da planarização; (b) Aspecto da lâmina após o lixamento; (c) Aspecto da lâmina após polimento final. 159

Figura 68 - Fotos dos filamentos tiradas com auxílio de um microscópio eletrônico de varredura. (a) Conjunto de filamentos sobre o microcanal de $500 \mu \mathrm{m}$; (b) Destaque do filamento de $100 \mu \mathrm{m}$ de largura; (c) Conjunto de filamentos com a forma de serpentina; (d) Destaque da estrutura de $100 \mu \mathrm{m}$ de largura. 160 Figura 69 - Detalhe da borda do microcanal, mostrando a continuidade do filamento. (a) Microcanal com largura de $500 \mu \mathrm{m}$; (b) Microcanal de $200 \mu \mathrm{m}$ sob o filamento no formato de serpentina. 162

Figura 70 - Fotos dos filamentos sobre o microcanal de $200 \mu \mathrm{m}$ tiradas com auxílio de um microscópio eletrônico de varredura. (a) Visão geral do microcanal; (b) Destaque do filamento de $100 \mu \mathrm{m}$ de largura; (c) Vista em perspectiva dos filamentos; (d) Detalhe do filamento de $200 \mu \mathrm{m}$ de largura na margem do microcanal.

Figura 71 - Fotos dos filamentos sobre o microcanal de $500 \mu \mathrm{m}$ de largura após o crescimento do filme de níquel. (a) Visão geral; (b) Detalhe da margem do microcanal para o filamento de $100 \mu \mathrm{m}$ de largura. 164 Figura 72 - Fotos de uma lâmina fabricada segundo o método 2 com tempo de corrosão de 15 minutos. (a) Visão geral das estruturas; Detalhes dos microcanais com largura de (b) $200 \mu \mathrm{m}$,

(c) $500 \mu \mathrm{m}$ e (d) $1 \mathrm{~mm}$ 165

Figura 73 - (a) Foto da lâmina obtida segundo o método 2, destacando alguns pontos negativos do processo de fabricação; (b) Representação das ondulações nos filmes de SiC. 
Figura 74 - Fotos dos filamentos fabricados sobre os microcanais de $200 \mu \mathrm{m}$ pelo método 2 tiradas com auxílio de um microscópio eletrônico de varredura. (a) Visão geral do microcanal; (b) Destaque do filamento de $100 \mu \mathrm{m}$ de largura; (c) Vista em perspectiva dos filamentos; (d) Detalhe dos filamentos vistos em perspectiva. ......168 Figura 75 - Fotos obtidas por microscópio óptico e eletrônico de varredura de uma lâmina fabricada segundo o método 2 com tempo de corrosão de 3 minutos. (a) Visão geral das estruturas; Detalhe do microcanal com largura de $500 \mu \mathrm{m}$ visto (b) no microscópio óptico e (c) no MEV; (d) Detalhe do microcanal de $200 \mu \mathrm{m}$ de largura. 169

Figura 76 - Representação esquemática do possível problema de cobertura de degrau do filme de a-SiC:H. (a) Vista em perspectiva; (b) Vista frontal. 170 Figura 77 - Fotos das estruturas em formato de serpentina fabricadas segundo o método 2.

(a) Lâmina da figura 72; (b) Lâmina da figura 75. 171 Figura 78 - Fotos de uma lâmina fabricada seguindo o método 3 após duas etapas distintas do processo de fabricação: (a) implantação iônica e (b) corrosão em solução de HF para formação dos microcanais. 172 Figura 79 - Fotos mostrando em detalhe as regiões dos filamentos nos microcanais com largura de (a) $200 \mu \mathrm{m}$, (b) $500 \mu \mathrm{m}$ e (c) $1 \mathrm{~mm}$. (d) Filamento de $200 \mu \mathrm{m}$ de largura no microcanal de $500 \mu \mathrm{m}$ de largura. 173 


\section{LISTA DE TABELAS}

Tabela 1 - Comparação entre os principais tipos de sensores de vazão. 29

Tabela 2 - Parâmetros do modelo de elementos finitos. 43

Tabela 3 - Condições para a deposição de titânio por Sputtering. 49

Tabela 4 - Condições para a deposição de cobre por Sputtering. .50

Tabela 5 - Formulação da solução para eletrodeposição de níquel. .52

Tabela 6 - Condições ótimas para a eletrodeposição de níquel. .53

Tabela 7 - Condições de processo para a soldagem por plasma. .59

Tabela 8 - Sensibilidade do sensor para quatro valores de corrente de polarização.

Tabela 9 - Temperatura máxima e média no filamento para quatro valores de corrente de polarização. .72

Tabela 10 - Principais características dos sensores testados. .79

Tabela 11 - Sensibilidade dos sensores testados na faixa de altas vazões $(\phi \gtrsim$ $130 \mu \mathrm{Lmin}$ ).

Tabela 12 - Sensibilidade dos sensores simulados por elementos finitos na faixa de altas vazões $(\phi \gtrsim 130 \mu$ Lmin $)$.... .85

Tabela 13 - Parâmetros do modelo de elementos finitos do sensor otimizado. 91

Tabela 14 - Parâmetros do modelo a elementos concentrados. .94

Tabela 15 - Condições para a deposição de cromo por Sputtering 114

Tabela 16 - Condições para a deposição de a-SiC:H por PECVD. 119

Tabela 17 - Condições de processo para corrosão dos filmes de a-SiC:H. 122

Tabela 18 - Condições para implantação iônica de $\mathrm{BF}_{2}{ }^{+}$

Tabela 19 - Parâmetros para validação do modelo a elementos concentrados.

Tabela 20 - Incremento de temperatura máximo e médio em relação à potência dissipada pelo filamento.

Tabela 21 - Valores dos números de Reynolds e Peclet em função da vazão.

Tabela 22 - Parâmetros de sensibilidade do sensor em função da potência dissipada pelo filamento.

Tabela 23 - Comparação entre os parâmetros de sensibilidade obtidos pela simulação e apresentados na referência 47. 
Tabela 24 - Parâmetros de sensibilidade do sensor projetado em função da potência

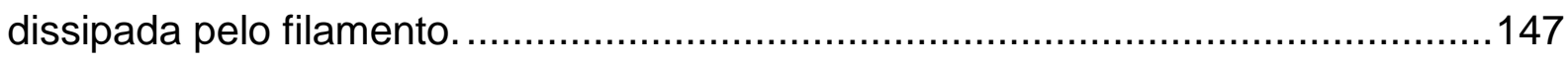
Tabela 25 - Parâmetros de sensibilidade do sensor projetado em função da potência

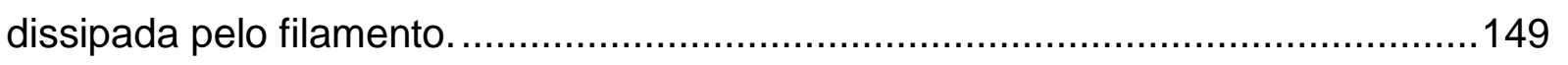
Tabela 26 - Incremento de temperatura máximo e médio em relação à potência dissipada pelo filamento para o sensor projetado. ...............................................150 


\section{SUMÁRIO}

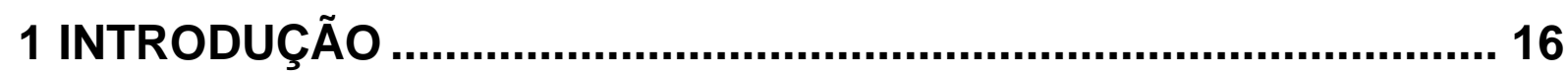

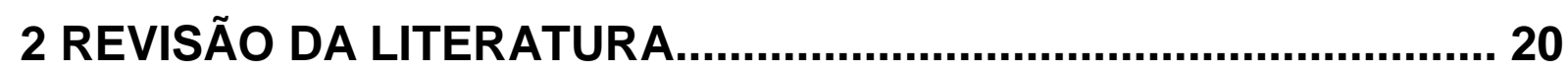

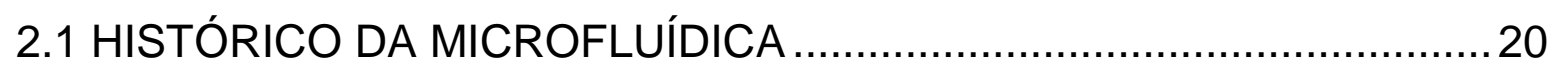

2.2 PRINCÍPIO DE FUNCIONAMENTO DOS SENSORES DE VAZÃO .....22

2.2.1 Sensor de vazão térmico ………………………………………….....22

2.2.2 Sensor de vazão por diferença de pressão ...........................................24

2.2.3 Sensor de vazão por transferência de força …………………………...26

2.2.4 Sensor de vazão óptico …………………………………………......27

2.3 EQUACIONAMENTO E MODELAGEM ...............................................29

2.4 PROCESSOS DE FABRICAÇÃO PARA MICROFLUÍDICA...................34

2.4.1 Microfabricação em PDMS ……………………………………….........

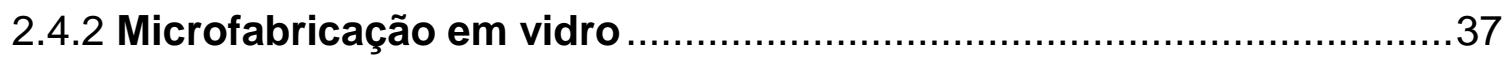

3 DESENVOLVIMENTO DO SENSOR DE VAZÃO ……..................... 40

3.1 DESCRIÇÃO DO SENSOR PROPOSTO …………………………....... 40

3.2 MODELO A ELEMENTOS FINITOS ………………………………..... 41

3.3 PROCESSO DE FABRICAÇÃO DO SENSOR PROPOSTO …..............47

3.3.1 Fabricação do filamento sobre o substrato de vidro ………...............49

3.3.2 Fabricação do microcanal na tampa de PDMS ……..........................56

4 RESULTADOS DO SENSOR DE VAZÃO ….................................. 62

4.1 SIMULAÇÕES POR ELEMENTOS FINITOS......................................... 62

4.2 FABRICAÇÃO DOS DISPOSITIVOS …………………………….......73

4.3 CARACTERIZAÇÃO ELÉTRICA DOS DISPOSITIVOS …………….....75

5 OTIMIZAÇÃO DO SENSOR DE VAZÃO PROPOSTO ……............... 87 


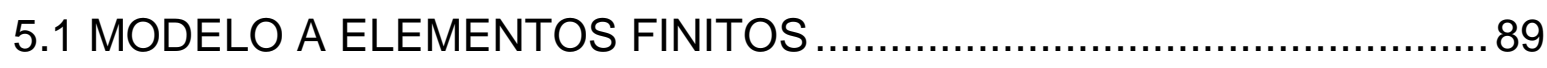

5.2 MODELO A ELEMENTOS CONCENTRADOS …...............................93

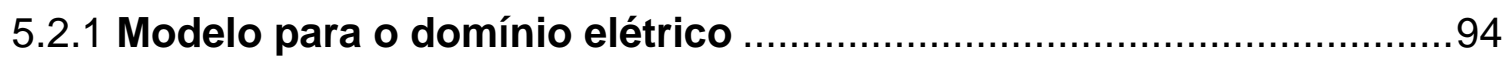

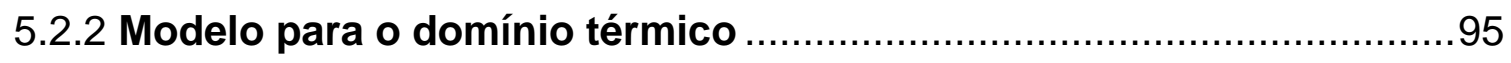

5.2.3 Modelo para o domínio fluídico ……………................................109

5.2.4 Observações quanto a melhoria do modelo apresentado.................111

5.3 PROCESSOS DE FABRICAÇÃO PARA OTIMIZAÇÃO DO SENSOR112

5.3.1 Método 1: Filamento fabricado sobre material sacrificial .................113

5.3.2 Método 2: Filamento encapsulado com carbeto de silício ................119

5.3.3 Método 3: Filamento de carbeto de silício dopado ...........................126

5.3.4 Fabricação do microcanal na tampa de PDMS ….............................132

6 RESULTADOS DO SENSOR DE VAZÃO OTIMIZADO .................. 133

6.1 SIMULAÇÃO POR ELEMENTOS FINITOS ......................................133

6.2 SIMULAÇÃO POR ELEMENTOS CONCENTRADOS ....................... 134

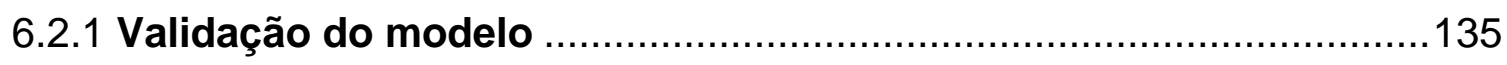

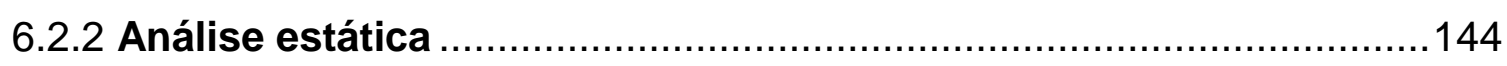

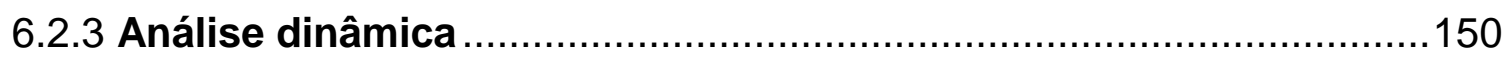

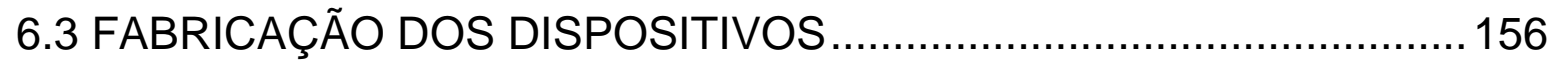

6.3.1 Determinação da taxa de corrosão dos microcanais.........................156

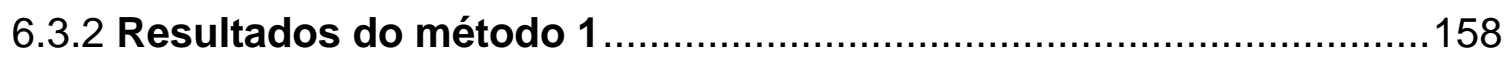

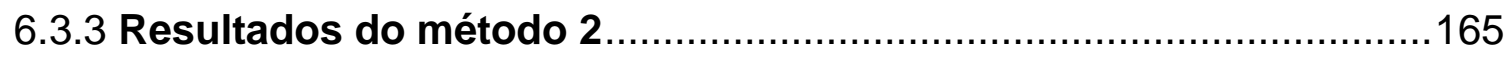

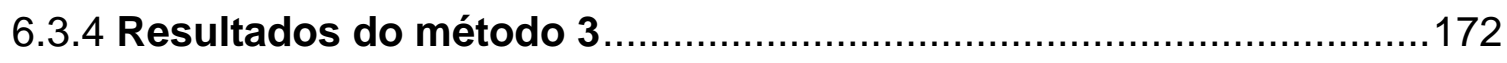

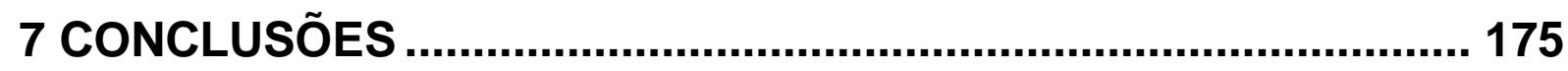

8 BIBLIOGRAFIA.......................................................................... 183

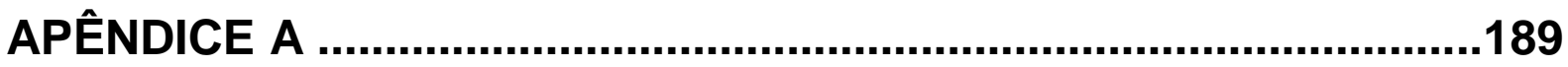




\section{INTRODUÇÃO}

Este trabalho tem como objetivo o desenvolvimento de um sensor térmico de vazão para aplicação em sistemas microfluídicos. Em particular será apresentada a modelagem, a fabricação e a caracterização de um sensor de vazão integrado a um microcanal. O sensor é composto basicamente por um filamento condutor de eletricidade que troca calor com o fluido que escoa pelo microcanal. A aferição da vazão no interior do microcanal é feita indiretamente através da medida da troca de calor entre o filamento e o fluido. Além do sensor proposto, serão apresentados três métodos de fabricação alternativos, com o objetivo de otimizar a resposta do sensor.

A microfluídica é a área do conhecimento que trata da manipulação de fluidos em escala microscópica, o que envolve a utilização de canais, reservatórios, válvulas, bombas e outras estruturas com dimensões da ordem de centenas de micrometros e portanto, volumes da ordem de nanolitros ou ainda menores (1).

Lidar com quantidades tão pequenas de fluidos é interessante por uma série de motivos. No contexto de aplicações químicas e biológicas, por exemplo, utilizar volumes diminutos em uma análise representa uma grande redução no consumo e no descarte de reagentes, o que é particularmente interessante quando se trabalha com compostos tóxicos ou de custo elevado. Além disso, muitas vezes o tempo de análise também é reduzido $(2,3)$.

Outro aspecto interessante é a redução do tamanho total do sistema. Sistemas microfluídicos podem implementar uma série de experimentos laboratoriais em um único biochip com dimensões de alguns centímetros. Isso acaba por conferir portabilidade aos sistemas, ou seja, as análises e processos não precisam necessariamente ficar restritos ao ambiente de laboratório, podendo ser realizados em campo, em sistemas portáteis. Outra vantagem é a autonomia que tais sistemas possuem já que geralmente consomem pouca energia e poucos reagentes $(4,5)$.

Um aspecto de grande interesse nos sistemas microfluídicos é a diferença no comportamento físico dos fluidos quando confinados em dimensões microscópicas. Por exemplo, em micro-escala o número de Reynolds, dado pela relação entre as 
forças inerciais e as forças viscosas, é muito pequeno, a ponto de ser menor do que o valor do número de Reynolds crítico $\left(R e<R e_{\text {crítico }}\right)$ para quase a totalidade dos escoamentos $(6,7,8)$. Isso significa que a grande maioria dos escoamentos em dispositivos microfluídicos é do tipo laminar, o que por um lado, permite uma grande simplificação no equacionamento dos escoamentos, mas por outro lado dificulta fenômenos como a mistura de dois ou mais fluidos, bastante evidente no mundo macroscópico. Além disso, sistemas microfluídicos apresentam estruturas com uma alta razão área/volume. De fato, microcanais e microreservatórios típicos possuem altura e largura da ordem de algumas dezenas de micrometros e comprimentos da ordem de milímetros e portanto, apresentam uma área relativamente grande comparada ao volume. O resultado disso é que pequenos volumes de líquidos ficam confinados em compartimentos com áreas relativamente grandes, o que tem grande influência em processos nos quais fenômenos superficiais têm um peso importante como fenômenos de troca de calor $(6,7,8)$. De fato, uma sub-área cada vez mais explorada dentro da microfluídica é a de trocadores de calor, com principal aplicação na eletrônica e na computação através do desenvolvimento de dissipadores de calor mais eficientes (9).

Forças de origem elétrica e magnética também são potencializadas na escala microscópica devido aos volumes reduzidos de fluidos. É possível encontrar, inclusive comercialmente $(10,11)$, bombas eletro-osmóticas que fazem uso de fenômenos elétricos para deslocar fluidos em microcanais. Também é bastante usual técnicas de separação de partículas por campo elétrico (como a eletroforese ou a dieletroforese) e a movimentação e separação utilizando campos magnéticos, dando origem a sub-áreas bastante novas como a eletrofluídica e a magnetofluídica, isso sem falar dos escoamentos em meios porosos $(7,8)$.

Em função do exposto, a microfluídica é uma área em franca expansão, que desperta grande interesse científico, tecnológico e comercial. Estima-se que até 2016 o mercado global de dispositivos microfluídicos deva movimentar 4 bilhões de dólares, com especial destaque para as aplicações em medicina e farmacologia $(12,13,14)$.

Nesse contexto, a microfluídica é uma área estratégica para o Brasil, não só como mercado consumidor (o mercado brasileiro representa $1 \%$ de todo o mercado global 
de artigos médicos e para diagnósticos (15)) mas também como desenvolvedor de novos produtos e tecnologias. De fato, um aspecto particularmente importante da microfluídica é que, contrariamente a outros setores da microeletrônica, como o dos chips de alto desempenho para processadores e memórias, ela não exige uma infraestrutura de ponta para ser desenvolvida. Isso acontece principalmente porque as microestruturas utilizadas em microfluídica possuem dimensões mínimas acima de $1 \mu \mathrm{m}$, podendo ser desenvolvidas e fabricadas em laboratórios e empresas com infra-estrutura mais modesta. Além disso, diversas técnicas de microfabricação têm sido propostas, algumas delas de baixo custo de produção $(16,17)$.

Por conta disso, a microfluídica no Brasil vem se desenvolvendo principalmente devido à iniciativa de grupos de pesquisas em universidades. Apesar de não muito numerosa, a comunidade brasileira em microfluídica é bastante ativa e vem desenvolvendo pesquisas de ponta $(16,17)$. Não por menos, em 2011 foi organizado o I Workshop de Microfluídica no Laboratório Nacional de Luz Síncroton (LNLS) (18), em Campinas, tendo atraído dezenas de pesquisadores. Devido ao enorme sucesso, a segunda edição do evento foi organizada no ano de 2012 (19).

Nesse cenário, o desenvolvimento de sensores e biossensores robustos, confiáveis e com pequeno tempo de resposta é uma tarefa essencial. Diversos princípios físicos podem ser explorados no funcionamento de um biosensor microfluídico, os quais podem envolver parâmetros e medidas ópticas, químicas, elétricas, etc., sendo estas últimas de grande interesse por apresentarem alta sensibilidade, baixo tempo de resposta e serem facilmente integráveis em microdispositivos, reduzindo seu tamanho final e dispensando a necessidade de transdução de sinais (de sinal óptico ou químico para elétrico). Por exemplo, no caso de sensores elétricos, a presença de um determinado composto (proteínas, íons etc.) em uma amostra de fluido ou até mesmo a vazão de fluído num microcanal, podem ser diretamente associados a uma variação de tensão, corrente ou impedância.

Entre as diversas aplicações de sensores, o controle da vazão é de particular importância, e algumas vezes crítico. Nos automóveis, por exemplo, sensores de vazão medem a quantidade de ar que entra no motor e a partir daí regulam a mistura entre ar e combustível. Em aparelhos médicos, como ventiladores pulmonares, a medida e o controle da vazão também são essências. Mais ainda, 
sistemas para controle do fluxo estão presentes na indústria, para o controle de processos em geral (20).

Dada a importância deste tipo de sensor, um aspecto de grande interesse é o desenvolvimento de dispositivos que possam ser integrados diretamente aos sistemas microfluídicos, sem afetar ou complicar demasiadamente os processos de fabricação desses sistemas. Daí a motivação para o desenvolvimento deste trabalho. Em particular, será apresentado o desenvolvimento de um sensor de vazão com princípio de funcionamento térmico, tratando desde o princípio de funcionamento até a fabricação e caracterização elétrica, passando pela modelagem por elementos finitos. Este trabalho foi desenvolvido junto ao Grupo de Novos Materiais e Dispositivos (GNMD) no Laboratório de Microeletrônica (LME) da Escola Politécnica da Universidade de São Paulo. 


\section{REVISÃO DA LITERATURA}

\subsection{HISTÓRICO DA MICROFLUÍDICA}

Microfluídica é a ciência e a engenharia que tratam da manipulação de pequenas quantidades de fluidos ( $10^{-9}$ a $10^{-18}$ litros) através de canais, reservatórios, válvulas e outras estruturas de dimensões microscópicas (1). Estruturas com tais dimensões abrem a possibilidade de estudar fenômenos físicos que estão fora de alcance na escala macroscópica (6), além de proporcionarem uma série de vantagens com relação a sistemas convencionais.

Os primeiros trabalhos em microfluídica datam do final da década de 70 e tratam basicamente da miniaturização de sistemas de cromatografia em fase gasosa $(21,22)$ e de estudos sobre bicos injetores de tinta para impressoras (23). Desde então, a microfluídica se desenvolveu a partir da fusão de interesses de quatro áreas: análise molecular, biossegurança, biologia molecular e microeletrônica (1).

$\mathrm{Na}$ área de análise molecular, o desenvolvimento de técnicas de microanálise, como cromatografia de fase gasosa (GPC), cromatografia líquida de alta pressão (HPLC) e eletroforese capilar (CE), combinadas com o poder de detecção óptica dos lasers, tornou possível obter alta sensibilidade e alta resolução usando pequenas quantidades de amostra. Isso gerou o interesse por sistemas ainda mais compactos e versáteis e a microfluídica mostrou ter potencial para superar tais desafios (1).

A área de biossegurança contribuiu com a microfluídica trazendo grandes investimentos para a área. $\mathrm{O}$ aumento do uso de armas químicas e biológicas com o fim da Guerra Fria, tanto por militares quanto por terroristas, fez com que o Departamento de Defesa dos EUA, por meio da DARPA (Defense Advanced Research Projects Agency), financiasse nos anos 90 uma série de programas para desenvolvimento de sistemas microfluídicos capazes de detectar em campo ameaças químicas e biológicas (1). 
$\mathrm{Na}$ biologia molecular, a explosão da Genômica na década de 80 , seguida do advento de outras áreas de microanálise relacionadas à biologia molecular, como o sequenciamento genético de alto desempenho, gerou a busca por métodos analíticos com desempenho ainda melhores, com maior resolução e maior sensibilidade em relação aos métodos tradicionais. A microfluídica destacou-se, então, por fornecer alternativas para que tais avanços pudessem acontecer (1).

Por último, a microfluídica pareceu ser a extensão natural da microeletrônica. Esperava-se que as técnicas de fabricação e a fotolitografia usadas na construção de circuitos integrados e de MEMS (Micro-Electro-Mechanical Systems ou sistemas micro-eletro-mecânicos) em silício fossem diretamente empregadas na microfluídica. No entanto, o silício é um material caro, rígido e que não permite a passagem de radiação no espectro visível e ultravioleta, o que inviabiliza seu uso em algumas aplicações. Com o tempo, o silício deu lugar ao vidro como material de preferência depois ambos foram sendo substituídos por compostos poliméricos, que além de serem transparentes e baratos, também podem ser flexíveis. Porém, mesmo com esses novos materiais exigindo técnicas diferentes daquelas normalmente empregadas, a microeletrônica foi essencial para 0 desenvolvimento da microfluídica (1).

Atualmente, a microfluídica movimenta um mercado global de bilhões de dólares $(12,13,14)$, que envolve sistemas comerciais de microcanais fabricados em silício, vidro e materiais poliméricos, para utilização em áreas como a microanálise química e clínica, a biologia molecular, a farmacologia e a medicina. Além disso, a portabilidade, a grande precisão alcançada na manipulação dos fluidos e a capacidade de integrar os microcanais a microválvulas, microbombas e eletrodos num único substrato, deram origem ao conceito de Lab on a Chip. Essa denominação se refere a sistemas complexos que podem realizar seqüencialmente ou em paralelo, análises de detecção, separação, filtragem, etc., permitindo substituir com grande economia em termos de espaço e equipamentos, instalações de laboratório convencionais $(4,5)$. Por outro lado, a microfluídica também tem se mostrado promissora em outras áreas, como microfluídica óptica (24), na qual fluidos opticamente densos são empregados como guias de onda, displays, microespelhos, e até no armazenamento e processamento da informação (25). 


\subsection{PRINCÍPIO DE FUNCIONAMENTO DOS SENSORES DE VAZÃO}

Quando se deseja determinar a quantidade de fluido escoando em um canal ou microcanal alguns tipos de medida podem ser efetuados. Geralmente são medidas a vazão volumétrica (volume pelo tempo), a vazão em massa (massa pelo tempo) ou mesmo a velocidade do fluido (distância pelo tempo). Para extrair os valores dessas medidas, vários princípios físicos podem ser utilizados, sendo mais comuns sensores que empregam princípios térmicos, por diferença de pressão, ópticos e por transferência de força $(20,26)$.

A seguir é apresentada uma breve descrição do principio de funcionamento dos principais sensores usados na determinação do fluxo ou vazão.

\subsubsection{Sensor de vazão térmico}

O sensor de vazão térmico ou a massa térmica, como também é conhecido, é composto basicamente por um fio ou filamento aquecido imerso no fluido, como mostra a figura 1. Existem basicamente dois modos de funcionamento para esse sensor: à potência constante e à temperatura constante $(20,26)$.

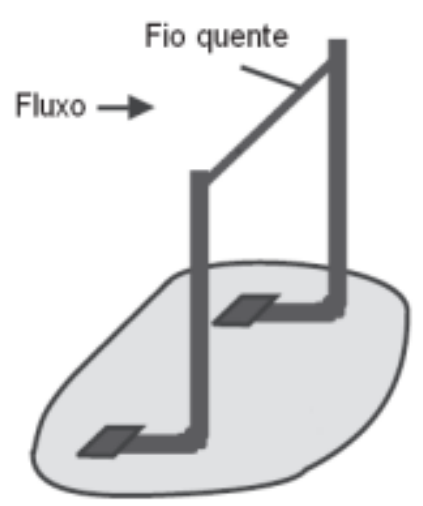

Figura 1 - Desenho esquemático de um sensor de vazão térmico (20). 
No modo a potência constante, o filamento é excitado por uma corrente $I$ de valor constante e é aquecido por efeito Joule até uma temperatura de equilíbrio. Para todos os efeitos, o filamento é um resistor de resistência $R$ e a potência dissipada por ele nesse caso é constante e igual a $P=R I^{2}$. Quando o fluido escoa pelo filamento ocorre transferência de calor do filamento para o fluido e a temperatura do filamento diminui. Como o valor da resistência elétrica é função da temperatura, a resistência também diminui e essa variação pode ser medida através da variação de tensão sobre o resistor. Quanto maior o fluxo, maior é a queda de temperatura $(20,26)$.

No modo a temperatura constante, a temperatura sobre o filamento é medida diretamente e é mantida constante em um valor acima da temperatura ambiente. A potência necessária para manter a temperatura constante é proporcional ao valor da vazão. Nesse modo de operação a resposta do sensor é muito rápida mas é necessário um circuito de controle mais complexo $(20,26)$.

Sensores com princípio de funcionamento térmico são amplamente utilizados na indústria, em automóveis, entre outros. Esse tipo de sensor apresenta boa sensibilidade, bom tempo de resposta e é bastante robusto. Uma desvantagem de seu uso é o fato de ele aquecer o fluido para efetuar a medida, o que pode ser inaceitável em algumas aplicações biológicas e químicas, por exemplo.

Alguns aspectos construtivos podem melhorar a resposta do sensor. Como regra geral, quanto menor a massa do elemento sensor e maior o seu isolamento térmico do restante do chip, mais rápida é a resposta do sensor a mudanças no fluxo e maior é a sua sensibilidade $(20,26)$. Outra característica a ser observada é o coeficiente de temperatura do material que compõe o elemento sensor, também chamado de TCR (Temperature Coefficient of Resistance). Quanto maior seu coeficiente, maior a sensibilidade do sensor. Por isso, geralmente são empregados materiais como platina, ouro, níquel, silício policristalino, entre outros $(20,26)$. Por outro lado, também podem ser empregadas outras configurações para o medidor utilizando, por exemplo, dois sensores de temperatura (um a montante e outro a jusante) e um elemento aquecedor. Além de tornar a medida mais confiável e aumentar a sensibilidade do sensor, essa configuração permite determinar qual o sentido do fluxo $(20,26,27)$. 
Neste trabalho foi estudado um sensor de vazão térmico composto por um único filamento de níquel fabricado no interior do microcanal. A escolha desse tipo de sensor foi feita por ele poder ser projetado para diversas faixas de valores, desde alguns $\mathrm{nL} / \mathrm{min}$ até centenas de $\mu \mathrm{L} / \mathrm{min}$, e pela simplicidade de fabricação. Mais detalhes sobre a modelagem e a fabricação desse sensor serão apresentados ao longo deste trabalho.

\subsubsection{Sensor de vazão por diferença de pressão}

Outro princípio de funcionamento utilizado em sensores de vazão é o de medir a diferença de pressão ou a perda de carga ao longo de um canal. Pode-se demonstrar (28) que, no escoamento em dutos de seção uniforme, o gradiente de pressão na direção do escoamento está relacionado ao perfil de velocidades dentro do duto. Conhecendo-se a geometria da seção, é possível determinar uma relação entre a diferença de pressão na entrada e na saída do duto e a vazão de fluido.

Outra forma de abordar o problema é usando uma analogia com circuitos elétricos. Nesse caso, determinar a vazão em um canal por meio da diferença de pressão é equivalente a determinar a corrente que passa por um resistor através da medida da tensão sobre ele. Para que essa medida seja confiável, é importante que o valor do resistor seja fixo. No caso fluídico, isso equivale a utilizar um microcanal com resistência fluídica fixa, ou seja, com geometria e características físico-químicas constantes $(20,26)$.

A medida da diferença de pressão normalmente é realizada com o auxílio de sensores capacitivos ou piezoelétricos. Um desenho esquemático de um sensor de vazão empregando sensores de pressão capacitivos é mostrado na figura $2(20,26)$. 


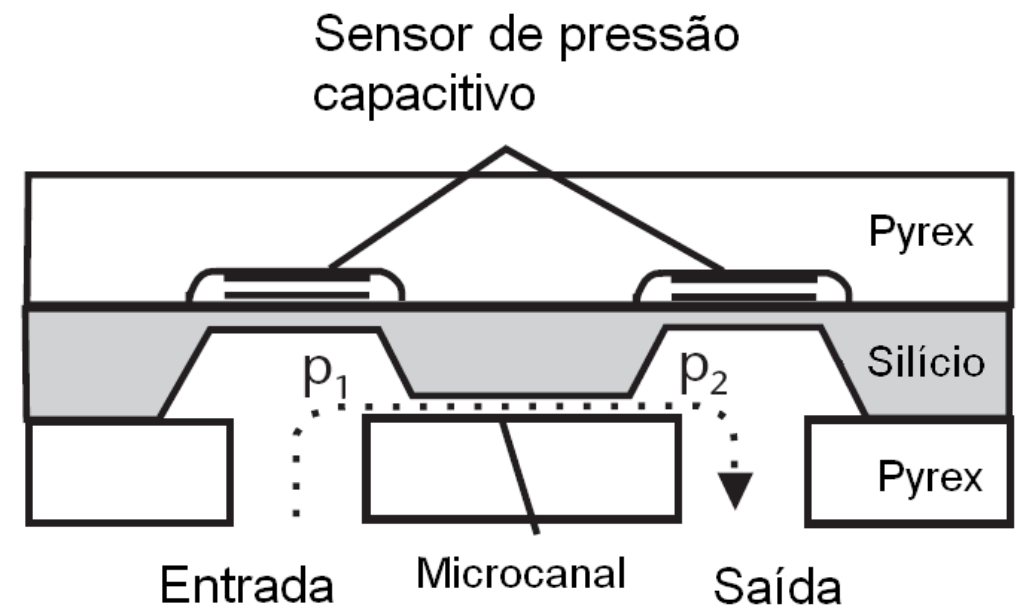

Figura 2 - Desenho esquemático de um sensor de vazão por diferença de pressão utilizando sensores de pressão capacitivos (20).

Nesse caso, o dispositivo é formado por uma lâmina de silício soldada a duas lâminas de vidro Pyrex. Sobre uma das lâminas de Pyrex são feitos furos que servem de acesso para o microcanal que é fabricado através da corrosão anisotrópica do silício. Duas câmaras também são fabricadas em silício para permitir que a pressão na entrada e na saída do microcanal seja medida. As câmaras são fabricadas de modo que se forme uma fina membrana de silício. Sobre essa membrana, pelo lado externo da lâmina, são depositados filmes metálicos que servem de eletrodos para o sensor de pressão. Sobre a segunda lâmina de Pyrex também são fabricadas pequenas cavidades nas quais são depositados eletrodos que formam par com os eletrodos fabricados no silício. Assim, a pressão em cada uma das câmaras é medida em relação a pressão atmosférica através da capacitância existente entre os pares de eletrodos. Quando o fluido escoa pelo microcanal, a pressão nas câmaras é alterada, provocando a deformação mecânica das membranas de silício. Isso faz com que a capacitância de cada um dos sensores varie e através da diferença de pressão medida pelos dois sensores capacitivos é possível conhecer qual a vazão de fluido escoando pelo microcanal.

Configurações diferentes da mostrada na figura 2 podem ser empregadas no sensor de vazão. Sensores piezoelétricos podem medir a deformação de uma membrana fabricada com um orifício centralizado e fornecerem uma medida indireta da diferença de pressão, ou até mesmo um dispositivo baseado em um tubo de Prandtl 
pode ser empregado como sensor de vazão. Em todos os casos, tal tipo de sensor apresenta como principal vantagem o fato de não ser necessário aquecer o fluido para realizar a medida. Contudo, tais dispositivos apresentam como desvantagem o fato de seu funcionamento ser influenciado por partículas e pela temperatura do fluido (já que isso altera sua viscosidade e sua densidade). Além disso, esse sensor introduz uma perda de carga no sistema, o que pode ser problemático em alguns casos, principalmente quando o bombeamento do fluido é feito através de uma microbomba, que geralmente possuem pressão de bombeamento limitada $(20,26)$.

\subsubsection{Sensor de vazão por transferência de força}

Outro princípio que tem sido explorado na medida de vazão é o de transferência de força, sendo mais comuns os sensores que funcionam por força de arrasto. Nesse caso, o sensor é composto por uma aba ou cantilever imerso no fluido e posicionado transversalmente ao escoamento como mostra a figura 3. O fluido escoa e interage com o sensor, deformando-o mecanicamente. A deformação é medida através de "strain gauges" ou mesmo por piezorresistores fabricados diretamente sobre a aba ou cantilever e é proporcional à vazão ou à velocidade do escoamento $(20,26)$.

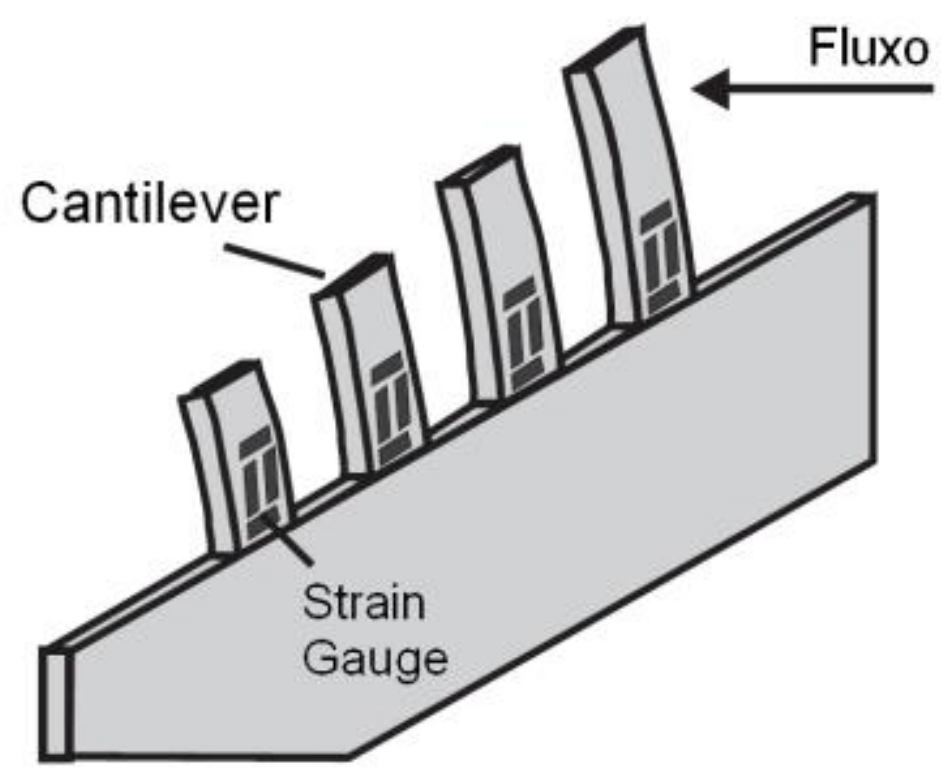

Figura 3 - Desenho esquemático de um sensor de vazão por transferência de força (20). 
Tais sensores apresentam a vantagem de serem muito pequenos e de não aquecer o fluido. Como desvantagem, eles são relativamente frágeis e seu funcionamento é influenciado por partículas que por ventura estejam presentes no fluido. Existe um compromisso entre a robustez desse tipo de sensor e sua sensibilidade, sendo que quanto mais robusto (por conta do aumento da espessura do elemento sensor), menos sensível é o sensor $(20,26)$.

\subsubsection{Sensor de vazão óptico}

Princípios ópticos também podem ser utilizados para medir a vazão. Na verdade, sensores ópticos são capazes de determinar não só a vazão mas o próprio perfil de velocidades em uma seção do escoamento. Para isso são usadas fontes de excitação por raio $X$, luz infravermelha (especialmente em substratos de silício) ou ultravioleta que incidem na amostra e são direcionadas para um detector, geralmente um microscópio ou diretamente um CCD. A medida óptica, entretanto, quase sempre exige a adição de partículas no fluido ou ao menos a inserção de marcadores fluorescentes. Devido a todos os componentes necessários, esse tipo de medida é cara e ocupa um grande espaço, já que as fontes de excitação e os detectores normalmente não são microscópicos (20).

Um sensor óptico com dimensões um pouco menores pode ser construído, por exemplo, a partir da adaptação de um sensor por força de arrasto (20). Nesse caso, ao invés dos piezorresistores utilizam-se guias de onda, como mostra a figura 4. A guia é fabricada sobre um substrato, interrompida em um determinado trecho e então liberada do substrato, transformando-se em um cantilever. Uma fonte luminosa é usada para injetar luz no cantilever e um detector óptico é posicionado na saída do conjunto. Fibras ópticas são utilizadas para facilitar a injeção e a extração de luz das guias. Por fim, o conjunto sensor é posicionado de modo que o cantilever esteja na transversal em relação à direção do escoamento. 

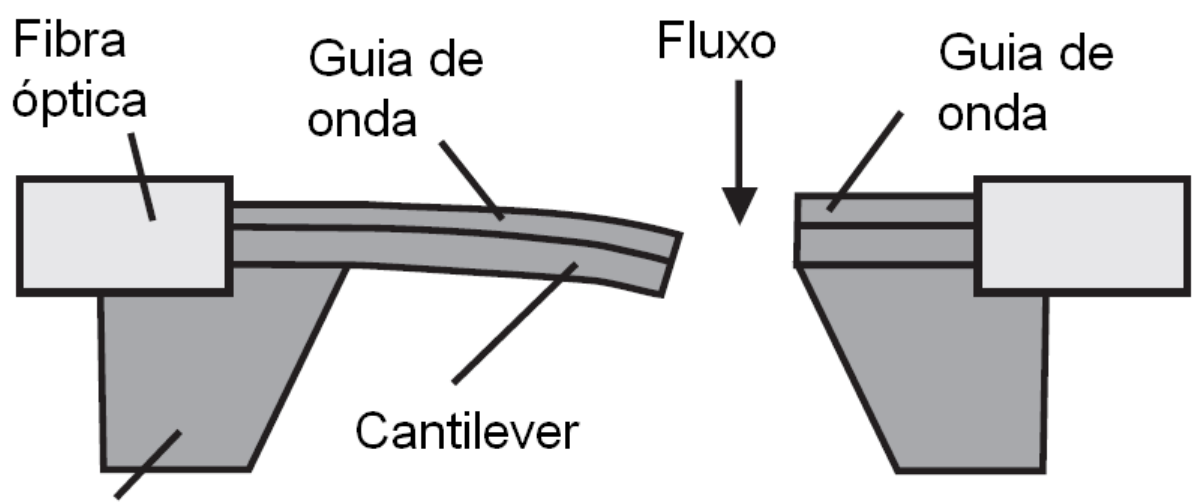

Silício

Figura 4 - Desenho esquemático de um sensor de vazão óptico (20).

$\mathrm{Na}$ ausência de escoamento (ou seja, com o fluido parado), o cantilever e a guia de saída estão alinhados, fazendo com que quase a totalidade da luz seja transferida do cantilever para a guia de saída. Quando há escoamento, a interação do fluido com o cantilever provoca um desalinhamento entre as guias, mudando a intensidade luminosa de saída. Assim, existe uma relação entre o sinal luminoso de saída e a vazão de fluido.

Outra possibilidade é a criação de detectores ópticos de bolhas ou partículas. Utilizando a mesma ideia do caso anterior, uma guia de onda interrompida ou mesmo um par de fibras ópticas posicionadas diametralmente opostas nas laterais de um microcanal são usados para medir a intensidade de luz transmitida através do mesmo. Enquanto o fluido escoa pelo canal, o sensor mede uma intensidade de fundo com valor constante. Contudo, quando uma bolha ou uma partícula passam pelo detector a intensidade luminosa sofre uma variação, indicando a passagem da partícula (20).

Além dos exemplos apresentados, diversos outros princípios de funcionamento podem ser explorados em sensores de vazão, dando origem, por exemplo, a sensores eletrohidrodinâmicos, eletroquímicos, por força de sustentação, de Coriollis, entre outros $(20,26)$. Tratar de todos esses princípios foge do escopo desse trabalho mas o leitor interessado pode consultar as referências 20, 26 e 27.

A tabela 1 mostra um resumo das principais características dos sensores de vazão apresentados. 
Tabela 1 - Comparação entre os principais tipos de sensores de vazão.

\begin{tabular}{|c|c|c|}
\hline $\begin{array}{c}\text { Princípio de } \\
\text { funcionamento }\end{array}$ & Vantagens & Desvantagens \\
\hline Térmico & $\begin{array}{c}\text { Simplicidade de } \\
\text { fabricação, boa } \\
\text { sensibilidade }\end{array}$ & Aquece o fluido \\
\hline $\begin{array}{c}\text { Diferença de } \\
\text { pressão }\end{array}$ & $\begin{array}{c}\text { Boa sensibilidade, não } \\
\text { aquece o fluido }\end{array}$ & $\begin{array}{c}\text { Funcionamento afetado } \\
\text { por partículas, introduz } \\
\text { perda de carga no sistema }\end{array}$ \\
\hline $\begin{array}{c}\text { Transferência de } \\
\text { força }\end{array}$ & $\begin{array}{c}\text { Tamanho reduzido, não } \\
\text { aquece o fluido }\end{array}$ & $\begin{array}{c}\text { Frágil, funcionamento } \\
\text { afetado por partículas }\end{array}$ \\
\hline Óptico & $\begin{array}{c}\text { Permite extrair mais } \\
\text { informações sobre o } \\
\text { escoamento além da } \\
\text { vazão }\end{array}$ & $\begin{array}{c}\text { Exige a adição de } \\
\text { partículas ou marcadores, } \\
\text { montagem final espaçosa }\end{array}$ \\
\hline
\end{tabular}

\subsection{EQUACIONAMENTO E MODELAGEM}

$\mathrm{Na}$ Mecânica dos Fluidos, a descrição de qualquer escoamento é feita a partir das chamadas equações de balanço, que expressam as leis de conversação de três quantidades físicas: massa, quantidade de movimento e energia. Essas equações descrevem o comportamento macroscópico do fluido e são aplicáveis quando se assume a hipótese de que o fluido é um meio contínuo $(28,29)$.

Tomando-se como referência um volume infinitesimal de fluido, a equação de balanço de massa estabelece basicamente que a massa de fluido deve permanecer constante no interior desse volume. Utilizando o princípio da continuidade, pode-se escrever a equação de balanço de massa como sendo $(28,29)$ :

$$
\frac{\partial \rho}{\partial t}+\nabla \cdot(\rho \vec{V})=0
$$

na qual $\rho$ representa a densidade do fluido, $t$ representa o tempo, $\vec{V}$ é o vetor velocidade que descreve a velocidade do fluido em todos os pontos do domínio e $\nabla$ é o operador nabla, definido como: 


$$
\nabla=\frac{\partial}{\partial x} \vec{\imath}+\frac{\partial}{\partial y} \vec{\jmath}+\frac{\partial}{\partial z} \vec{k}
$$

sendo $\vec{\imath}, \vec{\jmath}$ e $\vec{k}$ os vetores unitários do sistema de coordenadas cartesianas nas direções $x, y$ e $z$, respectivamente.

A partir da segunda Lei de Newton, que estabelece que a variação da quantidade de movimento é igual a somatória das forças agindo sobre o corpo, é possível derivar a equação de balanço de quantidade de movimento. Nesse caso, o corpo levado em consideração é uma partícula fluida, definida como a menor porção de fluido que ainda mantém suas propriedades. Assim, a equação pode ser escrita como sendo $(28,29)$ :

$$
\rho \frac{D \vec{V}}{D t}=\rho\left(\frac{\partial \vec{V}}{\partial t}+\vec{V} \cdot \nabla \vec{V}\right)=\vec{f}_{\text {campo }}+\vec{f}_{\text {superfície }}
$$

O operador $D / D t$ é chamado de derivada material ou substancial e representa a taxa total de variação de uma grandeza levando em conta a variação temporal e a variação convectiva devido ao campo de velocidades. Por definição:

$$
\frac{D}{D t}=\frac{\partial}{\partial t}+(\vec{V} \cdot \nabla)
$$

Na equação 3, o termo $\vec{f}_{\text {campo }}$ representa as forças provenientes de campos vetoriais agindo sobre o corpo sendo a mais comum delas a força da gravidade. No caso da microfluídica, outras forças podem ser levadas em consideração, como forças provenientes de campo elétrico ou magnético. O termo $\vec{f}_{\text {superfície }}$, por sua vez, descreve as forças de superfície agindo no corpo, sendo elas normalmente forças de pressão ou compressão e forças viscosas $(28,29)$.

O termo $\vec{f}_{\text {superfície }}$ pode ser descrito em termos do divergente do tensor de esforços agindo na superfície da partícula fluida. Os esforços agem nas direções normais e tangenciais à superfície, como representado na figura 5 , e o tensor de esforços $\tilde{\tau}$ pode ser escrito na forma $(28,29)$ : 


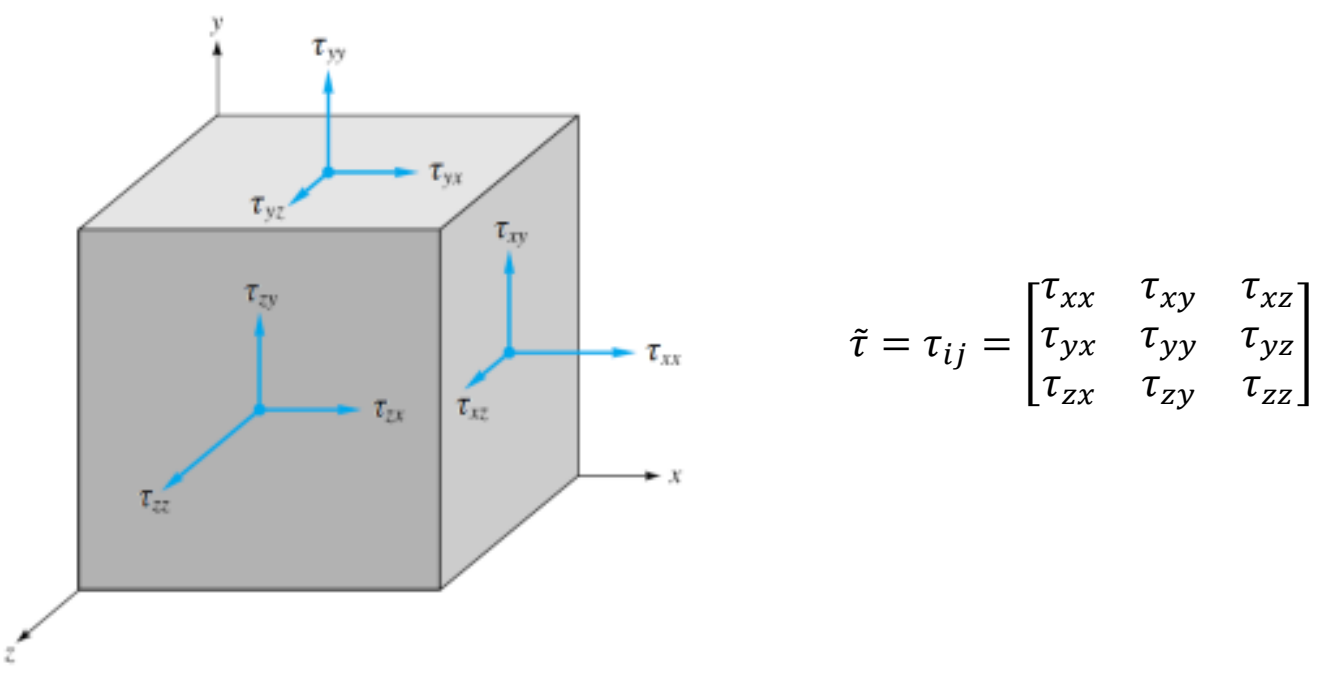

Figura 5 - Representação das tensões mecânicas agindo na partícula fluida.

Assim, desprezando todas as forças de campo com exceção da força da gravidade, a equação 3 pode ser reescrita na forma $(28,29)$ :

$$
\rho \frac{D \vec{V}}{D t}=\rho \vec{g}+\nabla \cdot \tilde{\tau} \quad(6)
$$

Por fim, a equação do balanço de energia pode ser derivada da primeira Lei da Termodinâmica que estabelece que a energia total de um sistema é igual a soma da energia que entra no sistema na forma de calor mais o trabalho realizado no sistema. Essa equação pode ser escrita de diversas formas mas uma forma conveniente de escrevê-la é em função da temperatura do fluido, o que leva a $(28,29)$ :

$$
\rho c_{p} \frac{D T}{D t}=\beta T \frac{D p}{D t}+\nabla \cdot(k \nabla T)+\Phi
$$

Nessa equação, $c_{p}$ representa o calor específico do fluido à pressão constante, $T$ é a temperatura, $\beta$ é o coeficiente de expansão térmica do fluido, $p$ descreve o campo de pressões no domínio, $k$ é o coeficiente de difusão térmica e $\Phi$ é a chamada função de dissipação, que está relacionada aos esforços viscosos.

As equações 1, 6 e 7 formam o conjunto básico de equações para a resolução de escoamentos, tendo como incógnitas o vetor velocidade $\vec{V}$, a pressão termodinâmica $p$ e a temperatura $T$. Contudo, além dessas incógnitas existem 
outras variáveis termodinâmicas presentes nas equações que devem ser quantificadas, como a densidade $\rho$ e a condutividade térmica $k$. Assim, além das equações de balanço, é necessário incluir no sistema outras equações, chamadas de equações de estado, que descrevem as propriedades do fluido em função da temperatura e da pressão $(28,29)$.

O sistema de equações resultante, formado pelas equações de balanço e de estado, é de difícil resolução analítica, principalmente para uma geometria genérica. De fato, trata-se de um sistema de equações diferenciais parciais de segunda ordem, que possui termos não-lineares (como o termo $\vec{V} \cdot \nabla \vec{V}$ da equação 3 , por exemplo) e equações acopladas, o que significa que as equações devem ser resolvidas simultaneamente $(28,29)$.

Como forma de tornar o problema mais simples, diversas hipóteses simplificadoras costumam ser adotadas. No caso do escoamento em microcanais tendo a água como fluido de trabalho, que constitui o foco deste trabalho, uma hipótese válida e bastante comum é assumir que o escoamento é incompressível. Isso significa que a densidade $\rho$ é tida como constante em todo o domínio. Além disso, supondo que não haja variações abruptas de temperatura, pode-se assumir que a viscosidade $\mu \mathrm{e}$ a condutividade térmica $k$ também são constantes em todo o domínio. Por fim, considera-se que a água se comporta como um fluido newtoniano $(7,8,28,29)$.

Com essas hipóteses e supondo ainda que o efeito da gravidade não seja relevante em escala microscópica, as equações de balanço podem ser simplificadas para a seguinte forma $(7,8,28,29)$ :

- Balanço de massa:

$$
\nabla \cdot \vec{V}=0
$$

- Balanço de quantidade de movimento:

$$
\rho \frac{D \vec{V}}{D t}=\rho\left(\frac{\partial \vec{V}}{\partial t}+\vec{V} \cdot \nabla \vec{V}\right)=-\nabla p+\mu \nabla^{2} \vec{V}
$$


- Balanço de energia:

$$
\rho c_{p} \frac{D T}{D t}=\rho c_{p}\left(\frac{\partial T}{\partial t}+\vec{V} \cdot \nabla \mathrm{T}\right)=k \nabla^{2} T
$$

As simplificações impostas ao problema permitem que o campo de velocidades seja calculado independentemente do campo de temperaturas, desacoplando as equações. Contudo, achar uma solução analítica para um problema com geometria qualquer continua sendo uma tarefa difícil. Por conta disso, é muito comum o emprego de métodos numéricos para resolução das equações. Dentre eles, o método dos elementos finitos recebe destaque por ser um dos mais empregados $(30,31)$.

O Método dos Elementos Finitos (MEF) é um método numérico para resolução de equações diferenciais parciais. A ideia básica do método é dividir o corpo ou o domínio de análise em elementos, compostos cada um por nós e faces, e extrair uma solução aproximada para as equações nesse domínio discretizado. Os elementos vizinhos são conectados por nós e compartilham faces, formando o que é chamado de malha. Como regra geral, quanto maior o número de elementos no domínio, mais precisa é solução encontrada. Por outro lado, maior é o custo computacional de processamento dos cálculos. Existem muitos aspectos envolvendo o método mas discuti-los aqui está fora do escopo do trabalho. Cabe ressaltar, porém, que existem programas livres e comerciais que implementam o método dos elementos finitos para resolução de problemas físicos. Um aspecto interessante é que esses softwares permitem a resolução de problemas com condições de contorno e geometrias complexas e em um ambiente de simulação multifísica, ou seja, que permite a interação entre vários domínios físicos como mecânico, térmico, eletromagnético etc $(30,31)$.

No projeto de sensores e MEMS em geral, softwares de simulação por elementos finitos produzem excelentes resultados mas geralmente exigem grande conhecimento do projetista e muitas horas de trabalho. Como alternativa, ao menos nos estágios iniciais de projeto, o emprego de modelos utilizando elementos concentrados produz bons resultados com menor esforço computacional. Assim como no MEF, o método a elementos concentrados permite a integração de vários domínios físicos, isto é, uma simulação na qual haja interação entre os domínios 
mecânico, elétrico, térmico, acústico etc.. Uma vantagem adicional é a possibilidade de simular o dispositivo juntamente com seu circuito de controle, já que esse tipo de simulação pode ser feita em ambiente SPICE (Simulation Program with Integrated Circuit Emphasis). Nesse caso, são extraídas representações simplificadas dos dispositivos que são expressas na forma de circuitos elétricos equivalentes a partir do uso de analogias elétricas. Essa representação é vantajosa pois dá acesso, através do ambiente SPICE e de modelos construídos com o uso de analogias elétricas, a inúmeras ferramentas desenvolvidas para a análise de circuitos como, por exemplo, análises pelo método Monte Carlo e análises de sensibilidade (32). Procedimentos de otimização de sistemas ou dispositivos também podem ser facilmente implementados nesse tipo de simulação.

$\mathrm{Na}$ análise do sensor térmico de vazão no interior de um microcanal é necessário considerar as interações entre três domínios físicos diferentes: elétrico, térmico e fluídico. Logo, um modelo para o sensor, seja ele a elementos concentrados ou elementos finitos, deve tomar conta da interação entre os três domínios.

O funcionamento do sensor de vazão proposto neste trabalho foi simulado utilizando o método dos elementos finitos. Além disso, um modelo a elementos concentrados foi proposto para o caso do sensor otimizado.

\subsection{PROCESSOS DE FABRICAÇÃO PARA MICROFLUÍDICA}

Vários dos materiais e das técnicas de microfabricação utilizadas em microfluídica são as mesmas empregadas em microeletrônica e na tecnologia dos MEMS (sistemas micro-eletro-mecânicos). Porém, o custo de implementação e manutenção de tais recursos é extremamente elevado, abrindo espaço para pesquisa de métodos alternativos. Além disso, o silício, material base da microeletrônica, nem sempre é o material mais adequado para algumas aplicações.

O sensor de vazão proposto neste trabalho faz uso de dois materiais base diferentes do silício, vidro borosilicato (Corning 7059) e PDMS (polidimetilsiloxano), que apresentam algumas peculiaridades em seu processamento. Depois de 
processados, esses dois materiais devem ser soldados um ao outro, técnica essa que também difere daquelas normalmente empregadas na microeletrônica.

As etapas do processo de fabricação serão apresentadas em detalhes nas seções 3.3 e 4.3 mas a seguir é mostrada uma breve descrição do processamento do PDMS e do vidro. Para maiores detalhes sobre os processos de microfabricação normalmente empregados na microeletrônica e em MEMS recomenda-se a consulta à referência 33.

\subsubsection{Microfabricação em PDMS}

PDMS ou polidimetilsiloxano é um elastômero muito usado na fabricação de dispositivos de microfluídica, em prototipagem rápida e na litografia macia. Ele apresenta boa transparência, é inerte e biocompatível. Quimicamente, o PDMS é composto por uma espinha dorsal inorgânica de siloxano e grupos orgânicos metil presos aos átomos de silício, o que lhe confere uma combinação única de propriedades (34).

O PDMS é processado para formar os microcanais através de uma técnica conhecida como soft lithography ou litografia macia. Assim como a fotolitografia, a litografia macia é usada para definir padrões sobre filmes e substratos e permitir a remoção seletiva dos mesmos mas sem o uso dos custosos equipamentos de exposição e alimento de luz utilizados na fotolitografia convencional (34).

Existem algumas técnicas para a execução da litografia macia, mas todas elas apresentam um aspecto em comum: a necessidade de um molde. Para fabricá-lo utiliza-se a fotolitografia convencional ou qualquer processo equivalente (litografia a raio $X$, electron beam etc.) de modo a definir o padrão desejado sobre um filme base, por exemplo o fotorresiste. O resiste fotogravado sobre o silício serve de molde para a criação de um bloco elastomérico no qual, nesse caso, são fabricados os microcanais (34). 
O processo de fabricação dos microcanais utilizado neste trabalho, conhecido como replicação de molde (replica molding), consiste em preparar o PDMS, vertê-lo ainda líquido sobre o molde, realizar sua cura e em seguida removê-lo do molde. Ao final, o bloco de PDMS é soldado a um substrato de vidro através de um tratamento superficial em plasma de oxigênio (35).

O preparo do PDMS é feito misturando-se uma base líquida de silicone (PDMS com terminação vinil) e um agente de cura (uma mistura de complexo de platina e copolímeros de metilidrosiloxano e dimetilsiloxano). Uma vez misturados, derramados sobre o molde em fotorresiste e aquecidos, a mistura líquida se torna sólida devido à formação de ligações cruzadas (cross-links), na reação de hidrosililação entre o grupo vinil $\left(\mathrm{SiCH}=\mathrm{CH}_{2}\right)$ e o grupo hidrosilano $(\mathrm{SiH})(34)$. Nesse momento, o PDMS sólido é removido do molde tendo assim adquirido o padrão ou relevo adquirido pelo fotorresiste. Essas etapas estão ilustradas na figura 6.

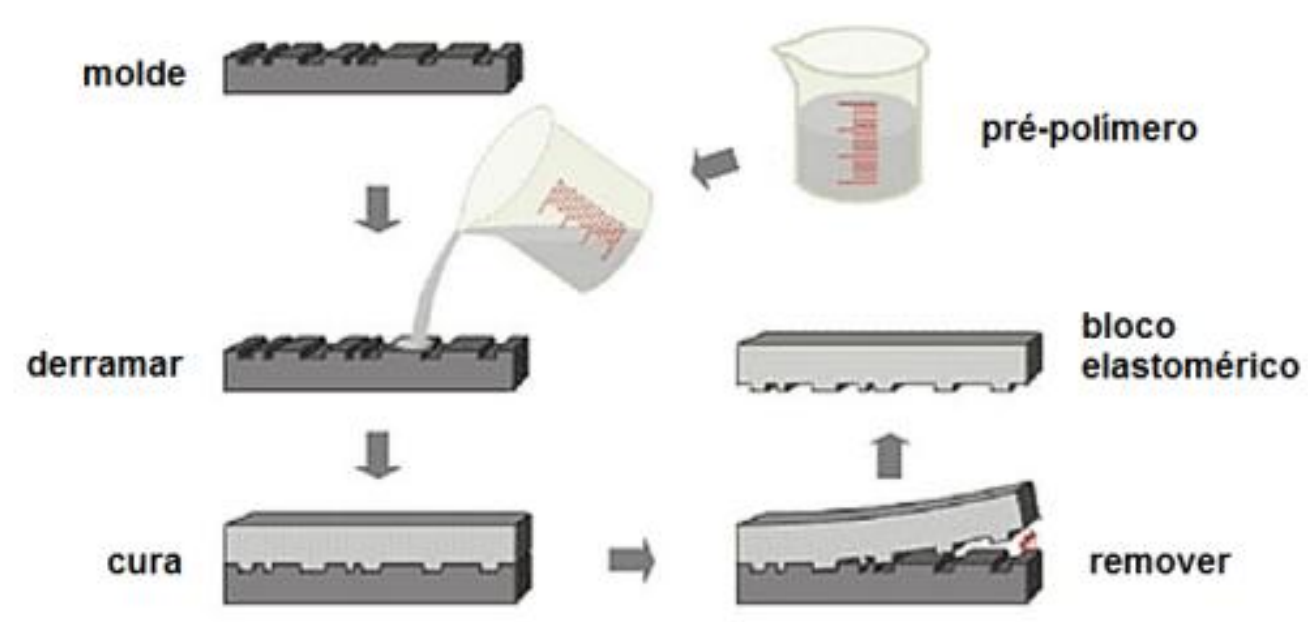

Figura 6 - Preparo do PDMS.

A etapa seguinte é soldar em um substrato de vidro o bloco elastomérico de PDMS contendo os microcanais. O substrato de vidro confere rigidez mecânica ao conjunto, já que o PDMS é flexível, e sela os microcanais, tornando-os fechados. Antes da soldagem, que é feita com um tratamento superficial em plasma de oxigênio, devem ser feitos os furos de acesso aos microcanais. 
Para finalizar o processo de fabricação, tubos para entrada e saída de fluido são colados com resina epóxi aos furos de acesso, o que propicia a vedação das interconexões contra vazamentos.

\subsubsection{Microfabricação em vidro}

Outro material muito utilizado na microfluídica é o vidro, em especial dos tipos borosilicato e quartzo. Ele é transparente, apresenta boa resistência química e térmica e é amplamente usado em laboratórios químicos e biológicos.

O vidro pode ser processado por diferentes técnicas para se obter microcanais, sendo as principais delas a corrosão úmida e seca (por plasma), a usinagem mecânica e a ablação a laser (36).

Em trabalhos anteriores do Grupo de Novos Materiais e Dispositivos $(37,38)$, foram estudadas técnicas de microfabricação em vidro com o objetivo de estabelecer um método de obtenção de sistemas microfluídicos completos nesse tipo de substrato. O vidro utilizado foi o Corning 7059, um bário-borosilicato muito usado em aplicações ópticas e eletrônicas, como na produção de displays, devido a sua boa resistência térmica e excelente uniformidade.

Os sistemas microfluídicos são compostos por duas lâminas de vidro soldadas uma na outra. Sobre uma das lâminas são fabricados microcanais pela técnica de corrosão úmida. Na outra lâmina são feitos furos de acesso aos microcanais com auxílio de uma furadeira de bancada e um sistema de microposicionadores controlados por computador. Essa lâmina também passa por um processo de corrosão úmida para se definir pequenas marcas que indicam as posições dos furos.

Basicamente o processo de corrosão úmida consiste em depositar um material de mascaramento sobre a lâmina de vidro, efetuar a fotogravação desse material com a geometria de interesse utilizando fotolitografia convencional e corroer a lâmina em uma solução de ácido fluorídrico (HF). Testes com diversas soluções de ácido fluorídrico e alguns materiais de mascaramento constataram que os melhores 
resultados são obtidos usando uma solução de ácido fluorídrico, ácido clorídrico e água deionizada (1 HF : $2 \mathrm{HCl}: 3 \mathrm{H}_{2} \mathrm{O}$ ) e o cromo como material de mascaramento. Vale ressaltar que esta é uma corrosão isotrópica, ou seja, a taxa de corrosão é a mesma em todas as direções. Isso confere um perfil arredondado aos microcanais.

A soldagem das lâminas é feita através da técnica de soldagem direta em temperatura ambiente (39). Nessa técnica, as lâminas de vidro a serem coladas são imersas em ácido sulfúrico $\left(\mathrm{H}_{2} \mathrm{SO}_{4}\right.$ a 38\%) por um período de 12 horas para promover a ativação da superfície. Em seguida, as lâminas são enxaguadas em água corrente em alta velocidade, ainda sob a água elas são alinhadas e então prensadas por pelo menos três horas. Por fim, são feitas as interconexões com o meio externo colando tubos metálicos (neste caso, scalps intravenosos de uso hospitalar) aos furos de acesso. As etapas de processo são representadas na figura 7. 


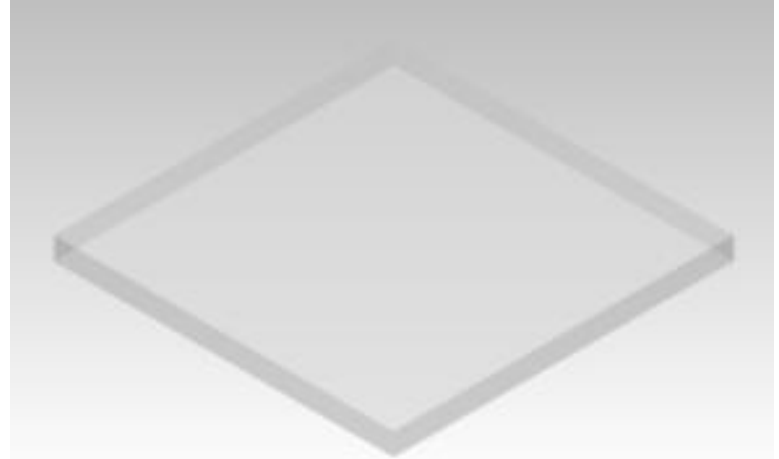

(a)

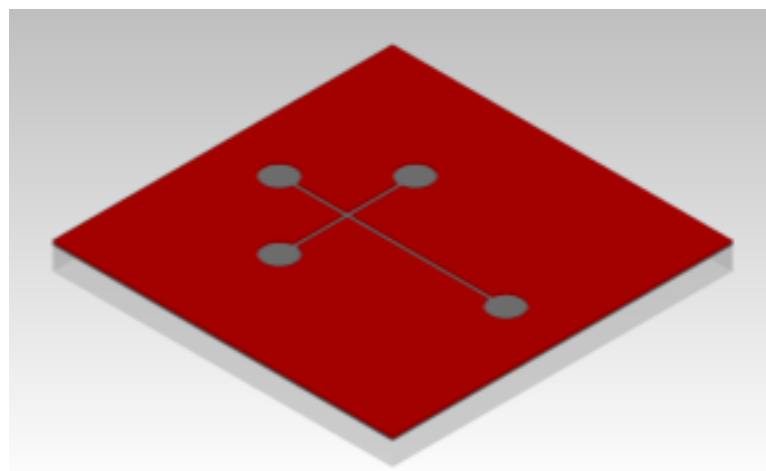

(c)

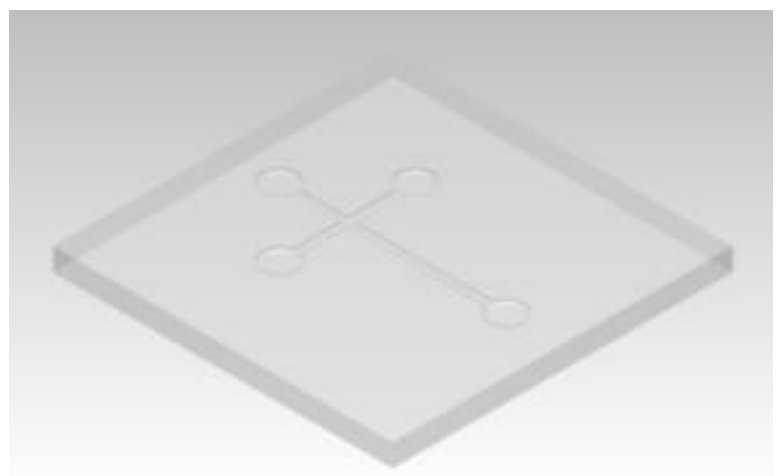

(e)

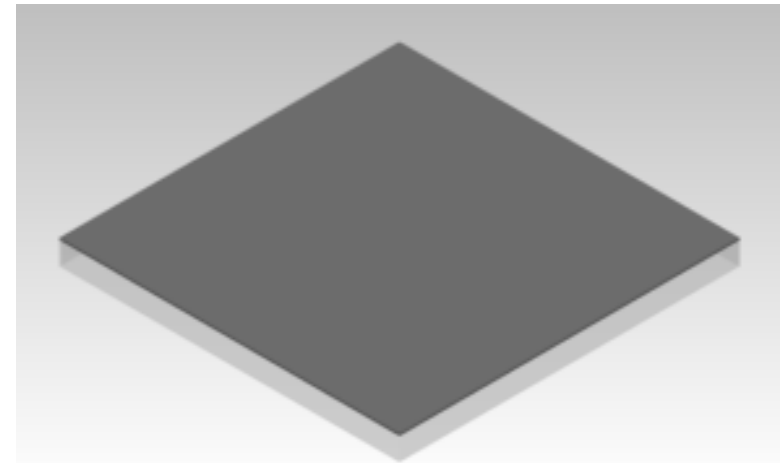

(b)

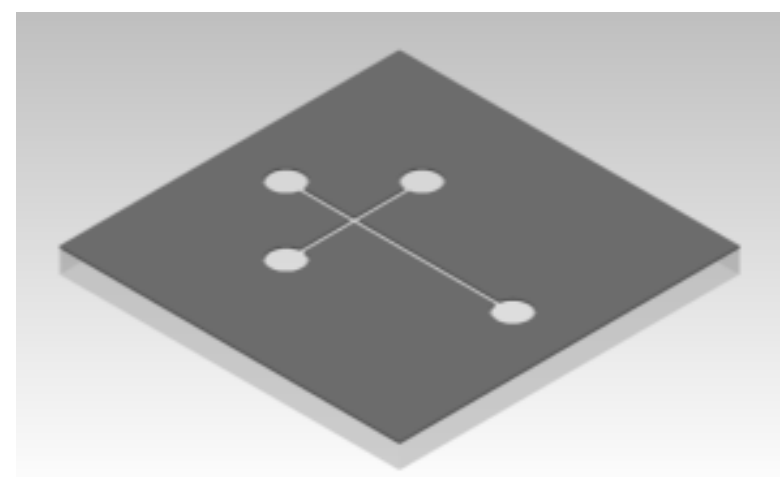

(d)

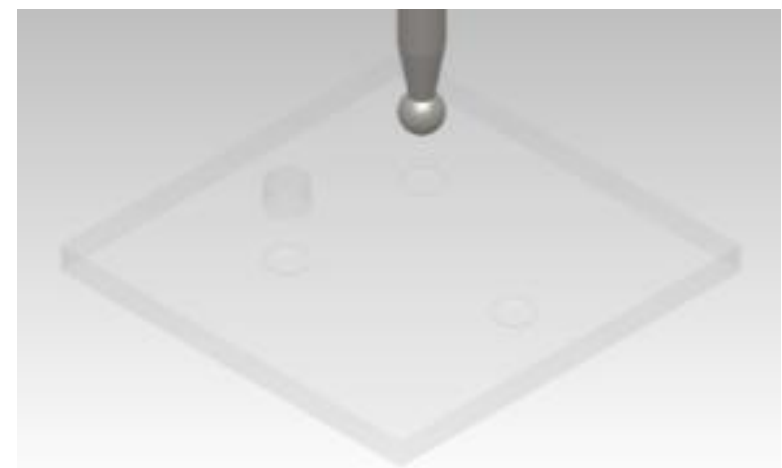

(f)

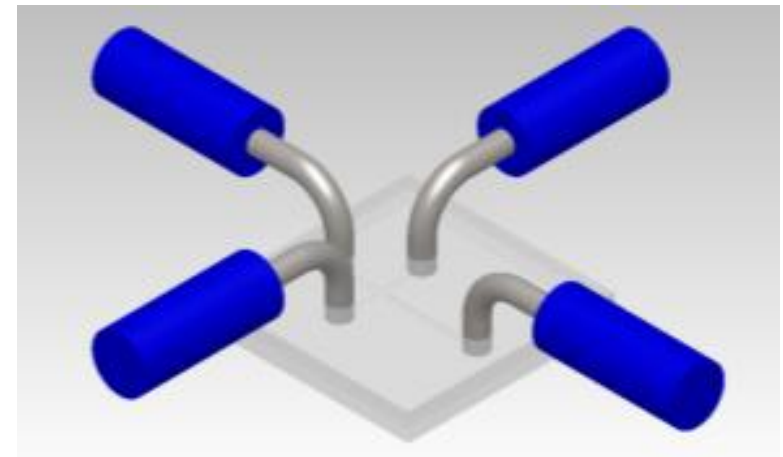

(g)

Figura 7 - Etapas do processo de fabricação dos microcanais em vidro: (a) sobre as lâminas de vidro Corning 7059, (b) é depositado um filme de cromo. (c) O filme passa por um processo de fotogravação e (d) é usado como material de mascaramento durante a corrosão das lâminas em solução da HF. Após a corrosão, (e) o filme de cromo é removido. (f) A lâmina de tampa passa ainda por uma etapa de furação. Por fim, (g) as lâminas são soldadas pela técnica de soldagem direta e os scalps são presos à estrutura. 


\section{DESENVOLVIMENTO DO SENSOR DE VAZÃO}

\subsection{DESCRIÇÃO DO SENSOR PROPOSTO}

O sensor de vazão apresentado neste trabalho usa o princípio de funcionamento térmico para fazer a aferição da vazão no interior de um microcanal. O sensor é composto por um filamento de níquel fabricado em um substrato de vidro, sobre o qual é soldado um bloco de PDMS contendo o microcanal. Um desenho esquemático do sensor está mostrado na figura 8. Os detalhes do processo de fabricação serão mostrados na seção 3.3.

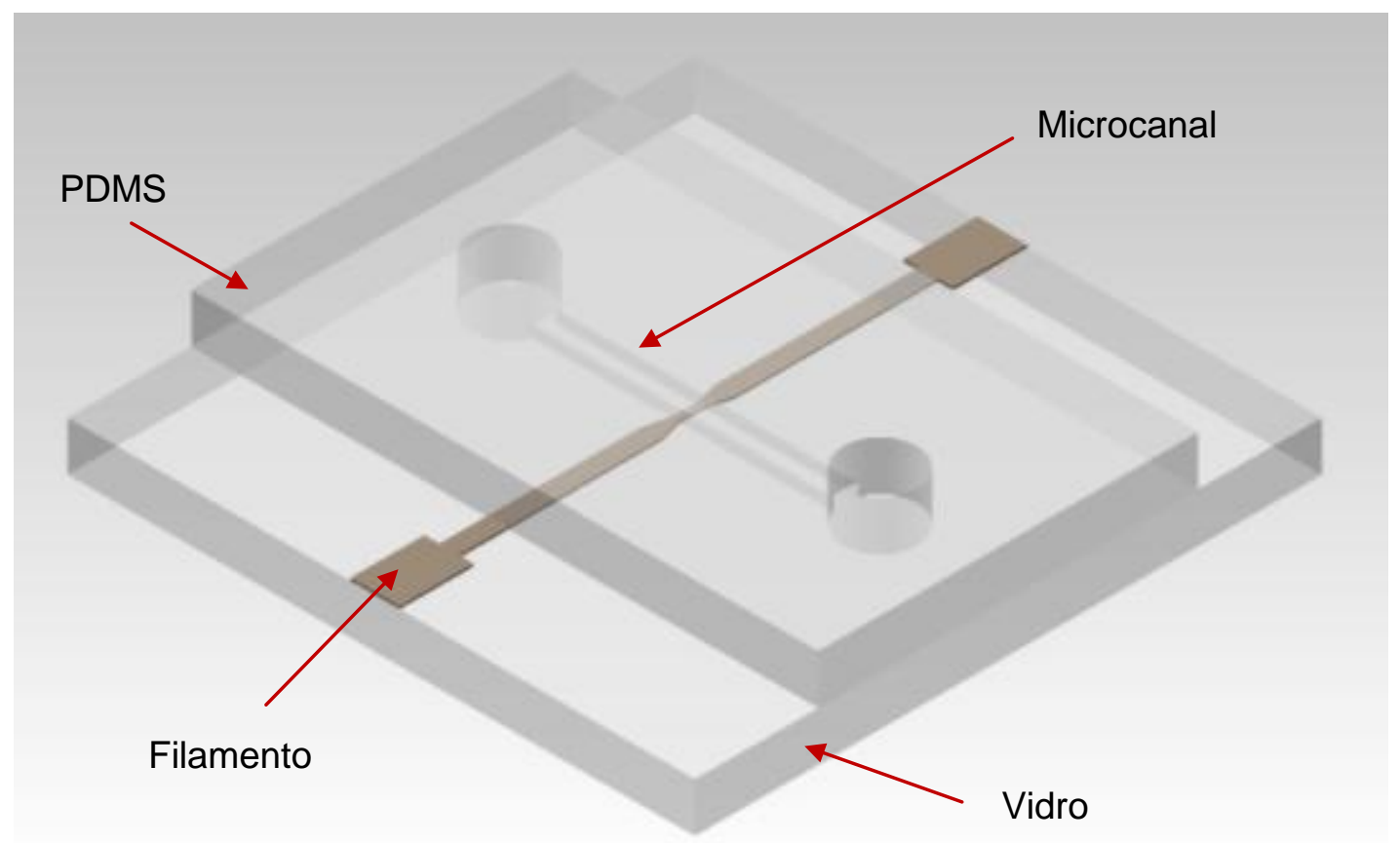

Figura 8 - Representação esquemática do sensor de vazão térmico proposto.

O sensor trabalha no modo de funcionamento à potência constante, ou seja, ele é polarizado com um valor de corrente constante e a saída do sensor é medida como uma variação no sinal da tensão. 
O sensor foi projetado para medir vazões típicas de sistemas microfluídicos, na faixa até aproximadamente $200 \mu \mathrm{L} / \mathrm{min}$, e possuir uma resolução da ordem de algumas dezenas de nanolitros por minuto. Uma das características buscadas no projeto do sensor foi a diminuição da temperatura máxima do filamento, possibilitando assim seu emprego em aplicações biológicas.

Além do sensor apresentado, no qual o filamento está em contato direto com o substrato de vidro, foram propostos três métodos alternativos de fabricação para deixar o filamento auto-sustentado no interior do microcanal. Espera-se com isso aumentar o isolamento térmico do filamento e, assim, a sensibilidade do sensor. Esses métodos serão apresentados no capítulo 5.

\subsection{MODELO A ELEMENTOS FINITOS}

Como mencionado na seção 2.3, na análise do sensor térmico de vazão no interior de um microcanal ocorrem interações entre três domínios físicos: elétrico, térmico e fluídico. Dentre eles, aquele de maior importância para o modelo é o domínio térmico já que é nele que está contido o princípio de funcionamento do sensor.

O problema de troca de calor no interior de um tubo ou duto foi extensivamente estudado. Basicamente dois fenômenos de transferência de calor estão envolvidos: condução e convecção térmica. Para problemas simplificados é possível encontrar uma expressão analítica que descreva esses fenômenos mas a grande maioria dos casos práticos requer artifícios matemáticos extremamente sofisticados ou, em última instância, métodos numéricos para se obter soluções aproximadas $(40,41,42)$.

Um parâmetro importante na análise da transferência de calor em escoamentos é o número de Péclet, que relaciona a troca de calor por condução e por convecção segundo a fórmula:

$$
P e=\frac{U \ell}{\kappa}
$$


sendo que $U$ é a velocidade característica do escoamento, $\ell$ é o comprimento característico do escoamento e $\kappa$ é a difusividade térmica, dada por:

$$
\kappa=\frac{k}{\rho c_{p}}
$$

lembrando que $k$ é o coeficiente de difusão térmica, $\rho$ é a densidade do fluido e $c_{p}$ é o calor específico do fluido à pressão constante. No caso do escoamento em um canal retangular, $U$ é escolhido como sendo a velocidade média do fluido na secção transversal do canal e $\ell$ a altura do canal.

Quando o número de Péclet é elevado, tipicamente maior do que 100, o efeito da convecção na troca de calor é significativo e isso permite que algumas simplificações sejam feitas, tornando o problema mais fácil de ser resolvido por métodos analíticos. Nesse caso, considera-se que todo o calor do filamento retirado pelo fluido é transportado no sentido do escoamento, ou seja, não existe fluxo de calor na direção contrária ao escoamento (42). Contudo, esse não é o caso para o escoamento do sensor proposto.

Considerando um microcanal com $500 \mu \mathrm{m}$ de largura e $50 \mu \mathrm{m}$ de altura e a vazão volumétrica de água passando por ele de $200 \mu \mathrm{L} / \mathrm{min}$, a velocidade média do escoamento pode ser calculada aproximadamente como sendo:

$$
U=\frac{200 \mu L / \mathrm{min}}{500 \mu \mathrm{m} \cdot 50 \mu \mathrm{m}}=\frac{200 \cdot 10^{-6} \cdot 10^{-3}}{60} \frac{\mathrm{m}^{3}}{\mathrm{~s}} \cdot \frac{1}{500 \cdot 10^{-6} \cdot 50 \cdot 10^{-6}} \frac{1}{\mathrm{~m}^{2}} \cong 0,13 \mathrm{~m} / \mathrm{s}
$$

Assim, o número de Péclet vale:

$$
P e=\frac{0,13 \cdot 50 \cdot 10^{-6}}{1,43 \cdot 10^{-7}} \cong 45
$$

Nessa situação, as trocas de calor por condução e convecção são da mesma magnitude e o fluxo de calor na direção contrária ao escoamento passa a ser importante, o que introduz uma dificuldade extra na resolução das equações. B. Weigand (42) apresenta um método analítico para resolução de problemas desse tipo em seu livro mas os procedimentos matemáticos envolvidos são extremamente 
complexos e inviabilizaram neste trabalho a construção de um modelo por elementos concentrados para o caso do sensor proposto.

Para contornar esse problema, foi realizada a modelagem do sensor pelo método de elementos finitos. Para isso, utilizou-se um software comercial para resolução de problemas por elementos finitos chamado Comsol Multiphysics ${ }^{\circledR}$.

A figura 9 mostra um desenho esquemático do sensor simulado visto em perspectiva (figura 9a), bem como duas vistas em corte: uma transversal (figura 9b) e outra longitudinal (figura 9c) à direção do escoamento. Também estão indicadas as principais dimensões do dispositivo.

Os valores numéricos das dimensões e de outros parâmetros empregados no modelo estão indicados na tabela 2. As dimensões empregadas foram baseadas nos valores reais dos dispositivos, que serão apresentados no item 3.3.

Tabela 2 - Parâmetros do modelo de elementos finitos.

\begin{tabular}{|c|c|}
\hline \multicolumn{2}{|c|}{ Dimensões do sensor } \\
\hline $\mathrm{L}=4 \mathrm{~mm}$ & $\mathrm{~L}_{\mathrm{f}}=1,9 \mathrm{~mm}$ \\
\hline $\mathrm{w}=500 \mu \mathrm{m}$ & $\mathrm{h}=50 \mu \mathrm{m}$ \\
\hline $\mathrm{t}=0,5 \mu \mathrm{m}$ & $a=50 \mu \mathrm{m}$ \\
\hline $\mathrm{t}_{\mathrm{v}}=1 \mathrm{~mm}$ & $t_{P D M S}=5 \mathrm{~mm}$ \\
\hline$a_{f}=500 \mu m$ & \\
\hline \multicolumn{2}{|c|}{ Propriedades da água (43) } \\
\hline \multicolumn{2}{|c|}{ Densidade $=998,2 \mathrm{~kg} / \mathrm{m}^{3}$} \\
\hline \multicolumn{2}{|c|}{ Viscosidade $=1,001.10^{-35}$ Pa.s } \\
\hline \multicolumn{2}{|c|}{ Condutividade térmica $=0,5984 \mathrm{~W} /(\mathrm{m} . \mathrm{K})$} \\
\hline \multicolumn{2}{|c|}{ Calor específico a pressão constante $=4183 \mathrm{~J} /(\mathrm{kg} . \mathrm{K})$} \\
\hline \multicolumn{2}{|c|}{ Propriedades do níquel (44) } \\
\hline \multicolumn{2}{|c|}{ Resistividade a $0^{\circ} \mathrm{C}=123,23 \cdot 10^{-9} \Omega \cdot \mathrm{m}$} \\
\hline \multicolumn{2}{|c|}{ Coeficiente de temperatura $(\mathrm{TCR})=0,0058661 / \mathrm{K}$} \\
\hline \multicolumn{2}{|c|}{ Condutividade térmica $=90,75 \mathrm{~W} /(\mathrm{m} . \mathrm{K})$} \\
\hline \multicolumn{2}{|c|}{ Propriedades do PDMS (45) } \\
\hline \multicolumn{2}{|c|}{ Condutividade térmica $=0,15 \mathrm{~W} /(\mathrm{m} . \mathrm{K})$} \\
\hline \multicolumn{2}{|c|}{ Propriedades do vidro (46) } \\
\hline Condutividad & n.K) \\
\hline
\end{tabular}




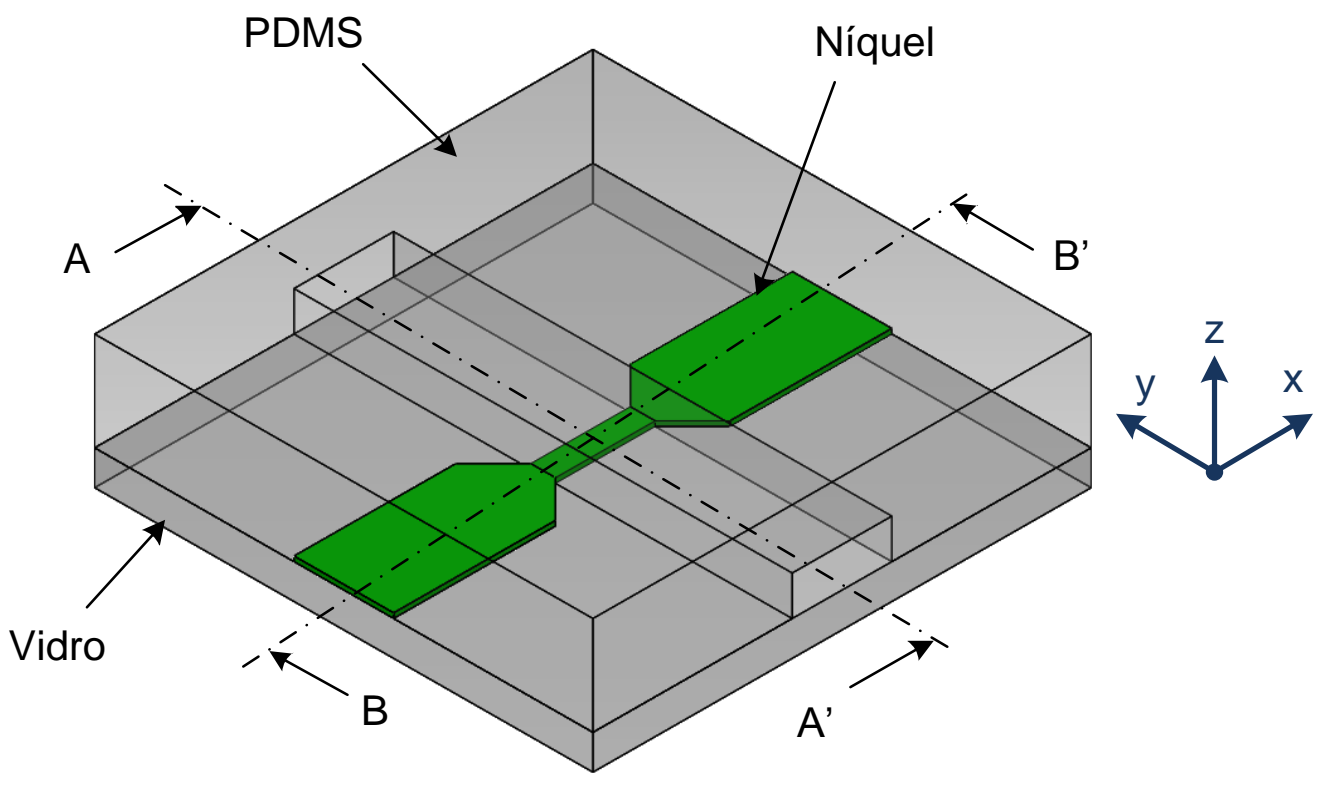

(a)

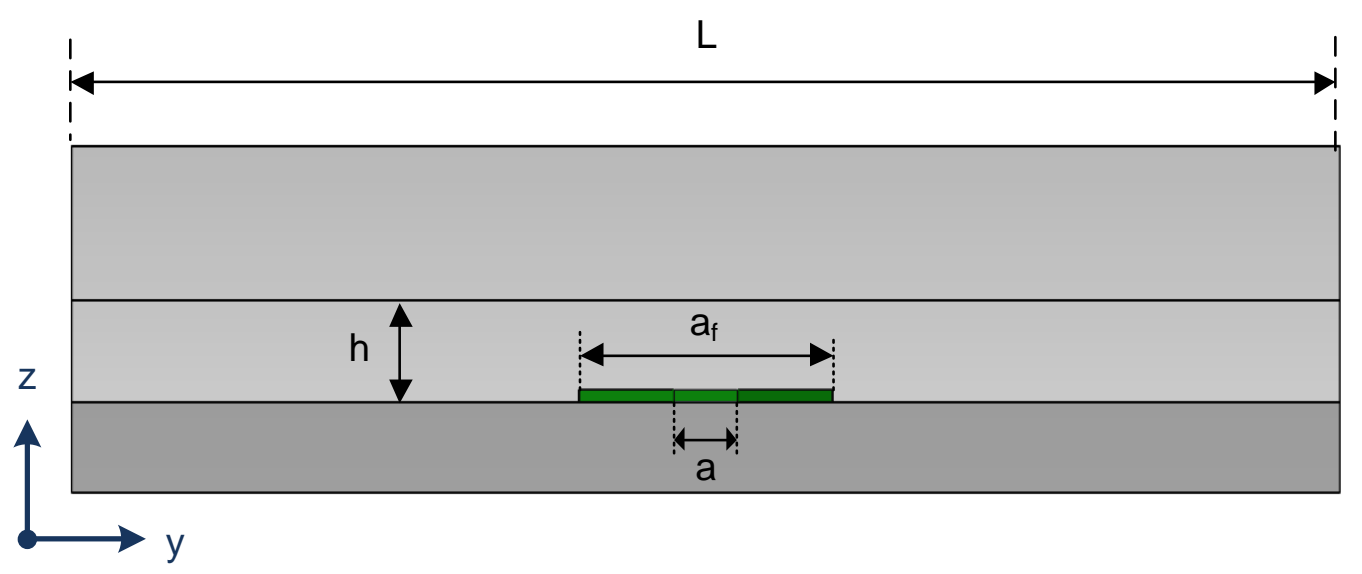

(b)

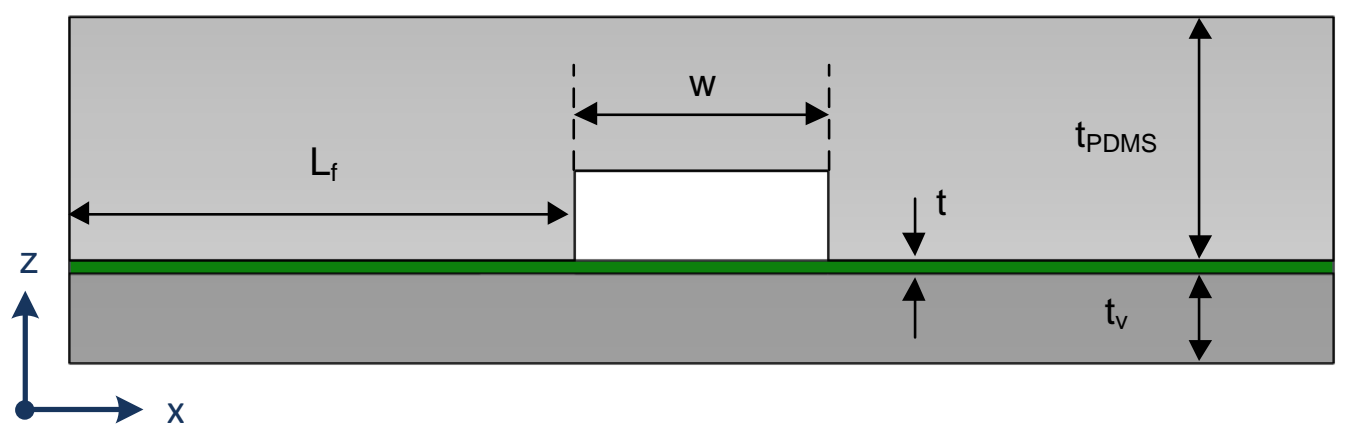

(c)

Figura 9 - Desenho esquemático do dispositivo. (a) Vista em perspectiva; (b) Vista no corte AA'; (c) Vista no corte BB'. 
Para diminuir o tempo de computação do modelo, os valores do comprimento do microcanal $(L)$ e do comprimento do filamento fora do microcanal $\left(L_{f}\right)$ foram escolhidos como sendo os menores valores que não interferissem na resposta do sensor. Além disso, dada a simetria do problema em relação ao plano xz passando pelo centro do microcanal, apenas metade do domínio foi simulado.

A simulação empregou uma malha não-estruturada com elementos tetraédricos, gerada a partir de algoritmos do próprio programa. Como condições de contorno, assumiu-se a passagem de uma corrente constante pelo filamento com valor de 20mA. A temperatura foi fixada em $20^{\circ} \mathrm{C}$ em três superfícies do domínio: entrada do microcanal, parte inferior do substrato de vidro e parte superior do bloco de PDMS. As demais bordas externas do domínio receberam a condição de contorno aberto (open boundary). Ela permite que o calor flua para dentro ou para fora do domínio de acordo com a temperatura especificada no exterior do domínio. Essa condição de contorno é útil para modelar domínios extensos, como é o caso do sensor.

Foram realizadas simulações estáticas para determinação do campo de temperaturas e da tensão sobre o filamento em regime estacionário, com a vazão volumétrica de entrada variando desde 0 a $200 \mu \mathrm{L} / \mathrm{min}$. A figura 10 mostra imagens do domínio de simulação no ambiente do programa e da malha gerada. O fluido escoa no sentido positivo do eixo y. Os resultados da simulação serão discutidos na seção 4.1 . 


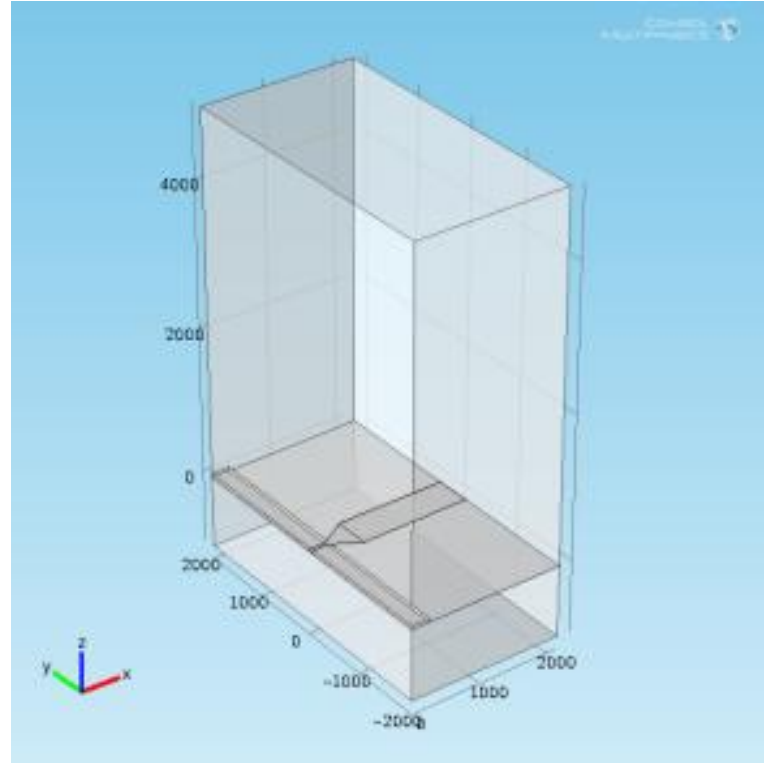

(a)

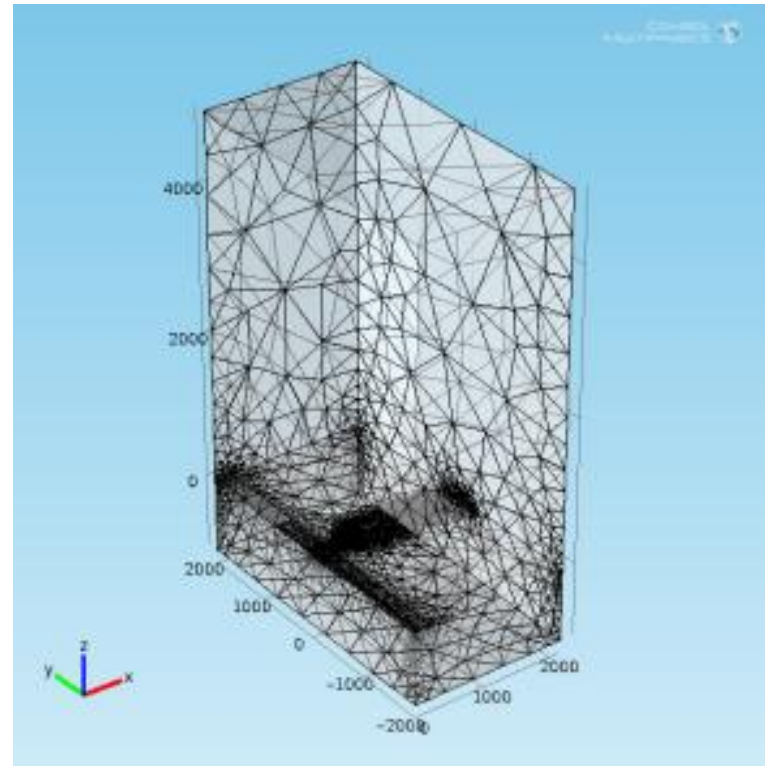

(c)

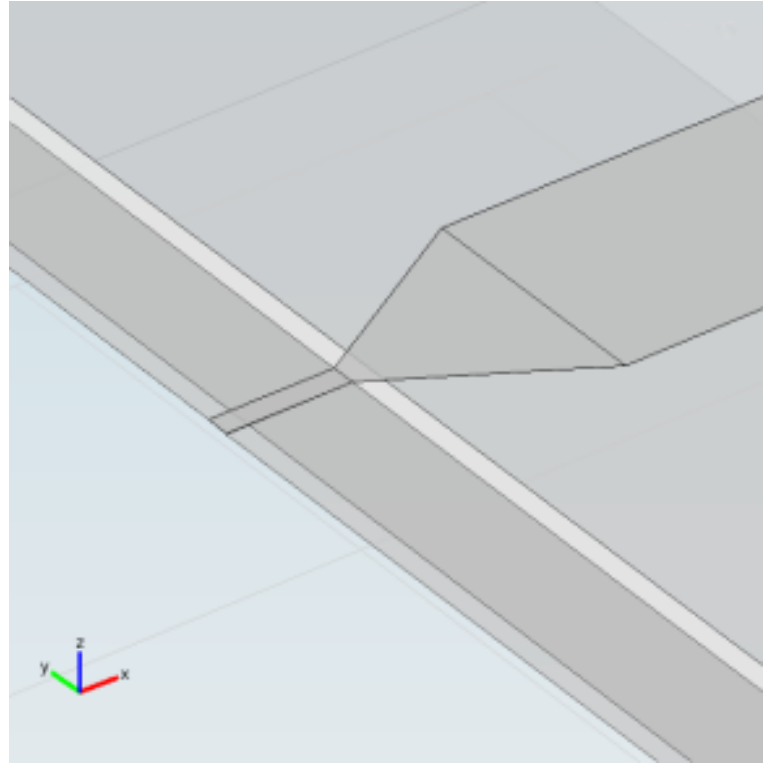

(b)

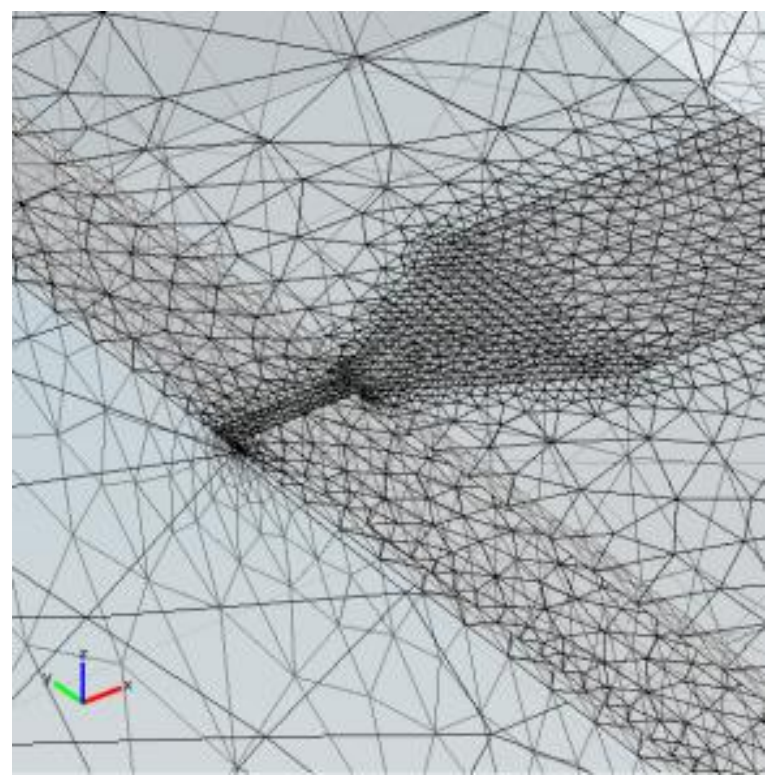

(d)

Figura 10 - Imagens do software de simulação por elementos finitos utilizado para simulação do sensor proposto. (a,b) Domínio de simulação; (c,d) Malha de elementos finitos gerada pelo programa. 


\subsection{PROCESSO DE FABRICAÇÃO DO SENSOR PROPOSTO}

Tendo sido adquirido o domínio sobre as técnicas de fabricação de microcanais em PDMS e em vidro (mostradas na seção 2.4), o desafio em fabricar o sensor de vazão está em incorporar a fabricação do filamento nos processos já existentes.

Um aspecto que tem impacto direto na resposta do sensor é o material que compõe o filamento. A principal característica a ser observada é o coeficiente de temperatura (Temperature Coefficient of Resistence ou TCR). Quanto maior o TCR do material, maior será a sensibilidade do sensor. Dentre os metais mais comuns na área de microfabricação, o níquel apresenta 0 maior coeficiente de temperatura $\left(\sim 0,005866^{\circ} \mathrm{C}^{-1}\right)$ e pode ser facilmente depositado pelas técnicas de eletrodeposição e Sputtering (33). Materiais semicondutores, como o silício policristalino e o carbeto de silício, também podem apresentar TCR elevado mas são mais incômodos de se trabalhar visto que normalmente exigem uma etapa adicional de implantação iônica após a deposição (47).

Dados os materiais e as técnicas disponíveis no laboratório, optou-se por fabricar o filamento em níquel. Entretanto, a seção 5.3.3 abordará um processo de fabricação alternativo ao aqui apresentado que emprega carbeto de silício dopado como material para o filamento.

A técnica escolhida para deposição do filme de níquel foi a eletrodeposição, por se tratar de uma técnica bastante simples, barata e estar disponível no laboratório. $\mathrm{Na}$ eletrodeposição, dois eletrodos são mergulhados em uma solução iônica e uma diferença de potencial é aplicada entre eles. A diferença de potencial força a passagem de uma corrente pela solução iônica que desencadeia uma reação de oxidorredução na região dos eletrodos. A reação de redução que ocorre no catodo (eletrodo com potencial negativo) faz com que os íons do metal presentes na solução sejam depositados sobre ele $(20,27,33)$.

A eletrodeposição é uma técnica bem estabelecida no meio industrial que foi adaptada como uma técnica de microfabricação para metais, principalmente ouro, cobre, níquel e ligas de níquel-aço (chamadas de Permalloy). Nesse caso, o filme 
geralmente já é depositado com a geometria de interesse, sem a necessidade de corrosão. Para isso é necessário aplicar e fotogravar o fotorresiste sobre a amostra, deixando expostas somente as regiões onde deve ser depositado o metal. Por se tratar de uma reação eletroquímica na qual há transferência de elétrons entre eletrodo e íons, a deposição só irá ocorrer nas regiões expostas da amostra. Caso a amostra não seja condutora é necessário depositar previamente uma camada condutora, normalmente de titânio, ouro ou platina, que serve de semente para o crescimento do filme. Parâmetros importantes que influenciam a deposição são a densidade de corrente de polarização, o pH, a temperatura, a agitação e a composição da solução $(20,27,33)$.

Uma vez que o filamento seja fabricado sobre o substrato de vidro, é necessário ainda fabricar o microcanal na lâmina da tampa e soldar as duas lâminas. Dadas as técnicas apresentadas na seção 2.4, o microcanal, ao menos em princípio, poderia ser fabricado tanto em PDMS como em vidro. Contudo, o processo de fabricação de microcanais em vidro (seção 2.4.2) inclui uma etapa extremamente agressiva de soldagem das lâminas. De fato, a técnica de soldagem direta exige um banho de 8 a 12 horas em ácido sulfúrico, o que deterioraria os filamentos de níquel. Assim, optou-se por fabricar o microcanal em PDMS.

Os filamentos são fabricados sobre lâminas de vidro de microscópio cortadas na dimensão $1 \times 1 \mathrm{pol}^{2}$. Uma vez que o vidro é um material isolante, é necessário depositar uma camada metálica sobre o substrato para que posteriormente seja feita a eletrodeposição do níquel. Por questões de aderência, foi necessária a deposição prévia de dois outros materiais: titânio e cobre. O filme de níquel eletrodepositado apresenta boa aderência sobre o cobre e má aderência sobre o titânio. O cobre, por sua vez, não apresenta boa aderência depositado diretamente sobre o vidro mas apresenta boa aderência sobre titânio. Assim, deposita-se primeiramente uma camada de titânio, que dá aderência para o filme de cobre que por sua vez serve de semente para deposição do filme de níquel. Ambos os filmes são depositados utilizando a técnica de Sputtering (33).

As etapas de fabricação do sensor de vazão foram dividas em duas partes detalhadas a seguir: fabricação do filamento sobre o substrato de vidro e fabricação do microcanal em PDMS. 


\subsubsection{Fabricação do filamento sobre o substrato de vidro}

\section{1) Preparo da lâmina de vidro}

As lâminas de vidro de microscópio com dimensão de $3 \times 1$ pol $^{2}$ são cortadas em lâminas menores de $1 \times 1$ pol $^{2}$ e então passam por um processo de limpeza para remoção de particulado e contaminantes, composta das seguintes etapas:

- Imersão das lâminas em solução de água deionizada $\left(\mathrm{H}_{2} \mathrm{O}\right.$ DI), hidróxido de amônio $\left(\mathrm{NH}_{4} \mathrm{OH}\right)$ e peróxido de hidrogênio $\left(\mathrm{H}_{2} \mathrm{O}_{2}\right)$, na proporção 5:1:1, no ultra-som por 15 minutos;

- Enxágüe em água corrente por 10 minutos;

- Imersão em álcool isopropílico (isopropanol) e aquecimento do mesmo até a total evaporação.

\section{2) Deposição do filme de titânio}

O filme de titânio que serve como camada de adesão para o filme de cobre é depositado por Sputtering. As condições de deposição são mostradas na tabela 3. O filme obtido possui espessura da ordem de $30 \mathrm{~nm}$.

Tabela 3 - Condições para a deposição de titânio por Sputtering.

\begin{tabular}{|l|l|}
\hline Fluxo de argônio & $10 \mathrm{sccm}$ \\
\hline Pressão na câmara & 2 mTorr \\
\hline Potência de RF & $150 \mathrm{~W}$ \\
\hline DC Bias & $-168 \mathrm{~V}$ \\
\hline Temperatura & Não controlada e não medida \\
\hline Tempo & 1 minuto \\
\hline
\end{tabular}




\section{3) Deposição do filme de cobre}

O filme de cobre é usado como semente para a eletrodeposição de níquel. Um filme fino de aproximadamente $30 \mathrm{~nm}$ é depositada seguindo as condições da tabela 4.

Tabela 4 - Condições para a deposição de cobre por Sputtering.

\begin{tabular}{|l|l|}
\hline Fluxo de argônio & $10 \mathrm{sccm}$ \\
\hline Pressão na câmara & $2 \mathrm{mTorr}$ \\
\hline Potência de RF & $70 \mathrm{~W}$ \\
\hline DC Bias & $-117 \mathrm{~V}$ \\
\hline Temperatura & Não controlada e não medida \\
\hline Tempo & 1,5 minuto \\
\hline
\end{tabular}

\section{4) Eletrodeposição do filme de níquel}

Para que o filme de níquel seja depositado seguindo o padrão desejado, primeiramente é feita a fotogravação do fotorresiste AZ-1518 com esse padrão. A lâmina então passa pela etapa de eletrodeposição, sendo que o filme de níquel será depositado apenas nas regiões onde o filme de cobre está exposto. Ao final removese o fotorresiste da superfície da lâmina.

O padrão utilizado neste caso é aquele mostrado na figura 11. São fabricados três sensores por microcanal (os microcanais serão definidos somente no processo de fabricação da tampa de PDMS na seção 3.3.2). Os sensores apresentam três valores de largura $(50 \mu \mathrm{m}, 100 \mu \mathrm{m}$ e $200 \mu \mathrm{m})$ e três valores de comprimento (400 $\mu \mathrm{m}, 700 \mu \mathrm{m}$ e 1,2 mm), de acordo com a largura do microcanal. Além dos filamentos retos, um conjunto de filamentos no formato de serpentina também é fabricado. Espera-se com isso aumentar a sensibilidade do sensor. Marcas de alinhamento podem ser vistas nos quatro cantos da fotomáscara (quadrados brancos). 


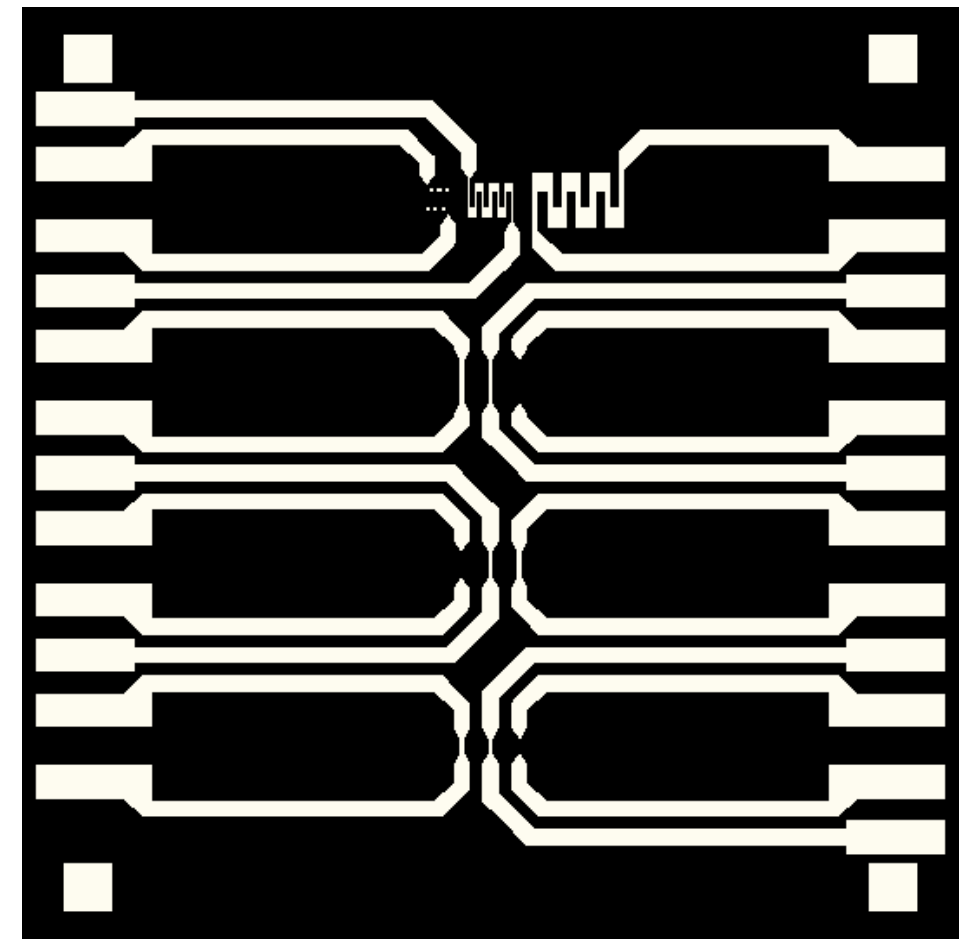

Figura 11 - Fotomáscara empregada na fabricação dos filamentos.

São empregados na eletrodeposição uma cuba de polipropileno, um eletrodo de níquel com alto grau de pureza inserido em um saco de polipropileno como anodo, uma solução contendo sais de níquel e ainda uma fonte de tensão. A amostra é presa a um suporte de teflon e pressionada contra uma placa de circuito impresso com auxílio de porcas, também de teflon. Sobre a placa foi feita uma abertura quadrada para que a solução pudesse entrar em contato com a amostra e foram definidas trilhas metálicas para realização do contato elétrico com as bordas da amostra.

A solução de sais de níquel é mantida aquecida a uma temperatura constante com auxílio de um hot plate e sob agitação de um agitador linear no qual o portaamostras é preso. O pólo positivo da fonte é conectado ao eletrodo de níquel e o pólo negativo à amostra na qual será depositado o níquel. Durante a eletrodeposição a corrente é mantida constante. Fotos do porta-amostras e da montagem experimental são mostrada na figura 12. 


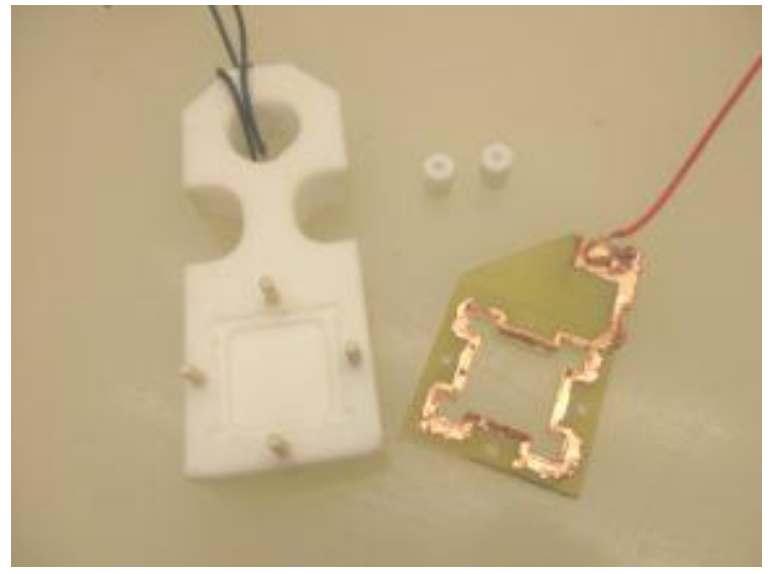

(a)

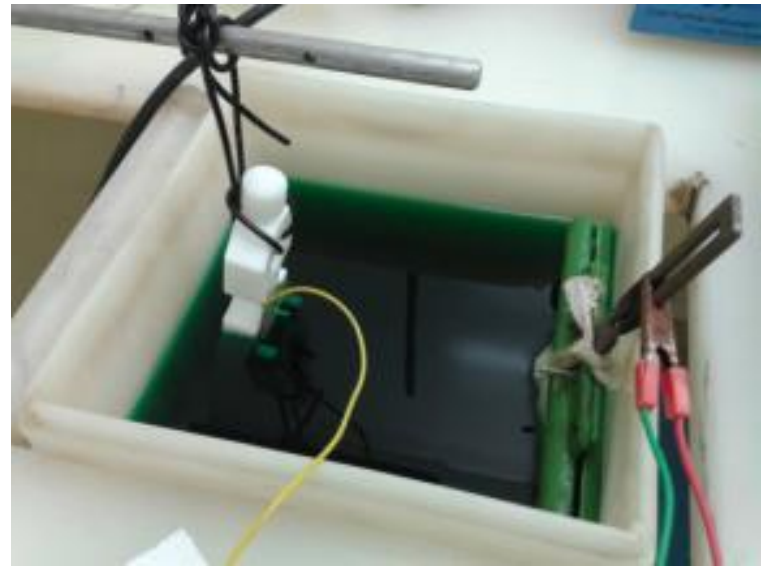

(b)

Figura 12 - Fotos da montagem experimental para realização da eletrodeposição. (a) Porta-amostras utilizado; (b) Montagem experimental.

Para melhorar a qualidade dos filmes obtidos, adicionam-se na solução, além dos sais de níquel, alguns aditivos. Os aditivos empregados são do modelo E-Brite 757, da EPi (Electrochemical Products Inc.), e a solução foi preparada segunda a formulação apresentada pelo fabricante, que está mostrada na tabela 5.

Tabela 5 - Formulação da solução para eletrodeposição de níquel.

\begin{tabular}{|l|c|c|}
\hline \multicolumn{1}{|c|}{ Ingredientes } & Faixa de tolerância & Valor sugerido \\
\hline Sulfato de níquel & $\begin{array}{c}239,65-374,45 \mathrm{~g} / \mathrm{L} \\
(32-50 \mathrm{oz} / \mathrm{gal})\end{array}$ & $\begin{array}{c}299,57 \mathrm{~g} / \mathrm{L} \\
(40 \mathrm{oz} / \mathrm{gal})\end{array}$ \\
\hline Cloreto de níquel & $\begin{array}{c}44,93-74,89 \mathrm{~g} / \mathrm{L} \\
(6-10 \mathrm{oz} / \mathrm{gal})\end{array}$ & $\begin{array}{c}59,91 \mathrm{~g} / \mathrm{L} \\
(8 \mathrm{oz} / \mathrm{gal})\end{array}$ \\
\hline Níquel metálico & $\begin{array}{c}59,91-97,36 \mathrm{~g} / \mathrm{L} \\
(8-13 \mathrm{oz} / \mathrm{gal})\end{array}$ & $\begin{array}{c}80,88 \mathrm{~g} / \mathrm{L} \\
(10,8 \mathrm{oz} / \mathrm{gal})\end{array}$ \\
\hline Ácido bórico & $\begin{array}{c}37,45-52,42 \mathrm{~g} / \mathrm{L} \\
(5-7 \mathrm{oz} / \mathrm{gal})\end{array}$ & $\begin{array}{c}44,93 \mathrm{~g} / \mathrm{L} \\
(6 \mathrm{oz} / \mathrm{gal})\end{array}$ \\
\hline Aditivo E-Brite 757Cr Carrier & $3-6 \% \mathrm{por}$ volume & $5 \% \mathrm{por}$ volume \\
\hline Aditivo E-Brite 757B & & $0,1 \%$ por volume \\
\hline Agente E-Wet 701W Air & & $0,1 \%$ por volume \\
\hline Agente E-Wet 702W BBL & & $0,1 \%$ por volume \\
\hline
\end{tabular}

* Valores convertidos de oz/gal. (onças por galão) para g/L (gramas por litro) e arredondados na segunda casa decimal. 
O fabricante recomenda que o pH da solução esteja entre 3,5 e 4,5 (idealmente 4) e que o processo seja feito entre 43,33 e $65,56^{\circ} \mathrm{C}\left(110\right.$ a $\left.150^{\circ} \mathrm{F}\right)$.

Testes de eletrodeposição foram feitos visando determinar a taxa de deposição e obter filmes com o melhor acabamento superficial. Os detalhes dos testes efetuados não estão relatados neste trabalho mas as condições de deposição ótima estão mostradas na tabela 6. A espessura esperada de filme é de 500 nm.

Tabela 6 - Condições ótimas para a eletrodeposição de níquel.

\begin{tabular}{|l|l|}
\hline Temperatura & $\sim 40^{\circ} \mathrm{C}$ \\
\hline Corrente & $25 \mathrm{~mA}$ \\
\hline Setpoint de tensão & $12 \mathrm{~V}$ \\
\hline Tensão real & $\sim 1 \mathrm{~V}$ \\
\hline Tempo & 10 minutos \\
\hline
\end{tabular}

\section{5) Corrosão dos filmes de titânio e cobre}

Os filmes de titânio e cobre que foram depositados sobre toda a lâmina devem ser removidos para que os filamentos não fiquem em curto. O filme de níquel recémdepositado serve como material de mascaramento para a corrosão desses filmes. A corrosão deve ser muito bem controlada para evitar que a parte dos filmes que está abaixo do níquel seja corroída, desprendendo assim os filamentos. Para tanto, foi utilizado um processo de remoção composto por três etapas.

A primeira etapa consiste em mergulhar a lâmina em uma solução de $100 \mathrm{~mL}$ de $\mathrm{H}_{2} \mathrm{O}$ deionizada : $1 \mathrm{~mL}$ de $\mathrm{H}_{2} \mathrm{O}_{2}: 1 \mathrm{~mL}$ de $\mathrm{NH}_{4} \mathrm{OH}$. Essa solução provoca a oxidação do cobre, levando à formação de uma camada muito fina e de espessura bastante controlada (algumas camadas atômicas) de óxido de cobre.

$\mathrm{Na}$ etapa seguinte, o óxido de cobre é corroído em ácido acético glacial. O ácido acético apresenta ótima seletividade entre cobre e óxido cobre, atacando apenas o segundo. Dado que a espessura da camada de óxido é muito pequena, essa técnica garante que a remoção do filme de cobre será feita de forma bastante controlada. 
Esses dois passos devem ser repetidos algumas vezes (tipicamente 2 ou 3 vezes) até que ocorra a remoção total do filme de cobre, deixando exposto o filme de titânio.

A terceira e última etapa consiste em corroer o filme de titânio. Para isso, a lâmina é mergulhada em uma solução de HF diluído em água deionizada na proporção 20:1 $\left(\mathrm{H}_{2} \mathrm{O}\right.$ DI : $\left.\mathrm{HF}\right)$. Mesmo diluído, o ácido fluorídrico ataca rapidamente o filme de titânio tendo essa etapa uma duração de poucos segundos.

A corrosão dos filmes de titânio e cobre conclui o processo de fabricação do filamento sobre o substrato de vidro. A figura 13 mostra uma representação da sequência de fabricação. 
$\begin{array}{llllllll}\text { LEGENDA } & 1 & \mathrm{Ti} & \mathrm{Cu} & \text { Fotorresiste } & 2 & \mathrm{Ni}\end{array}$
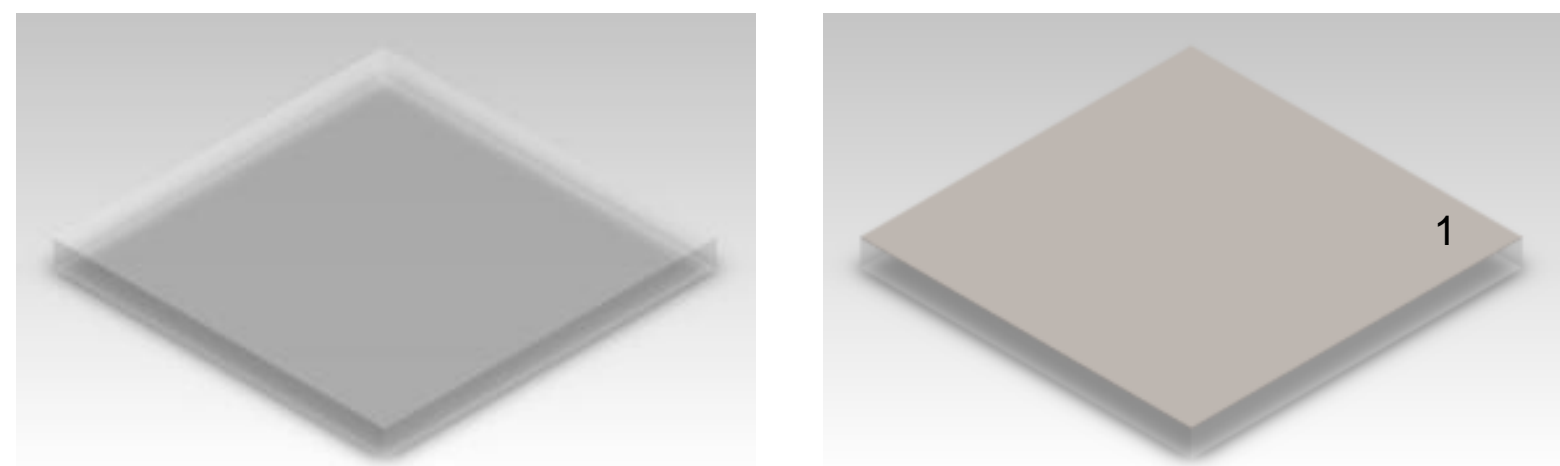

(a)

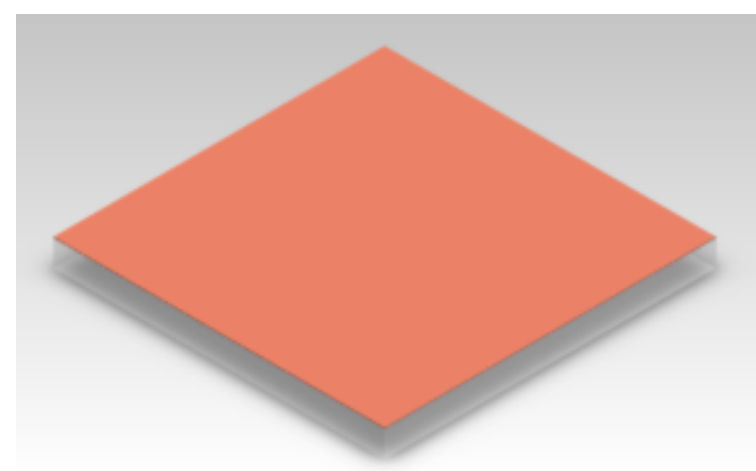

(c)

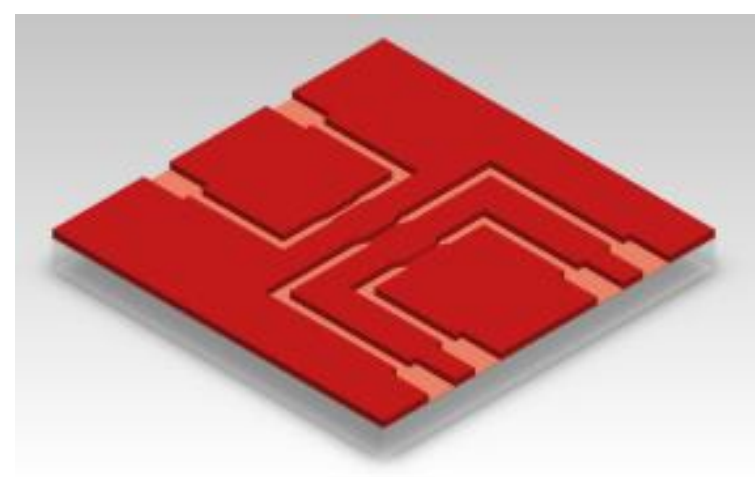

(e)

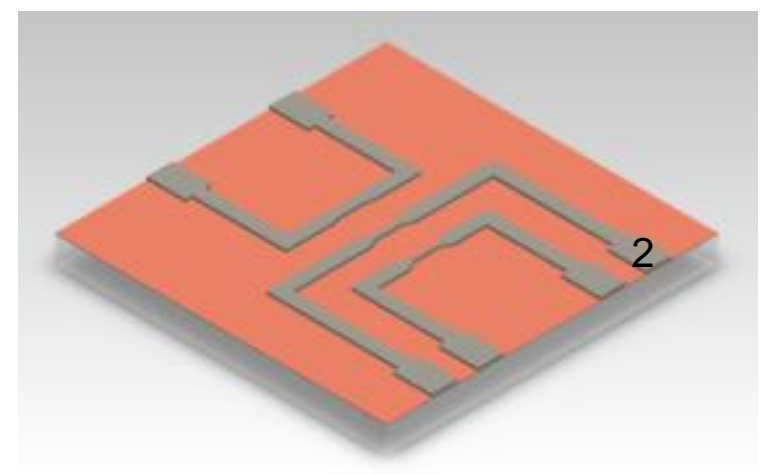

(g)

(b)

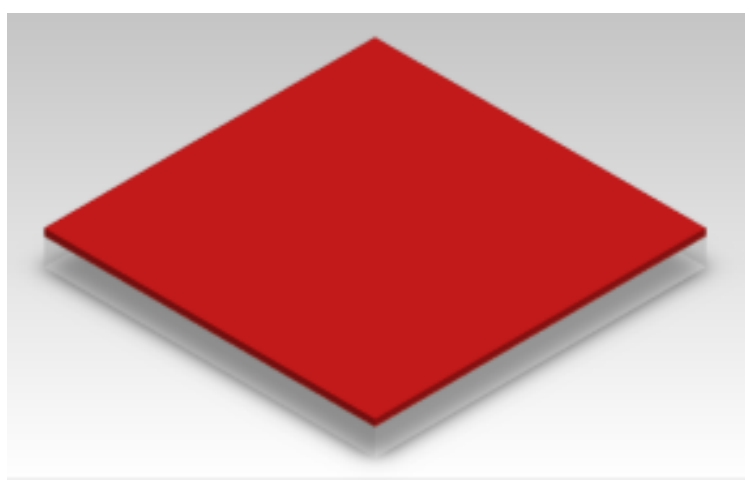

(d)

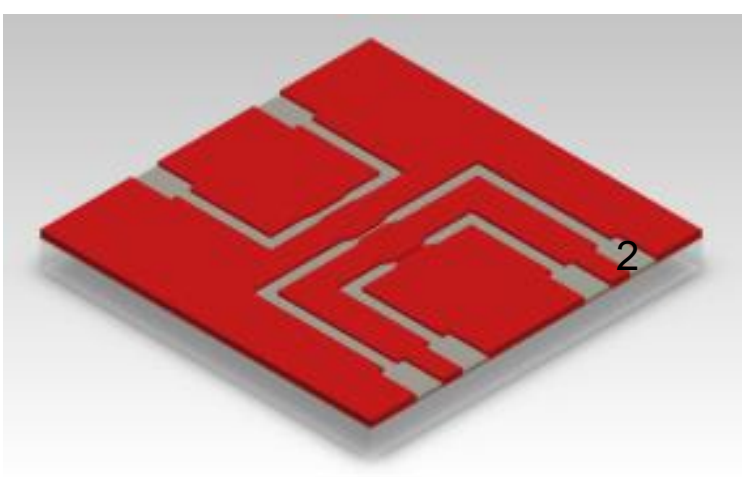

(f)

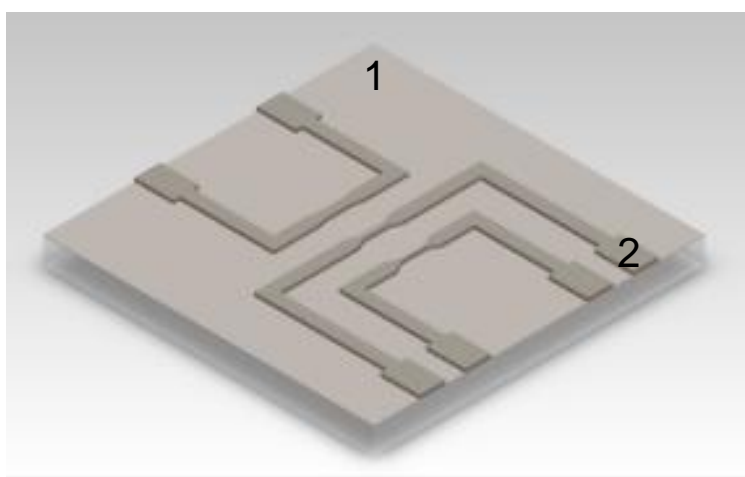

(h) 


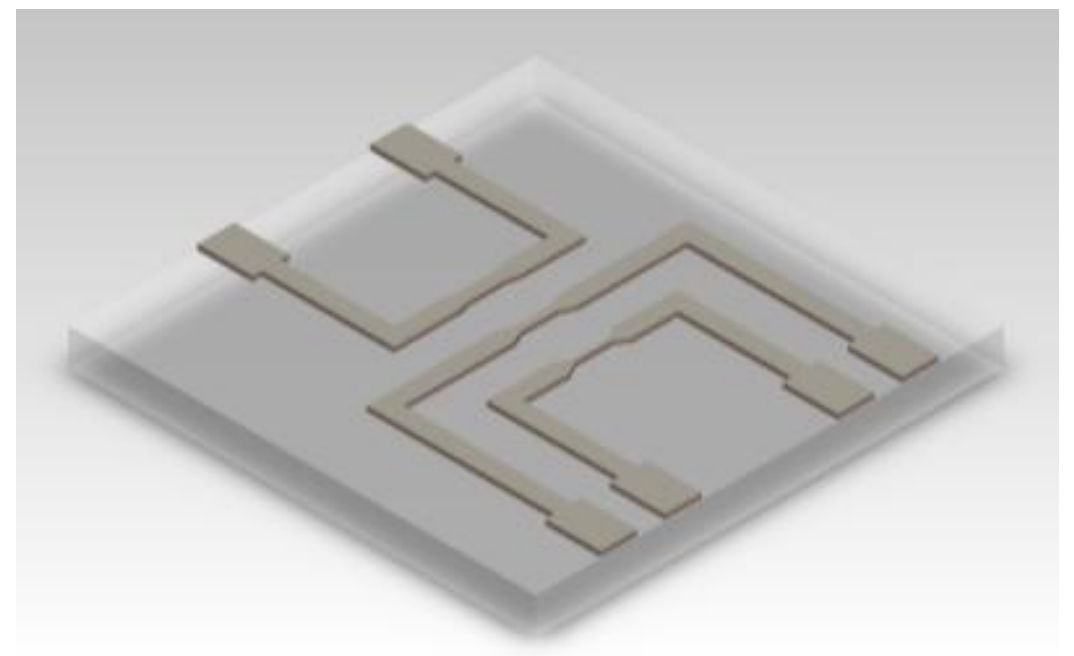

(i)

Figura 13 - Etapas do processo de fabricação do sensor de vazão proposto. (a) Partindo de uma lâmina de vidro limpa, deposita-se (b) um filme de titânio e (c) outro de cobre por Sputtering. Em seguida é feita (d) a aplicação e (e) a fotogravação do fotorresiste com o padrão dos filamentos. Através das aberturas no fotorresiste é feita (f) a eletrodeposição do filme de níquel. (g) $\mathrm{O}$ fotorresiste então é removido, bem como os filmes (h) de cobre e (i) de titânio, obtendo-se assim a lâmina com os sensores fabricados.

\subsubsection{Fabricação do microcanal na tampa de PDMS}

Uma vez produzidos os filamentos sobre o vidro, resta ainda fabricar a tampa contendo os microcanais. A tampa é feita em PDMS e os microcanais são fabricados pela técnica de litografia macia por replicação de molde. Para finalizar a fabricação do sensor, é necessário soldar a tampa de PDMS no substrato de vidro e preparar os acessos externos para entrada e saída de fluido. A sequência de processos é apresentada a seguir.

\section{1) Preparo da lâmina de silício}

Um wafer de silício de 4 polegadas de diâmetro é cortado em lâminas de $1 \times 1$ pol $^{2}$ sobre as quais será fabricado o molde de SU-8. As lâminas passam por uma limpeza inicial do tipo RCA para remoção de compostos orgânicos, metais, compostos alcalinos e óxido de silício. Essa limpeza segue as seguintes etapas: 
1. Imersão das lâminas em solução de ácido sulfúrico $\left(\mathrm{H}_{2} \mathrm{SO}_{4}\right)$ e peróxido de hidrogênio $\left(\mathrm{H}_{2} \mathrm{O}_{2}\right)$, na proporção $3: 1$, a $105^{\circ} \mathrm{C}$ por 15 minutos;

2. Enxágüe das lâminas em água corrente por 10 minutos;

3. Cascatinha por 5 minutos (as lâminas são colocadas em um copo Becker e um filete de água cai dentro dele, de modo a fazer com que o líquido transborde);

4. Imersão das lâminas em solução de água deionizada $\left(\mathrm{H}_{2} \mathrm{O} \mathrm{DI}\right)$, hidróxido de amônio $\left(\mathrm{NH}_{4} \mathrm{OH}\right)$ e peróxido de hidrogênio $\left(\mathrm{H}_{2} \mathrm{O}_{2}\right)$, na proporção $5: 1: 1$, a $75^{\circ} \mathrm{C}$ por 15 minutos;

5. Enxágüe em água corrente por 10 minutos;

6. Cascatinha por 5 minutos;

7. Imersão das lâminas em DLV $\left(4 \mathrm{HF}+25 \mathrm{NH}_{4} \mathrm{~F}\right)$, a temperatura ambiente por 15 segundos;

8. Enxágüe em água corrente por 15 minutos;

9. Imersão das lâminas em solução de água $\left(\mathrm{H}_{2} \mathrm{O}\right)$, peróxido de hidrogênio $\left(\mathrm{H}_{2} \mathrm{O}_{2}\right)$ e ácido clorídrico $(\mathrm{HCl})$, na proporção $6: 1: 1$, a $80^{\circ} \mathrm{C}$ por 15 minutos;

10. Cascatinha por 10 minutos;

11. Secagem das lâminas em jato de nitrogênio $\left(\mathrm{N}_{2}\right)$.

\section{2) Aplicação e fotogravação do fotorresiste}

O fotorresiste utilizado neste caso é o SU-8 Série 2000, muito empregado na litografia macia e na microfabricação de MEMS em geral. Ele apresenta boa estabilidade térmica e química, possibilita a criação de películas de até $200 \mu \mathrm{m}$ de 
espessura em uma única aplicação e apresenta paredes extremamente verticais após fotogravado. Trata-se de um fotorresiste negativo, ou seja, as regiões sensibilizadas com radiação ultravioleta tornam-se insolúveis ao revelador.

O SU-8 é aplicado sobre uma lâmina de silício por spin coating e então fotogravado com o padrão dos microcanais que serão fabricados em PDMS. Neste trabalho, foi utilizado o SU-8 2050, que possui espessura nominal 50 um quando aplicado a um rotação de 3000 rpm. O desenho da fotomáscara empregada está mostrado na figura 14. Ela contém quatro microcanais de $15 \mathrm{~mm}$ de comprimento (de centro a centro do círculo) e três diferentes larguras: 600 $\mu \mathrm{m}$ (repetido duas vezes), $900 \mu \mathrm{m}$ e $1,4 \mathrm{~mm}$. Os microcanais são propositadamente $200 \mu \mathrm{m}$ mais largos do que a região mais estreita dos filamentos. A intenção é impedir que algum desalinhamento que possa ocorrer no momento da soldagem por plasma venha a inviabilizar o uso da estrutura.

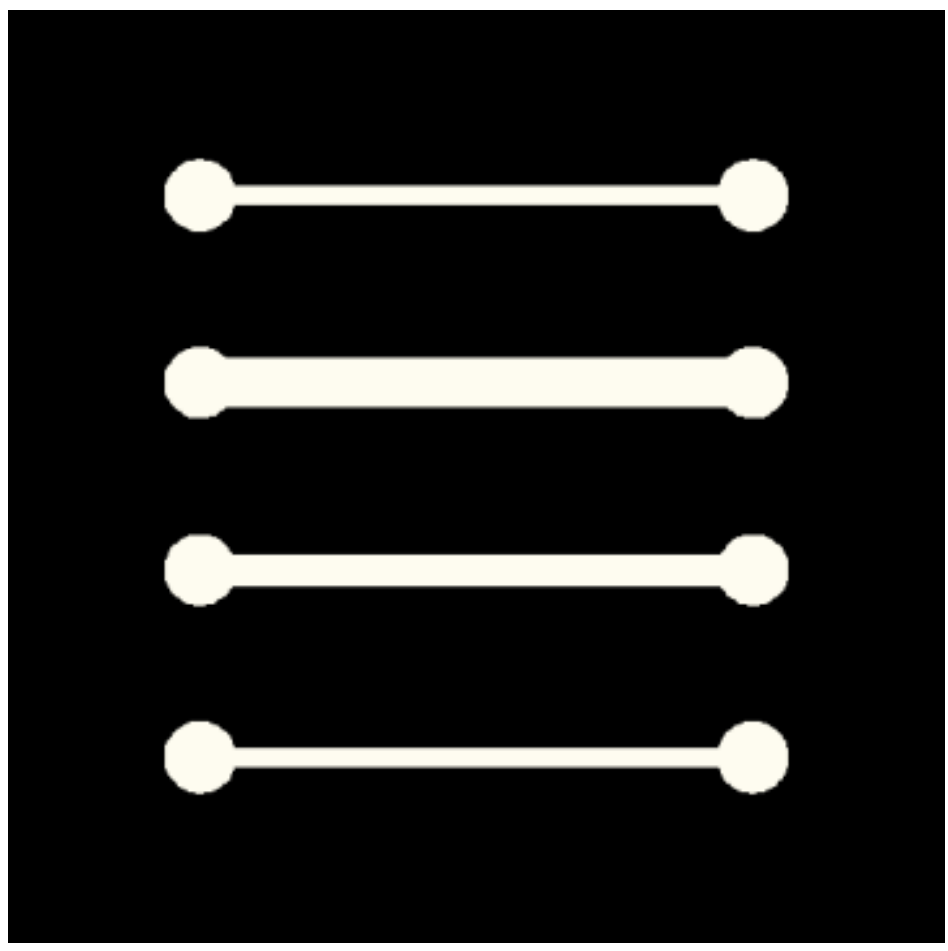

Figura 14 - Fotomáscara empregada na fabricação dos microcanais em PDMS. 


\section{3) Litografia macia do PDMS}

A base líquida de PDMS e seu agente de cura são misturados na proporção 10:1 (base : agente de cura) e derramados sobre o molde de SU-8. O conjunto é levado para uma câmara de vácuo para remoção das bolhas geradas na mistura dos dois compostos e então para um hot plate a $75^{\circ} \mathrm{C}$ para que seja feita a cura do PDMS durante 12 horas. Por fim, o bloco de PDMS é removido do molde e os furos de acesso são feitos.

\section{4) Soldagem do PDMS no vidro}

O bloco de PDMS e a lâmina de vidro contendo os sensores de vazão são soldados através da técnica de soldagem por plasma. Ambos são levados a um reator para um tratamento superficial em plasma de oxigênio. $O$ plasma ativa as superfícies promovendo a colagem das amostras. Antes disso, porém, a lâmina de vidro é colocada em um copo Becker com acetona fervente por 10 minutos e depois enxaguada em água deionizada como uma etapa prévia de limpeza antes da soldagem. As condições empregadas estão apresentadas tabela 7.

Tabela 7 - Condições de processo para a soldagem por plasma.

\begin{tabular}{|l|l|}
\hline Fluxo de oxigênio & $50 \mathrm{sccm}$ \\
\hline Pressão na câmara & 200 mTorr \\
\hline Potência de RF & $100 \mathrm{~W}$ \\
\hline Temperatura & Não controlada e não medida \\
\hline DC Bias & Não medido \\
\hline Tempo & 5 minutos \\
\hline
\end{tabular}

\section{5) Preparo dos acessos externos}

Os acessos externos são feitos conectando aos furos do PDMS tubos de plástico. Até o momento, estão sendo usados scalps de uso médico cuja ponta que contém a agulha tenha sido previamente removida. $O$ fato de o PDMS ser flexível garante a vedação na conexão, sem necessidade de cola ou qualquer outro artifício. 
As etapas desse processo de fabricação estão ilustradas na figura 15 a seguir.

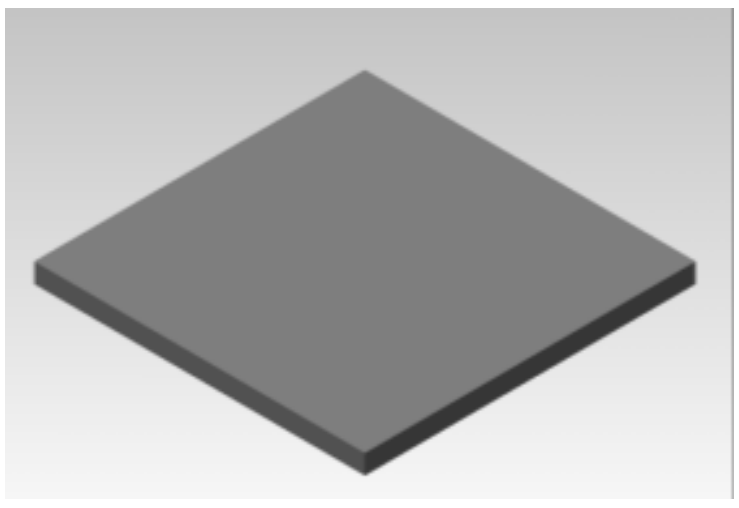

(a)

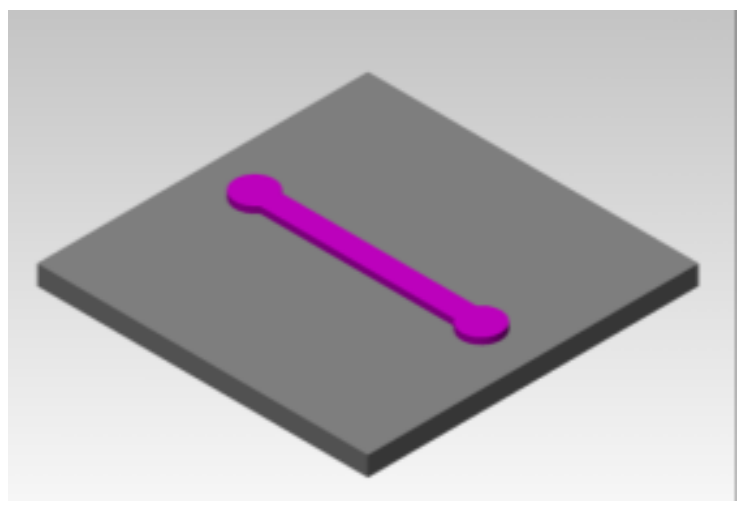

(c)

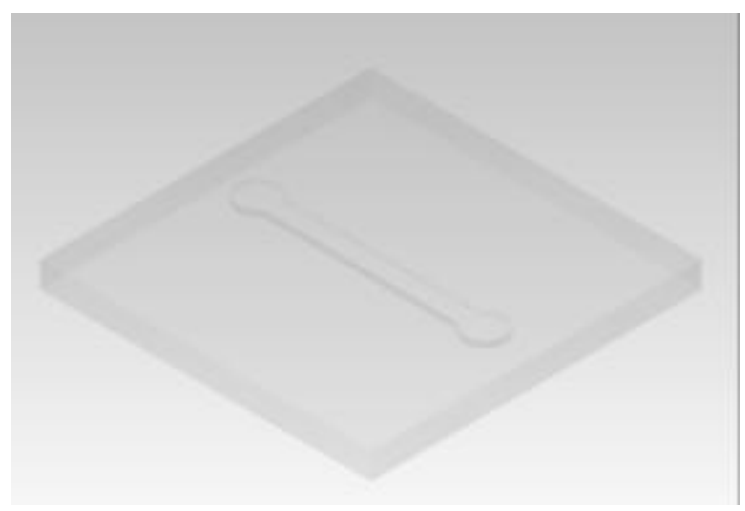

(e)

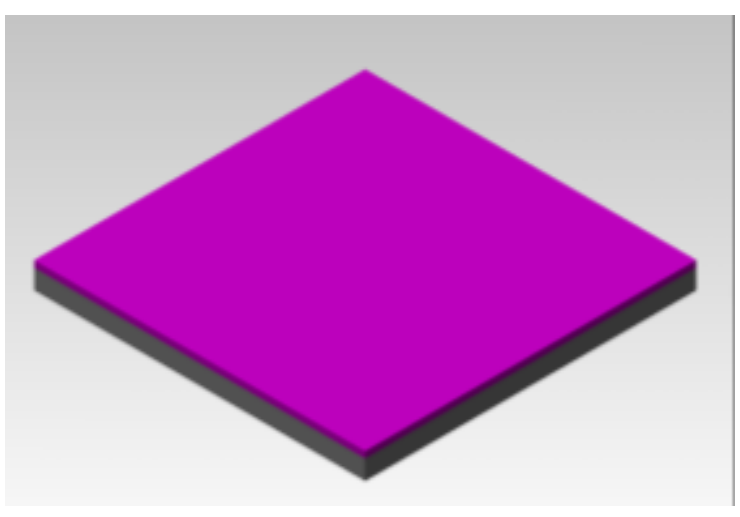

(b)

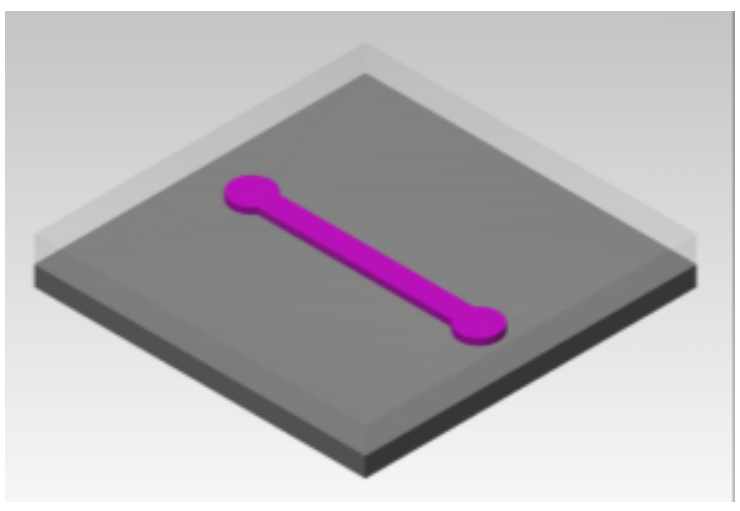

(d)

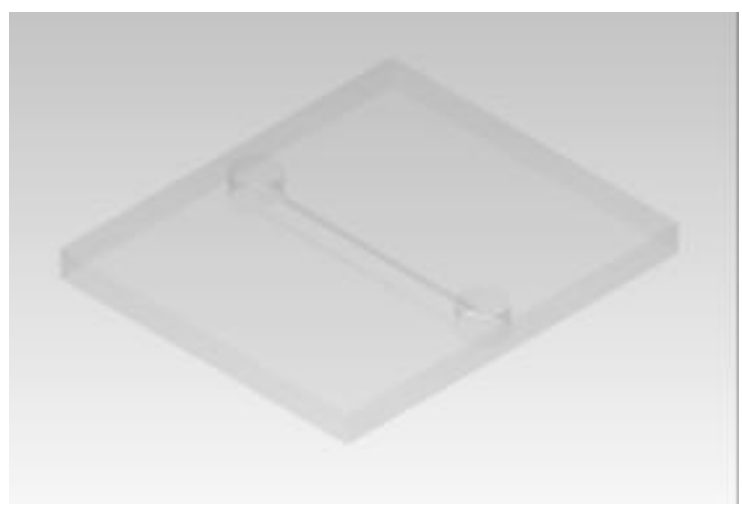

(f) 

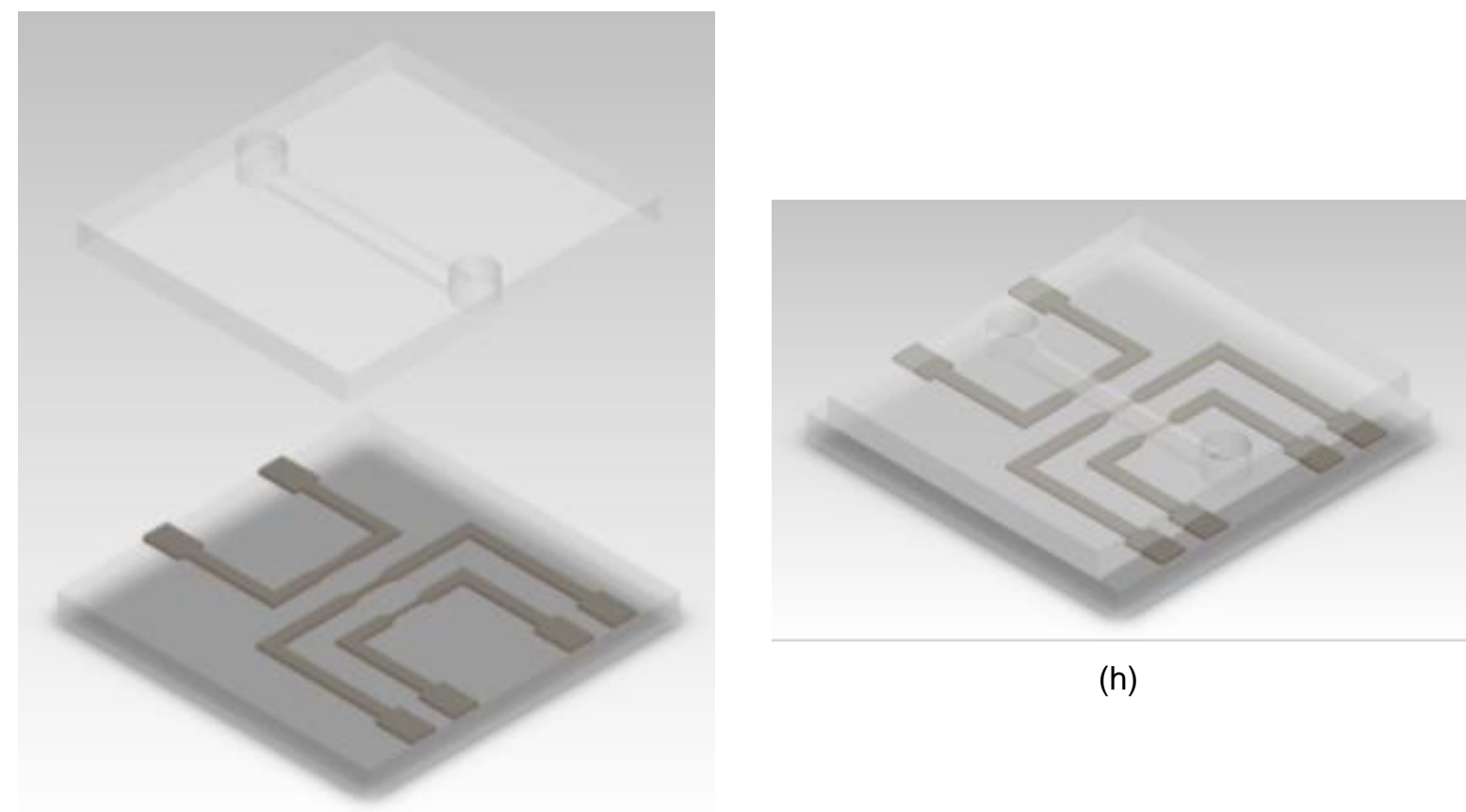

(h)

(g)

Figura 15 - Processo de fabricação do microcanal na tampa de PDMS e soldagem no sensor de vazão. 


\section{RESULTADOS DO SENSOR DE VAZÃO}

\subsection{SIMULAÇÕES POR ELEMENTOS FINITOS}

As simulações por elementos finitos do sensor de vazão proposto foram realizadas com auxílio do software Comsol Multiphysics ${ }^{\circledR}$ versão 4.0a. O modelo foi implementado com os parâmetros apresentados na seção 3.2. O objetivo foi determinar a resposta do sensor a diferentes valores de vazão, levantando a curva tensão $\times$ vazão $(V \times \phi)$ em função do valor da corrente de polarização.

O valor da vazão volumétrica no microcanal foi variado de 0 a $200 \mu \mathrm{L} / \mathrm{min}$. O gráfico da figura 16 apresenta a tensão de saída sobre o sensor em função da vazão para o caso de uma corrente de polarização de $20 \mathrm{~mA}$. Uma observação a ser feita é que o valor de tensão resultante do programa teve que ser multiplicado por dois visto que apenas metade do domínio está sendo simulado.

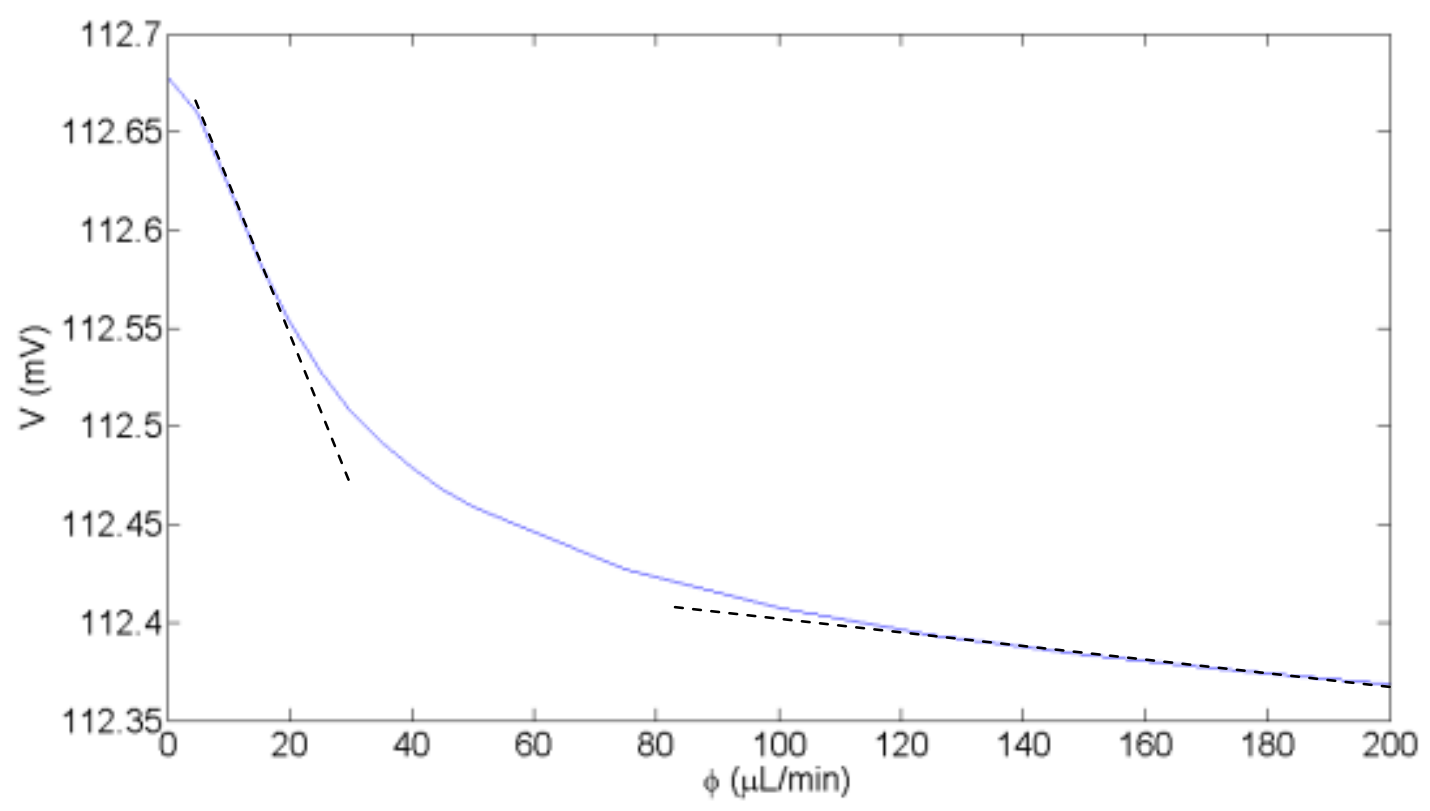

Figura 16 - Curva normalizada da tensão x vazão obtida da simulação por elementos finitos para o sensor de vazão proposto com corrente de polarização de $20 \mathrm{~mA}$. 
O resultado apresentado é coerente com o esperado. Quanto maior a vazão, mais calor é roubado do filamento e portanto menor é sua temperatura. A diminuição na temperatura do filamento causa uma diminuição no valor da resistência elétrica que, dado que a corrente de polarização é constante, se reflete em uma redução na tensão.

O gráfico mostra ainda que a resposta do sensor não é linear em toda a faixa de valores de vazão simulada. Entretanto, é possível definir duas regiões de operação aproximadamente lineares como mostrado pelas retas pontilhadas: uma para baixos valores de vazão $(\phi \lesssim 20 \mu L / \mathrm{min})$ e outra para valores altos de vazão $(\phi \gtrsim 130 \mu L / \mathrm{min})$.

Definindo a sensibilidade do sensor como sendo:

$$
S_{V}=\left|\frac{d V}{d \phi}\right|
$$

o que equivale à medir a inclinação das retas nessas duas regiões, conclui-se que a sensibilidade do sensor, em módulo, é aproximadamente 4 vezes maior para a região de baixa vazão do que para a de alta vazão:

$$
\begin{gathered}
S_{V} \approx 35,8 \mu V /(\mu L / \min ) \text { para } \phi \lesssim 20 \mu L / m i n ; \\
S_{V} \approx 8,4 \mu V /(\mu L / \mathrm{min}) \text { para } \phi \gtrsim 130 \mu L / \mathrm{min} .
\end{gathered}
$$

Esses valores indicam que, na prática, a resolução do sensor estará limitada à faixa de vazão de algumas centenas de $\mathrm{nL} / \mathrm{min}$, já que os valores de tensão envolvidos são da ordem de microvolts. Tensões nessa ordem de grandeza são equiparáveis ao valor de ruído eletromagnético e distinguir o sinal do sensor do ruído começa a tornar-se uma tarefa difícil. Isso mostra a necessidade de se buscar alternativas no processo de fabricação do sensor para que ele tenha a sensibilidade da ordem de algumas unidades de $\mathrm{nL} / \mathrm{min}$.

É possível notar uma pequena descontinuidade na curva próxima ao ponto de vazão igual a zero. Ela é resultado de algumas mudanças que tiveram que ser feitas no modelo para simular o caso sem escoamento no microcanal (fluido estanque) mas sua influência no resultado final da caracterização do sensor é mínima. 
A resposta do sensor pode ser normalizada em relação ao valor de tensão quando a vazão é igual a zero. Desse modo, definindo:

$$
\Delta V=V(\phi)-V(\phi=0)
$$

a resposta da diferença de tensão em função da vazão é igual à mostrada na figura 17.

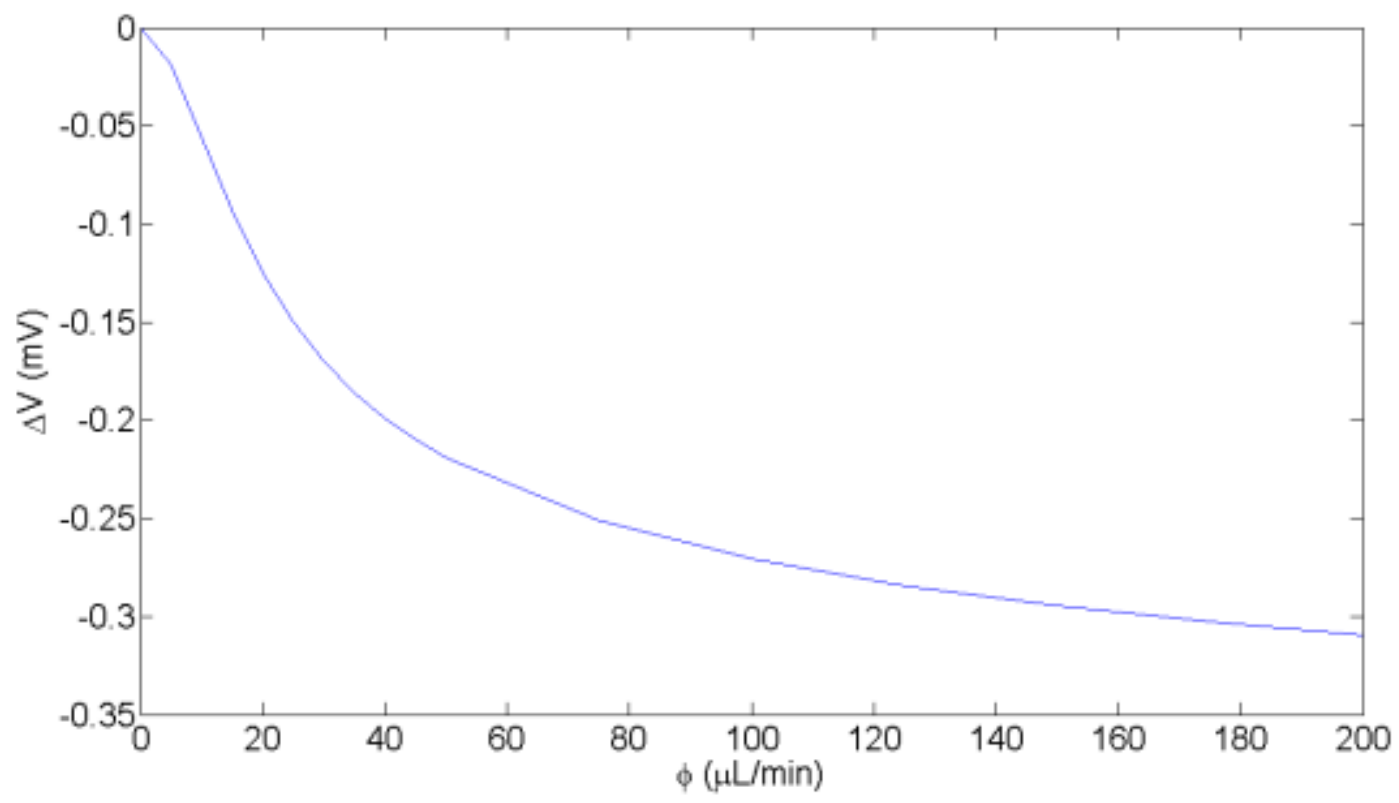

Figura 17 - Curva diferença de tensão x vazão obtida da simulação por elementos finitos para o sensor de vazão proposto com corrente de polarização de $20 \mathrm{~mA}$.

Esse é um modo mais conveniente de se apresentar a resposta do sensor pois permite a comparação de resultados entre sensores diferentes ou em pontos de polarização diferentes. Também neste caso observam-se as duas regiões lineares para valores de vazão menores do que $20 \mu \mathrm{L} / \mathrm{min}$ e maiores do que $130 \mu \mathrm{L} / \mathrm{min}$.

Outro ponto a ser observado é a distribuição de temperatura no sensor. O software possibilita a visualização do campo de temperaturas em todo o domínio simulado, como mostram as imagens da figura 18. A distribuição de temperatura está ilustrada para dois valores de vazão: $10 \mu \mathrm{L} / \mathrm{min}$ e $175 \mu \mathrm{L} / \mathrm{min}$. O fluido escoa no sentido positivo do eixo y. 


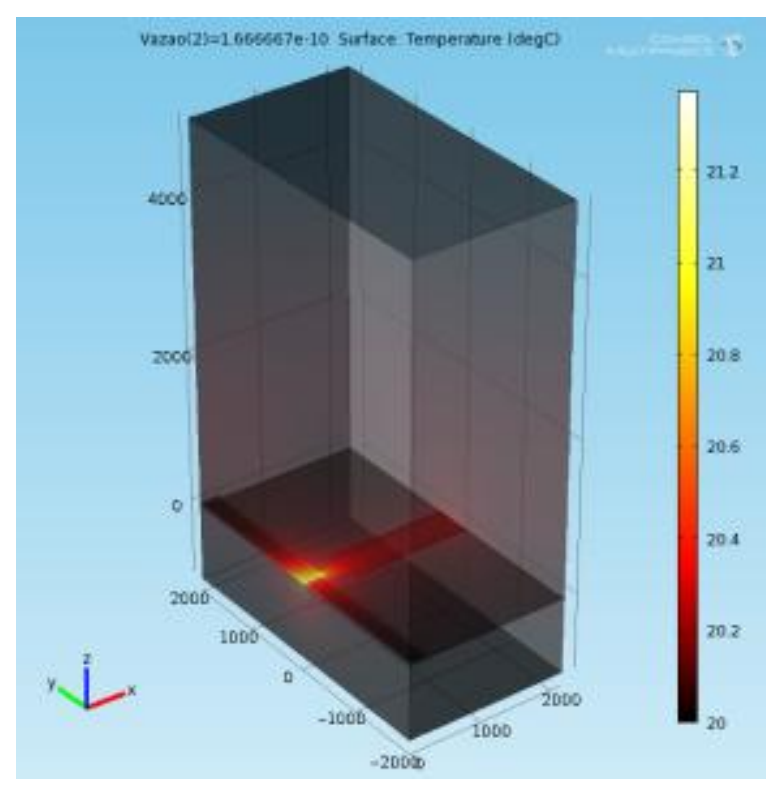

(a)

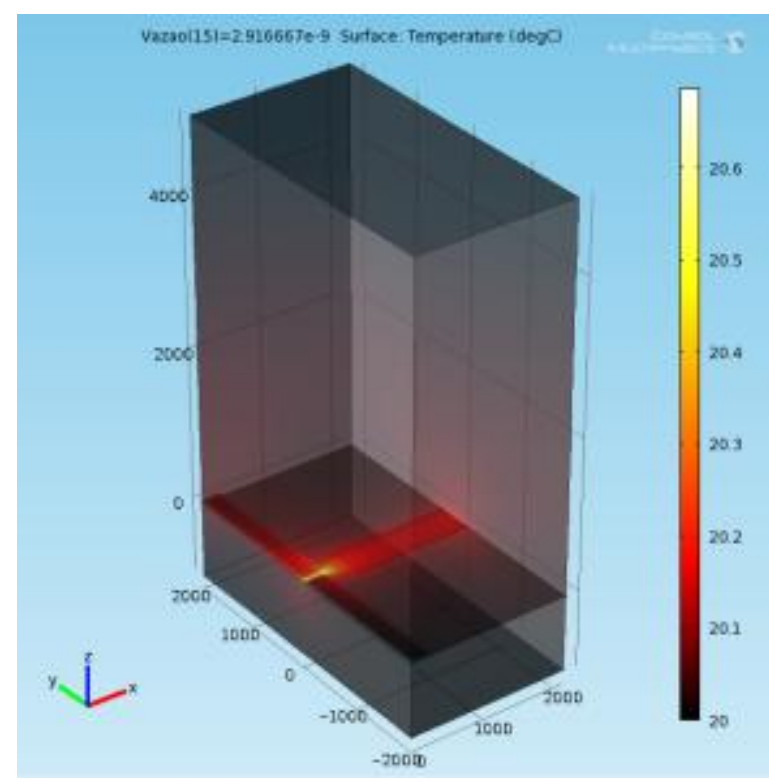

(c)

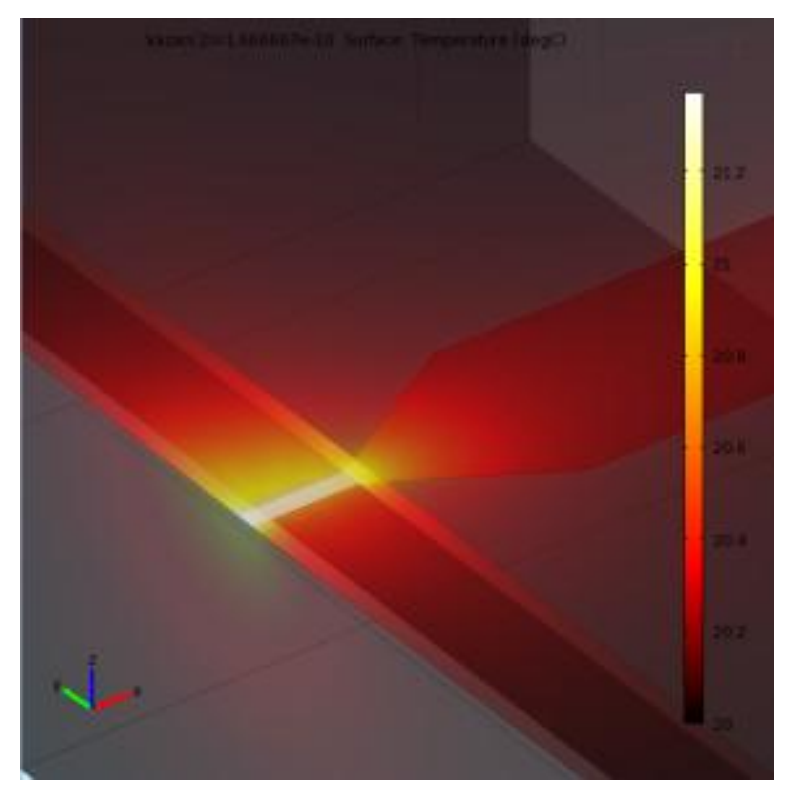

(b)

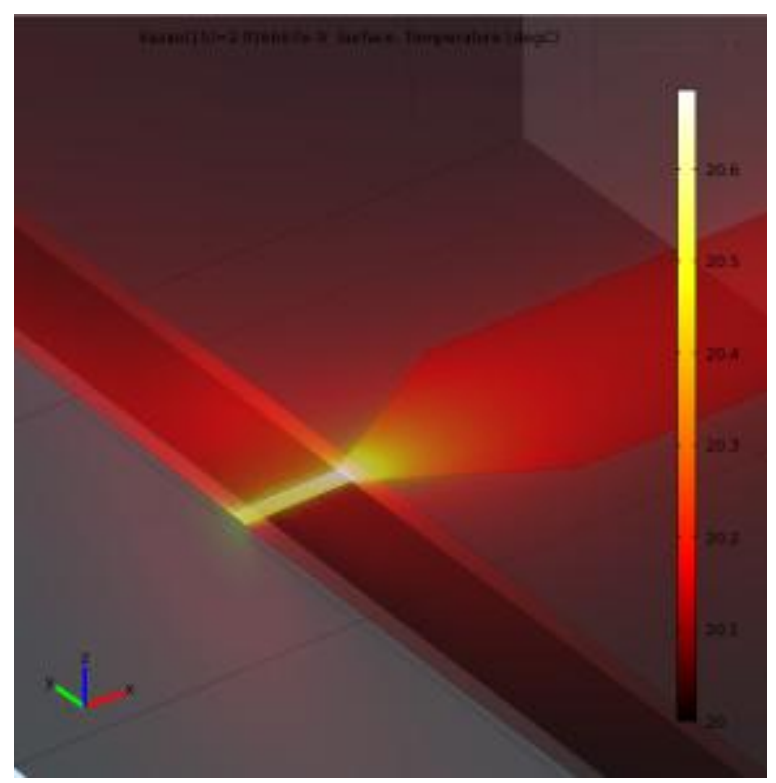

(d)

Figura 18 - Campo de temperaturas no sensor de vazão proposto para corrente de polarização igual a $20 \mathrm{~mA}$. (a,b) Vazão igual a $10 \mu \mathrm{L} / \mathrm{min}$. (c,d) Vazão igual a $175 \mu \mathrm{L} / \mathrm{min}$.

As figuras mostram que, ao menos do ponto de vista qualitativo, os resultados estão como esperado. Para valores baixos de vazão, a temperatura no filamento é maior do que na situação em que a vazão é mais alta (comparando os valores na barra de cores). Além disso, a região imediatamente próxima ao filamento também está mais quente. Ao contrário, para valores altos de vazão, além da região próxima ao filamento, uma região maior a jusante do filamento foi aquecida, o que indica que mais calor foi transportado pelo escoamento. Isso fica mais claro ao se observar o perfil de temperatura através das curvas isotermas no plano yz que passa pelo meio 
do filamento, como mostrado na figura 19. O sentido do escoamento de água é da esquerda para a direita da figura.

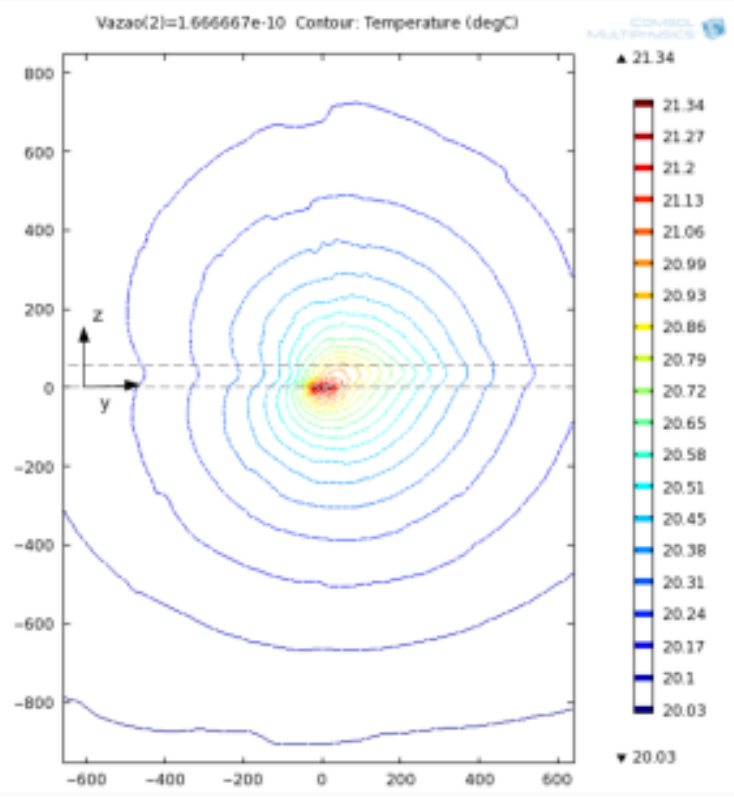

(a)

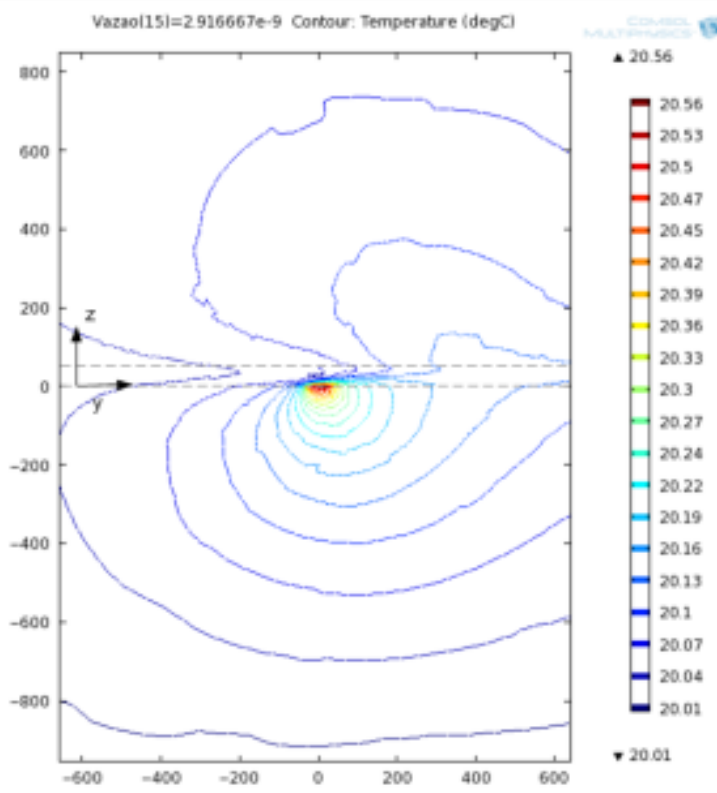

(b)

Figura 19 - Curvas isotermas na região do filamento para corrente de polarização igual a 20 mA. (a) Vazão igual a $10 \mu \mathrm{L} / \mathrm{min}$; (b) Vazão igual a $175 \mu \mathrm{L} / \mathrm{min}$. Microcanal indicado em linha tracejada.

As imagens mostram claramente que quando a vazão é igual a $10 \mu \mathrm{L} / \mathrm{min}$, as curvas isotermas possuem um formato quase circular, indicando que o fenômeno de transferência de calor preponderante é a condução. Já para o caso da vazão igual a $175 \mu \mathrm{L} / \mathrm{min}$, as curvas estão nitidamente deformadas na direção do escoamento, o que indica que o fenômeno da convecção passa a ser importante na transferência de calor. Essa informação é confirmada calculando-se o número de Péclet para os dois valores de vazão segundo a abordagem apresentada na seção 3.2. Para a vazão igual a $10 \mu \mathrm{L} / \mathrm{min}, P e \cong 2$ enquanto que para vazão igual a $175 \mu \mathrm{L} / \mathrm{min}$, $P e \cong 41$.

Outro resultado importante de se observar é a temperatura máxima e média no filamento. O pior caso ocorre quando não há circulação de água pelo microcanal. Analogamente ao que foi feito para a tensão no sensor, foram levantadas as curvas de temperatura máxima e temperatura média em função da vazão no microcanal. Para o cálculo da temperatura média, foi levada em conta apenas a região do filamento que está em contato com o fluido. Os gráficos obtidos estão mostrados na figura 20 , lembrando que a temperatura da água na entrada do microcanal é $20^{\circ} \mathrm{C}$. 


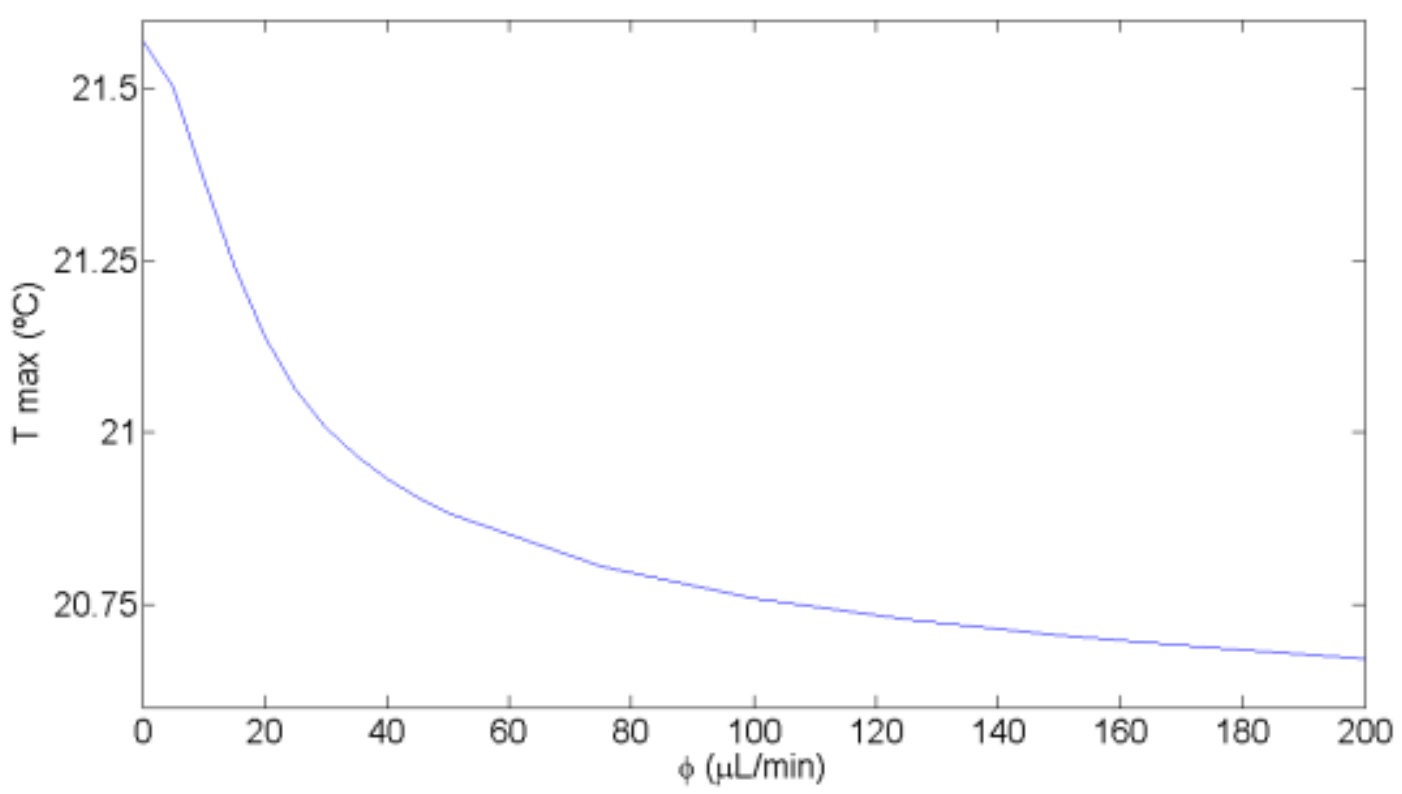

(a)

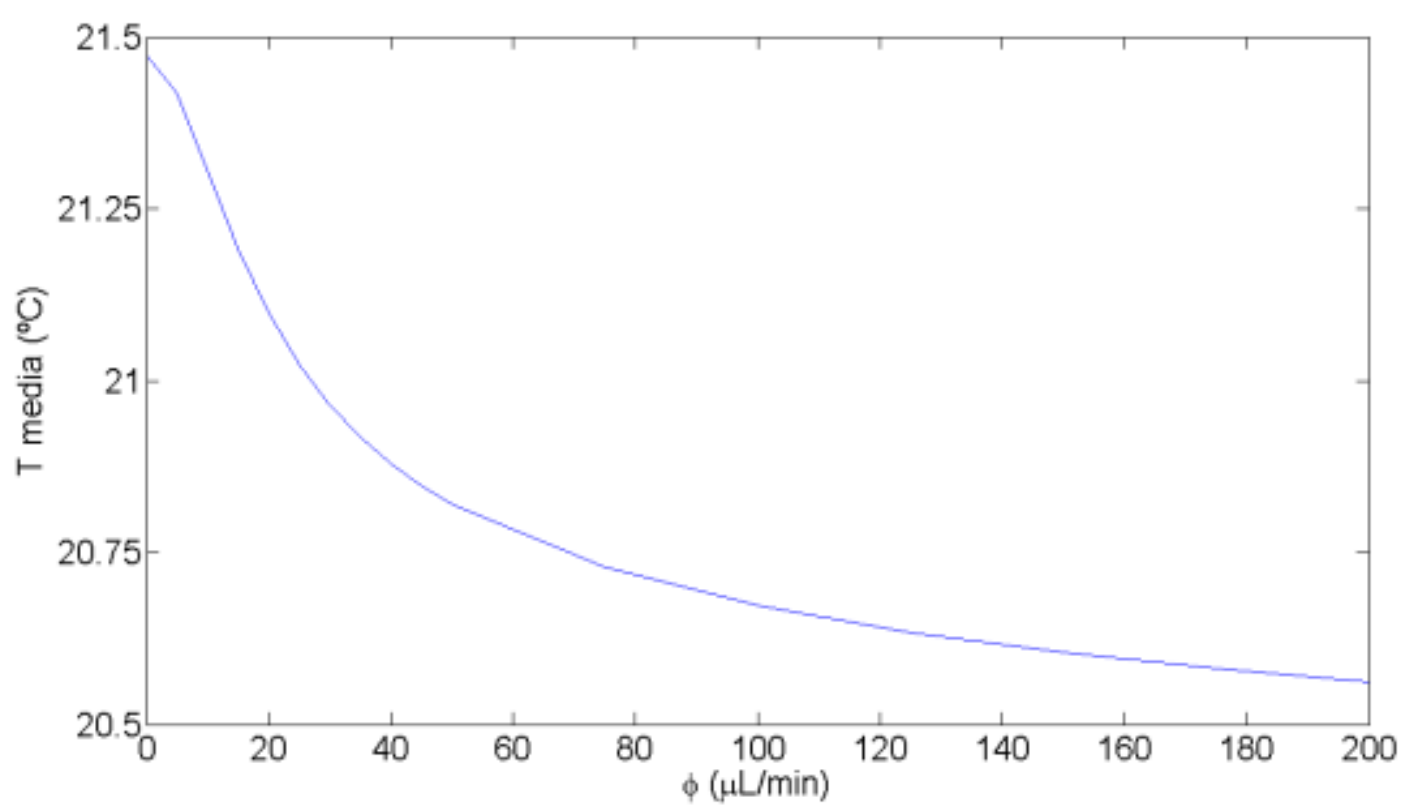

(b)

Figura 20 - Curva temperatura x vazão obtida da simulação por elementos finitos para o sensor de vazão proposto com corrente de polarização de 20 mA. (a) Temperatura máxima; (b) Temperatura média.

Os resultados obtidos são bastante satisfatórios visto que os maiores valores de temperatura máxima e média são da ordem de $21,6^{\circ} \mathrm{C}$ e $21,5^{\circ} \mathrm{C}$, respectivamente, ou seja, o máximo aquecimento provocado pelo filamento é de $1,5^{\circ} \mathrm{C}$. Isso permite que o sensor de vazão proposto seja empregado numa vasta gama de aplicações como era o intuito inicial deste trabalho. 
O efeito que a alteração da corrente de polarização causa sobre a resposta do sensor também foi avaliado. A figura 21 apresenta as curvas de diferença de tensão em função da vazão no microcanal para quatro valores de corrente de polarização: $10 \mathrm{~mA}, 20 \mathrm{~mA}, 30 \mathrm{~mA}$ e $40 \mathrm{~mA}$.

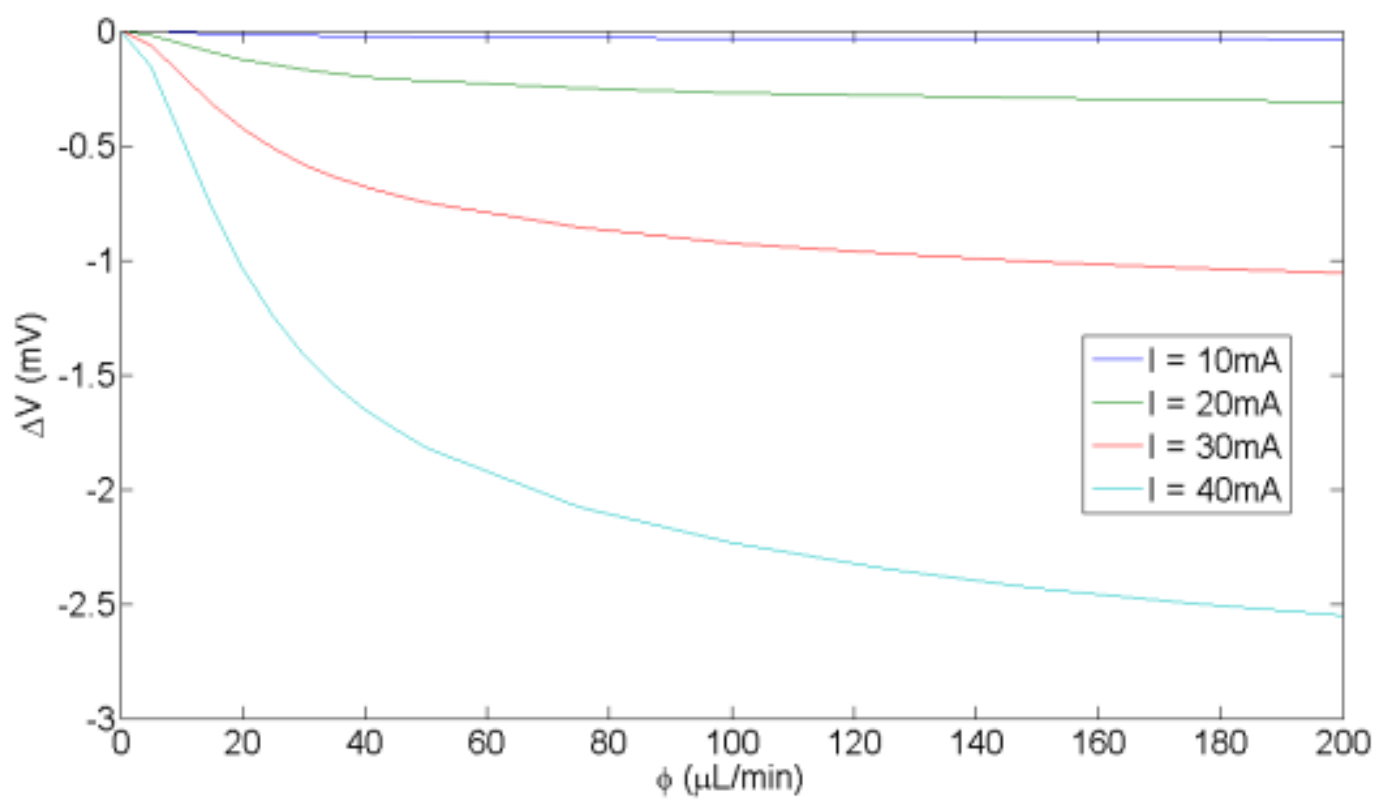

Figura 21 - Curvas da diferença de tensão x vazão para quatro valores de corrente de polarização.

O gráfico mostra que quanto maior a corrente de polarização maior é a diferença de tensão. Mais do que isso, a partir da medida da sensibilidade nas duas regiões lineares do gráfico é possível observar que a relação entre o aumento da corrente e o aumento da sensibilidade segue uma lei exponencial, como mostram os gráficos da figura 22. Os valores numéricos de sensibilidade estão indicados na tabela 8. 


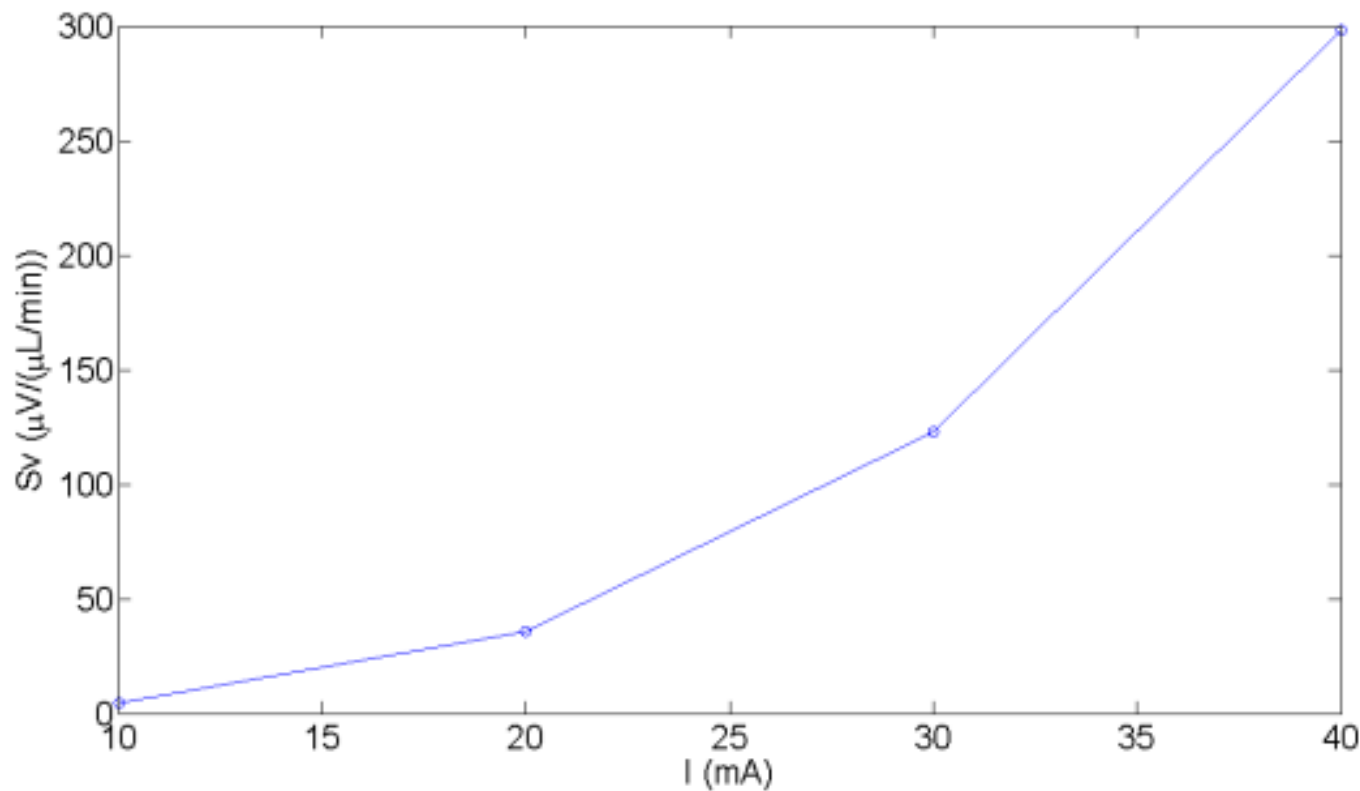

(a)

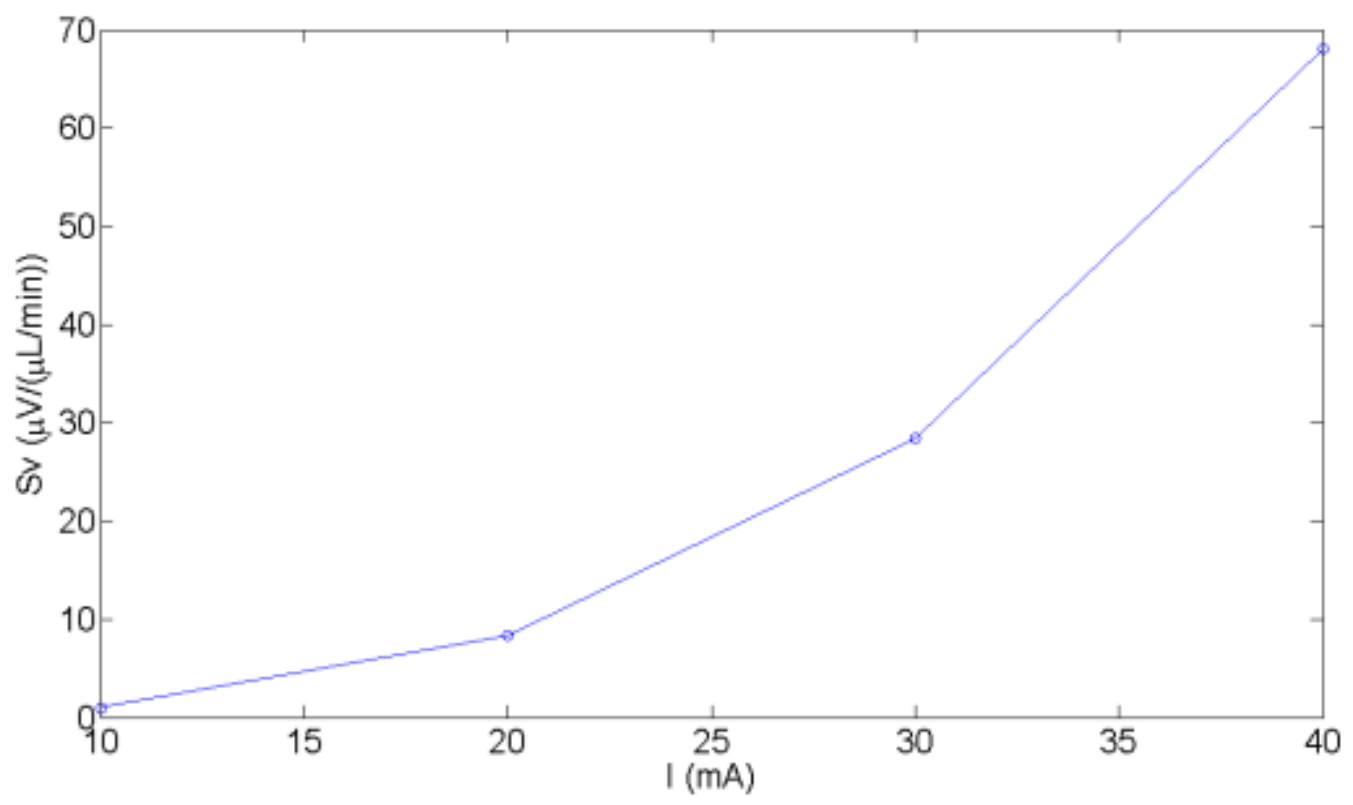

(b)

Figura 22 - Curvas da sensibilidade $x$ corrente de polarização para as duas regiões lineares da resposta do sensor: (a) Baixas vazões; (b) Altas vazões. 
Tabela 8 - Sensibilidade do sensor para quatro valores de corrente de polarização.

\begin{tabular}{|c|c|c|}
\hline \multirow{2}{*}{$\boldsymbol{I}(\boldsymbol{m} \boldsymbol{A})$} & \multicolumn{2}{|c|}{$\boldsymbol{S}_{\boldsymbol{V}}(\boldsymbol{\mu} \boldsymbol{V} /(\boldsymbol{\mu L} / \mathbf{m i n}))$} \\
\cline { 2 - 3 } & $\phi \leq 20 \mu \mathrm{m} / \mathrm{min}$ & $\phi \geq 130 \mu \mathrm{L} / \mathrm{min}$ \\
\hline 10 & 4,4 & 1,0 \\
\hline 20 & 35,8 & 8,4 \\
\hline 30 & 122,9 & 28,4 \\
\hline 40 & 298,1 & 68,0 \\
\hline
\end{tabular}

Os valores da tabela mostram que dobrando o valor da corrente de polarização de 20 para $40 \mathrm{~mA}$, a sensibilidade do sensor aumenta oito vezes. Elevar a corrente de polarização é portanto um bom modo de melhorar a sensibilidade do sensor. Contudo, um efeito indesejado resultante desse aumento é a elevação dos valores de temperatura em todo o sensor. Os gráficos da figura 23 mostram o efeito da variação da corrente sobre as temperaturas máxima e média do filamento.

Como era de se esperar, o aumento da corrente de polarização acarreta em um aumento na potência dissipada pelo filamento, elevando a temperatura do filamento. Os valores de temperatura máxima e média no caso da vazão igual a zero são mostrados na tabela 9 e nos gráficos da figura 24 . 


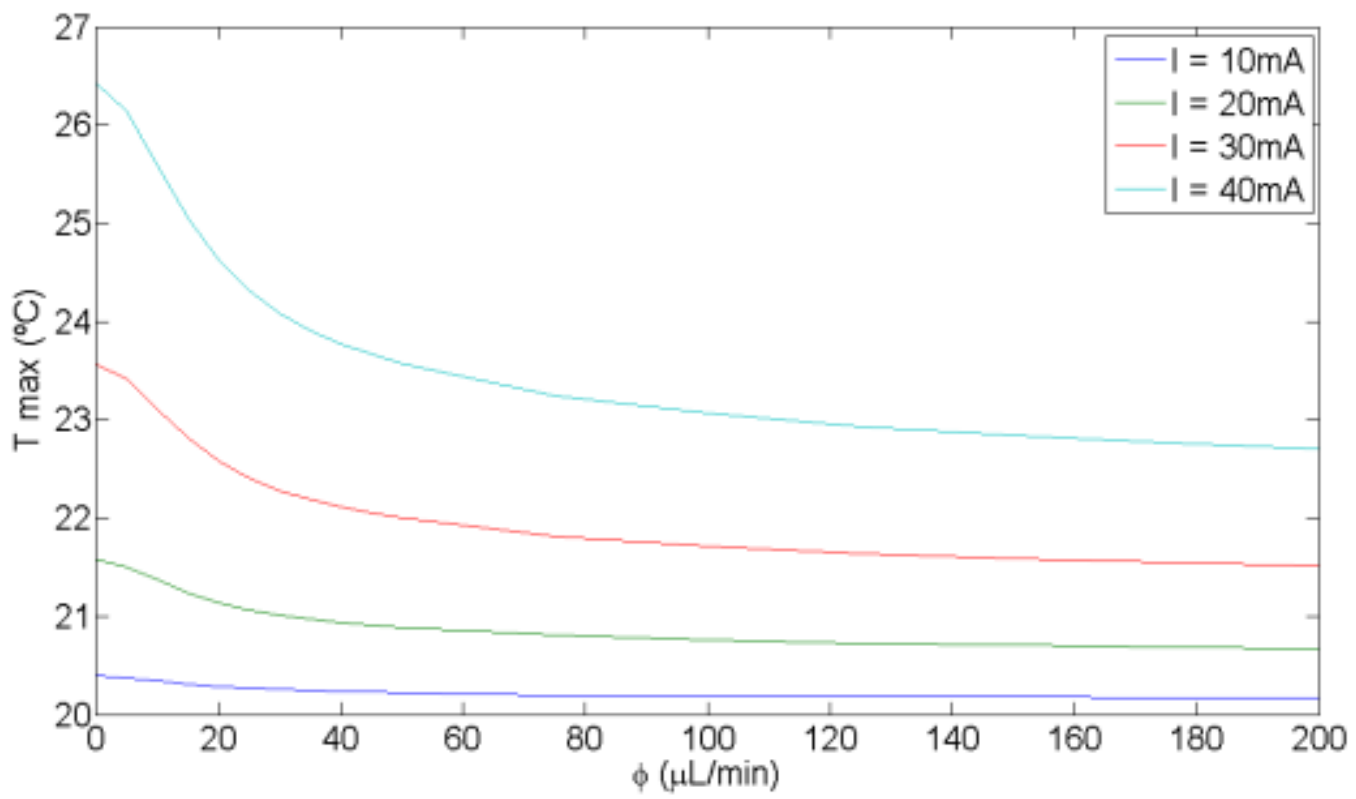

(a)

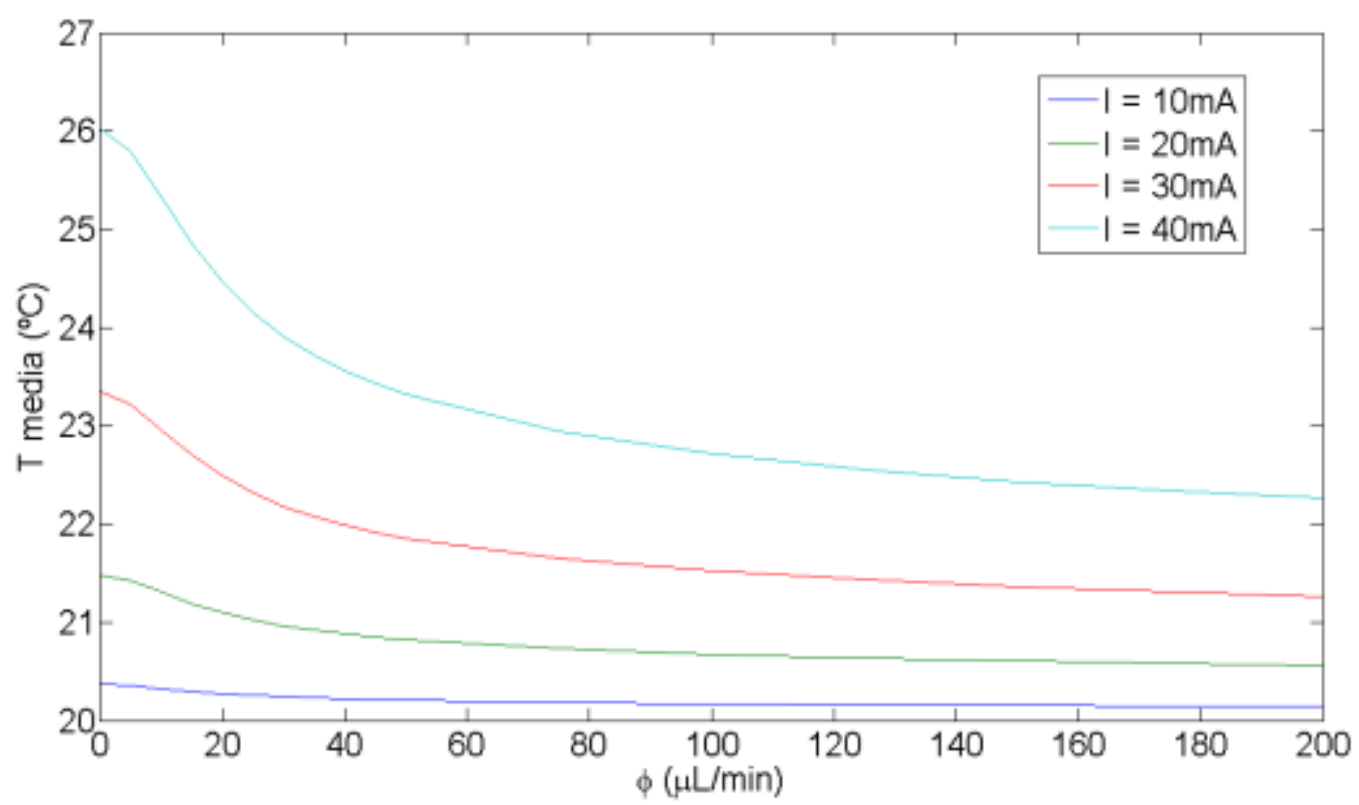

(b)

Figura 23 - Curvas da temperatura x vazão para quatro valores de corrente de polarização. (a) Temperatura máxima; (b) Temperatura média. 


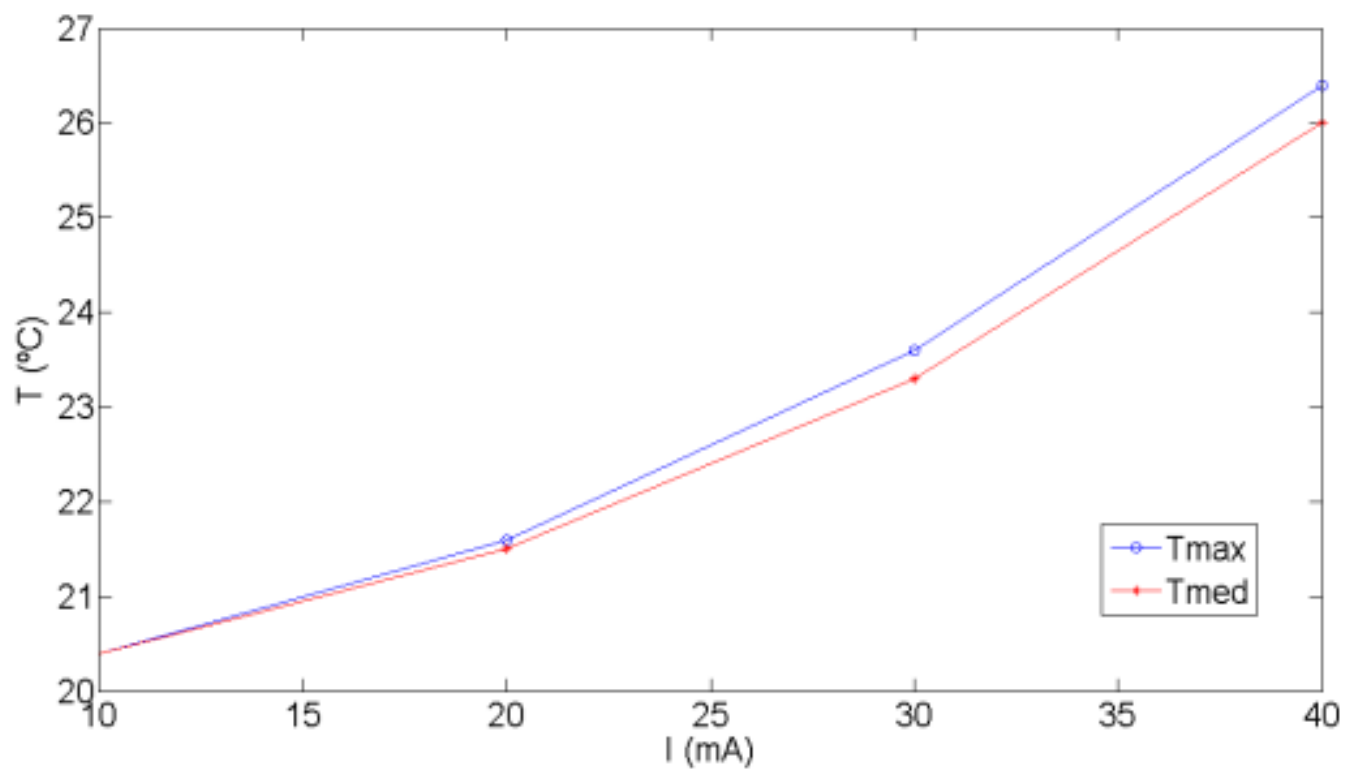

Figura 24 - Curvas da temperatura máxima e temperatura média x corrente de polarização para vazão igual a zero.

Tabela 9 - Temperatura máxima e média no filamento para quatro valores de corrente de polarização.

\begin{tabular}{|c|c|c|}
\hline $\boldsymbol{I}(\boldsymbol{m} \boldsymbol{A})$ & $\boldsymbol{T}_{\boldsymbol{m a ́ x}}\left({ }^{\circ} \boldsymbol{C}\right)$ & $\boldsymbol{T}_{\text {méd }}\left({ }^{\circ} \mathbf{C}\right)$ \\
\hline 10 & 20,4 & 20,4 \\
\hline 20 & 21,6 & 21,5 \\
\hline 30 & 23,6 & 23,3 \\
\hline 40 & 26,4 & 26,0 \\
\hline
\end{tabular}

Observa-se que o aumento na temperatura também segue uma lei exponencial e que dobrar o valor da corrente de 20 para $40 \mathrm{~mA}$ acarreta em uma aumento de temperatura da ordem de $5^{\circ} \mathrm{C}$.

A conclusão que se chega é que apesar do aumento da corrente de polarização ser um método bastante eficaz de se melhorar a sensibilidade do sensor, ele deve ser feito tomando-se cuidado para não elevar excessivamente a temperatura do filamento e portanto do fluido. 


\subsection{FABRICAÇÃO DOS DISPOSITIVOS}

Diversos dispositivos puderam ser fabricados seguindo o processo de fabricação apresentado na seção 3.3. Houve boa aderência entre as camadas metálicas e a soldagem da tampa de PDMS sobre a lâmina de vidro contendo os filamentos também foi bastante satisfatória. De fato, o bloco de PDMS foi soldado sobre uma lâmina de vidro que passou previamente por uma série de etapas de deposição, fotogravação e corrosão. Essa é uma informação importante e que abre a possibilidade para que em trabalhos futuros outros sensores ou dispositivos microfluídicos que façam uso de trilhas metálicas possam ser implementados.

Outra etapa de fabricação que teve aspectos positivos foi a deposição do filme de níquel. Foi possível controlar a taxa de deposição, normalmente elevada, diminuindo a corrente entre os eletrodos sem prejuízo aparente ao acabamento superficial do filme. Observou-se que a agitação da solução desempenha um papel muito importante na uniformidade do filme depositado. A espessura do filme de níquel nas laterais de algumas lâminas mostrou-se significativamente maior do que no centro quando a agitação por algum motivo não foi adequada.

A figura 25 mostra fotos de um dos dispositivos fabricados pela técnica proposta. $\mathrm{O}$ processo de deposição de níquel teve duração de 10 minutos, tendo sido crescido um filme com $500 \mathrm{~nm}$ de espessura. 


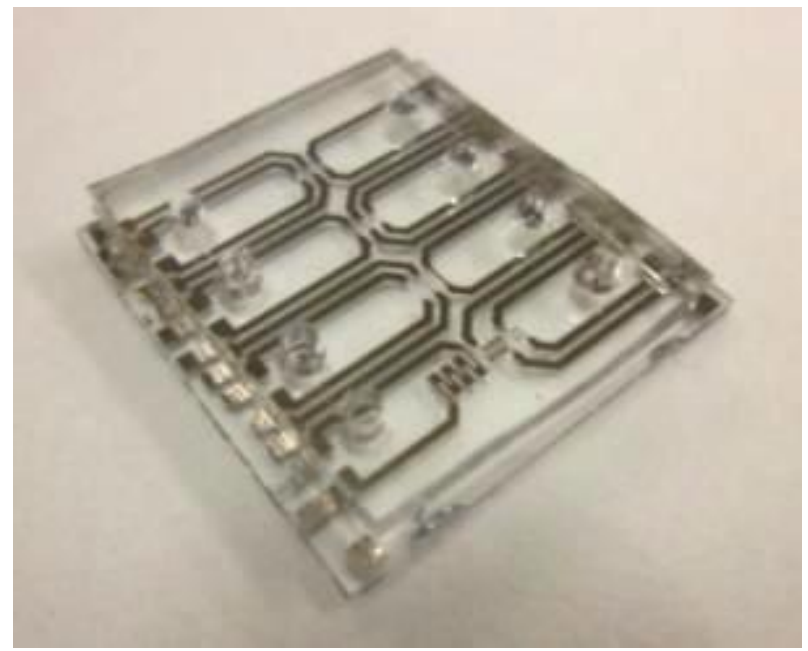

(a)

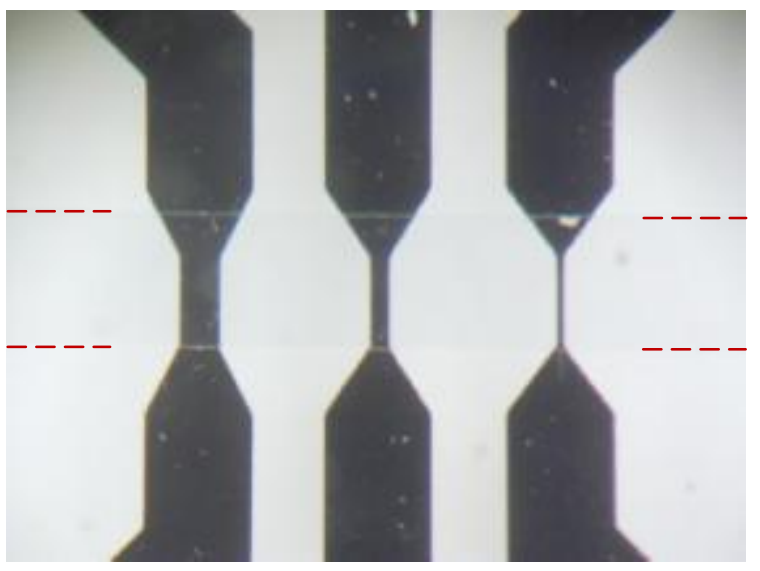

(b)

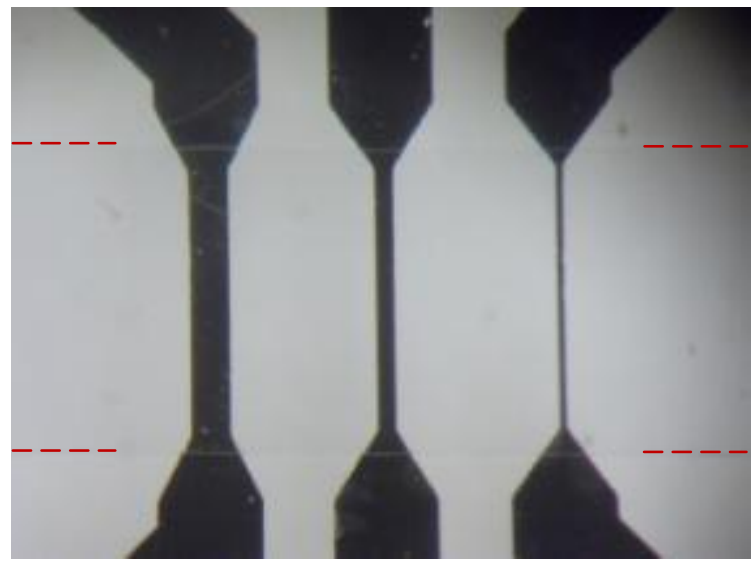

(d)

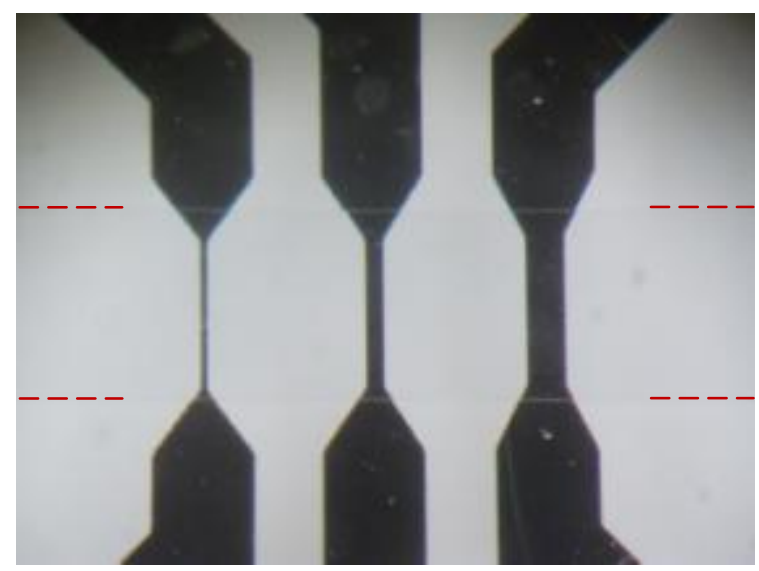

(c)

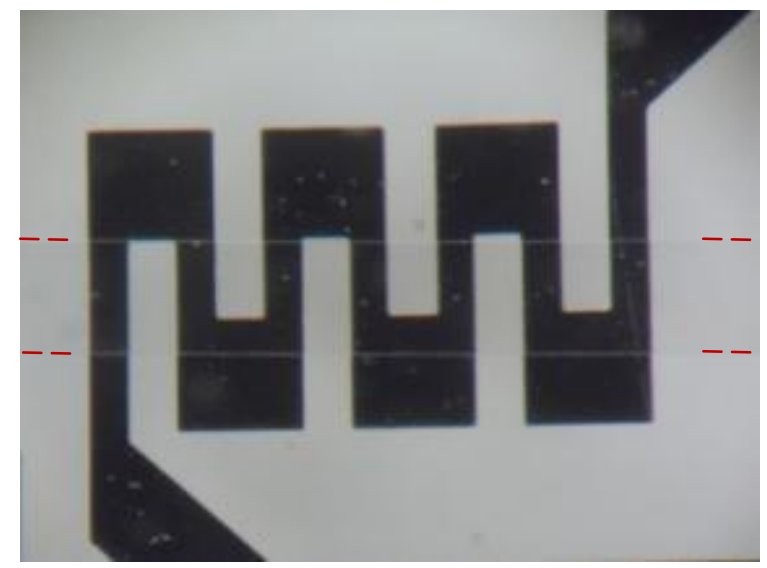

(e)

Figura 25 - Sensor de vazão proposto. (a) Visão geral do dispositivo; Detalhes dos filamentos nos microcanais com largura igual a (b) $600 \mu \mathrm{m}$, (c) $900 \mu \mathrm{m}$ e (d) $1,4 \mathrm{~mm}$. (e) Detalhe do filamento no formato de serpentina. Margens do microcanal indicadas em linha tracejada vermelha. 
Nota-se que apesar do processo de soldagem ter funcionado bastante bem, os microcanais não estão perfeitamente alinhados com os filamentos. Isso se deve ao fato do alinhamento da lâmina de vidro com o PDMS no momento da soldagem ser feito manualmente e a olho nu. Uma vez que os canais apresentam largura bastante pequena e que o PDMS é um material transparente, é muito difícil de conseguir um alinhamento perfeito entre as duas amostras. O impacto do desalinhamento é maior nos dois microcanais com largura de $600 \mu \mathrm{m}$ (figuras 25b e 25e). Mesmo as margens de segurança deixadas nas fotomáscaras não foram suficientes para corrigir os desvios no momento da solda. Esse é um aspecto a ser melhorado no processo de fabricação. Pode-se pensar, por exemplo, no uso de suportes especialmente fabricados para guiar as duas amostras no momento da cola ou alguma outra forma de automatizar do alinhamento das lâminas. Algo que restringe o número de soluções possíveis para esse problema é a forma como a soldagem das amostras é feita, isto é, emprega-se um reator RIE e as amostras devem ser coladas imediatamente após o tratamento superficial em plasma de $\mathrm{O}_{2}$.

Apesar das dificuldades de alinhamento entre microcanal e filamentos, alguns dispositivos puderam ser caracterizados eletricamente, como será mostrado a seguir.

\subsection{CARACTERIZAÇÃO ELÉTRICA DOS DISPOSITIVOS}

A caracterização elétrico do sensor de vazão foi feita aplicando-se uma corrente de polarização constante e medindo a tensão sobre o sensor em função de uma vazão aplicada. A vazão foi controlada através de uma bomba de seringas construída no próprio laboratório. A bomba possui uma base mecânica para apoio de até três seringas. Para cada seringa há um êmbolo que é empurrado através da atuação de um motor de passo. O motor faz girar um parafuso com rosca micrométrica, dando uma boa precisão no controle da vazão. Os motores são atuados através de um circuito eletrônico de interface que se comunica com um computador via porta paralela. Um software em LabVIEW foi criado especialmente para esse fim. Fotos da bomba de seringas são mostradas na figura 26. 


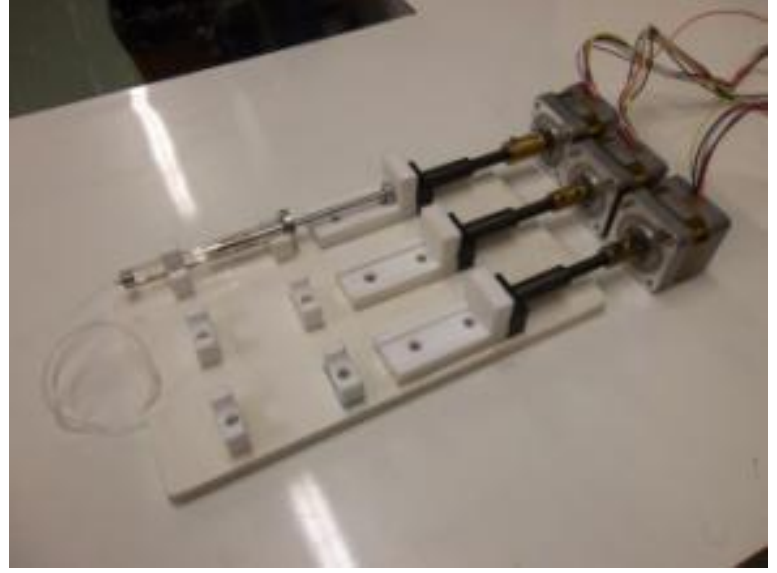

(a)

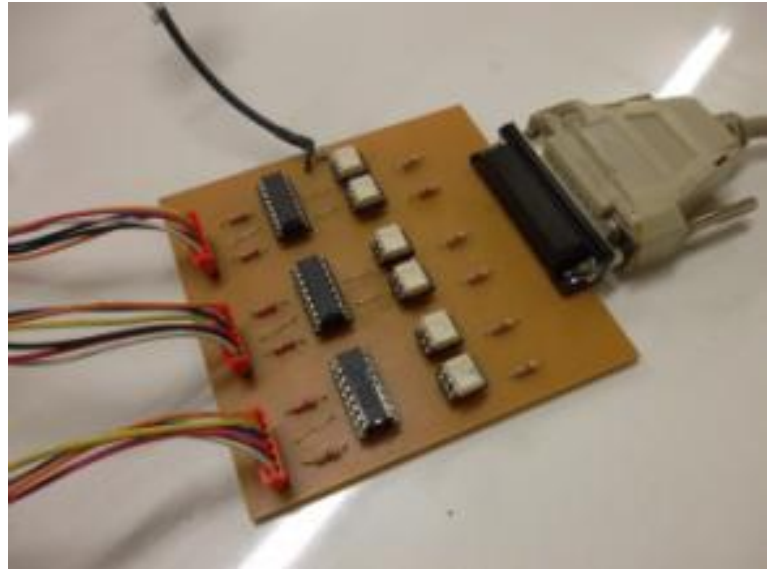

(b)

Figura 26 - Fotos da bomba de seringas montada no laboratório. (a) Suporte para seringas e atuadores; (b) Circuito eletrônico de interface com o computador.

Apesar de não possuir a mesma precisão que as bombas de seringas vendidas comercialmente, constatou-se, a partir de testes experimentais, que a bomba é capaz de fornecer valores de vazão aproximadamente constantes. Durante os experimentos, foram empregados quatro valores fixos de vazão: $45 \mu \mathrm{L} / \mathrm{min}, 90$ $\mu \mathrm{L} / \mathrm{min}, 135 \mu \mathrm{L} / \min$ e $180 \mu \mathrm{L} / \mathrm{min}$. Devido a limitações da bomba, não foi possível caracterizar o sensor para valores menores de vazão.

Além da bomba de seringas, foram empregados na montagem experimental uma fonte de tensão para polarização dos sensores (modelo E3649A da Agilent Technologies), um multímetro de bancada para medida da tensão de saída do sensor (modelo 34401A da Hewlett-Packard), um multímetro de mão para medida da corrente real da corrente passando pelo sensor (modelo 189 da Fluke) e dois computadores. Um computador era responsável por controlar a vazão na bomba de seringas enquanto o outro fazia a aquisição dos dados do sensor. Para tanto, outra rotina em LabVIEW foi criada para ajustar o valor da corrente de polarização do sensor e medir a tensão ao longo do tempo. A comunicação com a fonte de tensão e com o multímetro de bancada foi feita através do protocolo GPIB.

Diversos sensores foram testados com esse aparato experimental mas houve grande discrepância entre os dados coletados. Assume-se que isso esteja associado a problemas no contato elétrico dos sensores. Os contatos foram feitos utilizando microposicionadores com pontas de tungstênio, próprios para essa finalidade. 
Contudo, é difícil assegurar que o contato seja feito sempre da mesma forma. Outro fator relacionado com o problema é a espessura dos filmes metálicos. Como dito ao longo do texto, a espessura dos filmes que compõem o filamento são da ordem de centenas de nanômetros, o que significa que eles podem ser facilmente perfurados pelas pontas dos microposicionadores, o que explicaria as discrepâncias encontradas. A espessura dos filmes é tão pequena que impede que os contatos elétricos sejam feitos através da soldagem tradicional com estanho.

Para contornar esse problema, fios foram colados aos pads dos sensores com cola de prata. Cada amostra foi colada em uma placa de circuito impresso na qual foram definidos quadrados que servem de pads para conexão com os equipamentos. Fios com diâmetro menor que $1 \mathrm{~mm}$ tiveram uma das extremidades colada aos pads da amostra com cola de prata e a outra soldada sobre um dos quadrados da placa. Nesses mesmos quadrados foram soldados fios que se conectam aos equipamentos. Uma foto da amostra montada sobre a placa de circuito impresso está mostrada na figura 27.

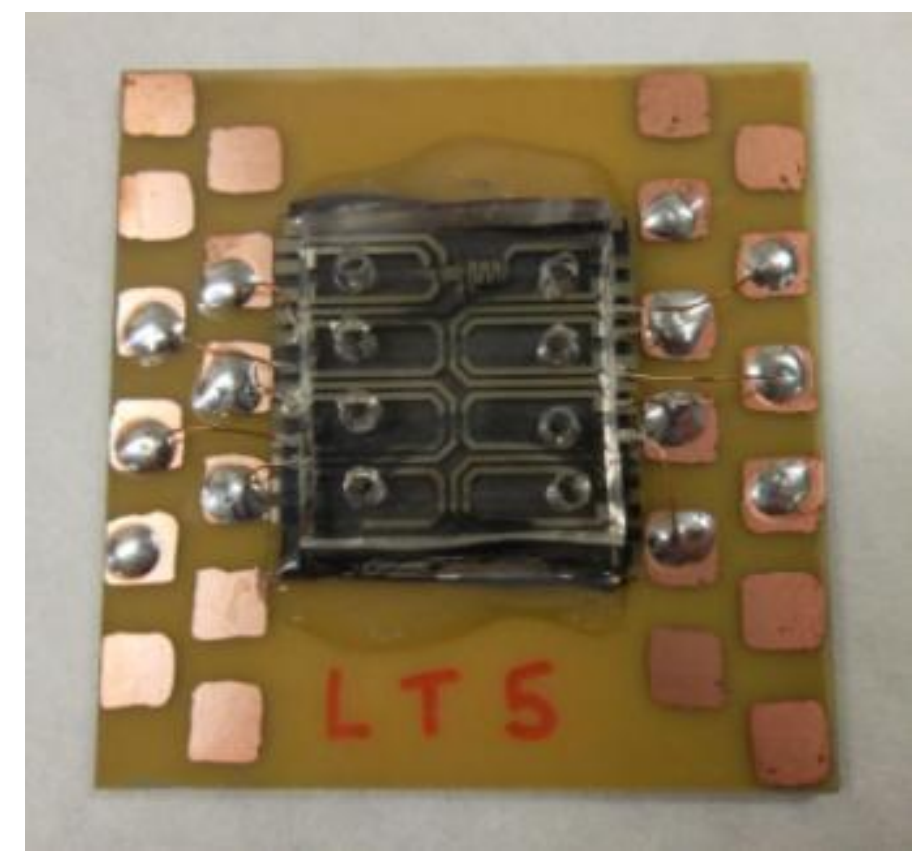

Figura 27 - Montagem do dispositivo na placa de circuito impresso para garantir bom contato elétrico.

A montagem final usada para caracterizar os sensores é mostrada na figura 28 . Um microscópio, modelo SZ61 da Olympus, foi usado para ajudar na visualização das amostras. 


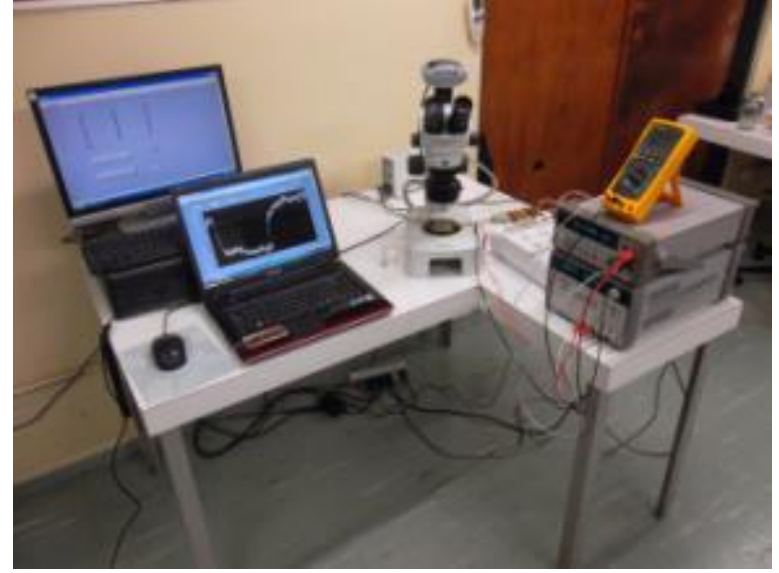

(a)

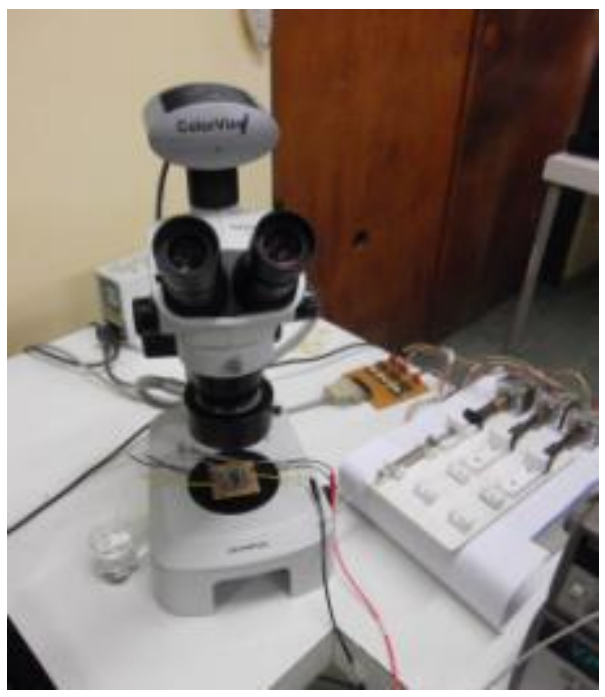

(c)

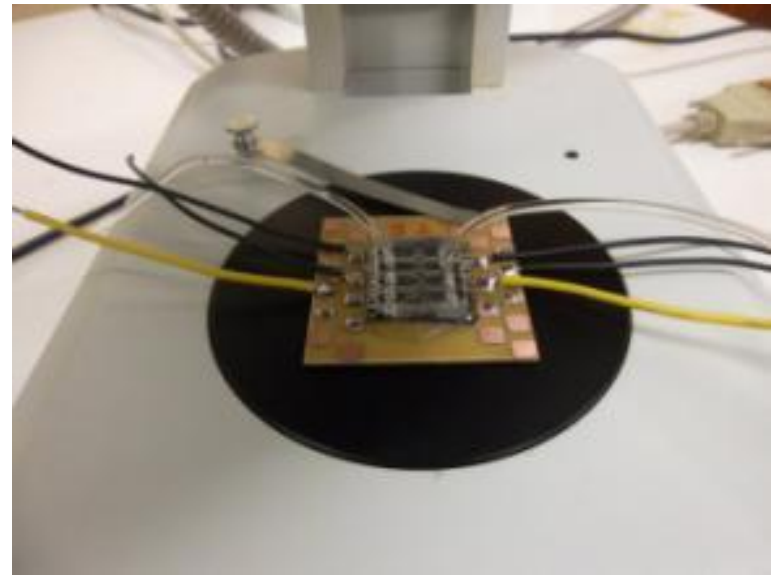

(b)

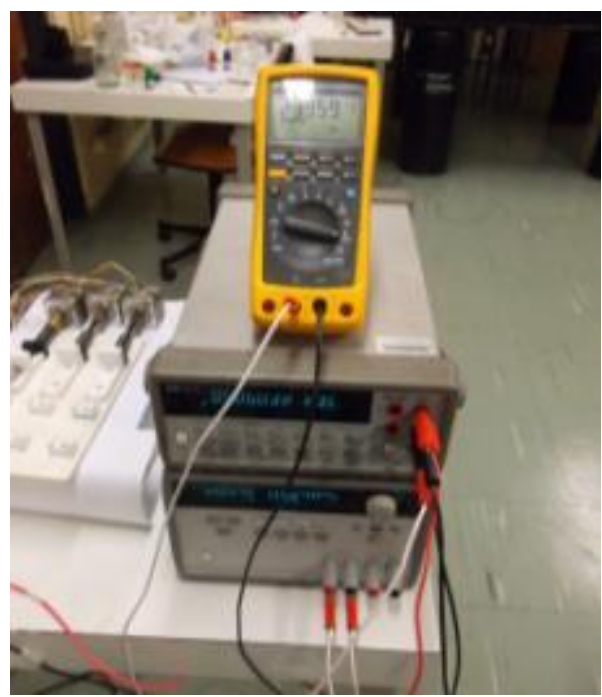

(d)

Figura 28 - Fotos da montagem experimental. (a) Visão geral da montagem; (b) Detalhe do dispositivo medido; (c) Microscópio e a bomba de seringas empregada; (d) Multímetros e fonte de tensão empregada.

Três sensores puderam ser caracterizados com a nova montagem. Para permitir que a resposta deles fosse comparada, as correntes de polarização foram escolhidas de modo que a densidade de potência dissipada (dada em $\mathrm{W} / \mathrm{m}^{2}$ ) na região que estava em contato com o fluido fosse a mesma. O fluido utilizado na caracterização dos sensores foi água deionizada. As principais características dos três sensores estão descritas na tabela 10. 
Tabela 10 - Principais características dos sensores testados.

\begin{tabular}{|c|c|c|c|}
\cline { 2 - 4 } \multicolumn{1}{c|}{} & Sensor 1 & Sensor 2 & Sensor 3 \\
\hline $\begin{array}{c}\text { Largura do } \\
\text { microcanal } \\
(\mu \mathrm{m})\end{array}$ & 500 & 500 & 500 \\
\hline $\begin{array}{c}\text { Largura do } \\
\text { filamento } \\
(\mu \mathrm{m})\end{array}$ & 50 & 50 & 100 \\
\hline $\begin{array}{c}\text { Espessura do } \\
\text { filme de Ni } \\
(\mathrm{nm})\end{array}$ & 250 & 500 & 500 \\
\hline $\begin{array}{c}\text { Corrente de } \\
\text { polarização } \\
(\mathrm{mA})\end{array}$ & 10 & 20 & 41 \\
\hline
\end{tabular}

A caracterização dos sensores foi feita de acordo com o seguinte procedimento:

1. Preenchimento do microcanal com água de modo a não restar nenhuma bolha;

2. Início da medida de tensão;

3. Polarização do sensor com corrente constante a uma vazão nula até a estabilização da medida;

4. Ativação da bomba de seringas com um valor fixo de vazão até a estabilização da medida;

5. Desligamento da bomba de seringas mantendo o sensor polarizado até a estabilização da medida;

6. Fim da medida de tensão. 
O gráfico da figura 29 mostra a resposta da tensão em função do tempo obtida para o sensor 1 quando a vazão no microcanal é de $180 \mu \mathrm{L} / \mathrm{min}$ e a corrente de polarização é $10 \mathrm{~mA}$.

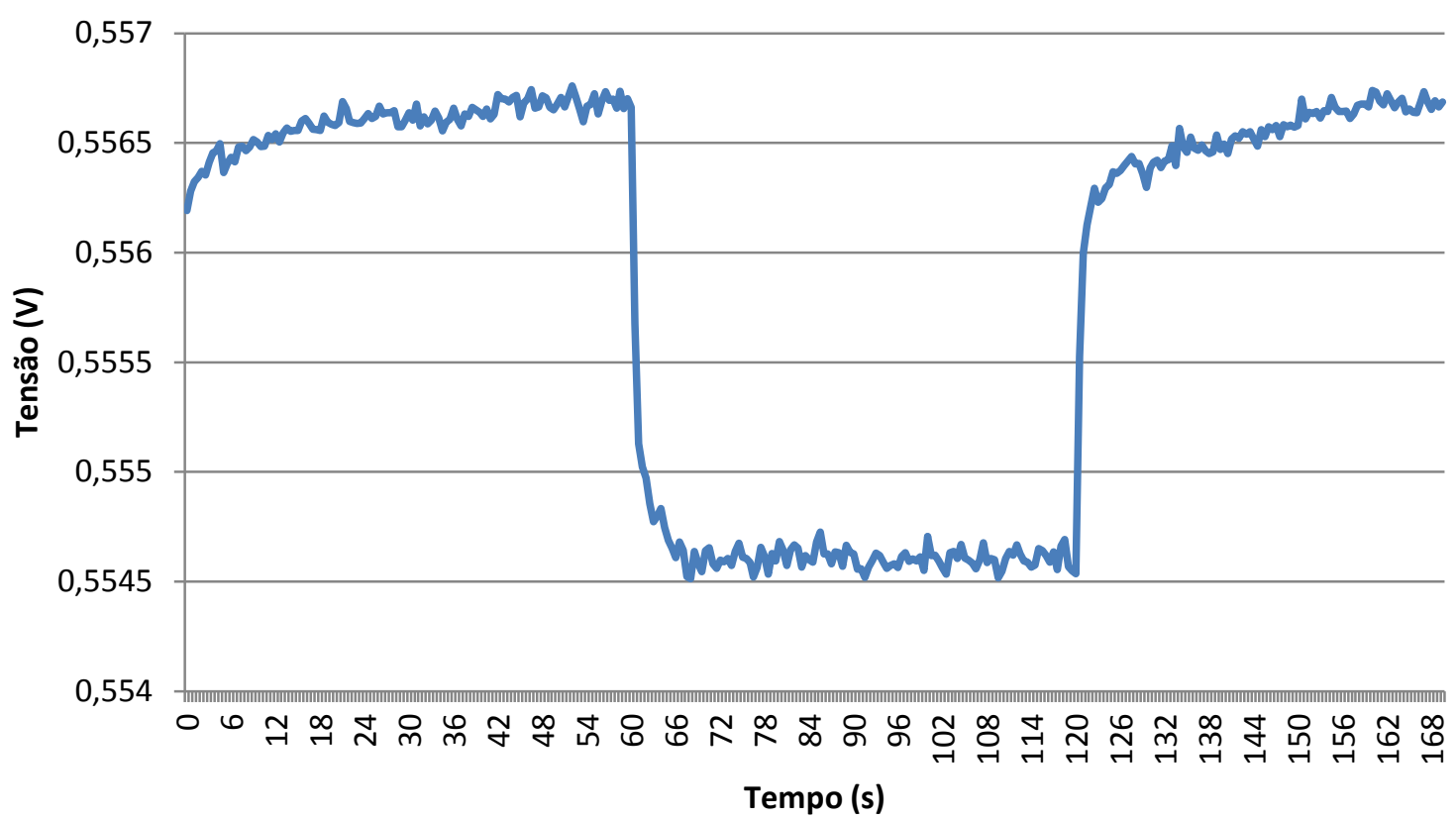

Figura 29 - Curva da tensão x tempo para o sensor 1 para uma vazão de $180 \mu \mathrm{L} / \mathrm{min}$

Três regiões podem ser observadas no gráfico, que correspondem às três fases da medida do procedimento seguido: vazão nula, vazão constante e diferente de zero e vazão igual a zero novamente. Como era de se esperar, a tensão sobre o sensor é menor na região em que há vazão no microcanal já que o fluido rouba calor e diminui a temperatura do filamento, diminuindo sua resistência elétrica. $O$ tempo de estabilização da medida é da ordem de 10 a 20 segundos, embora o sensor tenha permanecido em cada condição de fluxo por um tempo maior do que esse.

Esse procedimento experimental foi repetido para os quatro valores de vazão (45, 90, 135 e $180 \mu \mathrm{L} / \mathrm{min}$ ) em todos os três sensores. O gráfico da figura 30 mostra a sobreposição das quatro curvas de resposta do sensor 1 . 


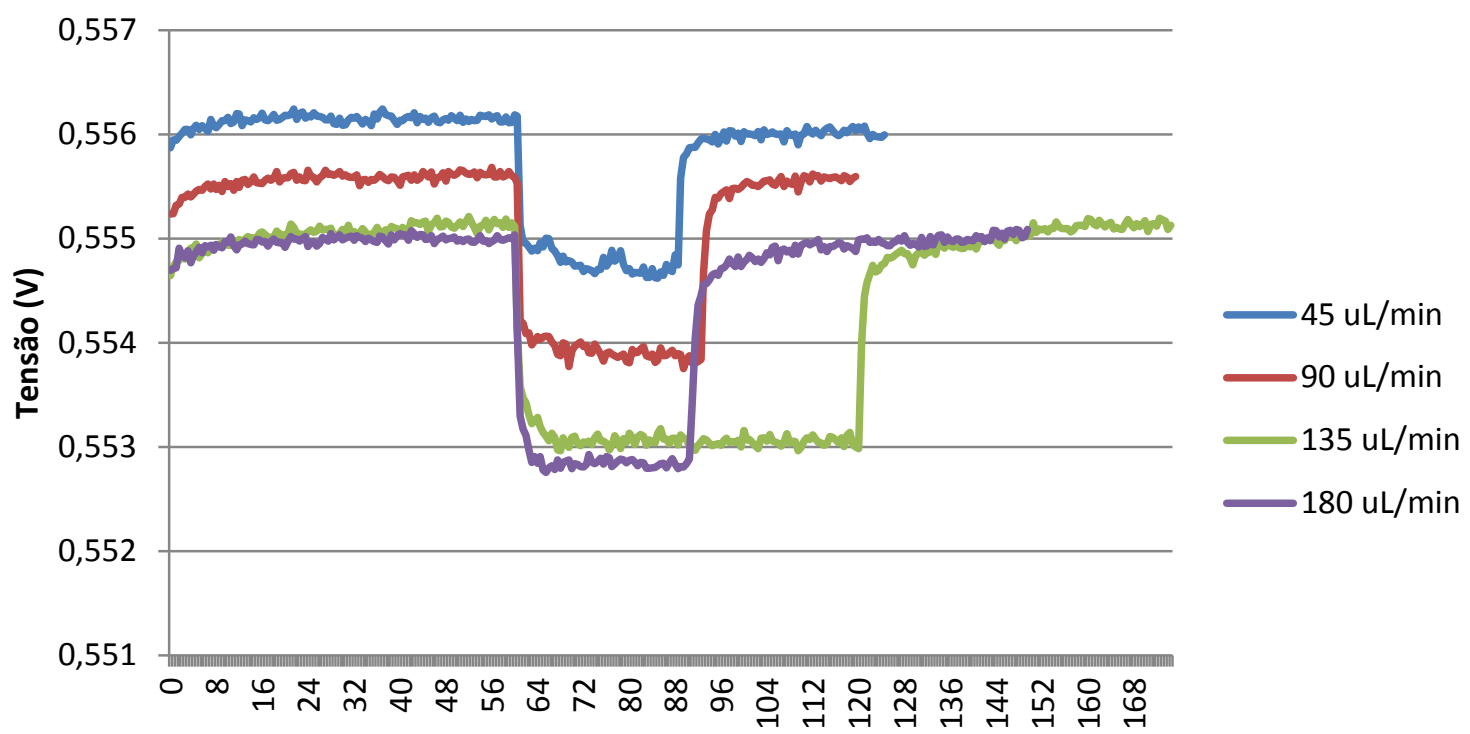

Tempo (s)

Figura 30 - Curva da tensão $x$ tempo para o sensor 1 com corrente de polarização de $10 \mathrm{~mA}$ para quatro valores de vazão.

Nota-se que apesar das curvas possuírem comportamento semelhante, o nível de offset das curvas é diferente. Essa diferença foi observada nos resultados de todos os sensores testados. A causa exata desse fenômeno ainda deve ser determinada, contudo acredita-se que ele esteja relacionado à diferença de temperatura inicial do sensor em cada ensaio. Os experimentos com cada sensor foram feitos em sequência, esperando-se um intervalo de poucos minutos entre uma medida e outra. Dada toda a massa térmica do sensor associada principalmente ao substrato de vidro e à tampa de PDMS, é de se esperar que eles não se encontrem sempre na mesma temperatura quando os experimentos são realizados em sequência e essa seria a causa do fenômeno.

Ajustando o nível de offset das curvas para que a primeira região sem fluxo fique sobreposta, é possível notar que há diferença entre o nível dos patamares para cada um dos valores de vazão, como mostram os gráficos da figura 31 . 


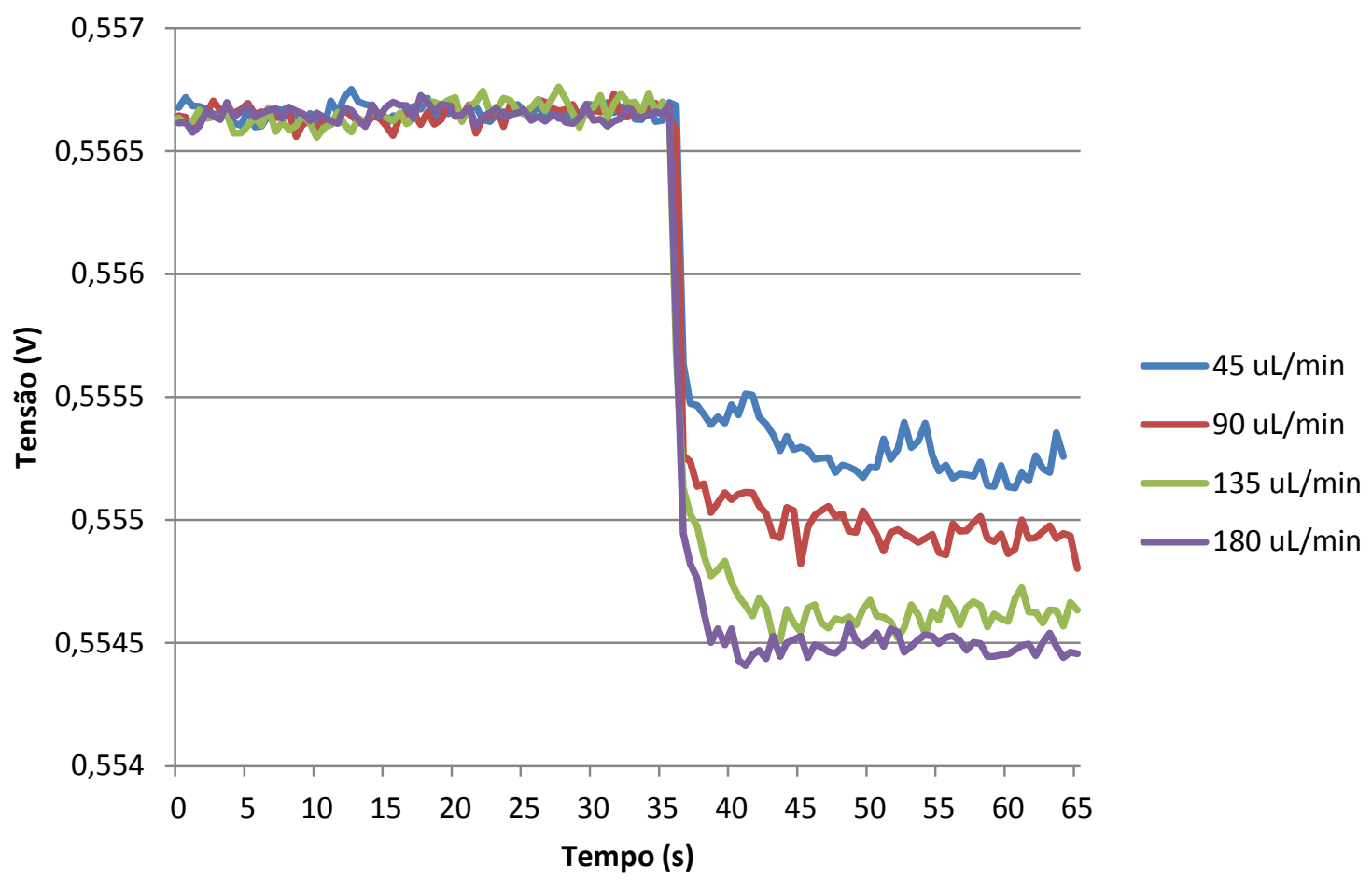

(a)

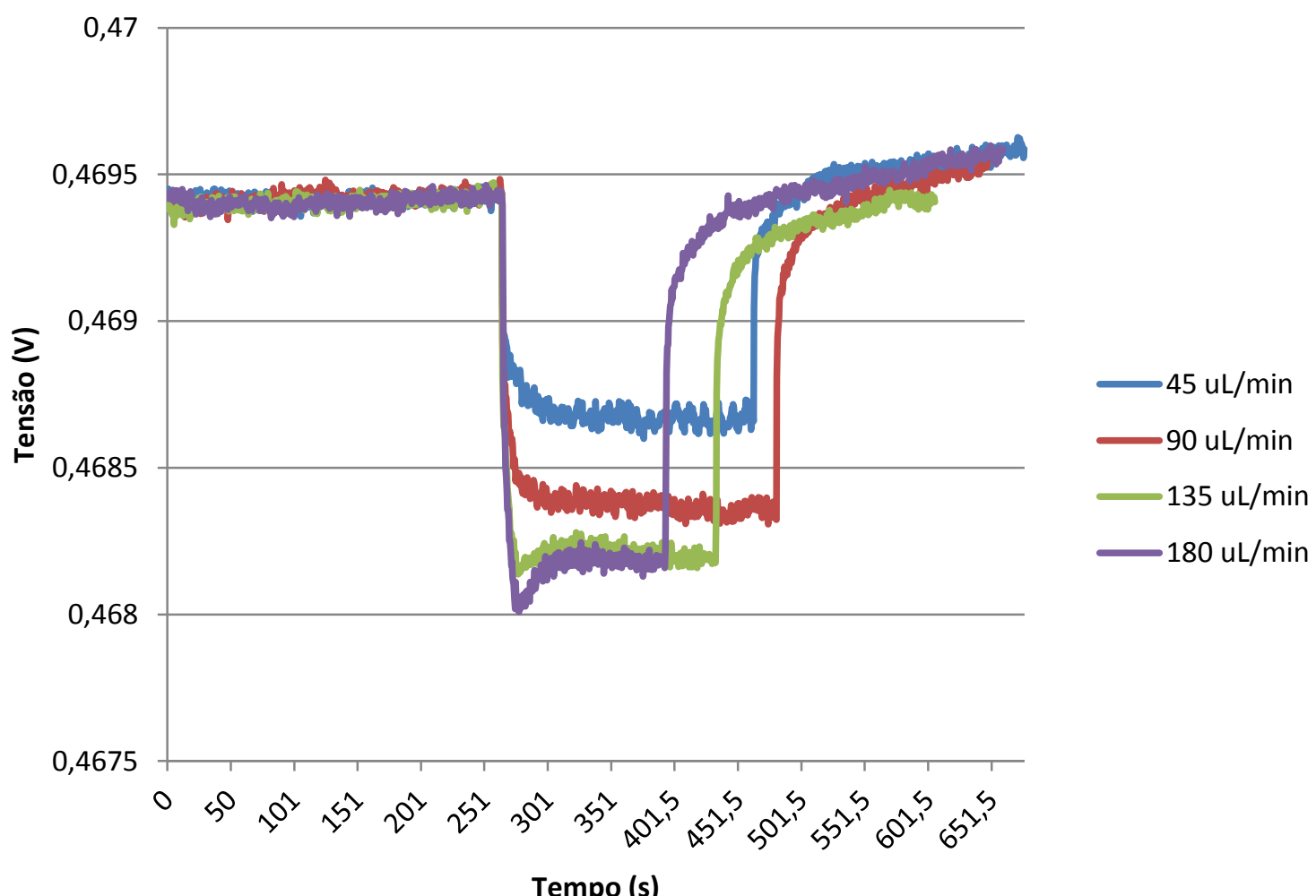

(b) 


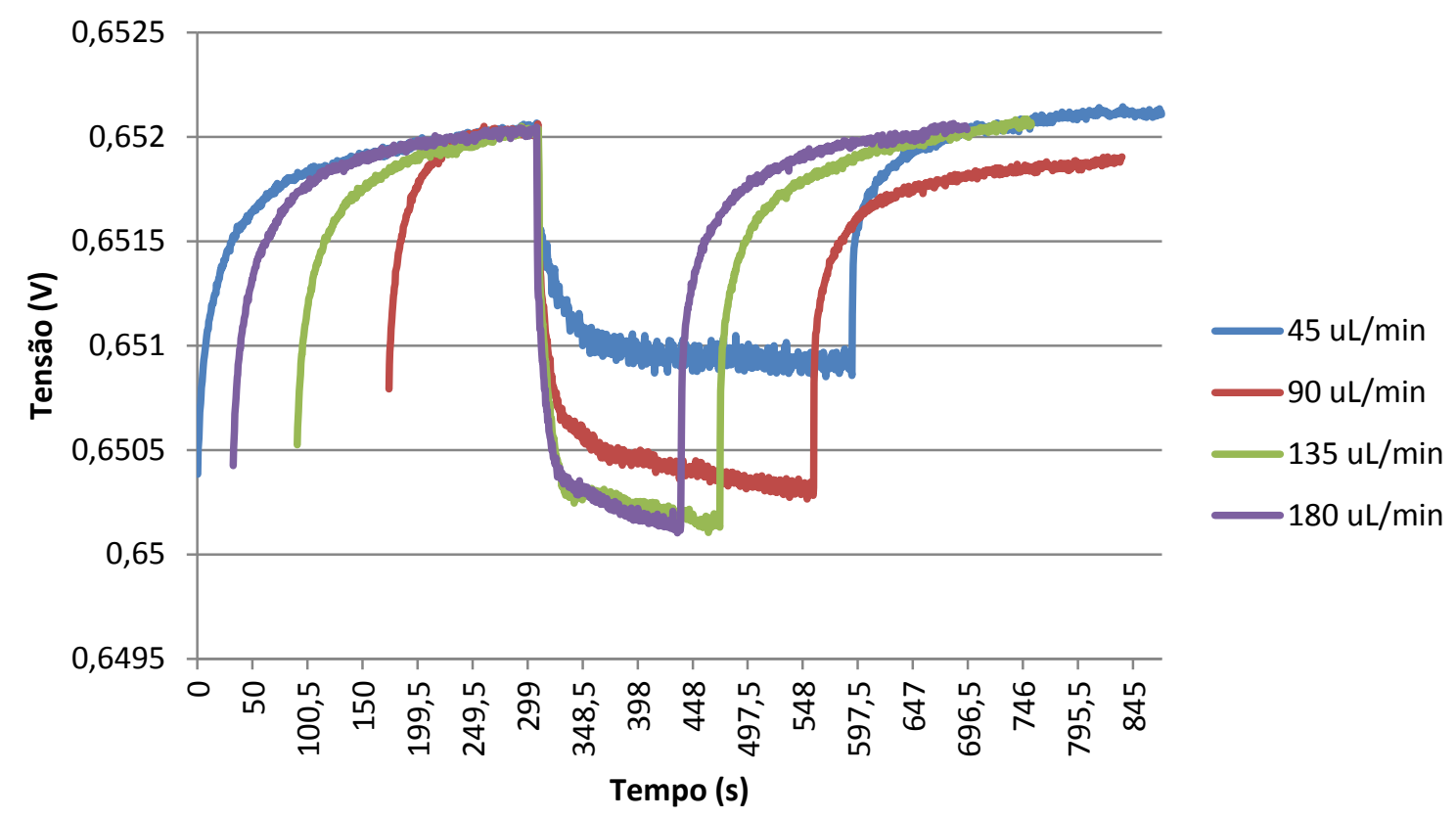

(c)

Figura 31 - Curvas da tensão x tempo normalizadas em relação ao valor de tensão sem escoamento para quatro valores de vazão. (a) Sensor 1; (b) Sensor 2; (c) Sensor 3.

Os gráficos da figura 31 deixam claro que o sensor está conseguindo diferenciar os quatro regimes de fluxo, ou seja, o sensor realmente consegue medir a vazão no microcanal. Pode-se observar com maior clareza a diferença entre os patamares de vazão igual a 45 e $90 \mu \mathrm{L} / \mathrm{min}$, enquanto que os patamares de vazão igual a 135 e $180 \mu \mathrm{L} / \mathrm{min}$ estão bastante próximos um do outro. As simulações por elementos finitos mostradas na seção 4.1 davam a indicação de que a resposta não era linear em toda a faixa de vazão simulada, ficando essa faixa linear restrita a valores mais baixos $(\phi \lesssim 20 \mu L / \mathrm{min})$ e mais altos de vazão $(\phi \gtrsim 130 \mu \mathrm{L} / \mathrm{min})$. De fato, a resposta para vazão igual a 45 e $90 \mu \mathrm{L} / \mathrm{min}$ não estão dentro de nenhuma dessas faixas de vazão.

Apesar de terem sido testados apenas quatro valores de vazão, estima-se a partir dos gráficos que a resolução do sensor seja da ordem de $10 \mu \mathrm{L} / \mathrm{min}$, tendo em vista o nível de ruído sobreposto aos sinais de tensão.

A figura 32 mostra as curvas da diferença de tensão entre a situação com e sem fluxo de água em função da vazão para os três sensores testados. 


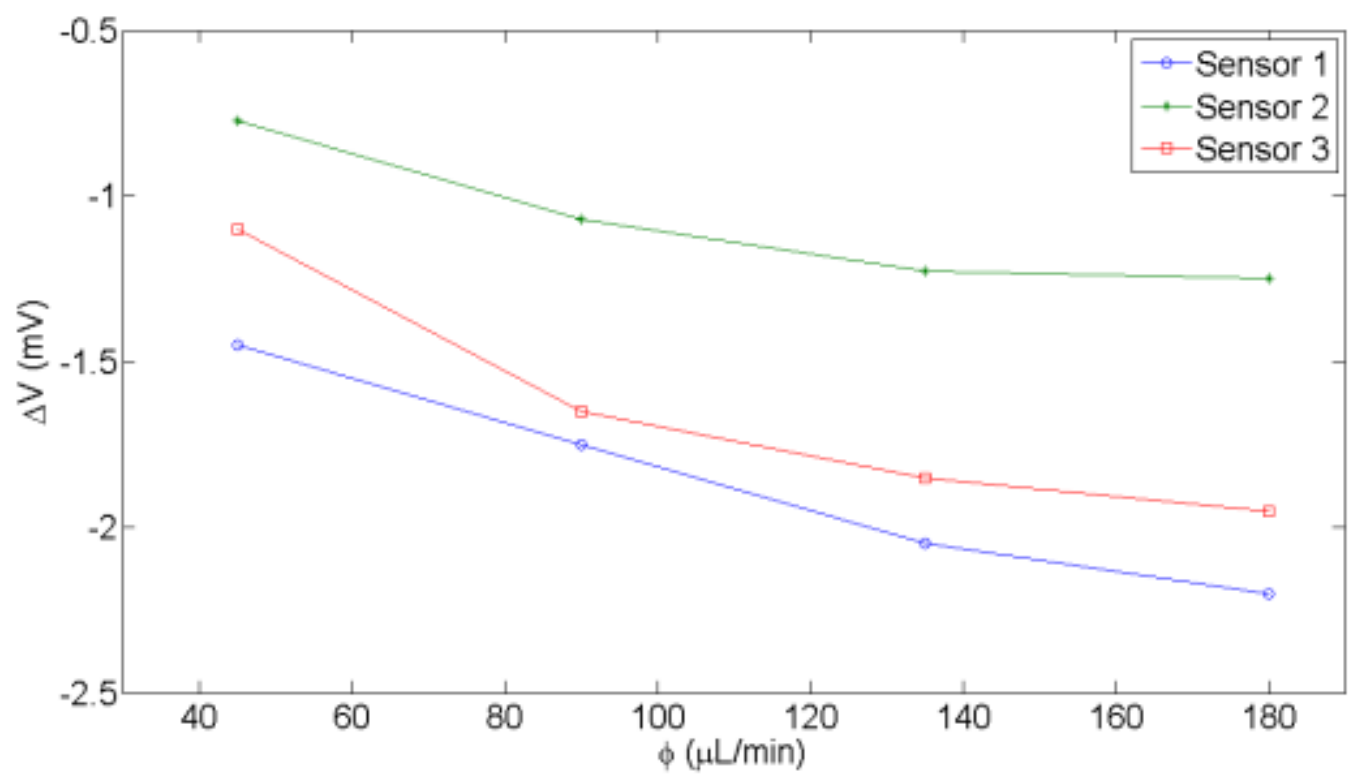

Figura 32 - Curvas da diferença de tensão x vazão obtidas da caracterização dos sensores.

Novamente observa-se que os três sensores foram capazes de detectar a variação de vazão no microcanal. Tomando-se apenas os dois últimos pontos do gráfico, que em tese estão dentro da faixa linear de altas vazões ( $\phi \gtrsim 130 \mu \mathrm{L} / \mathrm{min})$, foi calculada a sensibilidade dos sensores. Os resultados estão contidos na tabela 11.

Tabela 11 - Sensibilidade dos sensores testados na faixa de altas vazões $(\phi \gtrsim 130 \mu L / \mathrm{min})$.

\begin{tabular}{|c|c|c|c|}
\cline { 2 - 4 } \multicolumn{1}{c|}{} & Sensor 1 & Sensor 2 & Sensor 3 \\
\hline $\begin{array}{c}\boldsymbol{S}_{\boldsymbol{V}} \\
(\boldsymbol{\mu} \boldsymbol{V} /(\boldsymbol{\mu} / \min ))\end{array}$ & 150 & 25 & 100 \\
\hline
\end{tabular}

Observa-se que o sensor 2 é o que apresenta menor sensibilidade. Dadas todas as fontes de erro nas medidas, pode-se afirmar que o sensor 1 e o sensor 3 apresentam aproximadamente a mesma sensibilidade, que é aproximadamente quatro vezes maior do que a do sensor 2 . 
Esses resultados apontam que a diminuição na espessura do filme de níquel e que o aumento na largura do filamento impactam de maneira positiva na resposta do sensor, o que é confirmado apenas parcialmente pelas simulações por elementos finitos realizadas para os três sensores, como mostra a figura 33.

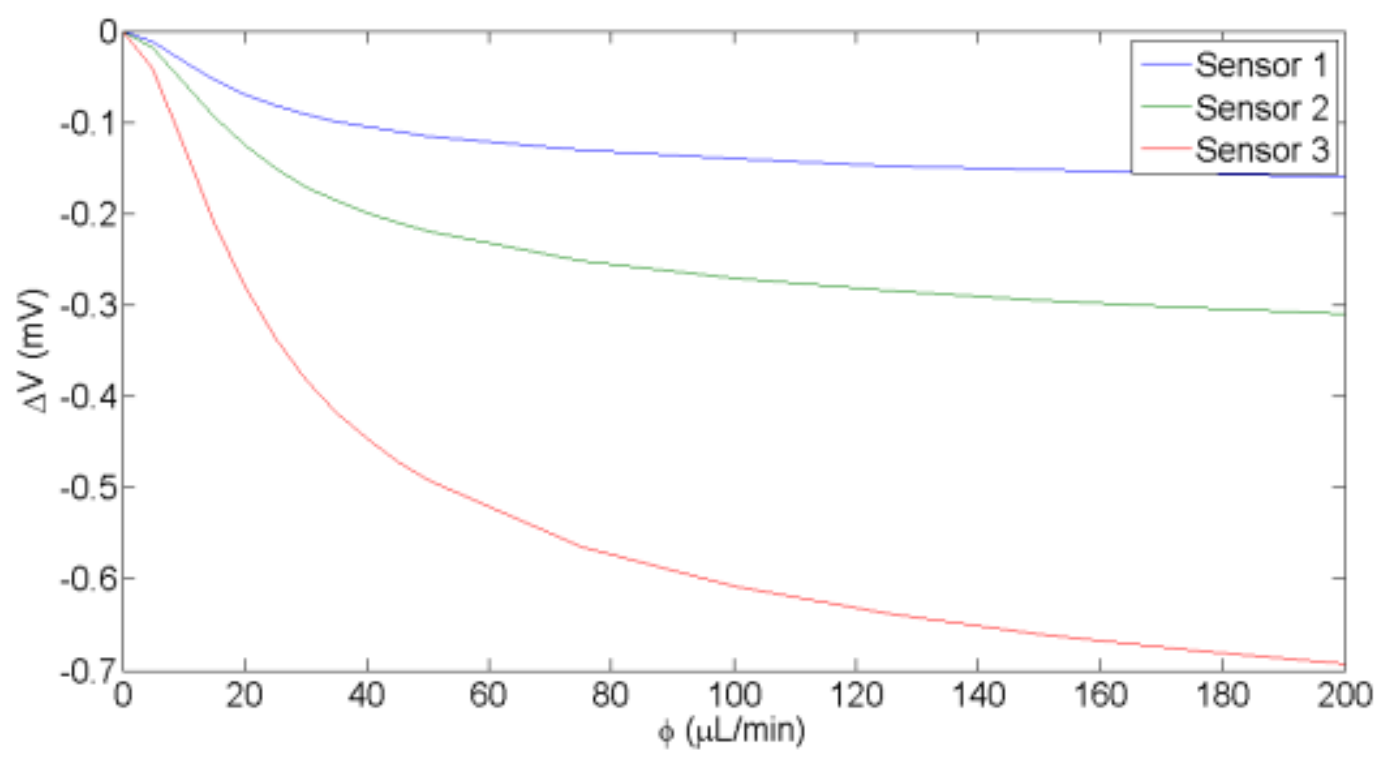

Figura 33 - Curvas da diferença de tensão x vazão obtidas da simulação por elementos finitos dos três sensores.

As curvas mostram que o aumento da largura do filamento realmente produz um efeito positivo na sensibilidade, no entanto, a diminuição na espessura dos filamentos acarreta em uma diminuição na sensibilidade. Esse resultado fica mais claro com os dados da tabela 12, que mostra os valores numéricos das sensibilidades calculadas na região de altas vazões.

Tabela 12 - Sensibilidade dos sensores simulados por elementos finitos na faixa de altas vazões $(\phi \gtrsim 130 \mu \mathrm{L} / \mathrm{min})$.

\begin{tabular}{|c|c|c|c|}
\cline { 2 - 4 } \multicolumn{1}{c|}{} & Sensor 1 & Sensor 2 & Sensor 3 \\
\hline $\begin{array}{c}\boldsymbol{S}_{\boldsymbol{V}} \\
(\boldsymbol{\mu} \boldsymbol{V} /(\boldsymbol{\mu} / \mathrm{min}))\end{array}$ & 4,3 & 8,4 & 18,3 \\
\hline
\end{tabular}


Os valores apresentados na tabela são bem mais modestos do que aqueles medidos nos sensores. Isso pode estar associado às diversas fontes de imprecisão que estão associadas a qualquer medida elétrica. Analisando os dados do ponto de vista qualitativo apenas, acredita-se que o motivo para a discrepância encontrada na sensibilidade do sensor 1 esteja associada à pequena espessura do filme de níquel, que é a metade do valor obtido nos sensores 2 e 3 . Isso dificulta a realização dos contatos elétricos, como mencionado anteriormente. Além disso, em uma película tão fina de filme, os problemas de desuniformidade tornam-se mais pronunciados e podem afetar a medida realizada.

Por outro lado, é muito difícil contruir um modelo que capture todos os fenômenos físicos relacionados com o funcionamento real do dispositivo. Sendo assim, é bastante razoável pensar que imprecisões no modelo também são responsáveis pela discrepância entre os resultados. 


\section{OTIMIZAÇÃO DO SENSOR DE VAZÃO PROPOSTO}

Como mencionado anteriormente, um aspecto importante quando se está desenvolvendo um sensor de vazão térmico é a escolha de um material com elevado coeficiente de resistência (TCR) para compor o filamento. Contudo, outros aspectos construtivos podem ser levados em consideração quando se deseja melhorar a sensibilidade do sensor. Aumentar $\mathrm{O}$ isolamento térmico do filamento, deixando-o suspenso ao invés mantê-lo em contato direto com o substrato, é uma forma de aumentar sua sensibilidade. Essa alteração construtiva possui a vantagem de que toda a eletrônica para polarização do sensor e aquisição do sinal de saída continua sendo a mesma, fato que não ocorreria caso se optasse por mudar a configuração do sensor.

Evidentemente, fabricar um filamento auto-sustentado no interior de um microcanal introduz uma série de complicações e desafios do ponto de vista da microfabricação. Um primeiro ponto a ser observado é que o material que compõe o filamento deve possuir baixo estresse intrínseco ou, de outra forma, o filamento se romperá quando deixado suspenso.

Nesse sentido, resultados preliminares não descritos neste trabalho, mostram que o níquel obtido por eletrodeposição é capaz de permanecer auto-sustentado em comprimentos de até centenas de micrometros. Isso, aliado a seu alto coeficiente de resistência (TCR), torna-o um bom material para compor o filamento tanto em contato com o substrato como na forma auto-sustentada. Outro material que possui baixo estresse residual e foi amplamente estudado pelo Grupo de Novos Materiais e Dispositivos, é o carbeto de silício ( $\mathrm{SiC}$ ), em especial o carbeto de silício amorfo hidrogenado (a-SiC:H) $(48,49,50)$. Quando dopado, o carbeto de silício tem seu coeficiente de resistência aumentado, tornando-o também um bom material com o qual fabricar o filamento.

Uma vez que existam técnicas estabelecidas para se obter materiais com baixo estresse residual, outro aspecto a ser levado em consideração é como fabricar o filamento auto-sustentado. No caso do sensor de vazão proposto, existem basicamente duas formas de fazê-lo: (1) fabricar o filamento sobre o substrato e 
depois liberá-lo, por exemplo, por meio de um processo de corrosão do substrato, ou (2) fabricá-lo diretamente sobre uma cavidade ou microcanal que tenha sido feito previamente no substrato. Neste caso, seria necessário preencher a cavidade com algum material sacrificial, de modo que o filamento possa ser depositado, fotogravado e por fim liberado através da remoção desse material sacrificial.

Essas possibilidades de otimização (filamento auto-sustentado e alternativas de fabricação) começaram a ser exploradas neste trabalho e embora se trate de um estudo ainda em andamento, considera-se pertinente incluir nesta dissertação uma descrição do estágio atual desses estudos. Assim, a seguir será apresentada uma descrição detalhada dessa proposta de otimizaçao do sensor de vazão e alguns resultados preliminares relativos à simulação por elementos finitos e concentrados e também à fabricação dos dispositivos.

Com relação à fabricação, as duas abordagens de fabricação do filamento autosustentado mencionadas anteriormente foram estudadas neste trabalho. A abordagem 1 (fabricar o filamento e depois fabricar o microcanal deixando 0 filamento auto-sustentado) pareceu ser a forma mais natural de se fabricar o sensor de vazão. Entretanto, existe um sério problema de compatibilidade entre os processos de fabricação nessa abordagem. Os microcanais são fabricados através da corrosão em solução de HF (como mostrado no item 2.4.2), a mesma solução que corrói o titânio usado como camada de aderência. Sendo assim, o processo de fabricação dos microcanais destruiria o filamento caso se optasse por fabricar o microcanal depois de ter sido fabricado o filamento.

Para solucionar esse problema, o filamento teve que ser encapsulado entre duas camadas de um filme que resistisse à solução de HF. Esse filme deveria ainda apresentar boas características mecânicas, já que ele também deverá permanecer suspenso. Para isso, optou-se por encapsular o filamento entre duas camadas de a-SiC:H intrínseco (sem dopantes).

Uma vez que o a-SiC:H é capaz de suportar a corrosão em solução de HF, explorouse também a possibilidade de se fabricar o filamento diretamente em a-SiC:H dopado. Além simplificar o processo de fabricação, reduzindo o número de etapas, o a-SiC:H dopado possui resistividade muito maior do que a do níquel. Assim, para 
uma mesma corrente de polarização, a tensão de saída do sensor é maior para o filamento de a-SiC:H dopado, tornando-a mais fácil de ser medida.

A segunda abordagem de fabricação também foi testada, sendo sua principal vantagem o fato de ser um método mais simples e que exige menos etapas de processo em sala limpa. Nesse caso, o material sacrificial utilizado foi o fotorresiste AZ-1518, pois ele pode ser facilmente removido em acetona. A metodologia utilizada foi aplicar o fotorresiste manualmente sobre a lâmina, de modo a preencher completamente os microcanais e formar uma camada espessa de fotorresiste. Em seguida foi feita uma etapa de planarização para nivelar a superfície do fotorresiste com a do microcanal. Nesse momento foi feita a deposição dos materiais de aderência, definida a geometria do filamento e eletrodepositado o níquel. Por fim, o fotorresiste é removido em acetona.

Como forma de avaliar a melhora na sensibilidade do sensor introduzida pelas mudanças no processo de fabricação, foram feitas simulações do sensor por elementos finitos. Além disso, algumas simplificações puderam ser introduzidas na análise do escoamento ao redor do filamento auto-sustentado e isso permitiu que se criasse um modelo a elementos concentrados para esse tipo de sensor.

A modelagem por elementos finitos e elementos concentrados, bem como os três processos de fabricação propostos para otimizar a resposta do sensor estão apresentados nas seções a seguir.

\subsection{MODELO A ELEMENTOS FINITOS}

A simulação por elementos finitos para o caso do filamento auto-sustentado foi feita com o auxílio do software Comsol Multiphysics ${ }^{\circledR}$. A figura 34 mostra um desenho esquemático do sensor simulado em perspectiva (figura 34a), bem como as vistas do corte transversal (figura 34b) e longitudinal (figura 34c) à direção do escoamento. As principais dimensões do dispositivo também estão ilustradas na figura 34 e os valores numéricos assumidos estão indicados na tabela 13. 


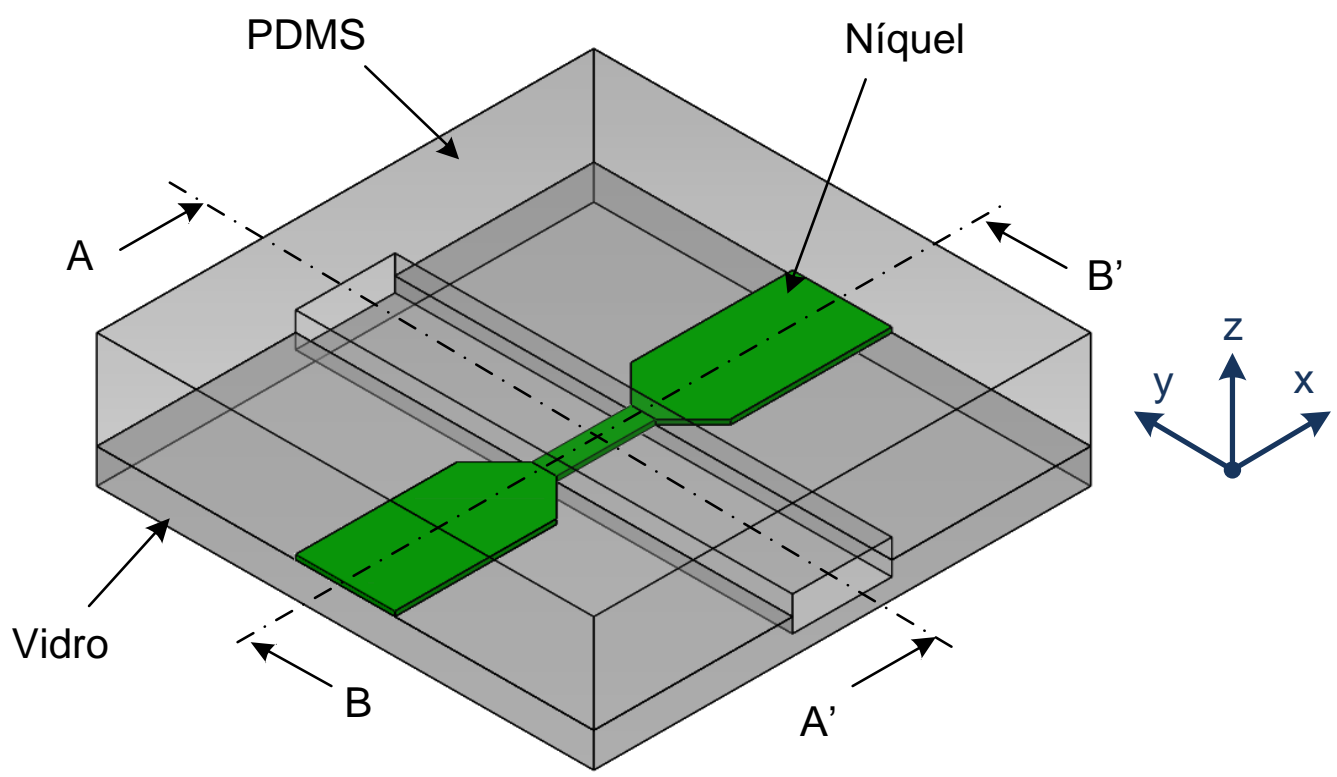

(a)

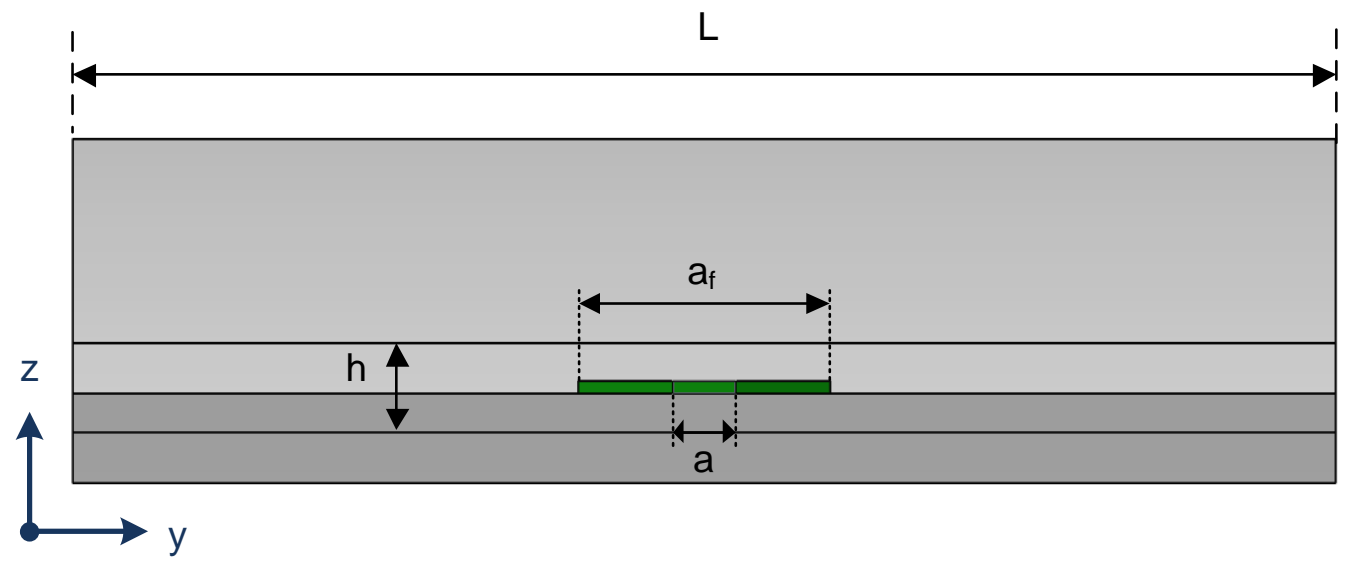

(b)

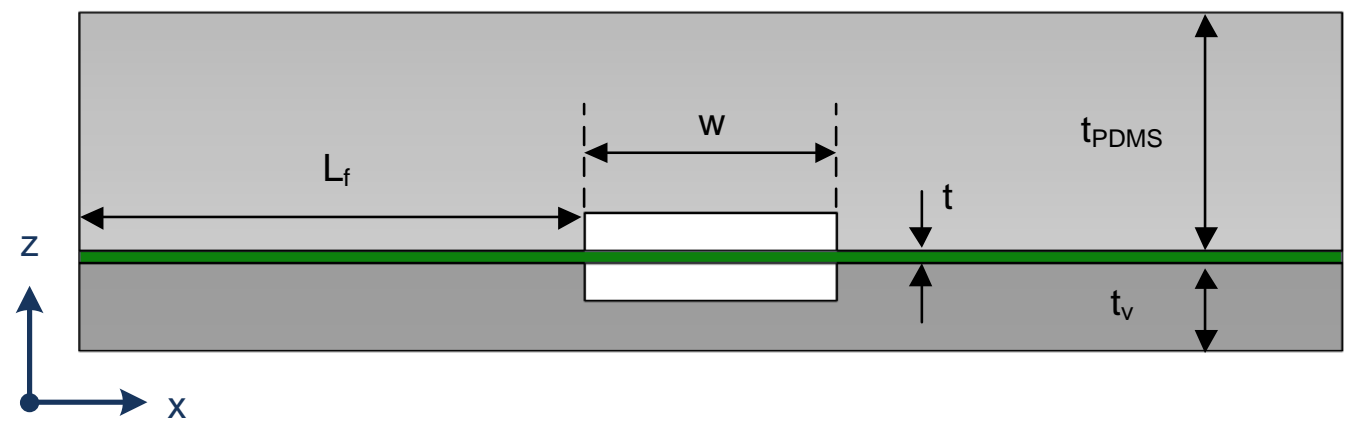

(c)

Figura 34 - Desenho esquemático do dispositivo com filamento auto-sustentado. (a) Vista em perspectiva; (b) Vista no corte AA'; (c) Vista no corte BB'. 
Tabela 13 - Parâmetros do modelo de elementos finitos do sensor otimizado.

\begin{tabular}{|c|c|}
\hline \multicolumn{2}{|c|}{ Dimensões do sensor } \\
\hline $\mathrm{L}=4 \mathrm{~mm}$ & $\mathrm{~L}_{\mathrm{f}}=1,9 \mathrm{~mm}$ \\
\hline $\mathrm{w}=500 \mu \mathrm{m}$ & $\mathrm{h}=50 \mu \mathrm{m}$ \\
\hline $\mathrm{t}=0,5 \mu \mathrm{m}$ & $a=50 \mu \mathrm{m}$ \\
\hline $\mathrm{t}_{\mathrm{v}}=1 \mathrm{~mm}$ & $\mathrm{t}_{\mathrm{PDMS}}=5 \mathrm{~mm}$ \\
\hline$a_{f}=500 \mu m$ & \\
\hline \multicolumn{2}{|c|}{ Propriedades da água (43) } \\
\hline \multicolumn{2}{|c|}{ Densidade $=998,2 \mathrm{~kg} / \mathrm{m}^{3}$} \\
\hline \multicolumn{2}{|c|}{ Viscosidade $=1,001.10^{-35}$ Pa.s } \\
\hline \multicolumn{2}{|c|}{ Condutividade térmica $=0,5984 \mathrm{~W} /(\mathrm{m} . \mathrm{K})$} \\
\hline \multicolumn{2}{|c|}{ Calor específico a pressão constante $=4183 \mathrm{~J} /(\mathrm{kg} . \mathrm{K})$} \\
\hline \multicolumn{2}{|c|}{ Fator de compressibilidade $=1$} \\
\hline \multicolumn{2}{|c|}{ Propriedades do níquel (44) } \\
\hline \multicolumn{2}{|c|}{ Resistividade a $0^{\circ} \mathrm{C}=123,23 \cdot 10^{-9} \Omega \cdot \mathrm{m}$} \\
\hline \multicolumn{2}{|c|}{ Coeficiente de temperatura $(\mathrm{TCR})=0,0058661 / \mathrm{K}$} \\
\hline \multicolumn{2}{|c|}{ Condutividade térmica $=90,75 \mathrm{~W} /(\mathrm{m} . \mathrm{K})$} \\
\hline \multicolumn{2}{|c|}{ Propriedades do PDMS (45) } \\
\hline \multicolumn{2}{|c|}{ Condutividade térmica $=0,15 \mathrm{~W} /(\mathrm{m} . \mathrm{K})$} \\
\hline \multicolumn{2}{|c|}{ Propriedades do vidro (46) } \\
\hline
\end{tabular}

Mais uma vez, fez-se uso da simetria do problema em relação ao plano xz passando pelo centro do microcanal para diminuir o tempo de computação. Além disso, os valores do comprimento do microcanal $(L)$ e do comprimento do filamento fora do microcanal $\left(\mathrm{L}_{\mathrm{f}}\right)$ foram reduzidos para os menores valores que não interferissem na resposta do sensor.

A simulação empregou uma malha não-estruturada com elementos tetraédricos e as mesmas condições de contorno do caso do sensor em contato com o substrato, sendo elas: corrente de polarização do filamento constante e igual à $20 \mathrm{~mA}$, temperatura de entrada do microcanal, da parte inferior do substrato de vidro e da parte superior do bloco de PDMS igual à $20^{\circ} \mathrm{C}$ e condição de contorno aberto (open boundary) para demais bordas externas do domínio. 
Foram realizadas simulações estáticas para determinação do campo de temperaturas e da tensão sobre o filamento em regime estacionário, com a vazão volumétrica de entrada variando de 0 a $200 \mu \mathrm{L} / \mathrm{min}$. A figura 35 mostra imagens do domínio de simulação no ambiente do programa e da malha gerada. Os resultados da simulação serão apresentados na seção 6.1 .

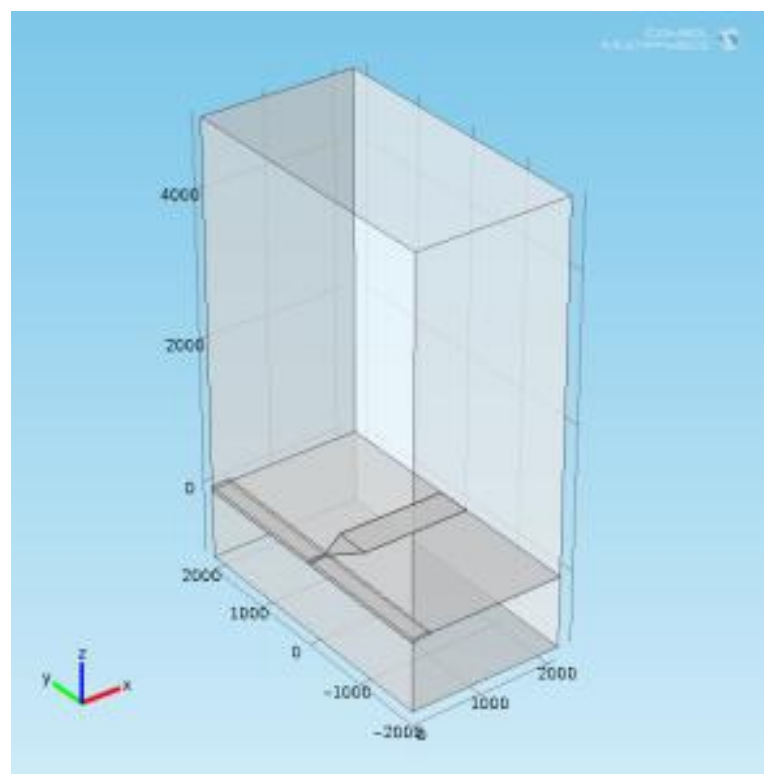

(a)

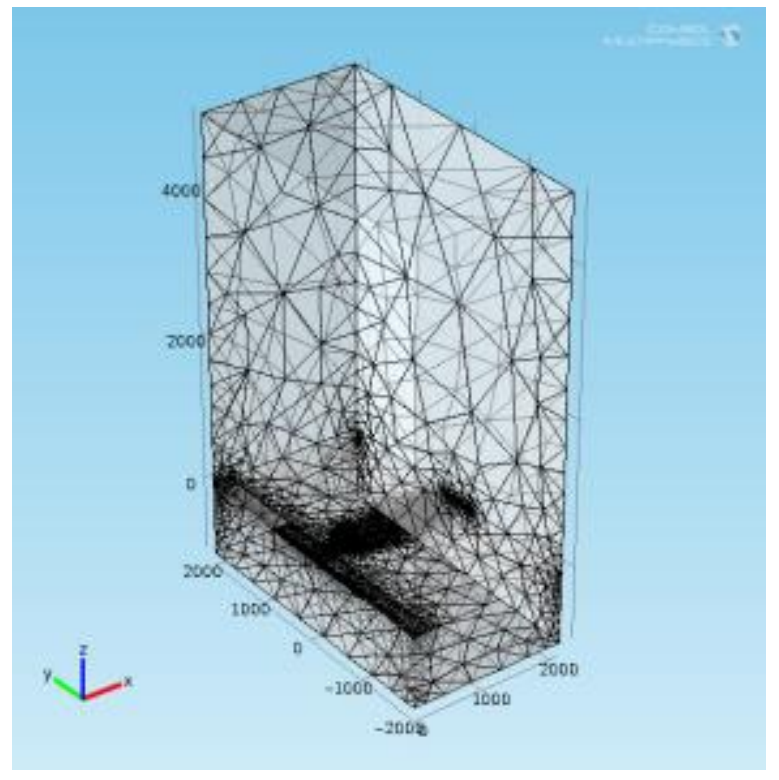

(c)

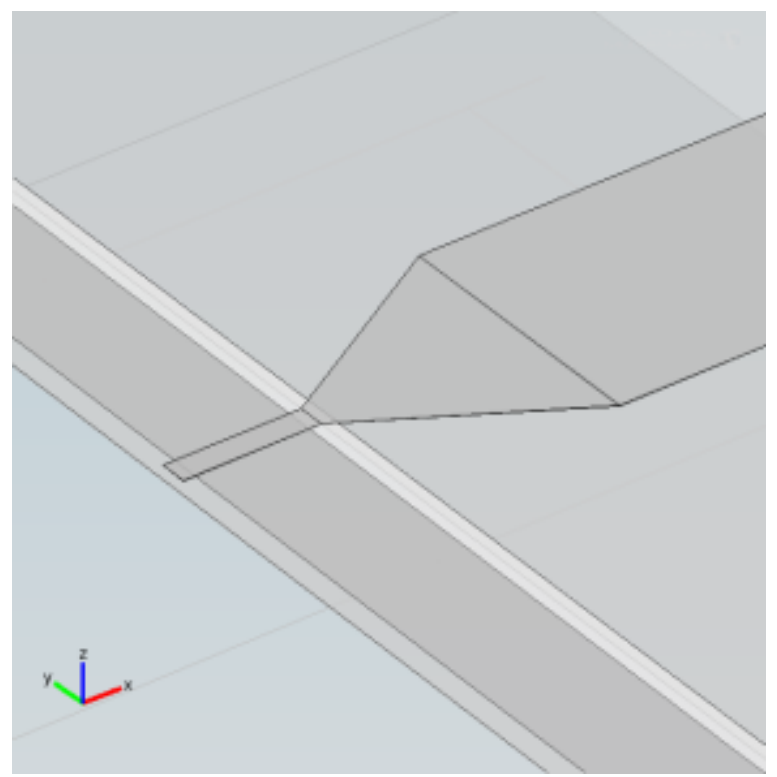

(b)

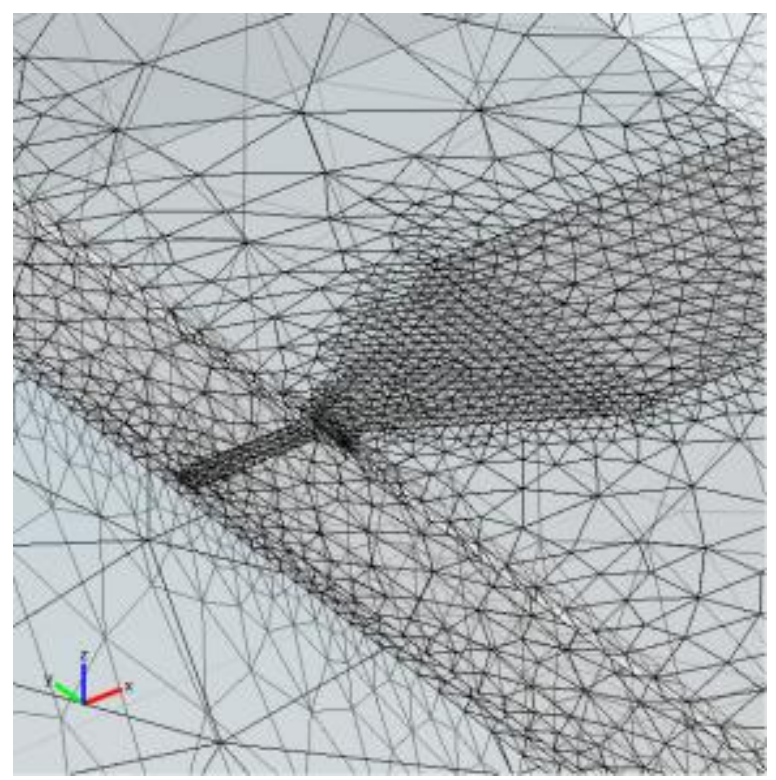

(d)

Figura 35 - Imagens do software de simulação por elementos finitos utilizado para simulação do sensor otimizado. (a,b) Domínio de simulação; (c,d) Malha de elementos finitos gerada pelo programa. 


\subsection{MODELO A ELEMENTOS CONCENTRADOS}

Como mencionado anteriormente, na análise do sensor térmico de vazão no interior de um microcanal ocorrem interações entre três domínios físicos: elétrico, térmico e fluídico. Logo, um modelo a elementos concentrados para esse sensor deve fazer uso de analogias eletrotérmica e eletrofluídica. $O$ circuito elétrico equivalente que modela o funcionamento do sensor foi dividido em três subcircuitos, cada um correspondente a um domínio físico, conforme mostrado nas seções a seguir.

Para construir o modelo, assumiu-se que o microcanal apresenta seção retangular e que o filamento fabricado em níquel encontra-se no centro do canal, na metade de sua altura, como mostrado anteriormente na figura 34 . O fluido de trabalho considerado é a água.

Na modelagem do domínio térmico, assumiu-se que as trocas de calor por condução entre o fluido e o substrato de vidro e entre o fluido e a tampa de PDMS estão confinadas em uma região próxima ao filamento. Assim, definiu-se um comprimento efetivo de microcanal para as trocas de calor $\left(L_{e f}\right)$, baseado nas dimensões do dispositivo. Ao contrário do que foi feito na simulação por elementos finitos, o comprimento do microcanal $(\mathrm{L})$ e o comprimento do filamento fora do microcanal $\left(\mathrm{L}_{\mathrm{f}}\right)$ foram considerados os mesmos dos dispositivos fabricados. Todos os parâmetros da simulação por elementos concentrados estão mostrados na tabela 14.

Visando modelar os sensores fabricados de acordo com os processos alternativos de fabricação, os valores geométricos usados neste caso foram alterados para valores que descrevem melhor a realidade desses processos de fabricação, sendo portanto diferentes dos empregados nas simulações por elementos finitos. 
Tabela 14 - Parâmetros do modelo a elementos concentrados.

\begin{tabular}{|l|c|}
\hline \multicolumn{2}{|c|}{ Dimensões do sensor } \\
\hline $\mathrm{L}=15 \mathrm{~mm}$ & $\mathrm{~L}_{\mathrm{f}}=13 \mathrm{~mm}$ \\
\hline $\mathrm{W}=200 \mu \mathrm{m}=30 \mu \mathrm{m}$ \\
\hline $\mathrm{t}=2 \mu \mathrm{m}$ & $\mathrm{a}=50 \mu \mathrm{m}$ \\
\hline $\mathrm{t}_{\mathrm{v}}=1 \mathrm{~mm}$ & $\mathrm{t}_{\mathrm{PDMS}}=5 \mathrm{~mm}$ \\
\hline $\mathrm{a}_{\mathrm{f}}=500 \mu \mathrm{m}$ & $\mathrm{L}_{\mathrm{ef}}=2 \mathrm{a}$ \\
\hline \multicolumn{2}{|c|}{ Propriedades da água (43) } \\
\hline Densidade $=998,2 \mathrm{~kg} / \mathrm{m}^{3}$ \\
\hline Viscosidade $=1,001.10^{-3} \mathrm{~Pa} . \mathrm{s}$ \\
\hline Condutividade térmica $=0,5984 \mathrm{~W} /(\mathrm{m} . \mathrm{K})$ \\
\hline Calor específico a pressão constante $=4183 \mathrm{~J} /(\mathrm{kg} . \mathrm{K})$ \\
\hline Fator de compressibilidade $=1$ \\
\hline \multicolumn{2}{|c|}{ Propriedades do níquel (44) } \\
\hline Resistividade a $0^{\circ} \mathrm{C}=123,23.10^{-9} \Omega . \mathrm{m}$ \\
\hline Coeficiente de temperatura $(\mathrm{TCR})=0,0058661 / \mathrm{K}$ \\
\hline Condutividade térmica $=90,75 \mathrm{~W} /(\mathrm{m} . \mathrm{K})$ \\
\hline \multicolumn{2}{|c|}{ Propriedades do PDMS (45) } \\
\hline Condutividade térmica $=0,15 \mathrm{~W} /(\mathrm{m} . \mathrm{K})$ \\
\hline Propriedades do vidro (46) \\
\hline Condutividade térmica $=1,05 \mathrm{~W} /(\mathrm{m} . \mathrm{K})$ \\
\hline
\end{tabular}

Os circuitos equivalentes foram construídos e simulados utilizando o software $\mathrm{NI}$ Multisim Analog Devices Edition 10, que é uma versão grátis do software da National Instruments.

\subsubsection{Modelo para o domínio elétrico}

Do ponto de vista elétrico, visto que o sensor trabalha no modo de funcionamento à potência constante, o sensor se resume apenas a uma resistência excitada por uma fonte de corrente. O valor dessa resistência não é fixo mas é sim função da temperatura e segue a expressão: 


$$
R_{\text {elétrica }}(T)=\frac{\varrho(T) \ell}{A}=\frac{\varrho(T) w}{a t}, \quad \varrho(T)=\varrho_{0}\left(1+\alpha\left(T-T_{0}\right)\right)
$$

na qual $\varrho$ é a resistividade, $\varrho_{0}$ é a resistividade à temperatura $T_{0}$ e $\alpha$ é o coeficiente de temperatura (TCR).

Para deixar mais claro a resposta elétrica do sensor, a resistência elétrica do filamento foi dividida em duas partes: uma correspondente apenas ao filamento no interior do microcanal $\left(\boldsymbol{R}_{\text {canal }}\right)$ e outra correspondente às trilhas metálicas que não estão em contato direto com o fluido mas sim com o substrato ( $\left.\boldsymbol{R}_{\text {substrato }}\right)$. O circuito equivalente para o domínio elétrico é mostrado na figura 36.

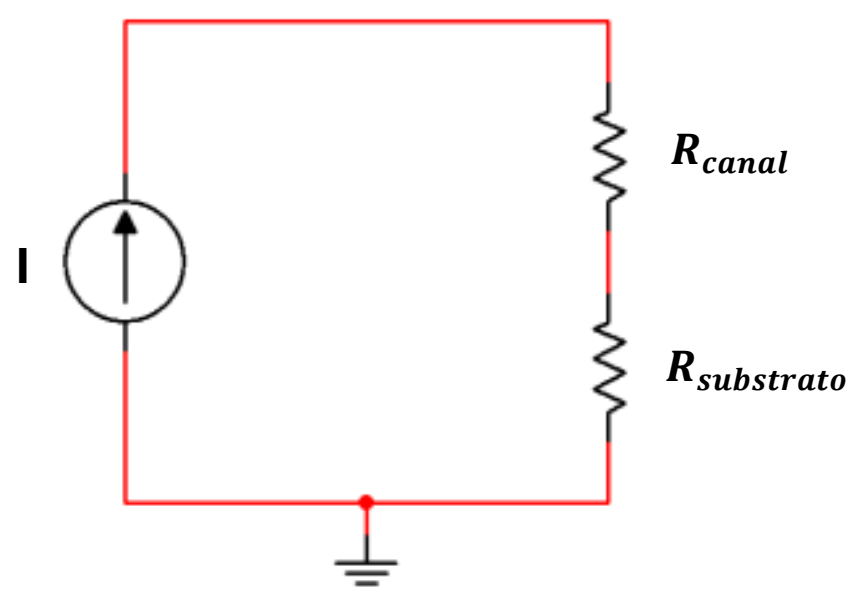

Figura 36 - Circuito equivalente para o domínio elétrico.

\subsubsection{Modelo para o domínio térmico}

A modelagem do domínio térmico é a que exige maior cuidado já que nele está contido o princípio de funcionamento do sensor.

Por ser mantido aquecido, o filamento funciona como uma fonte de calor, dissipando uma potência térmica constante. As trocas de calor envolvendo filamento, fluido e 
substrato ocorrem por meio de dois fenômenos: condução e convecção. Como as temperaturas envolvidas são relativamente baixas (abaixo de $100^{\circ} \mathrm{C}$ ) a transferência de calor por radiação foi desprezada.

Para construção do circuito equivalente no domínio térmico as seguintes analogias foram empregadas:

\section{Analogia eletrotérmica}

$\begin{array}{lll}\text { Diferença de temperatura }(\Delta \mathrm{T}) & \leftrightarrow & \text { Tensão }(\mathrm{V}) \\ \text { Fluxo de calor }(\dot{Q}) & \leftrightarrow & \text { Corrente }(\mathrm{I}) \\ \text { Massa térmica }\left(\mathrm{M}_{\mathrm{T}}\right) & \leftrightarrow & \text { Capacitância }(\mathrm{C}) \\ \text { Resistência térmica }\left(\mathrm{R}_{\mathrm{T}}\right) & \leftrightarrow & \text { Resistência elétrica }(\mathrm{R})\end{array}$

Nessa analogia, o fluxo de calor $\dot{Q}$ é dado em Watts e a massa térmica, também chamada de capacidade térmica, segue a expressão $M_{T}=\Delta E / \Delta T=m$. $c$, sendo $m$ a massa dada em quilogramas e c o calor específico dado em J/(kg.K).

A resistência térmica pode ser definida por duas expressões, dependendo do mecanismo de transferência de calor que está sendo considerado. No caso da condução, a resistência segue a expressão:

$$
R_{\text {cond }}=\frac{\ell}{k A} \quad(16)
$$

sendo $\ell$ a distância de condução considerada, $k$ a condutividade térmica e $A$ a área pela qual ocorre troca de calor.

No caso da convecção, a resistência térmica é dada por:

$$
R_{\text {conv }}=\frac{1}{h_{c} A}
$$

sendo $h_{c}$ o coeficiente de convecção e $A$ a área pela qual ocorre troca de calor.

A transferência de calor por condução acontece nas interações filamento-fluido, fluido-substrato e filamento-substrato, além da condução de calor ao longo do 
próprio filamento. Já a convecção ocorre na interação entre o fluido que escoa sobre o filamento e o próprio filamento.

Uma hipótese assumida neste modelo é que a dissipação de calor é uniformemente distribuída ao longo do filamento, ou seja, $\dot{Q}=$ cte. Como consequência, o perfil de temperaturas ao longo do filamento não é constante, mas segue uma distribuição parabólica. Esse fato pode ser demonstrado analisando-se a troca de calor por condução ao longo do filamento no caso unidimensional. A equação que descreve esse fenômeno é:

$$
\dot{Q}(x)=-k \frac{\partial^{2} T}{\partial x^{2}}
$$

Realizando a dupla integração dessa equação, visto que $\dot{Q}(x)=\dot{Q}=$ cte , obtém-se que:

$$
T(x)=-\frac{\dot{Q}}{2 k} x^{2}+C_{1} x+C_{2}
$$

com $C_{1}$ e $C_{2}$ sendo constantes de integração a serem determinadas através da aplicação das condições de contorno. Supondo que a temperatura é conhecida nas extremidades do filamento:

$$
\left\{\begin{array}{l}
T(x=0)=T_{0} \\
T(x=w)=T_{0}
\end{array}\right.
$$

a expressão para o perfil de temperaturas ao longo do filamento é:

$$
T(x)=-\frac{\dot{Q}}{2 k} x^{2}+\frac{\dot{Q} w}{2 k} x+T_{0}
$$

Da equação 21 é possível extrair que o ponto de máxima temperatura $\widehat{T}$ encontra-se no centro do filamento, ou seja, $\widehat{T}=T(x=w / 2)$.

A informação do perfil de temperatura ao longo do filamento é importante para a determinação do modelo para o domínio térmico como será mostrado a seguir. 


\section{- Condução}

Visto que a distribuição de temperatura no filamento segue um perfil parabólico e que o ponto de máximo encontra-se no centro do microcanal, é possível explorar a simetria do problema e modelar apenas metado do dispositivo. As resistências térmicas de condução consideradas estão mostradas na figura 37, que apresenta um corte transversal do microcanal (plano $\mathrm{xz}$ ).

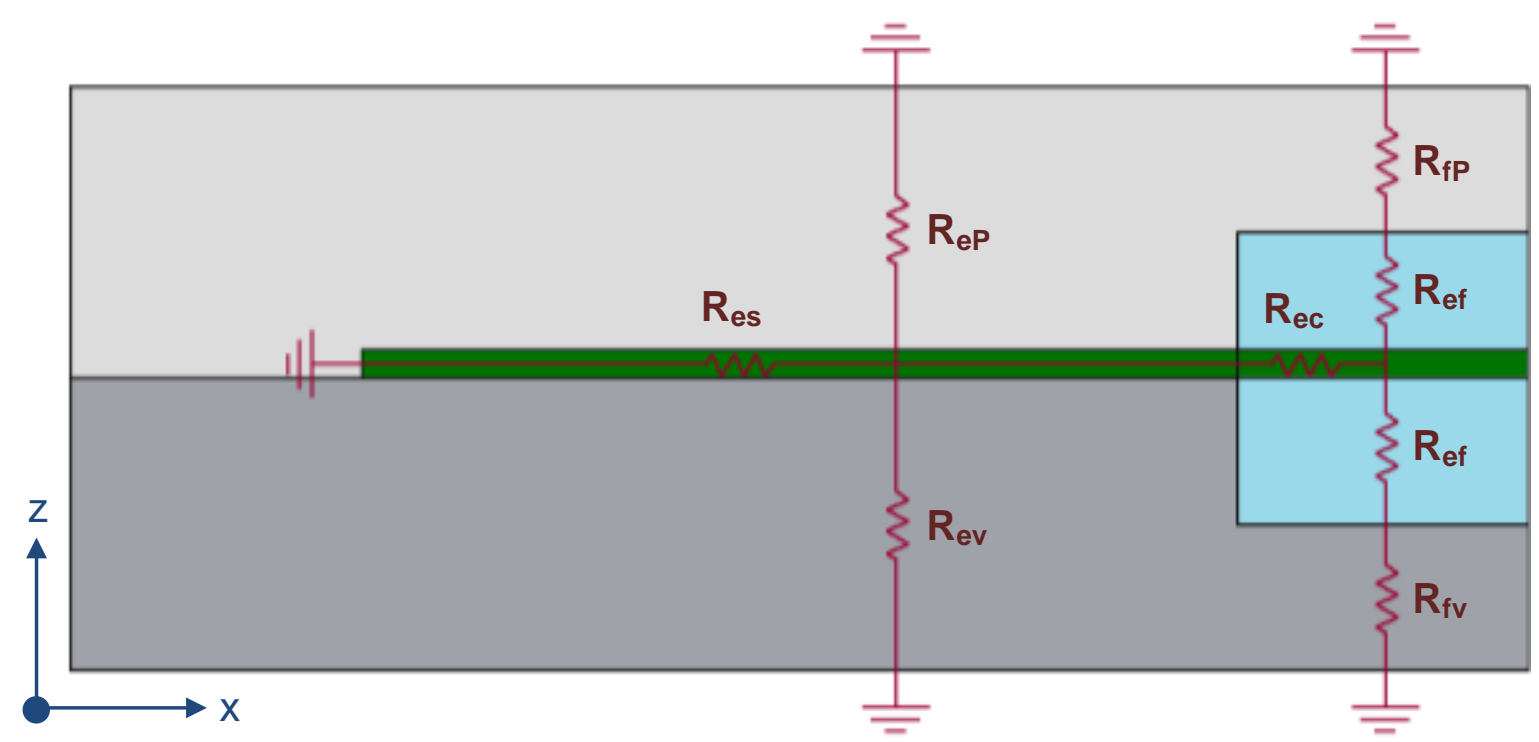

Figura 37 - Diagrama mostrando as resistências térmicas de condução consideradas.

As resistências de condução podem ser calculadas seguindo as fórmulas:

Resistência de condução entre filamento e fluido:

$$
R_{e f}=\frac{h / 2}{k_{f} a^{w} / 2}=\frac{h}{k_{f} a w}
$$

Resistência de condução entre fluido e PDMS:

$$
R_{f P}=\frac{t_{P D M S}-h / 2}{k_{P D M S} L_{e f} w / 2}=\frac{2\left(t_{P D M S}-h / 2\right)}{k_{P D M S} L_{e f} w}
$$


Resistência de condução entre fluido e vidro:

$$
R_{f v}=\frac{t_{v}-h / 2}{k_{v} L_{e f} w / 2}=\frac{2\left(t_{v}-h / 2\right)}{k_{v} L_{e f} w}
$$

Resistência de condução ao longo do filamento (fora do microcanal):

$$
R_{e s}=\frac{L_{f}}{k_{N i} a_{f} t}
$$

Resistência de condução entre filamento e PDMS (fora do microcanal):

$$
R_{e P}=\frac{t_{P D M S}}{k_{P D M S} a_{f} L_{f}}
$$

Resistência de condução entre filamento e vidro (fora do microcanal):

$$
R_{e v}=\frac{t_{v}}{k_{v} a_{f} L_{f}}
$$

A resistência de condução ao longo do filamento $R_{e c}$ merece atenção especial. A resistência total do filamento dentro do microcanal é dada por

$$
R_{T \text { cond }}=\frac{w}{k_{N i} a t}
$$

Como a dissipação de energia é uniforme ao longo do filamento não se pode considerar, por simetria, que $R_{e c}=R_{T \text { cond }} / 2$.

Para modelar $R_{e c}$ utilizou-se a abordagem apresentada por S. T. Todd et al $(51,52)$. O diagrama da figura 38 ilustra a situação do ponto de vista térmico, sendo que $R_{T L}$ e $R_{T R}$ são as resistências térmicas vistas pelo filamento do lado esquerdo e direito, respectivamente. 


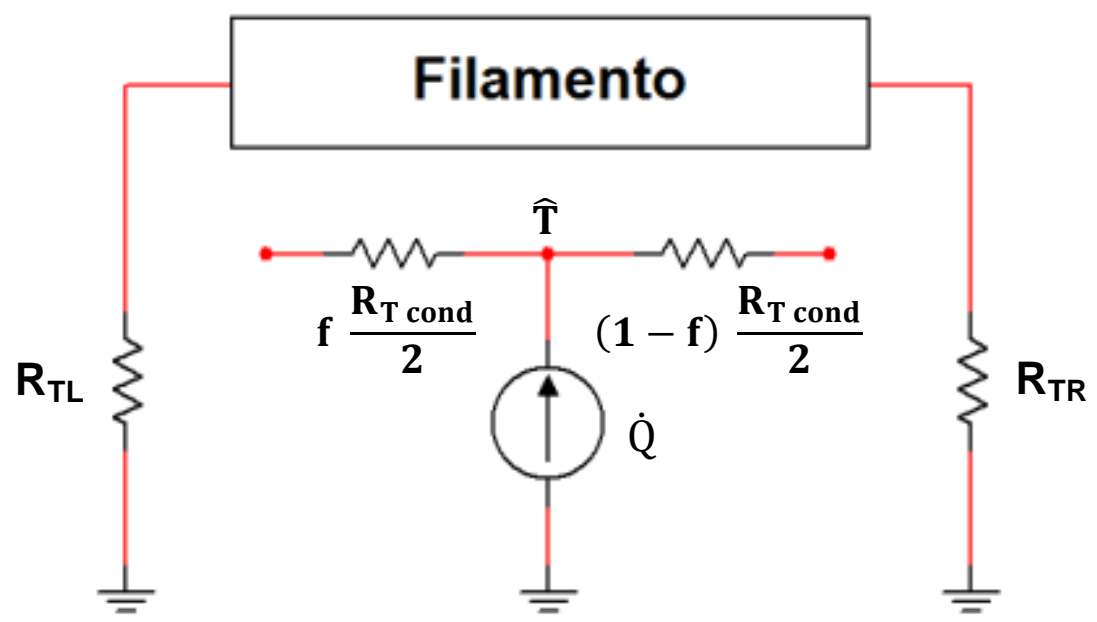

Figura 38 - Diagrama ilustrando o modelo de condução do filamento e suas condições de contorno.

Considera-se que toda a potência térmica entra no filamento no ponto de temperatura máxima $\widehat{T}$ e se divide entre duas resistências térmicas. O parâmetro fé chamado de fator de equilíbrio e indica como o fluxo de calor é dividido. Ele é definido como:

$$
f=\frac{R_{T \text { cond }} / 2+R_{T R}}{R_{T L}+R_{T \text { cond }}+R_{T R}}
$$

A distribuição de temperatura ao longo do filamento, dada pela equação 21 , pode ser adaptada para essa situação e resulta:

$$
T(x)=\dot{Q}\left[R_{T \text { cond }}\left(\frac{-x^{2}}{2 w^{2}}+\frac{f x}{w}\right)+f R_{T L}\right]
$$

Sendo que o ponto de máxima temperatura está localizado na posição $x=f w$.

Dada a simetria geométrica do dispositivo e levando em conta as resistências de condução mostradas anteriormente:

$$
R_{T L}=R_{T R}=R_{e P}+R_{e s}+R_{e v}
$$

o que faz com que $f=1 / 2$. Assim, o ponto de temperatura máxima está localizado no centro do filamento e o fluxo de calor se divide igualmente entre as duas resistências de condução. Com essas informações determina-se que: 


$$
R_{e c}=f \frac{R_{T \text { cond }}}{2}=\frac{1}{2} \frac{R_{T \text { cond }}}{2}=\frac{1}{4} \frac{w}{k_{N i} a t}
$$

e que a distribuição de temperatura ao longo do filamento segue a expressão:

$$
T(x)=\dot{Q}\left[\frac{R_{T \text { cond }}}{2 w}\left(\frac{-x^{2}}{w}+x\right)+\frac{R_{T L}}{2}\right]
$$

Apesar de ter sido encontrada uma fórmula para a resistência de condução do filamento, o problema ainda não está completamente resolvido. O valor da resistência elétrica do filamento depende da temperatura do mesmo e como mostrado, ela não é constante mas apresenta um perfil parabólico. Logo, uma alternativa é tomar a temperatura média do filamento para determinar a resistência elétrica. Contudo, no modelo obtido até agora é possível determinar apenas a temperatura máxima do filamento.

A solução então é dividir a resistência $R_{e c}$ em duas, de modo que o nó entre elas represente a temperatura média $\bar{T}$. O circuito equivalente ao filamento levando-se em conta apenas metade do problema fica como mostrado na figura 39.

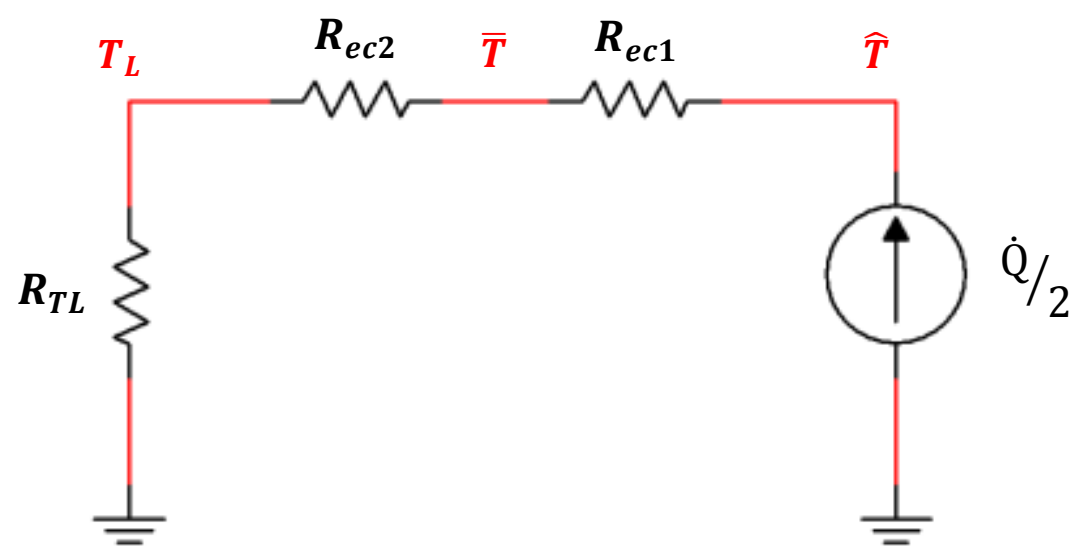

Figura 39 - Circuito equivalente do filamento.

Conhecidos os valores de $\widehat{T}, \bar{T}$ e $T_{L}$, que podem ser extraídos da expressão do perfil de temperaturas $T(y)$, as resistências $R_{e c 1}$ e $R_{e c 2}$ são determinadas a partir do próprio circuito equivalente. Assim, o valor da temperatura máxima $\widehat{T}$ é igual a: 


$$
\begin{gathered}
\hat{T}=T(x=w / 2)=\dot{Q}\left[\frac{R_{T \text { cond }}}{2 w}\left(\frac{-(w / 2)^{2}}{w}+\frac{w}{2}\right)+\frac{R_{T L}}{2}\right] \rightarrow \\
\rightarrow \hat{T}=\dot{Q}\left[\frac{R_{T \text { cond }}}{2 w}\left(\frac{-(w / 2)^{2}}{w}+\frac{w}{2}\right)+\frac{R_{T L}}{2}\right] \rightarrow \hat{T}=\dot{Q}\left[\frac{R_{T \text { cond }}}{8}+\frac{R_{T L}}{2}\right]
\end{gathered}
$$

a temperatura média ao longo do filamento é:

$$
\begin{gathered}
\bar{T}=\frac{1}{w / 2} \int_{0}^{w / 2} T(x) d x=\frac{2}{w} \int_{0}^{w / 2} \dot{Q}\left[\frac{R_{T \text { cond }}}{2 w}\left(\frac{-x^{2}}{w}+x\right)+\frac{R_{T L}}{2}\right] d x \rightarrow \\
\rightarrow \bar{T}=\frac{2 \dot{Q}}{w} \int_{0}^{w / 2}\left[-\frac{R_{T \text { cond }}}{2 w^{2}} x^{2}+\frac{R_{T \text { cond }}}{2 w} x+\frac{R_{T L}}{2}\right] d x \rightarrow \\
\rightarrow \bar{T}=\frac{\dot{Q}}{w}\left[-\frac{R_{T \text { cond }}}{2 w^{2}} \frac{x^{3}}{3}+\frac{R_{T \text { cond }}}{2 w} \frac{x^{2}}{2}+\frac{R_{T L}}{2} x\right]_{0}^{w / 2} \rightarrow \bar{T}=\dot{Q}\left[\frac{R_{T \text { cond }}}{12}+\frac{R_{T L}}{2}\right]
\end{gathered}
$$

e a temperatura na extremidade do filamento é:

$$
T_{L}=T(x=0)=\dot{Q}\left[\frac{R_{T \text { cond }}}{2 w}\left(\frac{-(0)^{2}}{w}+0\right)+\frac{R_{T L}}{2}\right] \rightarrow T_{L}=\dot{Q}\left[\frac{R_{T L}}{2}\right]
$$

Portanto, as resistências $R_{e c 1}$ e $R_{e c 2}$ valem:

$$
\begin{aligned}
& R_{e c 1}=\frac{\widehat{T}-\bar{T}}{\dot{Q} / 2} \rightarrow R_{e c 1}=\frac{R_{T \text { cond }}}{12}=\frac{1}{12} \frac{w}{k_{N i} a t} \\
& R_{e c 2}=\frac{\bar{T}-T_{L}}{\dot{Q} / 2} \rightarrow R_{e c 2}=\frac{R_{T \text { cond }}}{6}=\frac{1}{6} \frac{w}{k_{N i} a t}
\end{aligned}
$$

Desse modo, todas as resistências de condução foram determinadas. Para finalizar o modelo de elementos concentrados do domínio térmico, resta apenas determinar qual o valor da resistência de convecção. Isso se resume a determinar o coeficiente de convecção $h_{c}$. 


\section{- Convecção}

Problemas práticos de transferência de calor em microcanais são de difícil resolução analítica, como discutido na seção 2.3. Entretanto, no caso do filamento autosustentado no interior do microcanal, algumas hipóteses podem ser assumidas de modo a simplificar o problema e permitir que ele seja resolvido de modo analítico, mesmo que de modo aproximado.

A primeira hipótese a ser assumida é a de que as paredes estão suficientemente distantes do filamento, de modo a não interferirem nos fenômenos que ocorrem próximo a ele. Apesar do comprimento do filamento ser da mesma ordem de grandeza da altura do microcanal $(a=50 \mu \mathrm{m}$ e $\mathrm{h}=30 \mu \mathrm{m})$, sua espessura é duas ordens de grandeza menor $(\mathrm{t}=0,5 \mu \mathrm{m}$ e $\mathrm{h}=30 \mu \mathrm{m})$, assim essa hipótese é tida como válida.

Desse modo, considerando o problema bidimensional, o escoamento no caso do sensor é equivalente ao escoamento ao redor de uma placa plana mostrado na figura 40. Como a influência das paredes foi desprezada, o perfil de velocidades a montante do filamento é assumido como sendo constante de valor $U_{\infty}$.

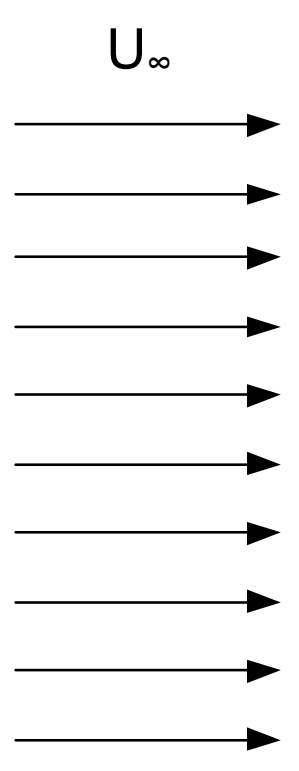

$\mathrm{T}_{\infty}$

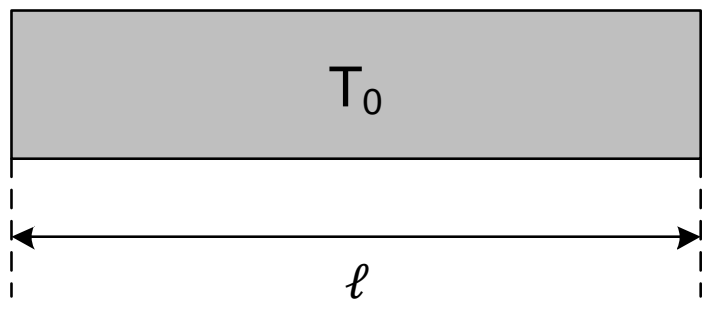

Figura 40 - Escoamento ao redor de uma placa plana. 
A análise da troca de calor nesse escoamento pode ser feita através da equação de balanço de energia (equação 10 da página 33), de modo semelhante à apresentada na referência 53, aplicadas as seguintes condições de contorno:

$$
\begin{aligned}
& T=T_{0} \text { na superfície do filamento } \\
& T \rightarrow T_{\infty} \quad \text { muito distante do filamento. }
\end{aligned}
$$

Pode-se adimensionalizar a equação da energia para determinar a importância de cada um de seus termos tomando-se as seguintes variáveis adimensionais:

$$
\vec{V}^{*}=\frac{\vec{V}}{U_{\infty}} \quad \vec{r}^{*}=\frac{\vec{r}}{\ell} \quad \theta=\frac{T-T_{\infty}}{T_{0}-T_{\infty}}
$$

com $\vec{r}$ sendo o vetor posição e $\ell$ a dimensão característica do escoamento (neste caso, $\ell=a$ ). A equação da energia adimensional resultante, no caso de escoamento estacionário, é:

$$
P e\left(\vec{V}^{*} \cdot \nabla^{*} \theta\right)=\nabla^{* 2} \theta
$$

sendo que $\nabla^{*}$ é o operador nabla adimensional e $P e$ é o número de Péclet. A essa equação são aplicadas as seguintes condições de contorno:

$$
\begin{aligned}
& \theta=1 \text { na superfície do filamento } \\
& \theta \rightarrow 0 \text { quando }\left|\vec{r}^{*}\right| \rightarrow \infty .
\end{aligned}
$$

Analisando a equação 39 , é possível notar que a temperatura $\theta$ deve depender da posição ou da geometria do corpo, da velocidade e do número de Péclet. Como a velocidade está associada ao número de Reynolds, definido como:

$$
R e=\frac{\rho U_{\infty} \ell}{\mu} \quad(40),
$$

pode-se escrever que $\theta$ é função de $\vec{r}^{*}$, do número de Reynolds e do número de Péclet:

$$
\theta=\theta\left(\vec{r}^{*}, R e, P e\right)
$$


ou ainda que $\theta$ é função de $\vec{r}^{*}$, do número de Reynolds e do número de Prandlt:

$$
\theta=\theta\left(\vec{r}^{*}, R e, P r\right)
$$

já que:

$$
P e=\operatorname{RePr} \quad \text { (43), } \quad \operatorname{Pr}=\frac{\mu c_{p}}{k}
$$

sendo Pr o número de Prandtl, um parâmetro adimensional que só depende das características do fluido.

Para eliminar a necessidade de se conhecer a geometria do corpo para resolver o problema, pode-se empregar outro parâmetro adimensional, o número de Nusselt, que é definido como:

$$
N u=\frac{2 \dot{Q}}{A k\left(T_{0}-T_{\infty}\right) / \ell}
$$

Outra forma de escrever o número de Nusselt é através da expressão:

$$
N u=\frac{h_{c} \ell}{k} \quad \text { (46) , }
$$

na qual o coeficiente de convecção $h_{c}$ aparece explicitamente. Logo, fica evidente que o número de Nusselt relaciona o transporte de calor por convecção e condução.

O problema se resume agora a determinar:

$$
N u=N u(R e, P r)
$$

O escoamento sobre uma placa plana mantida a uma temperatura $T_{0}$ é tradicionalmente abordado no estudo da convecção forçada. Para o caso do escoamento laminar, E. Pohlhausen $(40,41)$ determinou experimentalmente uma expressão para o número de Nusselt, cujo valor médio é:

$$
N u=0,664 \operatorname{Re}^{1 / 2} \operatorname{Pr}^{1 / 3} \quad \text { (48) }
$$


A expressão 48 é aplicável ao problema de camada limite térmica que leva em conta o escoamento apenas sobre uma face da placa plana (portanto ligeiramente diferente ao representado na figura 40) e é válida para $0,6 \leq \operatorname{Pr} \leq 10$.

Nos escoamentos em escala microscópica, o número de Reynolds é muito pequeno e a propagação de calor na direção contrária ao escoamento deve ser considerada (seção 2.3). Com isso, a hipótese de camada limite térmica não pode ser aplicada e a expressão 48 deixa de ser válida.

L. Gary Leal apresenta em seu livro (53) a resolução do problema de troca de calor ao redor de um corpo de geometria arbitrária para $R e \ll 1$ e $P e \ll 1$ através do método de perturbação singular ou do casamento assintótico (em inglês, Method of matched asymptotic expansions). Esse é um dos diversos métodos contidos na Teoria de Perturbação para resolução aproximada de problemas.

A hipótese de que $R e \ll 1$ e $P e \ll 1$ pode ser observada no escoamento do sensor quando a vazão é suficientemente baixa. Considerando, por exemplo, que a altura do microcanal é de $50 \mu \mathrm{m}$, que sua largura é $500 \mu \mathrm{m}$ e que a vazão volumétrica de fluido é de $100 \mathrm{~nL} / \mathrm{min}$, a velocidade $U_{\infty}$ tida como a velocidade média do escoamento na seção do microcanal é:

$$
\begin{aligned}
U_{\infty}=\frac{\phi}{a w}=\frac{100 \mathrm{~nL} / \mathrm{min}}{50 \mu \mathrm{m} \cdot 500 \mu \mathrm{m}} & =\left(\frac{100 \cdot 10^{-12}}{60} \mathrm{~m}^{3} / \mathrm{s}\right) \cdot \frac{1}{\left(50 \cdot 10^{-6} \mathrm{~m}\right) \cdot\left(500 \cdot 10^{-6} \mathrm{~m}\right)} \rightarrow \\
& \rightarrow U_{\infty}=6,67 \cdot 10^{-5} \mathrm{~m} / \mathrm{s}
\end{aligned}
$$

Com isso, o número de Peclet é obtido como sendo:

$$
P e=\frac{U_{\infty} \ell}{\kappa}=\frac{6,67 \cdot 10^{-5} \cdot 50 \cdot 10^{-6}}{1,43 \cdot 10^{-7}} \rightarrow P e=0,023 \ll 1
$$

Visto que o valor de vazão adotado é adequado para um sistema microfluídico, a hipótese assumida é válida.

Para resolução do escoamento nessa condição, assume-se que a expansão da equação 49 para a temperatura adimensional é uma aproximação de primeira ordem para a solução da equação 39 numa região próxima ao filamento: 


$$
\theta=\theta_{0}+P e \theta_{1}+O(P e)
$$

Assim, a expressão para o número de Nusselt médio que satisfaz o problema, calculada a partir da equação 45, é:

$$
N u=N u_{0}+\frac{1}{4}\left(N u_{0}\right)^{2} P e+O(P e) \quad(50),
$$

sendo que $N u_{0}$ é o número de Nusselt calculado levando-se em conta apenas a transferência de calor por condução:

$$
N u_{0}=\frac{2 \dot{Q}_{\text {cond }}}{A k\left(T_{0}-T_{\infty}\right) / \ell}
$$

Através do modelo equivalente construído para a condução, consegue-se calcular com grande facilidade o valor de $\dot{Q}_{c o n d}$, que corresponde a:

$$
\dot{Q}_{\text {cond }}=2 \frac{\left(T_{0}-T_{\infty}\right)}{R_{e f}}
$$

sendo que o fator 2 surge do fato de estar sendo considerada a dissipação de calor pelos dois lados do filamento.

Portanto, considerando que a largura do filamento a representa o comprimento característico do corpo:

$$
N u_{0}=2\left(2 \frac{\left(T_{0}-T_{\infty}\right)}{R_{e f}}\right) \frac{1}{A k\left(T_{0}-T_{\infty}\right) / \ell}=4 \frac{1}{\frac{h}{k w a}} \frac{1}{\frac{w / 2 a k}{a}} \rightarrow N u_{0}=\frac{8 a}{h}
$$

Substituindo o valor de $N u_{0}$ na equação, obtém-se:

$$
\begin{gathered}
N u=\frac{8 a}{h}+\frac{1}{4}\left(\frac{8 a}{h}\right)^{2} P e=\frac{8 a}{h}+\frac{1}{4} \frac{64 a^{2}}{h^{2}} \operatorname{RePr}=\frac{8 a}{h}+\frac{16 a^{2}}{h^{2}} \frac{\rho U_{\infty} a}{\mu} \frac{\mu c_{p}}{k} \rightarrow \\
\rightarrow \quad N u=\frac{8 a}{h}+\frac{16 \rho U_{\infty} a^{3} c_{p}}{h^{2} k}
\end{gathered}
$$

Utilizando a segunda definição do número de Nusselt, determina-se finalmente o coeficiente de convecção $h_{c}$ : 


$$
N u=\frac{h_{c} a}{k}=\frac{8 a}{h}+\frac{16 \rho U_{\infty} a^{3} c_{p}}{h^{2} k} \rightarrow h_{c}=k\left(\frac{8}{h}+\frac{16 \rho U_{\infty} a^{2} c_{p}}{h^{2} k}\right)
$$

A resistência térmica devido à convecção é portanto:

$$
R_{\text {conv }}=\frac{1}{h_{c} A} \rightarrow R_{\text {conv }}=\left[\frac{k w a}{2}\left(\frac{8}{h}+\frac{16 \rho U_{\infty} a^{2} c_{p}}{h^{2} k}\right)\right]^{-1}
$$

Esse resultado é uma contribuição importante deste trabalho.

É importante lembrar que para se chegar até a expressão 56 as seguintes hipóteses foram assumidas:

1. As propriedades do fluido são as mesmas em todo o microcanal e não mudam com a temperatura, ou seja, $\rho, \mu, k$ e $c_{p}$ são constantes em todo o domínio;

2. O número de Reynolds do escoamento é muito pequeno $(R e \ll 1)$, assim como o número de Peclet $(P e \ll 1)$;

3. A temperatura é constante ao longo de toda a superfície do corpo, no caso, o filamento;

4. As paredes do microcanal encontram-se infinitamente distantes do filamento;

5. O perfil de velocidades em todo o percurso até o corpo é uniforme, ou seja, $\vec{V}=U_{\infty}=$ cte em toda a seção de entrada e a montante do corpo.

A hipótese 1 foi assumida durante a derivação das equações de balanço e tanto ela quanto a hipótese 2 mostraram-se válidas no contexto da microfluídica. Assumir que a temperatura é constante ao longo do filamento não condiz com o que foi feito na derivação das resistências de condução térmica mas é aceitável desde que essa temperatura seja assumida como sendo a temperatura média do filamento. De fato, a hipótese 4, que trás com ela a hipótese 5, é a mais contraditória. Por mais fino que seja o filamento, a influência da parede superior e inferior, e principalmente das paredes laterais, do microcanal deve ser considerada. Contudo, considerar essa 
influência deixaria o problema intratável do ponto de vista analítico e portanto se assume que as hipóteses são válidas, tendo consciência de que discrepâncias nos resultados estarão presentes.

O circuito equivalente final para o domínio térmico levando também em consideração a massa térmica do fluido está mostrado na figura 41.

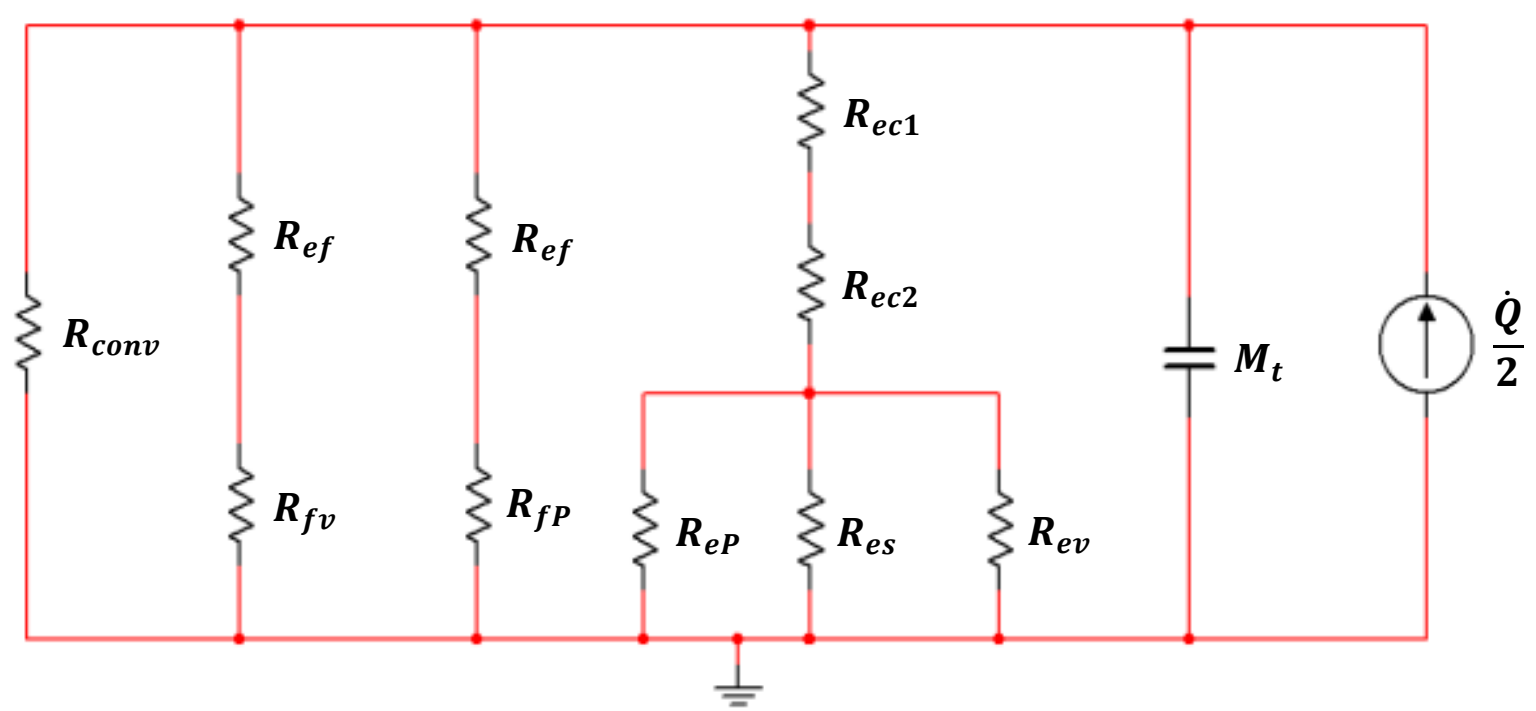

Figura 41 - Circuito equivalente para o domínio térmico.

\subsubsection{Modelo para o domínio fluídico}

O fenômeno a ser modelado no domínio fluídico é o escoamento do fluido no interior do microcanal. O efeito causado pela presença do filamento é desprezado pois ele apresenta dimensões bastante reduzidas se comparadas com as do microcanal em si.

Para determinar o modelo a elementos concentrados para o domínio fluídico, foi usada a seguinte analogia (54): 


\section{Analogia eletrofluídica}

$\begin{array}{lll}\text { Diferença de pressão }(\Delta \mathrm{p}) & \leftrightarrow & \text { Tensão }(\mathrm{V}) \\ \text { Vazão volumétrica }(\phi) & \leftrightarrow & \text { Corrente }(\mathrm{I}) \\ \text { Resistência fluídica }\left(\mathrm{R}_{\mathrm{f}}\right) & \leftrightarrow & \text { Resistência elétrica }(\mathrm{R}) \\ \left.\text { Inércia fluídica (massa / } \mathrm{A}^{2}\right) & \leftrightarrow & \text { Indutância }(\mathrm{L}) \\ \text { Rigidez fluídica (rigidez / } \mathrm{A}^{2} \text { ) } & \leftrightarrow & \text { Capacitância }(\mathrm{C})\end{array}$

A resistência fluídica representa a dissipação de energia por efeitos viscosos. A indutância fluídica modela a inércia do fluido no interior do microcanal quando é aplicada uma diferença de pressão. Basicamente ela representa a inércia do fluido à mudança de velocidade devido a uma variação na pressão. A rigidez fluídica modela os efeitos de compressibilidade do fluido. Na analogia acima, $A$ representa a área da seção do microcanal normal ao escoamento.

A resistência fluídica, que é a razão entre a diferença de pressão e a vazão, $R_{f}=\Delta p / \phi$, é determinada a partir da solução do campo de velocidades do escoamento. No caso de um escoamento em dutos, também chamado de escoamento de Poiseuille, a resistência fluídica para um canal com seção retangular é igual a $(28,55)$ :

$$
R_{f}=\frac{\frac{12 \mu L}{h w^{3}}}{1-\frac{192 w}{\pi^{5} h} \sum_{i=1,3,5, \ldots}^{\infty} \frac{\tanh (i \pi h / 2 w)}{i^{5}}}
$$

A inércia e a rigidez fluídica podem ser determinadas segundo as expressões:

$$
\begin{gathered}
\Delta p=\rho \frac{L}{A} \frac{d \phi}{d t}=L_{f} \frac{d \phi}{d t} \rightarrow L_{f}=\rho \frac{L}{A} \\
\Delta p=\frac{1}{\chi L A} \int \phi d t=\frac{1}{C_{f}} \int \phi d t \rightarrow C_{f}=\chi L A
\end{gathered}
$$

sendo que $\chi$ é o fator de compressibilidade, dado por: 


$$
\chi=\frac{p \tilde{V}}{R T} \quad(60)
$$

em que $\tilde{V}$ é o volume molar do gás.

Conclui-se portanto que o circuito equivalente para o domínio fluídico é como o ilustrado na figura 42.

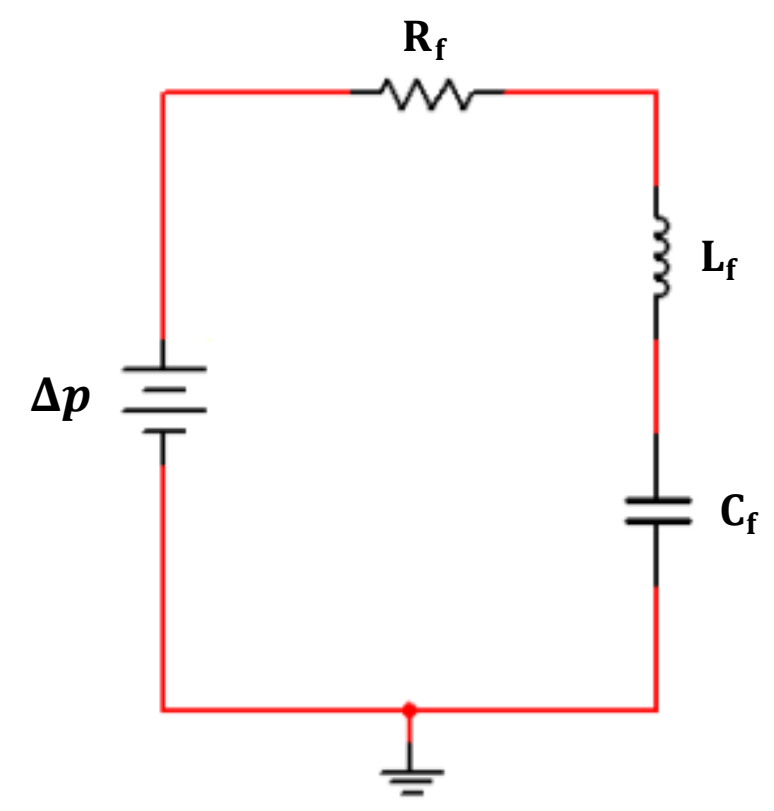

Figura 42 - Circuito equivalente para o domínio fluídico.

\subsubsection{Observações quanto a melhoria do modelo apresentado}

Estudos ainda em andamento com relação ao modelo de elementos concentrados proposto neste trabalho indicam que algumas mudanças podem ser feitas nos circuitos equivalentes de modo a representar melhor a realidade e, assim, tornar o modelo mais preciso. Elementos concentrados que modelam o comportamento de regiões com grande extensão física, como é o caso do filamento, podem ser subdividos em mais elementos, aumentando a discretização nessas regiões e permitindo uma descrição melhor dos fenônmenos físicos que alí ocorrem. Assim, por exemplo, a resistência de condução térmica $R_{e s}$ poderia ser dividida em três ou 
mais resistências. Juntas, o valor das resistências seria o mesmo de $R_{e s}$ porém dividir a resistência térmica equivalente em mais elementos permitiria determinar de modo aproximado qual o perfil de temperatura na região do filamento fora do microcanal, o que não pode ser feito com apenas um elemento.

O aumento da discretização também deve ser feito em regiões com gradientes elevados, como nas regiões de interface entre sólido e fluido. Esses e outros aspectos podem ser mudados no modelo visando melhores respostas mas nenhum resultado dessas alterações será apresentado neste trabalho.

\subsection{PROCESSOS DE FABRICAÇÃO PARA OTIMIZAÇÃO DO SENSOR}

Três processos alternativos de fabricação foram proposto para otimizar a resposta do sensor de vazão, o que como já foi dito, é conseguido fazendo com que o filamento permaneça auto-sustentado no interior do microcanal, aumentando assim seu isolamento térmico em relação ao substrato.

No primeiro método proposto, o microcanal é fabricado sobre a lâmina de vidro e preenchido com um material sacrificial antes que o filamento de níquel seja fabricado. Ao invés de lâminas de vidro de microscópio são usadas lâmina de vidro Corning 7059, por permitirem maior reprodutibilidade nas taxas de corrosão em solução de HF. Concluída a fabricação do filamento, o material sacrificial é removido, fazendo com que o filamento permaneça auto-sustentado. Por fim, a tampa de PDMS contendo a outra metade do microcanal é soldada à lâmina de vidro pelo processo de soldagem por plasma.

No segundo método, o microcanal é fabricado depois que o filamento de níquel tenha sido definido no substrato de vidro. Para evitar que o filamento seja danificado durante a corrosão do microcanal, este deve ser protegido através de um encapsulado entre dois filmes finos de carbeto de silício amorfo hidrogenado (a-Si:H), que devem ser depositados antes e depois do filamento. 
No terceiro e último método proposto, o próprio filamento é feito de a-SiC:H. Para obter a condutivividade elétrica necessária, o a-SiC:H é implantado com difluoreto de boro $\left(\mathrm{BF}_{2}{ }^{+}\right)$, para obter a-SiC:H dopado tipo P. Neste caso, o filamento também é deixado auto-sustentado através da corrosão de um microcanal no substrato de vidro.

Os detalhes do processo de fabricação seguidos em cada um dos métodos são apresentados a seguir.

\subsubsection{Método 1: Filamento fabricado sobre material sacrificial}

\section{1) Preparo da lâmina de vidro}

A lâmina de vidro Corning 7059 de $1 \times 1$ pol$^{2}$ passa por uma limpeza inicial para remoção de particulado e contaminantes, composta das seguintes etapas:

- Imersão das lâminas em solução de água deionizada $\left(\mathrm{H}_{2} \mathrm{O}\right)$, hidróxido de amônio $\left(\mathrm{NH}_{4} \mathrm{OH}\right)$ e peróxido de hidrogênio $\left(\mathrm{H}_{2} \mathrm{O}_{2}\right)$, na proporção 5:1:1, no ultrassom por 15 minutos;

- Enxágüe em água corrente por 10 minutos;

- Imersão em álcool isopropílico (isopropanol) e aquecimento do mesmo até a total evaporação.

\section{2) Deposição do filme de cromo}

Um filme fino de cromo ( 250 nm) é depositado pela técnica de Sputtering e serve como material de mascaramento para a etapa de corrosão do substrato. A deposição segue as condições da tabela 15. 
Tabela 15 - Condições para a deposição de cromo por Sputtering

\begin{tabular}{|l|l|}
\hline Fluxo de argônio & $10 \mathrm{sccm}$ \\
\hline Pressão na câmara & 2 mTorr \\
\hline Potência de RF & $70 \mathrm{~W}$ \\
\hline DC Bias & $-147 \mathrm{~V}$ \\
\hline Temperatura & Não controlada e não medida \\
\hline Tempo & 15 minutos \\
\hline
\end{tabular}

\section{3) Fotolitografia do filme de cromo}

O padrão dos microcanais é transferido para o filme de cromo através da fotolitografia. O fotorresiste utilizado é o AZ-1518. O padrão utilizado como fotomáscara está mostrado na figura 43. Ele contém quatro microcanais de $15 \mathrm{~mm}$ de comprimento (de centro a centro do círculo) e três diferentes larguras: $200 \mu \mathrm{m}$ (repetido duas vezes), $500 \mu \mathrm{m}$ e $1 \mathrm{~mm}$. A largura dos microcanais no vidro é $200 \mu \mathrm{m}$ menores do que o comprimento dos filamentos e $400 \mu \mathrm{m}$ menor do que os microcanais no PDMS. Os quadrados brancos nos cantos da fotomáscara são marcas de alinhamento.

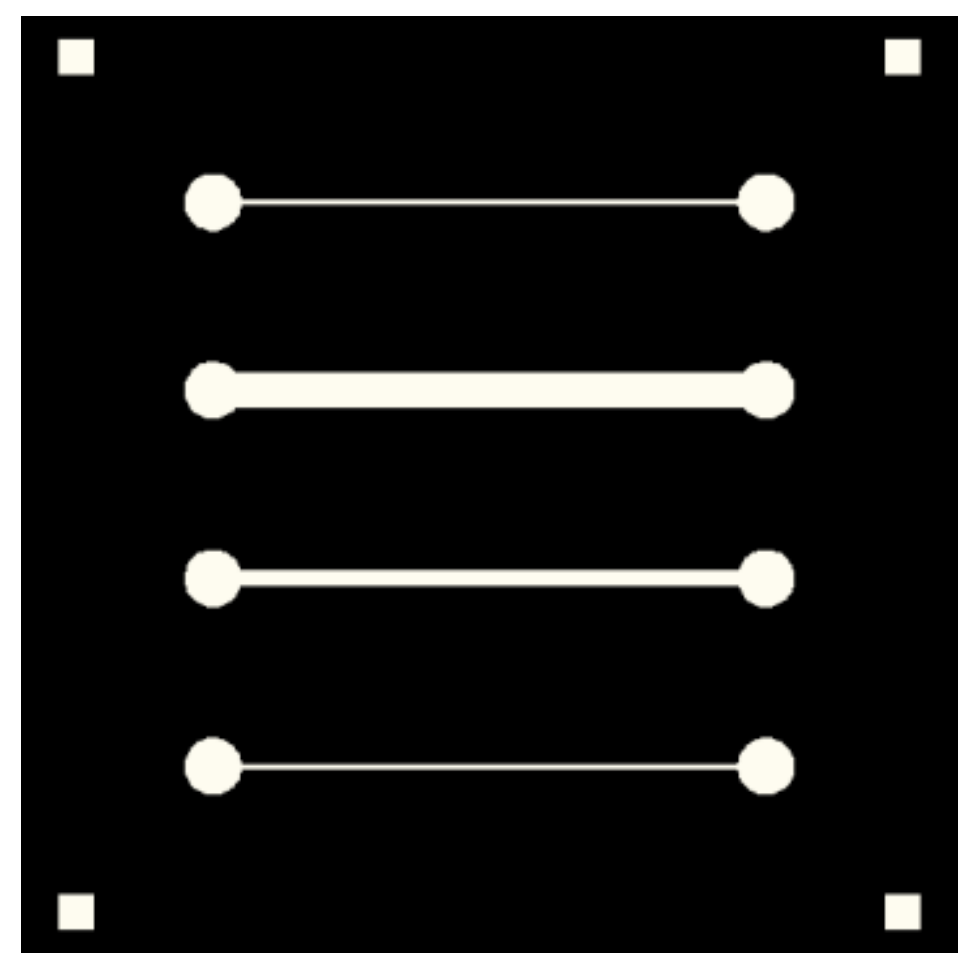

Figura 43 - Fotomáscara empregada na fabricação dos microcanais em vidro. 
Após a exposição e revelação do fotorresiste com o padrão dos microcanais, é feita a corrosão do filme de cromo através das aberturas no fotorresiste em solução de $40 \mathrm{~g}$ de nitrato cérico amoniacal $\left(\left(\mathrm{NH}_{4}\right)_{2} \mathrm{Ce}\left(\mathrm{NO}_{3}\right)_{6}\right), 11 \mathrm{~mL}$ de ácido acético e $200 \mathrm{~mL}$ de água deionizada.

\section{4) Corrosão úmida da lâmina de vidro}

A corrosão é realizada em solução de ácido fluorídrico, ácido clorídrico e água deionizada (1 $\mathrm{HF}: 2 \mathrm{HCl}: 3 \mathrm{H}_{2} \mathrm{O}$ ). A solução é agitada com um agitador magnético e é mantida a temperatura ambiente. Tendo em vista a taxa de corrosão obtida através de testes (apresentados posteriormente no item 6.3.1), a profundidade esperada dos microcanais é de $15 \mu \mathrm{m}$.

\section{5) Remoção do filme de cromo}

Uma vez que o filme de cromo tenha exercido sua função de material de mascaramento para a corrosão dos microcanais, ele se torna dispensável e é corroído na mesma solução de nitrato cérico amoniacal e ácido acético utilizada na fotogravação dos microcanais.

\section{6) Preenchimento dos microcanais com fotorresiste}

O mesmo fotorresiste utilizado no processo de fotogravação (AZ-1518) é usado nesta etapa. Algumas gotas de fotorresiste são aplicadas sobre a lâmina de vidro corroída e espalhadas manualmente com o intuito de formar uma camada espessa que cubra completamente os microcanais. Em seguida, a lâmina é colocada em um forno a $80^{\circ} \mathrm{C}$ por aproximadamente 3 horas para que o fotorresiste seque. 


\section{7) Planarização do fotorresiste}

A lâmina passa por uma etapa de lixamento em lixa d'água $n^{\circ} 1200$ para diminuir a espessura do fotorresiste. Em seguida, ela passa por uma sequência de polimentos realizados em uma máquina polidora, modelo Minimet 1000 (Buehler). O polimento é feito primeiramente utilizando uma pasta de polimento contendo esferas de $3 \mu \mathrm{m}$ de diâmetro e então é repetido para uma pasta com esferas de $1 \mu \mathrm{m}$ de diâmetro. $\mathrm{O}$ tempo médio de polimento com cada pasta é de 2 horas. $O$ polimento é feito até que o fotorresiste fique nivelado com o topo do microcanal.

\section{8) Fabricação do filamento de níquel}

A fabricação do filamento sobre a lâmina contendo o fotorresiste planarizado segue exatamente as mesmas etapas do processo de fabricação do sensor proposto que está em contato direto com o substrato de vidro (seção 3.3.1). São depositados os filmes de titânio e cobre sobre toda a lâmina, em seguida é feita a fotogravação da geometria dos filamentos e posteriormente realiza-se a eletrodeposição do filme de níquel. Por fim, o fotorresiste fotogravado com a geometria dos filamentos, bem como os filmes de titânio e cobre, que servem de semente para a deposição de níquel, são removidos.

Nenhum cuidado especial é tomado com a lâmina exceto pelo fato de ela não poder ser limpa com acetona ou álcool isopropílico antes da conclusão das etapas de deposição, já que isso removeria total ou parcialmente o fotorresiste de dentro dos microcanais. Assim, após a etapa de planarização, a lâmina é enxaguada com água deionizada e segue diretamente para a deposição dos filmes de titânio e cobre.

\section{9) Liberação dos filamentos}

Os filamentos são liberados fazendo escorrer acetona por sobre a lâmina e em seguida mergulhando-a em um copo Becker com acetona. Essa etapa deve ser realizada com muito cuidado pois um jato forte de acetona ou mesmo a tensão superficial do líquido pode danificar as estruturas 
A figura 44 apresenta uma série de imagens esquematizando o processo de fabricação apresentado.

$\begin{array}{lllllllllllll}\text { LEGENDA } & 1 & \mathrm{Ti} & \mathrm{Cu} & \text { Fotorresiste } & 2 & \mathrm{Ni} & 3 & \mathrm{Cr}\end{array}$

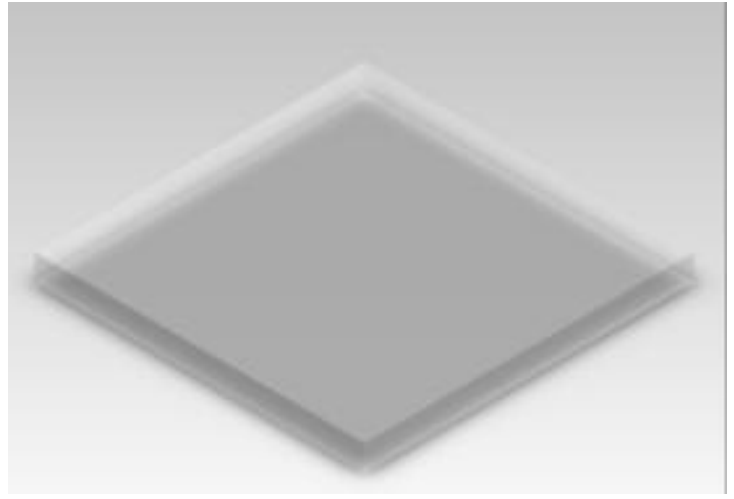

(a)

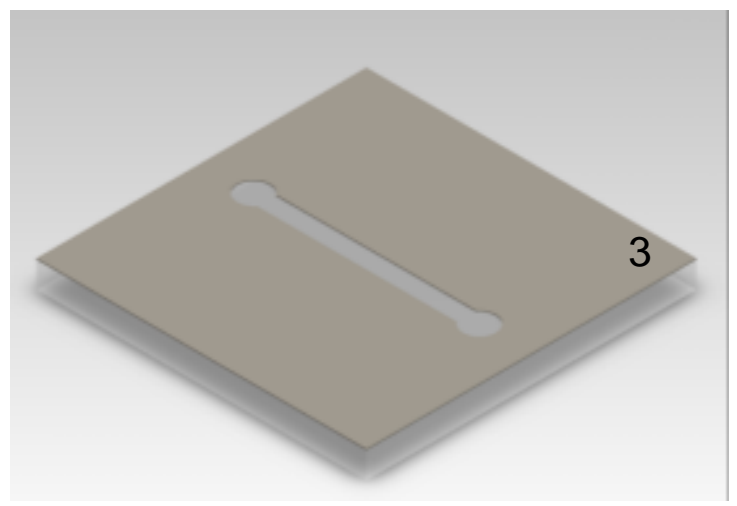

(c)

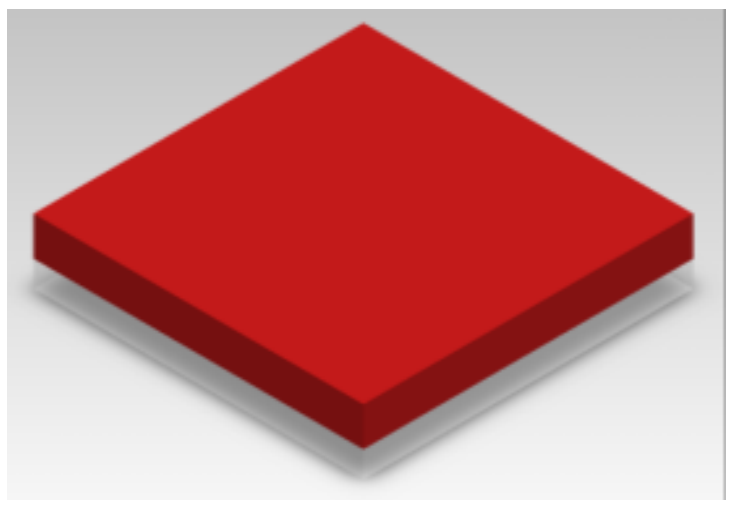

(e)

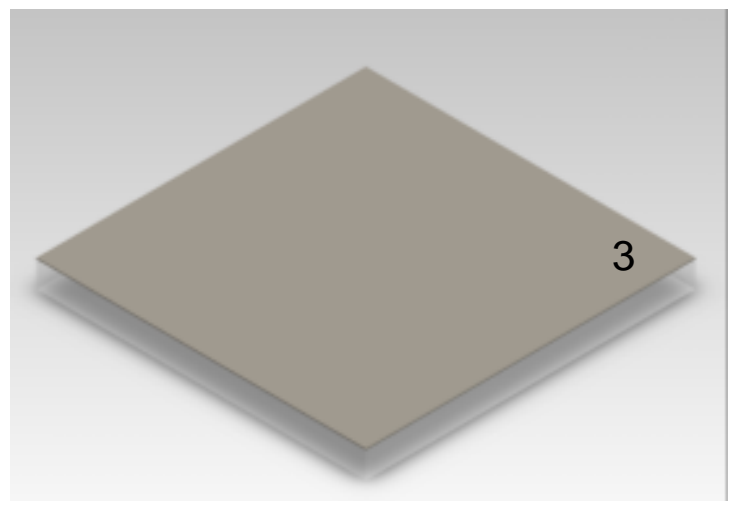

(b)

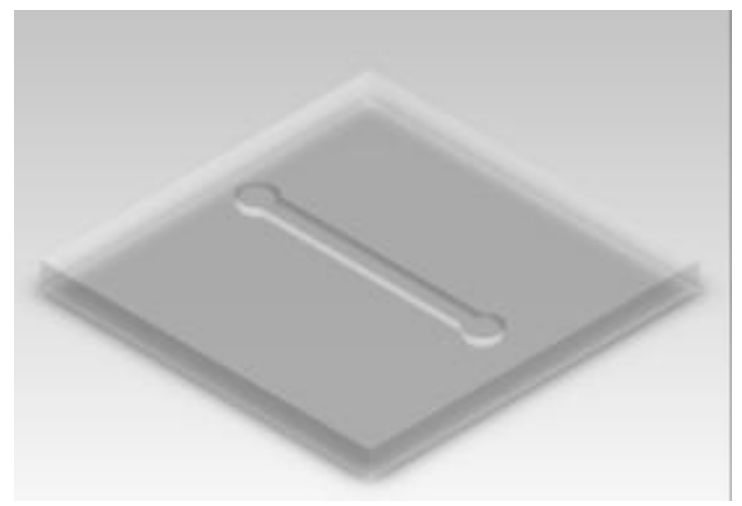

(d)

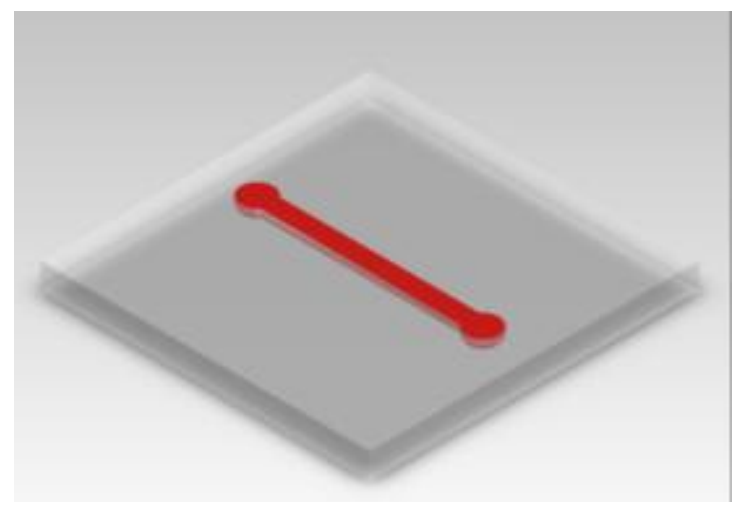

(f) 


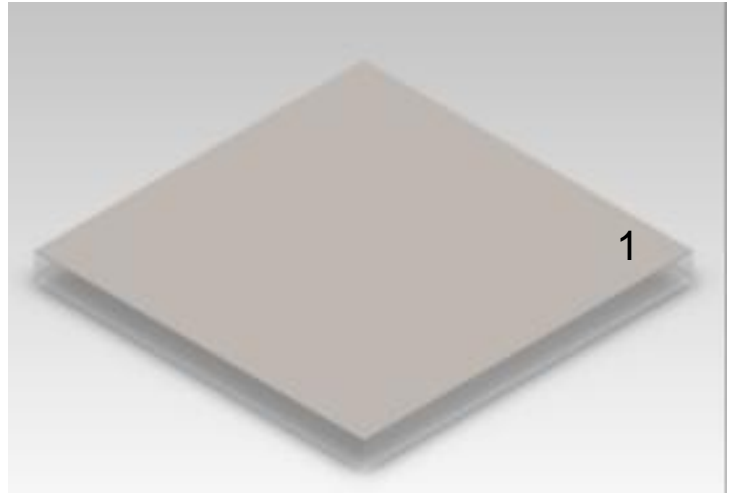

(g)

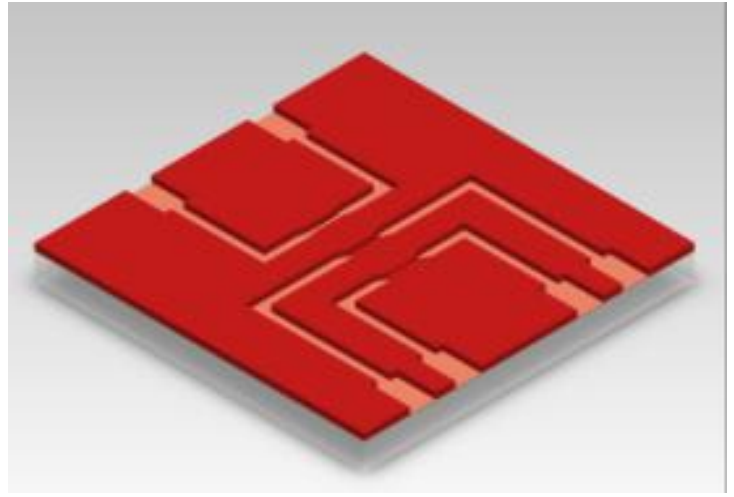

(i)

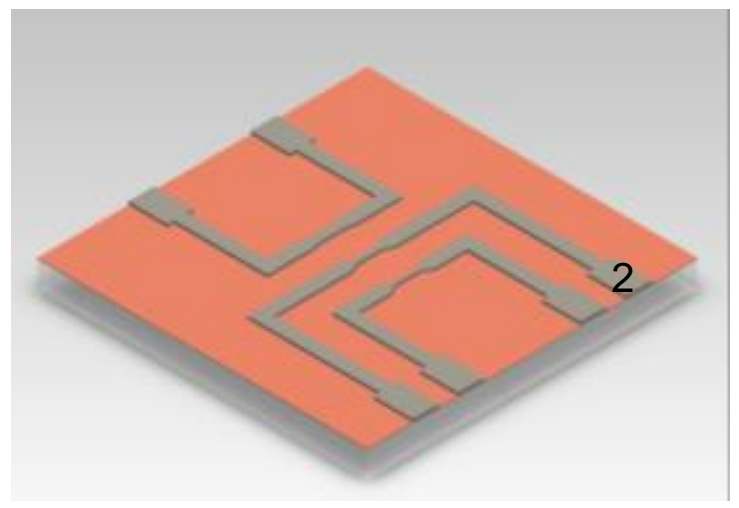

(k)

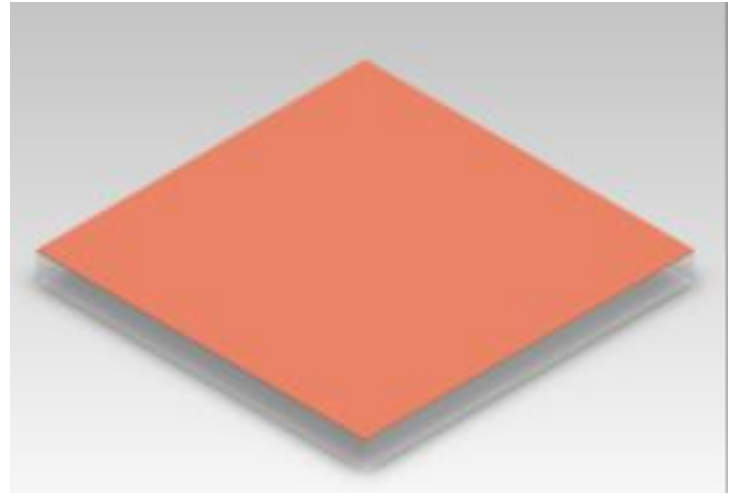

(h)

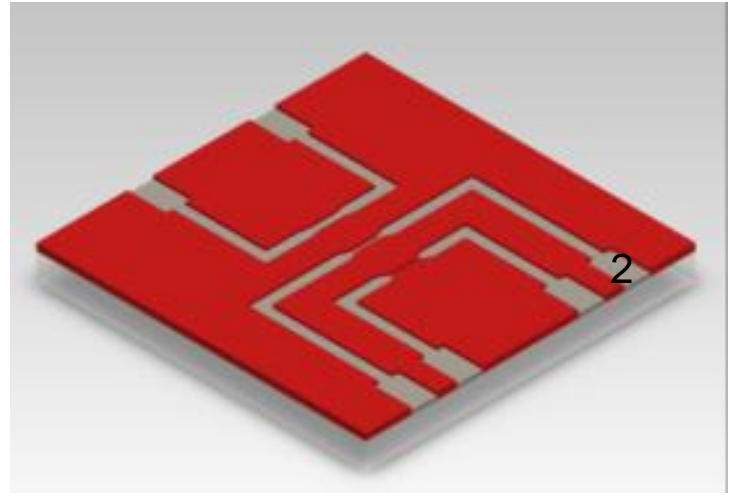

(j)

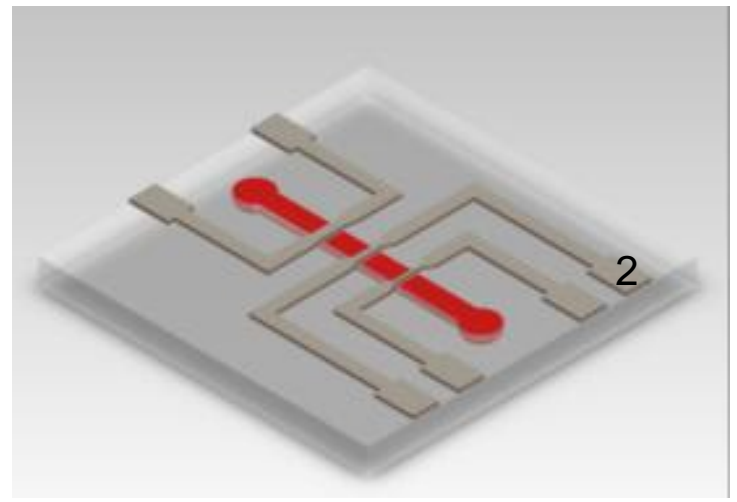

(l)

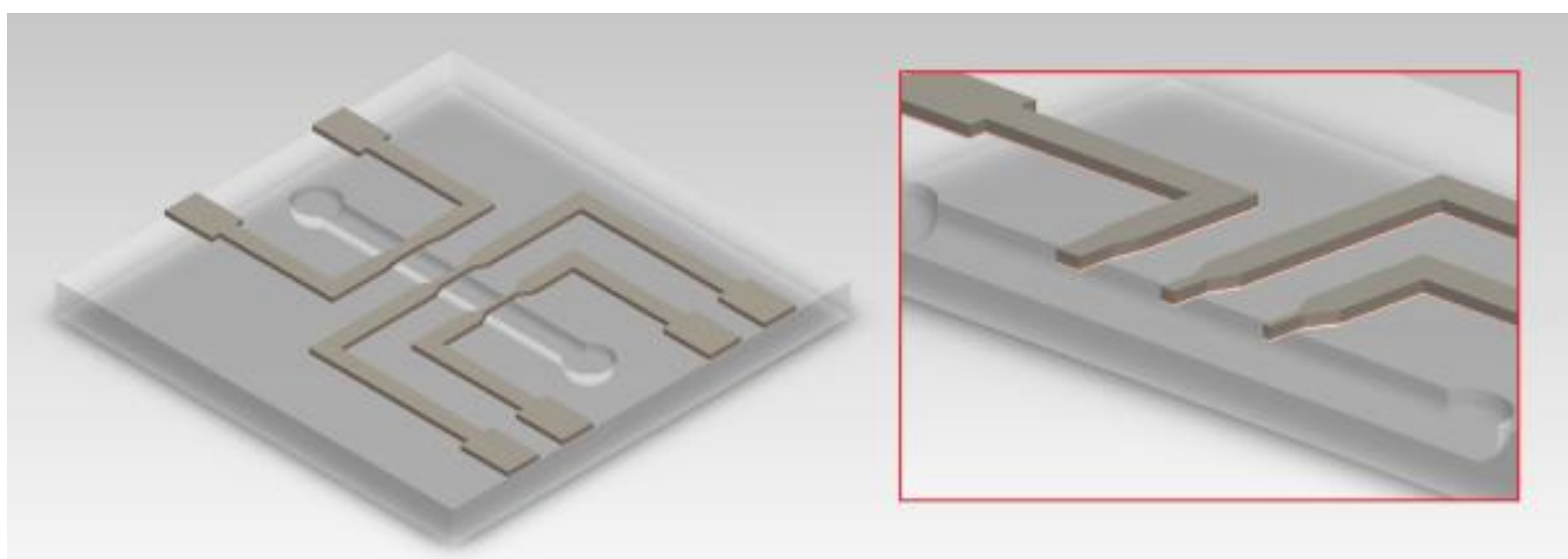

(m)

Figura 44 - Processo de fabricação do sensor de vazão seguindo o método 1. 


\subsubsection{Método 2: Filamento encapsulado com carbeto de silício}

\section{1) Preparo da lâmina de vidro}

Novamente o material base para fabricação do sensor é o vidro Corning 7059 de $1 \mathrm{x}$ $1 \mathrm{pol}^{2}$. Ele passa pela mesma sequência de limpeza indicada no item 1 das seções 3.3.1 e 5.3.1 para remoção de particulado e contaminantes

\section{2) Deposição do primeiro filme de carbeto de silício}

O filme de carbeto de silício amorfo hidrogenado (a-SiC:H) é usado para encapsular o filamento metálico, protegendo-o no processo de corrosão do microcanal e ainda evitando que o filamento entre em contato direto com o fluido que escoa no microcanal. Ele é depositado pela técnica de PECVD (Plasma Enhanced Chemical Vapor Deposition) (33), segundo as condições mostradas na tabela 16. Essas são as mesmas condições determinadas por Pelegrini, M. V. et al. (50) para obtenção de um filme de carbeto de silício amorfo hidrogenado de baixo estresse intrínseco (aSiC:H 3690H). A espessura do filme obtido é de aproximadamente $500 \mathrm{~nm}$.

Tabela 16 - Condições para a deposição de a-SiC:H por PECVD.

\begin{tabular}{|l|l|}
\hline Fluxo de gases & \\
\hline \multicolumn{1}{|c|}{$\mathrm{SiH}_{4}$} & $3,6 \mathrm{sccm}$ \\
\hline \multicolumn{1}{|c|}{$\mathbf{C H}_{4}$} & $32,4 \mathrm{sccm}$ \\
\hline $\mathbf{H}_{2}$ & $100 \mathrm{sccm}$ \\
\hline Pressão na câmara & Não controlada \\
\hline Potência de RF & $300 \mathrm{~W} \quad\left(750 \mathrm{~mW} / \mathrm{cm}^{2}\right)$ \\
\hline DC Bias & $-554 \mathrm{~V}$ \\
\hline Temperatura & $320^{\circ} \mathrm{C}$ \\
\hline Tempo & 1 hora e 30 minutos \\
\hline
\end{tabular}




\section{3) Fabricação do filamento de níquel}

O filamento de níquel é fabricado sobre o filme de carbeto de silício segundo o mesmo processo descrito na seção 3.3.1. A etapa de limpeza da lâmina é dispensável.

\section{4) Deposição do segundo filme de carbeto de silício}

Para promover o total encapsulamento do filamento uma segunda película de a-SiC:H é depositada. Esse segundo filme deve cobrir completamente o filamento, evitando que a solução de HF que será utilizada para fabricar o microcanal entre em contato com o filamento. Assim, visto que a espessura prevista para o filme de níquel é de $500 \mathrm{~nm}$, um filme de a-SiC:H com pelo menos essa espessura deve ser depositado para garantir uma boa cobertura de degrau.

A deposição segue as mesmas condições da primeira deposição de a-SiC:H, que estão mostradas na tabela 16 apresentada anteriormente.

\section{5) Deposição do filme de cromo}

Assim como no processo de corrosão dos microcanais em vidro, o filme de cromo é usado neste caso como material de mascaramento para a etapa de corrosão dos filmes de a-SiC:H. O filme de cromo é depositado pela técnica de Sputtering e segue as mesmas condições apresentadas na tabela 15 da seção 5.3.1.

\section{6) Fotolitografia do filme de cromo}

O padrão dos microcanais é transferido para o filme de cromo através da fotolitografia. O fotoresiste utilizado é o AZ-1518. O padrão utilizado como fotomáscara está mostrado na figura 45 . Ele contém quatro microcanais de $15 \mathrm{~mm}$ de comprimento (de centro a centro do círculo) e três diferentes larguras: $200 \mu \mathrm{m}$ (repetido duas vezes), $500 \mu \mathrm{m}$ e $1 \mathrm{~mm}$. Além dos microcanais é possível observar 
diversos retângulos brancos, que correspondem às aberturas para os pads que fazem contato com os filamentos.

Cada microcanal é interrompido em três regiões, que correspondem às regiões em que se encontram os filamentos. A largura dessas interrupções é ligeiramente maior do que a largura dos filamentos (15 $\mu \mathrm{m}$ para cada lado) para garantir que eles fiquem completamente encapsulados.

Depois que o padrão dos microcanais é transferido para o fotorresiste, o filme de cromo é corroído em solução de nitrato cérico amoniacal e ácido acético.

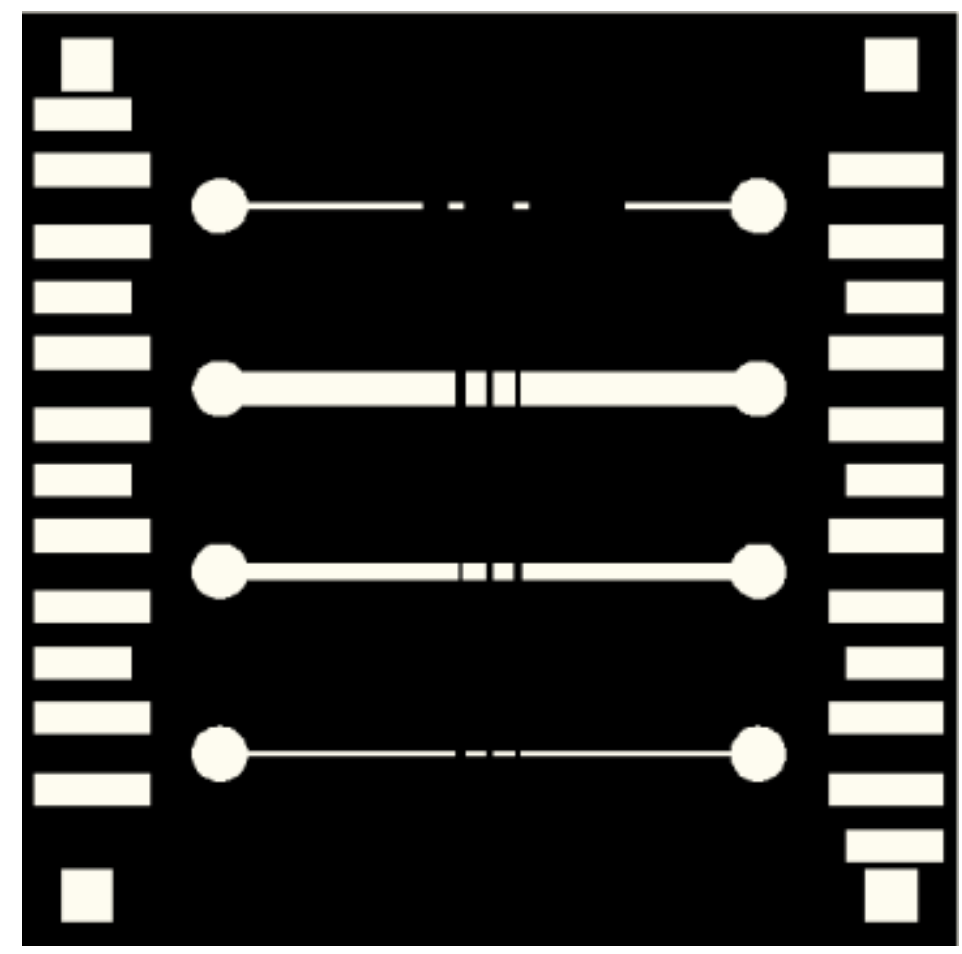

Figura 45 - Fotomáscara empregada na corrosão de carbeto de silício para posterior corrosão dos microcanais em vidro.

\section{7) Corrosão dos filmes de carbeto de silício}

Os filmes de a-SiC:H são completamente corroídos em plasma de $\mathrm{CHF}_{3}$ e $\mathrm{O}_{2}$. $\mathrm{A}$ corrosão avança através das aberturas feitas no filme de cromo (regiões brancas da figura 45), até que o substrato de vidro seja exposto. Nas aberturas retangulares dos 
pads, apenas o primeiro filme de a-SiC:H será completamente corroído já que o filme de níquel não é corroído no plasma e protege a primeira camada de a-SiC:H da corrosão.

O processo é feito em um reator RIE (Reactive Ion Etching) segundo as condições mostradas na tabela 17.

Tabela 17 - Condições de processo para corrosão dos filmes de a-SiC:H.

\begin{tabular}{|l|l|}
\hline Fluxo de gases & \\
\hline \multicolumn{1}{|c|}{ CHF $_{3}$} & $3,6 \mathrm{sccm}$ \\
\hline \multicolumn{1}{|c|}{$\mathbf{O}_{2}$} & $32,4 \mathrm{sccm}$ \\
\hline Pressão na câmara & 100 mTorr \\
\hline Potência de RF & $100 \mathrm{~W}$ \\
\hline DC Bias & Não medido \\
\hline Temperatura & Não controlada e não medida \\
\hline Tempo & 2 horas \\
\hline
\end{tabular}

\section{8) Corrosão dos microcanais}

A fabricação dos microcanais é feita através da corrosão úmida em solução contendo ácido fluorídrico, ácido clorídrico e água deionizada ( $1 \mathrm{HF}: 2 \mathrm{HCl}: 3 \mathrm{H}_{2} \mathrm{O}$ ). A solução é agitada com auxílio de um agitador magnético e mantida à temperatura ambiente. A corrosão ocorre através das aberturas criadas nos filmes de $\mathrm{SiC}$ e avança por baixo dos filamentos, deixando-os suspensos, em um fenômeno chamado de under etch.

O under etch é essencial para que os filamentos sejam liberados do substrato e deve ocorrer de modo controlado. Para isso, é importante conhecer a taxa de corrosão do substrato de vidro na solução de $\mathrm{HF}, \mathrm{HCl}$ e $\mathrm{H}_{2} \mathrm{O}$. Uma vez que a corrosão é isotrópica e avança pelos dois lados do filamento, o cálculo do tempo que a lâmina deve permanecer na solução leva em consideração uma distância de corrosão igual à metade da largura do filamento. Assim, supondo que a taxa de 
corrosão é de $5 \mu \mathrm{m} / \mathrm{min}$, o filamento com largura de $50 \mu \mathrm{m}$ deve permanecer imerso na solução por pelo menos (50/2) / $5=5$ minutos. A determinação da taxa de corrosão será apresentada posteriormente no item 6.3.1.

Para evitar que a solução consuma os pads que estão expostos, eles são protegidos com apiezon. Esse material apresenta boa resistência à solução ácida empregada e pode ser facilmente removido da lâmina com auxílio de tricloroetileno. Para aplicá-lo, basta dissolvê-lo em xileno e espalhá-lo sobre a lâmina com ajuda de um pincel. Esse mesmo material também é usado para evitar a corrosão da parte de trás das lâminas.

\section{9) Remoção do filme de cromo}

Concluída a fabricação dos microcanais, as lâminas passam por uma etapa final de limpeza para remoção do filme de cromo e de outras impurezas. As etapas de limpeza são:

- Remoção do apiezon em tricloroetileno (TCE);

- Remoção total do filme de cromo em solução de $40 \mathrm{~g}$ de nitrato cérico amoniacal $\left(\left(\mathrm{NH}_{4}\right)_{2} \mathrm{Ce}\left(\mathrm{NO}_{3}\right)_{6}\right), 11 \mathrm{~mL}$ de ácido acético e $200 \mathrm{~mL}$ de água deionizada;

- Enxague em acetona, álcool isopropílico e água deionizada.

Cuidado especial deve ser tomado com as lâminas durante este processo já que os filamentos auto-sustentados são frágeis.

A figura 46 mostra imagens que esquematizam o processo de fabricação descrito nesta seção. 
$\begin{array}{lllllllllll}\text { LEGENDA } & 1 & \mathrm{Ti} & \mathrm{Cu} & \text { Fotorresiste } & 2 & \mathrm{Ni} & 3 & \mathrm{Cr} & \text { a-SiC:H }\end{array}$

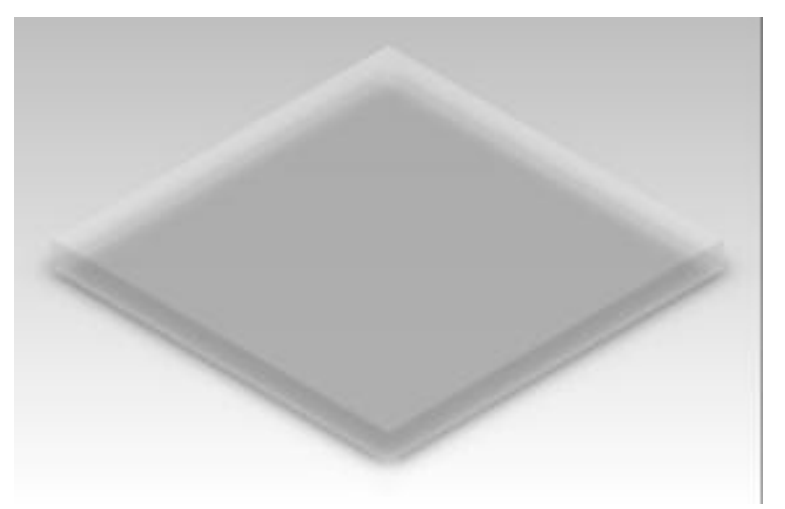

(a)

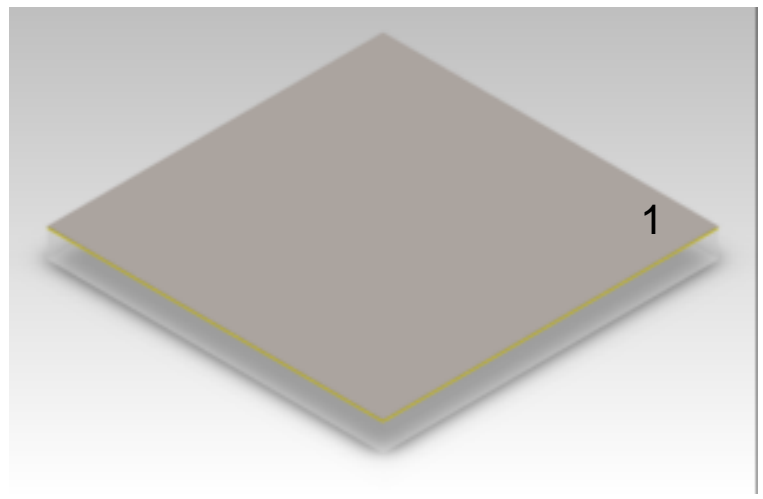

(c)

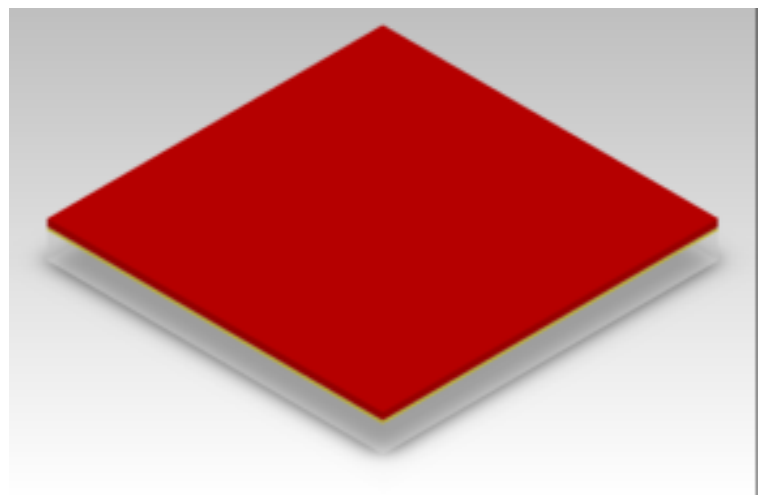

(e)

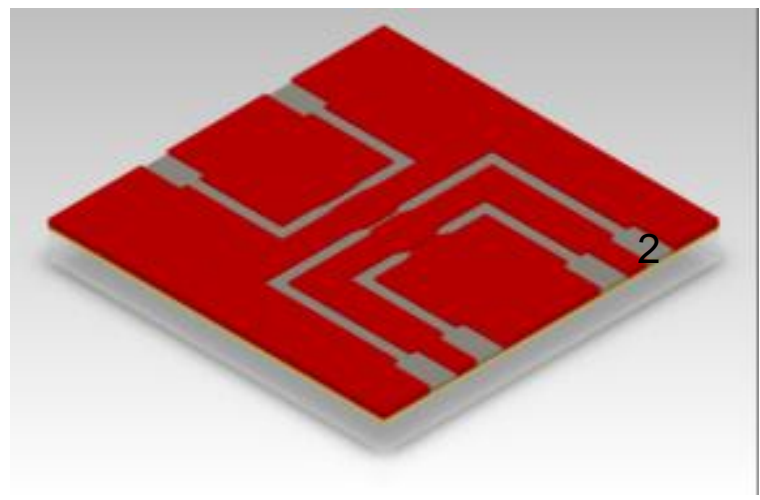

(g)

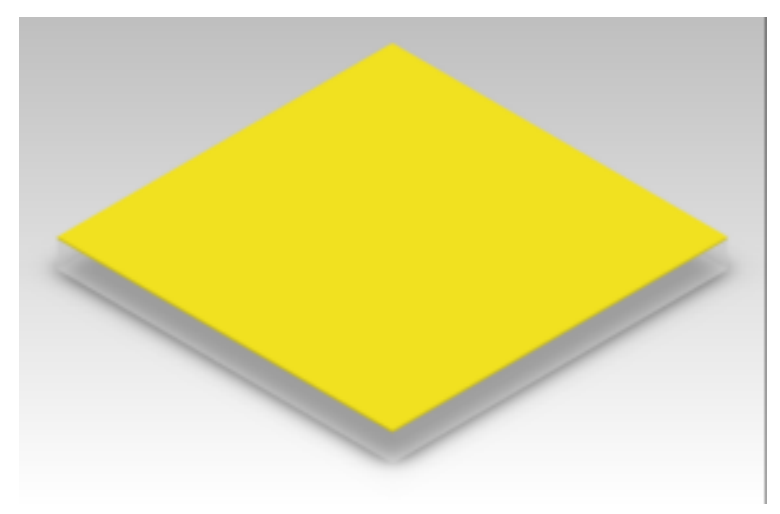

(b)

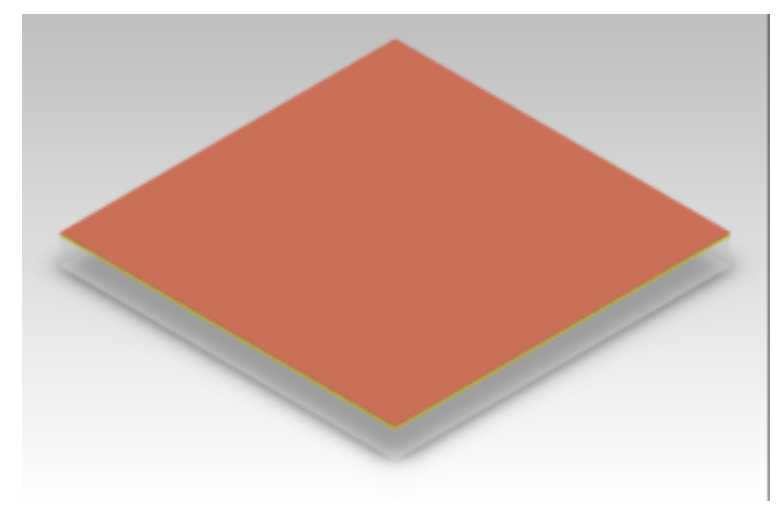

(d)

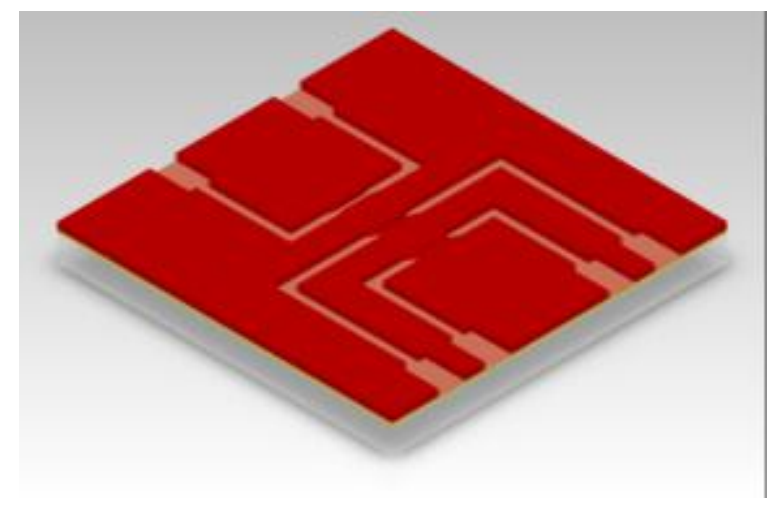

(f)

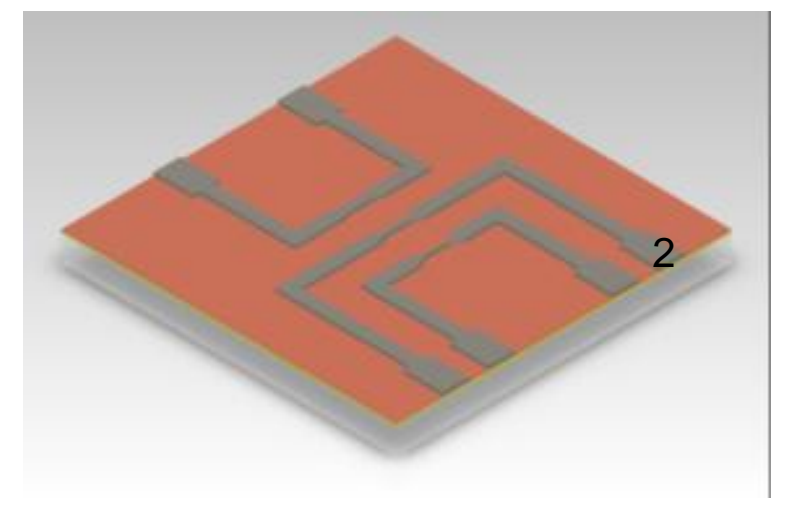

(h) 


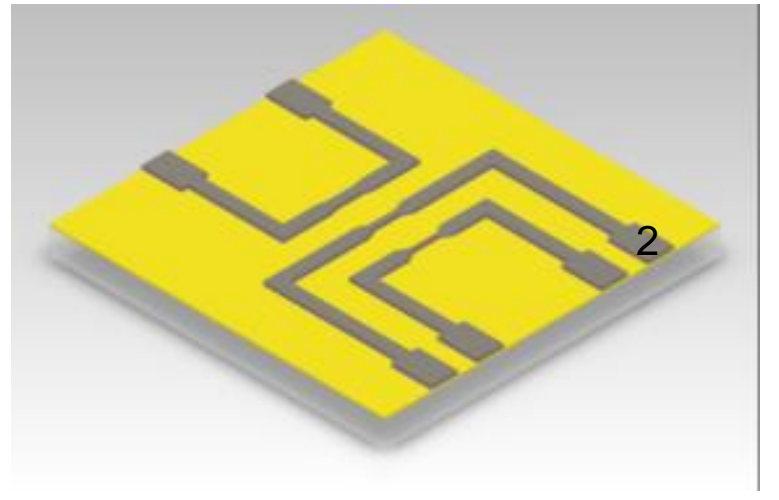

(i)

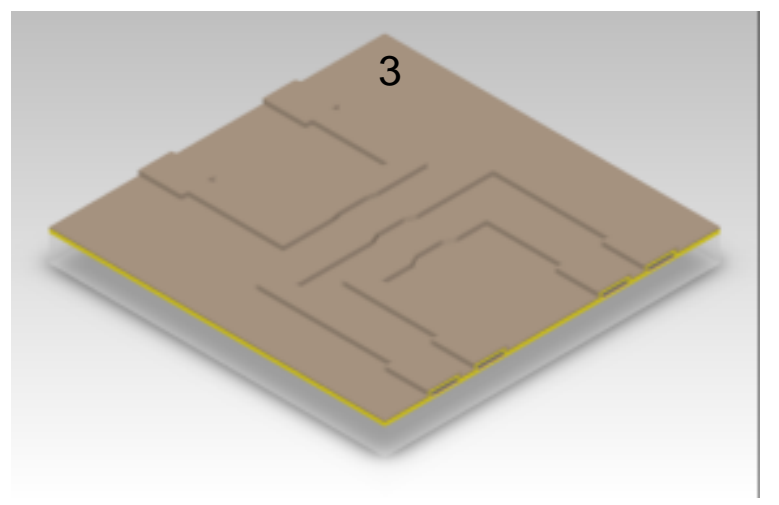

(k)

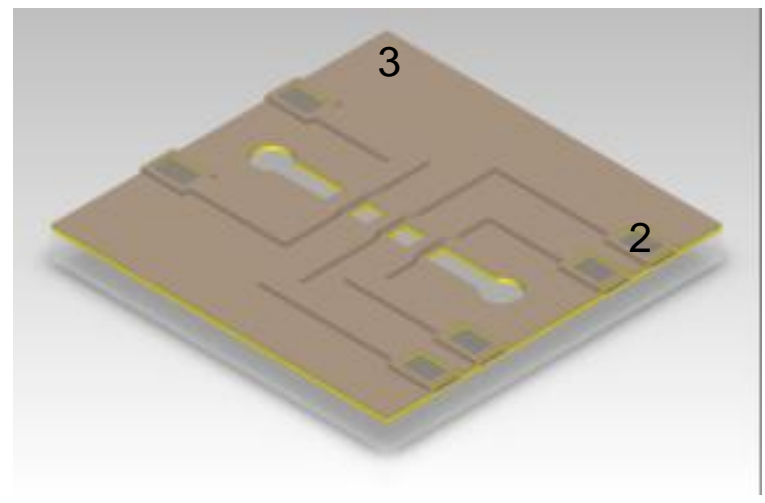

(m)

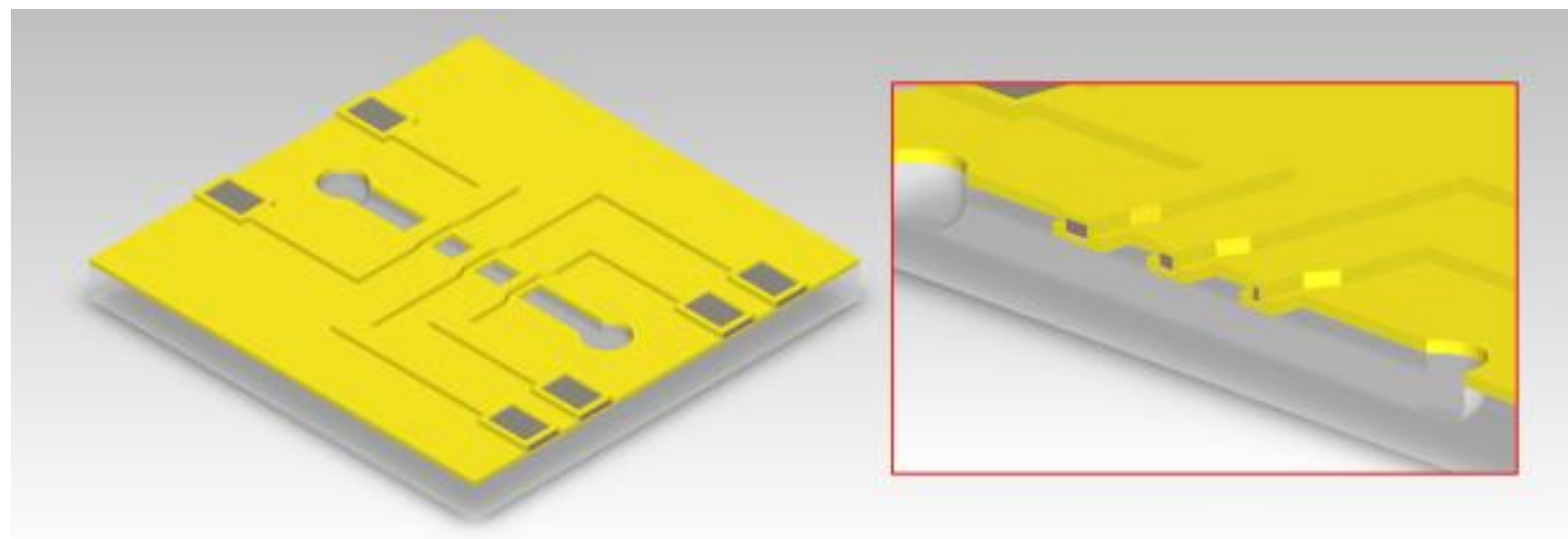

(o) 


\subsubsection{Método 3: Filamento de carbeto de silício dopado}

\section{1) Preparo da lâmina de vidro}

O terceiro método apresentado também faz uso do vidro Corning 7059 de $1 \times 1 \mathrm{pol}^{2}$ como material base para o desenvolvimento do sensor. Ele passa pela mesma sequência de limpeza indicada no item 1 das seções 3.3.1, 5.3.1 e 5.3.2 para remoção de particulado e contaminantes

\section{2) Deposição do filme de carbeto de silício}

O mesmo filme de a-SiC:H que no método 2 é usado para encapsular o filamento é usado neste método como material base para o filamento. Ele é obtido pela técnica de PECVD (Plasma Enhanced Chemical Vapor Deposition) (33), seguindo as condições mostradas anteriormente na tabela 16, com exceção do tempo de deposição que passou a ser 30 minutos. Com isso, a espessura do filme passou de aproximadamente $500 \mathrm{~nm}$ para $200 \mathrm{~nm}$.

Optou-se por um filme de a-SiC:H mais fino por duas razões. A primeira é que a força de tração ou compressão proveniente do estresse intrínseco dos materiais é proporcional à espessura do filme. Assim, diminuir a espessura do filme de a-SiC:H diminui a força sobre ele tornando-o, em teoria, mais resistente. A segunda razão é que o perfil de dopagem utilizado que será mostrado no próximo item, havia sido inicialmente pensado para um filme de espessura de $200 \mathrm{~nm}$.

\section{3) Implantação iônica do carbeto de silício com $\mathrm{BF}_{2}{ }^{+}$}

Apesar de ser um semicondutor, o a-SiC:H intrínseco apresenta condutividade elétrica muito baixa, a ponto de inviabilizar seu uso como filamento. Como forma de melhorar essa característica do material, métodos de dopagem de a-SiC:H foram estudados por Oliveira, A. R. (56) e foi concluído que a técnica e o dopante que produzem o filme de a-SiC:H mais condutor dados os recursos disponíveis no 
laboratório é a implantação iônica de $\mathrm{BF}_{2}{ }^{+}$. Esse processo, realizado no implantador iônico do próprio Laboratório de Microeletrônica, foi utilizado na fabricação dos filamentos de a-SiC:H deste trabalho segundo as condições apresentadas na tabela 18. Foram feitos três procedimentos de implantação com o intuito de formar um perfil uniforme de dopantes ao longo da espessura do filme, como descrito na referência 56 .

Tabela 18 - Condições para implantação iônica de $\mathrm{BF}_{2}{ }^{+}$

\begin{tabular}{|l|l|l|l|}
\hline Concentração & $1.10^{20}$ átomos $/ \mathrm{cm}^{3}$ \\
\hline Energia & $10 \mathrm{keV}$ & $30 \mathrm{keV}$ & $65 \mathrm{keV}$ \\
\hline Dose & $5.10^{14} \mathrm{~cm}^{-2}$ & $1.10^{14} \mathrm{~cm}^{-2}$ & $1,5.10^{15} \mathrm{~cm}^{-2}$ \\
\hline
\end{tabular}

Antes da implantação, no entanto, é necessário realizar uma etapa de fotogravação para definir as regiões onde será feita a implantação. A máscara utilizada é a mesma mostrada na figura 11 (seção 3.3.1) para definição da geometria dos filamentos de níquel. O fotorresiste fotogravado serve como material de mascaramento para a etapa de implantação iônica.

Realizada a implantação do a-SiC:H, o fotorresiste AZ-1518 é removido mergulhando a lâmina em acetona fervente por 10 minutos e em seguida no ultrassom. Para completa remoção do fotorresiste, essas duas etapas devem ser repetidas aproximadamente três vezes.

Ao final, o filme de a-SiC: $\mathrm{H}$ deve passar por um tratamento térmico a $550^{\circ} \mathrm{C}$ por 1 hora para a ativação dos dopantes. Para tanto, foi empregado um criostato com aquecimento por lâmpadas halógenas. $O$ tratamento foi feito em um ambiente com fluxo contínuo de nitrogênio $\left(\mathrm{N}_{2}\right)$ a uma pressão controlada de 100 Torr.

\section{4) Corrosão do filme de carbeto de silício dopado}

A corrosão do filme de a-SiC:H é feita utilizando o cromo como material de mascaramento. As etapas de fabricação envolvidas nesse processo são as mesmas listadas nos itens 5, 6 e 7 do método 2 (seção 5.3.2). 
O padrão utilizado na fotogravação do cromo também é o mesmo do método 2 (figura 45) sendo que as interrupções nos microcanais acabam por definir os filamentos que permanecerão auto-sustentados. Porém, as aberturas para os pads neste caso são desnecessárias e foram cobertas com fotorresiste AZ-1518 antes da corrosão em plasma de $\mathrm{CHF}_{3}$ e $\mathrm{O}_{2}$ para evitar a corrosão indesejada dessas áreas.

Visto que apenas um filme de a-SiC:H deve ser corroído e que a espessura desse filme é menor se comparada com a espessura dos filmes de SiC usados no método 2, o tempo de corrosão foi reduzido para 30 minutos.

Ao final da corrosão, o filme de cromo é completamente removido em solução de nitrato cérico amoniacal e ácido acético.

\section{5) Deposição de alumínio para contatos elétricos}

Como forma de melhorar o contato elétrico que será feito nas regiões dos pads do filme de $\mathrm{SiC}$ dopado, um filme de alumínio é depositado pela técnica de evaporação térmica (33).

Para definir a geometria desse filme de alumínio, utiliza-se a técnica de lift-off (33). Para isso, antes de ser realizada a deposição, é feita a fotogravação do fotorresiste AZ-1518 com o padrão de interesse. A fotomáscara da figura 45 foi reaproveitada nesta fotolitrografia cobrindo-se, contudo, a região dos microcanais antes da exposição do fotorresiste. Assim, apenas o padrão dos pads (retângulos brancos) foi transferido para o fotorresiste.

A deposição então é feita, cobrindo toda a lâmina com um filme de alumínio. Foi utilizada uma massa de $0,528 \mathrm{~g}$ de alumínio puro, o suficiente para depositar um filme com aproximadamente $500 \mathrm{~nm}$ de espessura.

Por fim, a lâmina é colocada em acetona fervente e em ultrassom para remoção do fotorresiste. Essas duas etapas devem ser repetidos 2 ou 3 vezes para que 0 fotorresiste seja completamente removido da lâmina. Ao final, o filme de alumínio fica presente apenas nas regiões dos pads. 


\section{6) Corrosão dos microcanais}

A corrosão dos microcanais ocorre através das aberturas feitas no filme de a-SiC:H. Ao contrário do que foi feito no método 2, não existe filme de cromo sobre o a-SiC:H, ou seja, o próprio a-SiC:H dopado serve de material de mascaramento para corrosão dos microcanais. Isso porque o filme de cromo interferiria com o filme de alumínio depositado sobre os pads para melhorar o contato elétrico, não havendo seletividade na corrosão dos dois filmes.

A corrosão foi feita, como antes, em solução de $1 \mathrm{HF}: 2 \mathrm{HCl}: 3 \mathrm{H}_{2} \mathrm{O}$, explorando o fenômeno de under etch para deixar os filamentos auto-sustentados. Para que o filme de alumínio sobre os pads não fosse corroído na solução, ele foi protegido com apiezon, que foi removido após o processo.

Esta etapa encerra o processo de fabricação dos filamentos de a-SiC:H dopado. A figura 47 ilustra a sequência de fabricação apresentada. 


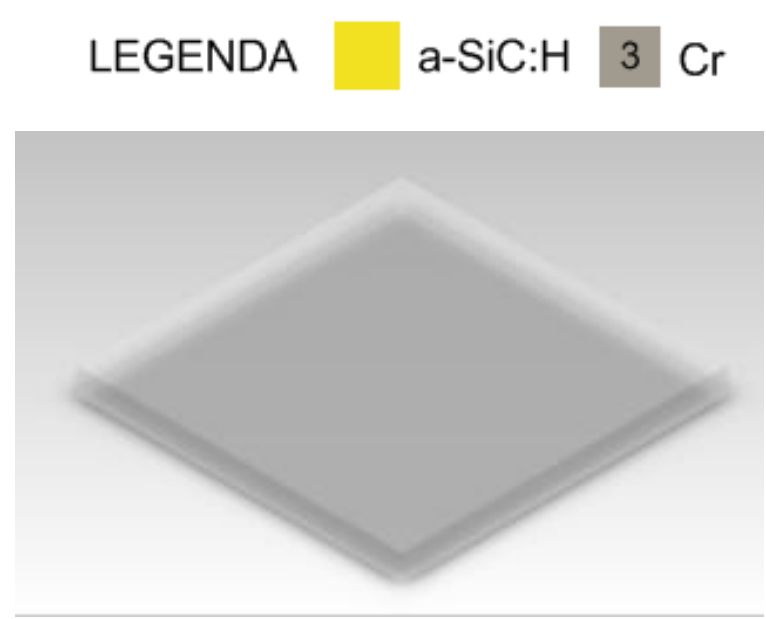

(a)

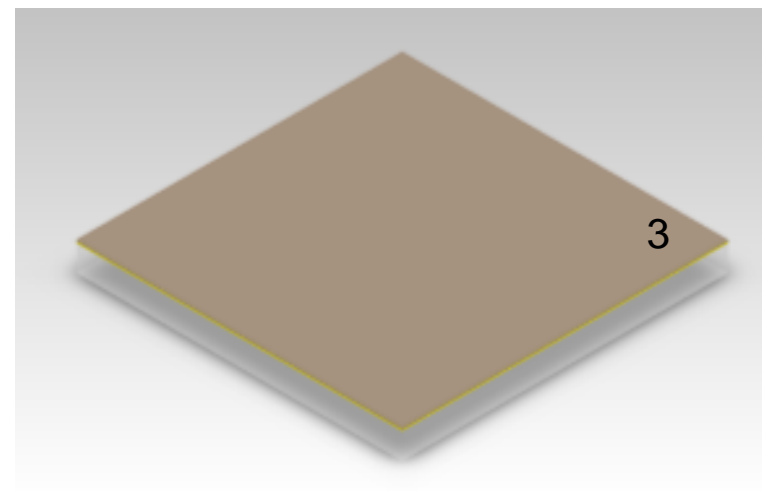

(c)

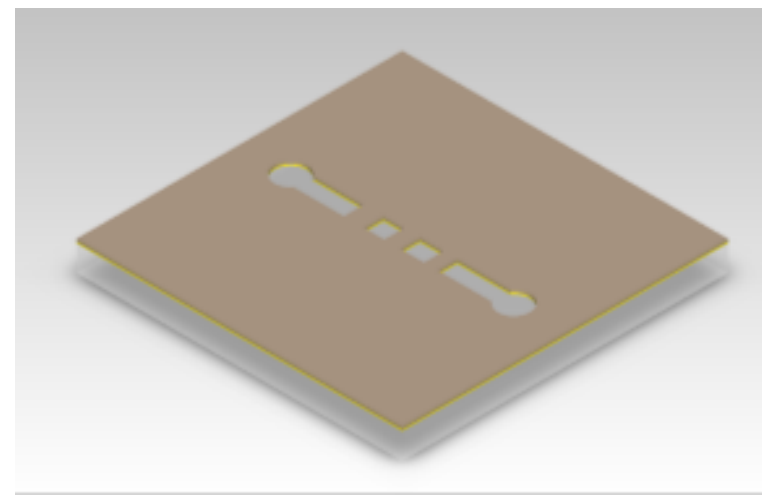

(e)

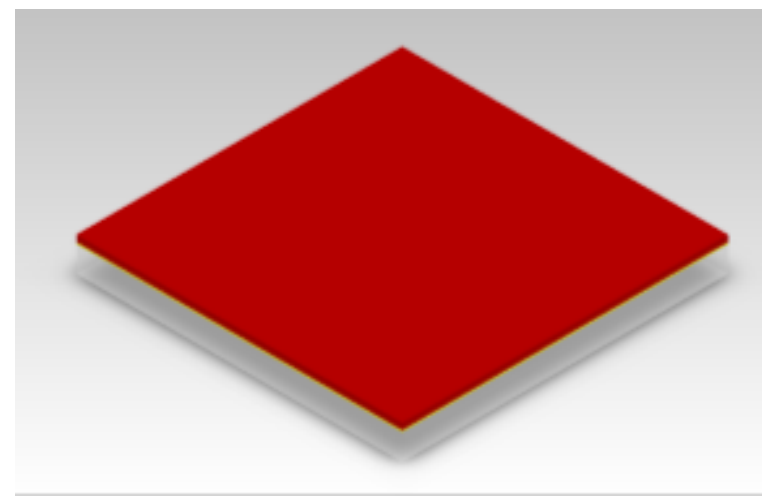

(g)
Fotorresiste $\quad \begin{aligned} & \text { a-SiC:H } \\ & \text { dopado }\end{aligned} 4$ Al

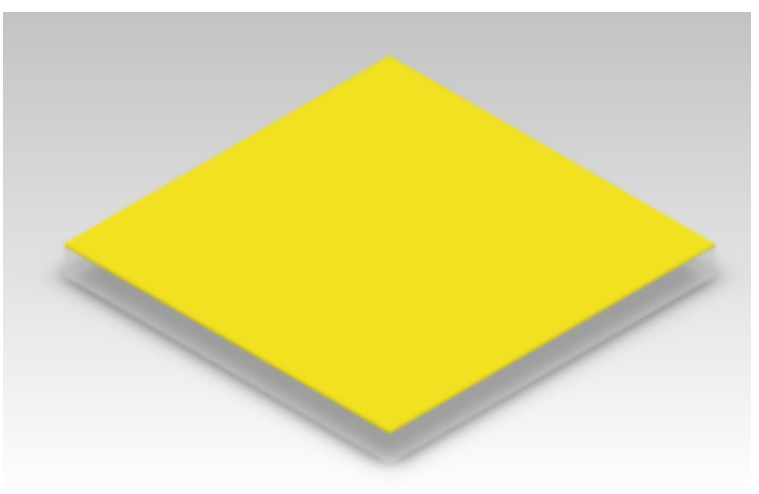

(b)

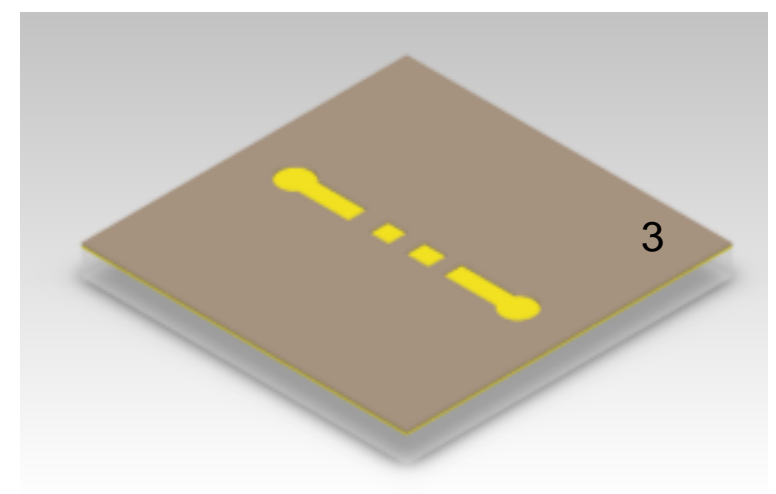

(d)

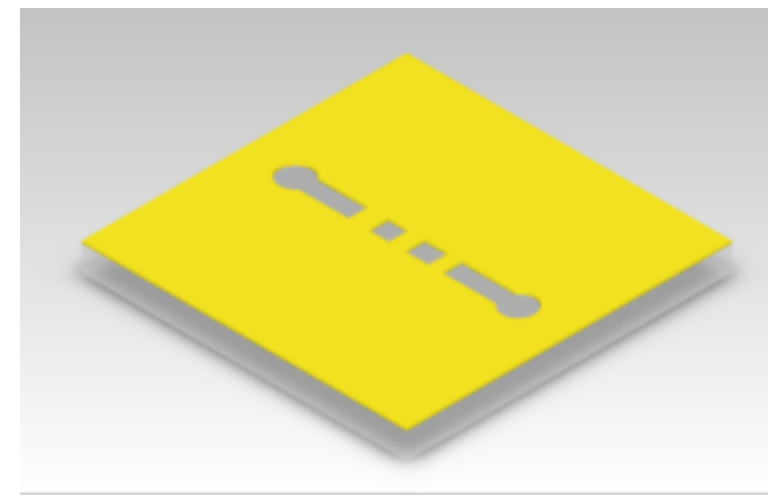

(f)

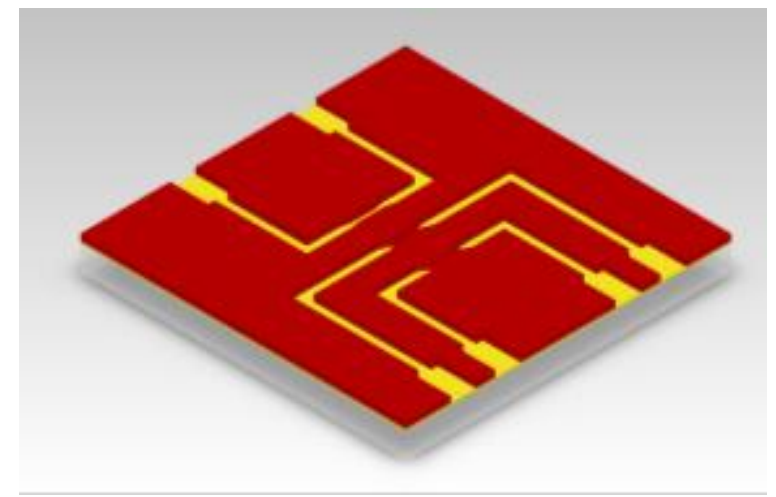

(h) 


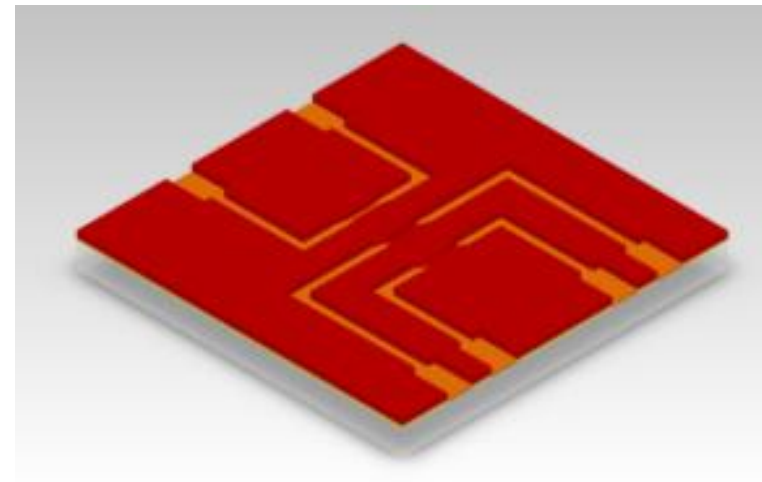

(i)

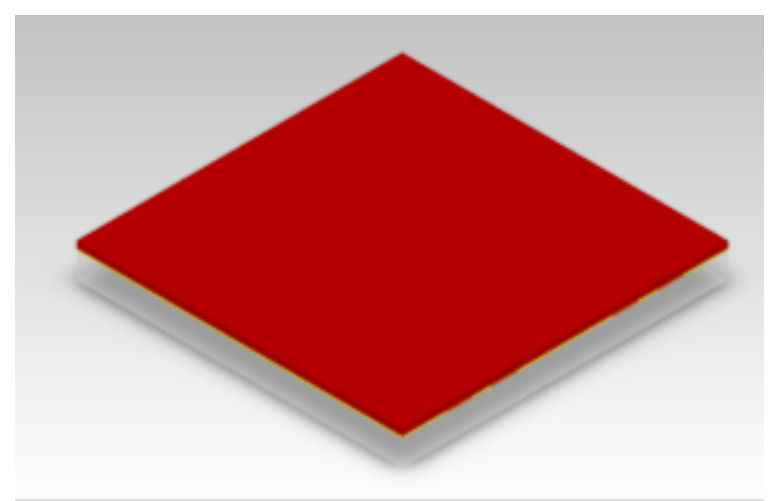

$(\mathrm{k})$

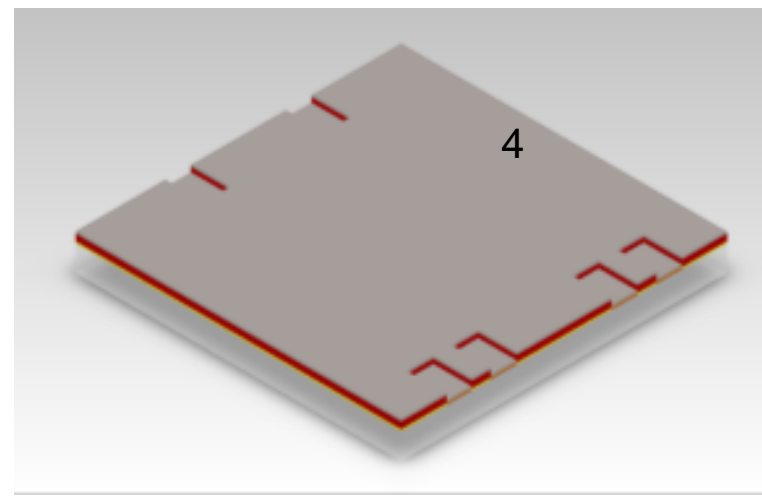

(m)

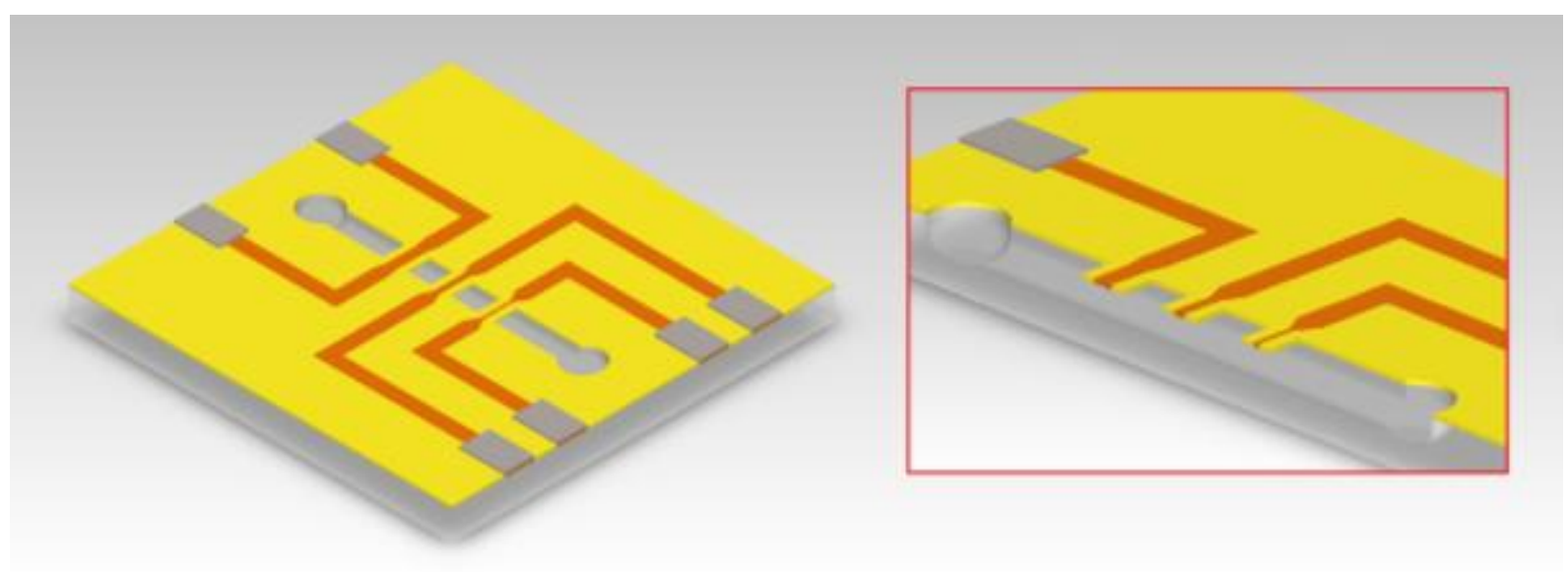

(0)

Figura 47 - Processo de fabricação do sensor de vazão segundo o método 3. 


\subsubsection{Fabricação do microcanal na tampa de PDMS}

Independentemente do método escolhido para se fabricar os filamentos autosustentados, a fabricação do sensor de vazão só será concluída após terem sido feitos microcanais na tampa de PDMS e ela ter sido soldada sobre a lâmina de vidro. A fabricação dos microcanais é feita através da técnica de litografia macia por replicação de molde e a soldagem das amostras é feita através do tratamento superficial em plasma de oxigênio $\left(\mathrm{O}_{2}\right)$. As etapas de processo são as mesmas apresentadas anteriormente e podem ser consultadas na seção 3.3.2. 


\section{RESULTADOS DO SENSOR DE VAZÃO OTIMIZADO}

\subsection{SIMULAÇÃO POR ELEMENTOS FINITOS}

O modelo de elementos finitos construído para o caso do filamento preso ao substrato de vidro foi alterado para a situação em que o filamento encontra-se autosustentado no interior do microcanal. A curva da diferença de tensão em função da vazão para os dois casos está mostrada na figura 48.

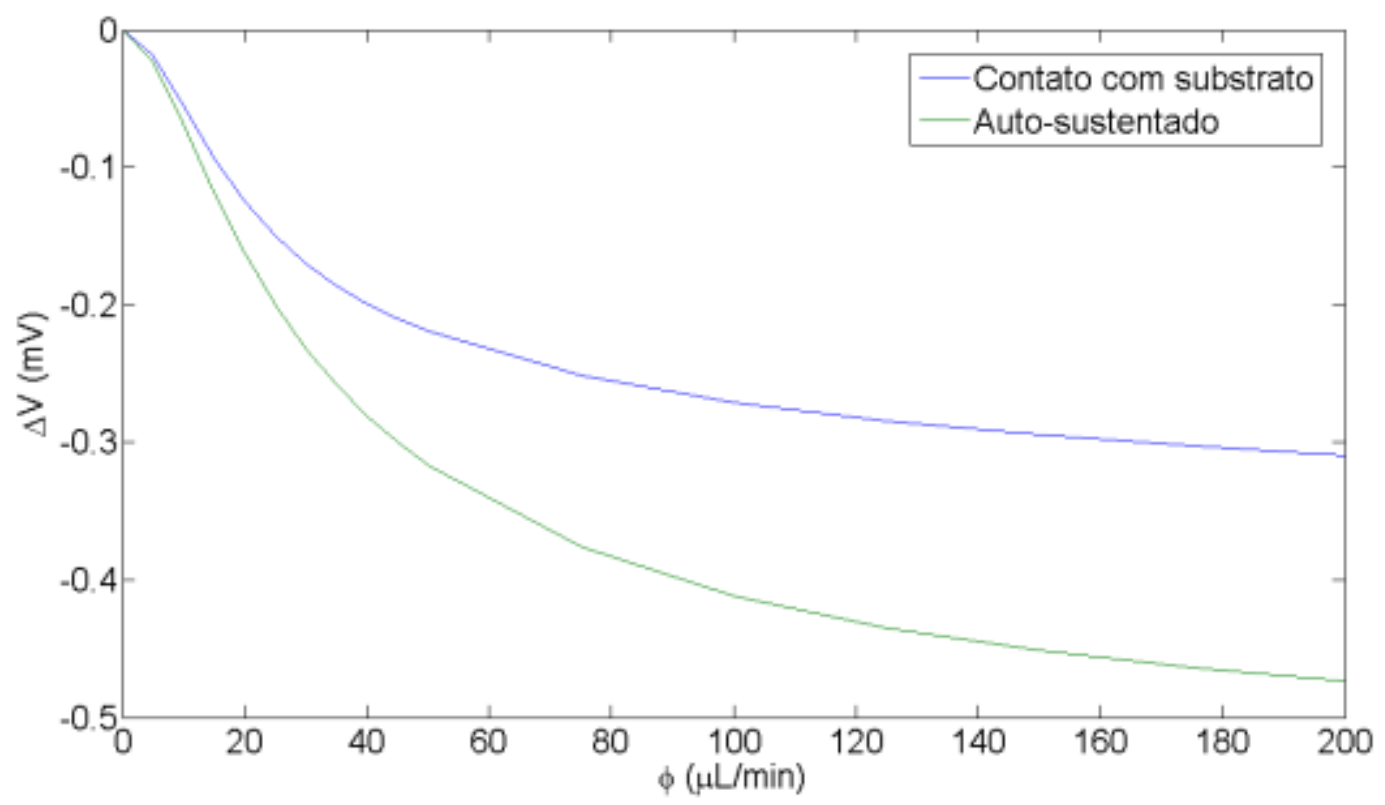

Figura 48 - Curva da diferença de tensão x vazão obtida da simulação por elementos finitos para o caso do filamento em contato com o substrato e auto-sustentado.

Observa-se que de fato deixar o filamento auto-sustentado, melhora a sensibilidade do sensor. Nas condições simuladas, a melhora na sensibilidade é de aproximadamente $31 \%$ na região de baixas vazões $(\phi \leq 20 \mu \mathrm{L} / \mathrm{min})$ e de $54 \%$ na região de altas vazões $(\phi \gtrsim 130 \mu L / \mathrm{min})$.

A temperatura média no filamento auto-sustentado no pior caso (sem fluxo) é ligeiramente maior do que no caso do filamento em contato com o substrato. 
Contudo, a queda de temperatura com a passagem de fluido é mais acentuada no filamento auto-sustentando como mostra a figura 49 .

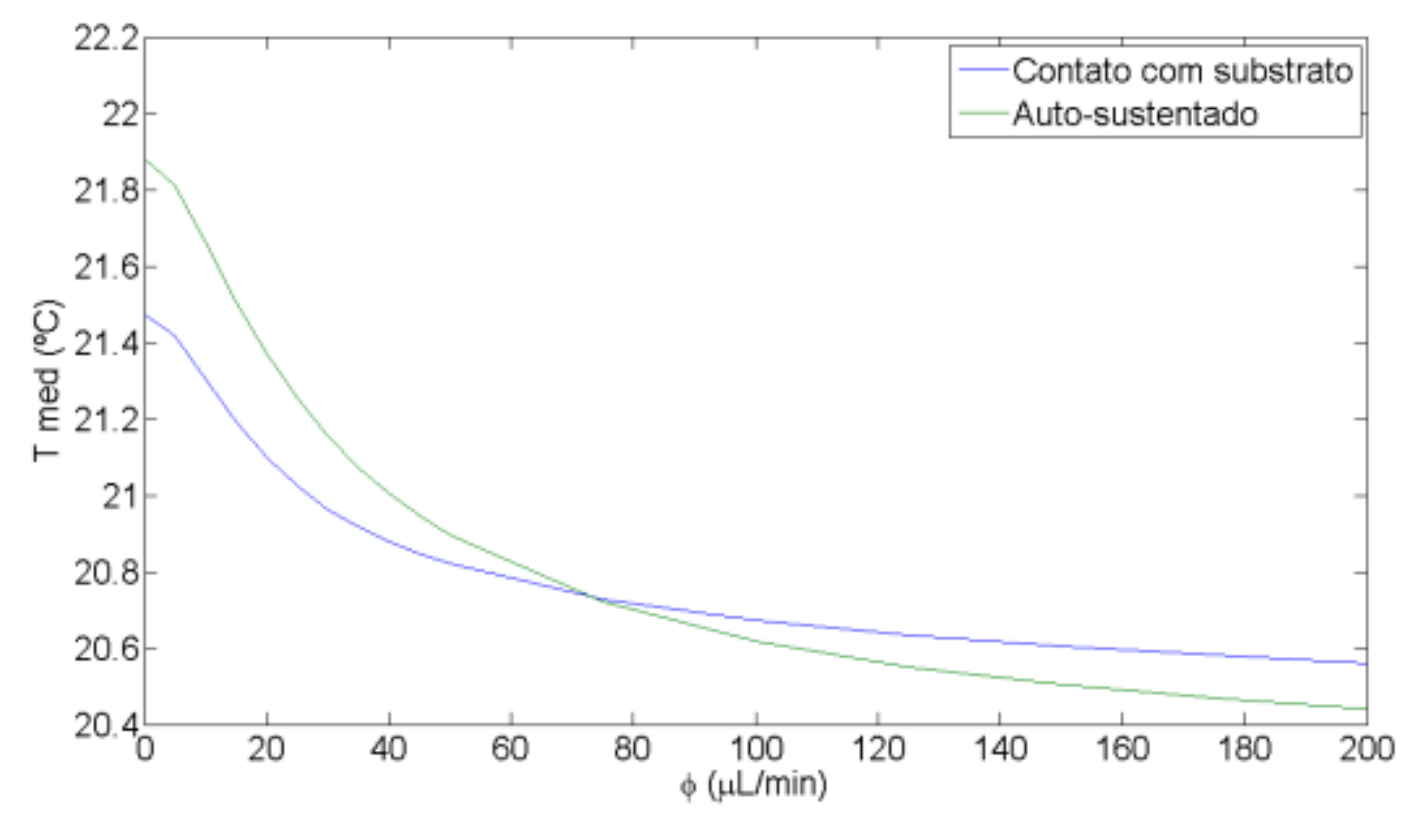

Figura 49 - Curva da temperatura média x vazão obtida da simulação por elementos finitos para o caso do filamento em contato com o substrato e auto-sustentado.

Estes resultados são preliminares e o estudo destas simulações deverá ser continuado em trabalhos futuros.

\subsection{SIMULAÇÃO POR ELEMENTOS CONCENTRADOS}

As simulações comportamentais foram realizadas utilizando a implementação do SPICE disponível no software Multisim Analog Devices Edition 10 (National Instruments). Diversas simulações foram realizadas a partir do modelo de elementos concentrados proposto para o sensor de vazão descrito no capítulo 5. O objetivo foi levantar a resposta estática e dinâmica do sensor. Para calcular os valores dos parâmetros do circuito equivalente utilizou-se uma rotina feita em Matlab, que é apresentada no apêndice $A$. 


\subsubsection{Validação do modelo}

Como forma de validar o modelo a parâmetros concentrados, foram realizadas simulações com dados encontrados na literatura para comparação dos resultados. Em particular, S. Wu et al (47) reportaram a fabricação e caracterização de um sensor térmico capaz de medir vazões na faixa de nanolitros por minuto, com uma resolução que pode chegar até a $0,4 \mathrm{~nL} / \mathrm{min}$. $O$ sensor é formado por um filamento de silício policristalino dopado com boro, fabricado não dentro mas sobre um microcanal de $2 \mu \mathrm{m}$ de altura por $20 \mu \mathrm{m}$ de largura. O microcanal possui paredes de nitreto de silício fabricadas sobre um substrato de silício. A figura 50 mostra uma representação do sensor.

O artigo apresenta um estudo sobre a influência que alguns aspectos construtivos do sensor podem ter sobre sua sensibilidade, sendo eles o comprimento e o grau de dopagem do filamento e $\mathrm{o}$ isolamento térmico do sensor em relação ao substrato. Para isso, foram fabricados dispositivos com três configurações diferentes, como mostra a figura 50 .

Apesar de o sensor apresentado no artigo não possuir exatamente a mesma configuração proposta neste trabalho, a comparação de resultados é possível pois ambos apresentam o mesmo princípio e o mesmo modo de funcionamento (potência constante), empregam um único filamento reto que atravessa o microcanal (e não um elemento em forma de serpentina, por exemplo) e foram projetados para trabalhar em faixas de vazão próximas (no caso o modelo é valido para vazão menores do que $\sim 200 \mathrm{~nL} / \mathrm{min}$ ).

Para tornar os resultados comparáveis, os valores do modelo a parâmetros concentrados foram calculados usando as dimensões apresentadas no artigo. Entretanto, os demais aspectos construtivos foram mantidos iguais ao do processo de fabricação proposto neste trabalho. Assim, considerou-se que o filamento é feito de níquel e não silício policristalino, e permanece suspenso no interior do microcanal formado pela soldagem de uma lâmina de vidro e de um bloco de PDMS. 


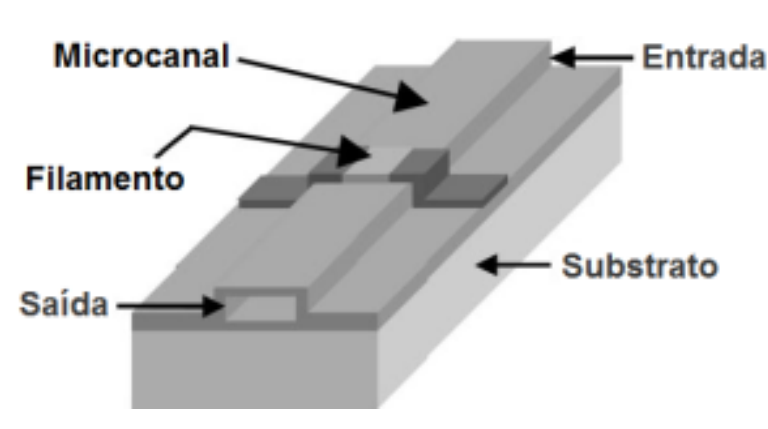

(a)

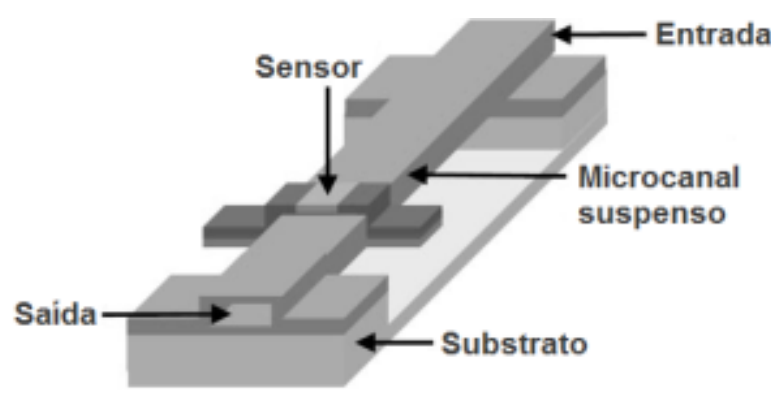

(b)

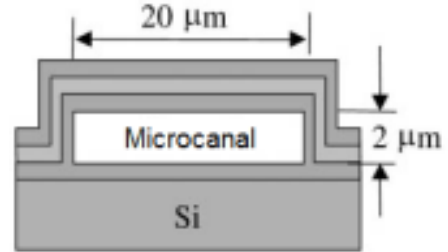

Sensor \#1

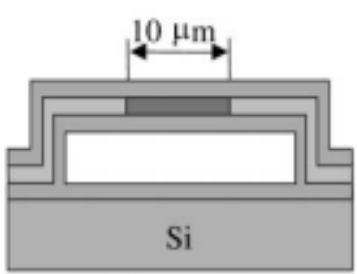

Sensor \#2

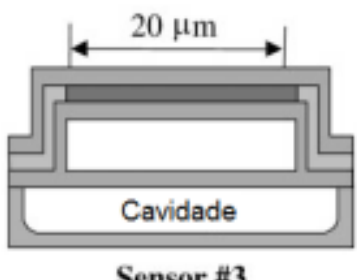

Sensor \#3

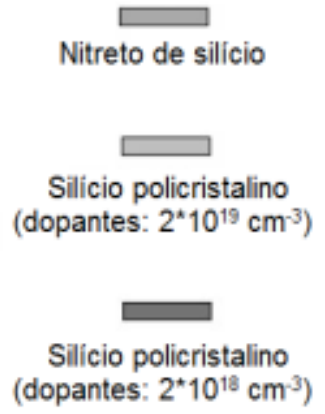
(dopantes: $2^{\star} 10^{18} \mathrm{~cm}^{-3}$ )

Figura 50 - Representação do sensor de vazão extraído da literatura (47) para validação do modelo a parâmetros concentrados. (a) Configuração do sensor \#2; (b) Configuração do sensor \#3; (c) Características construtivas das três configurações de sensor.

Com tais simplificações, não se espera uma concordância total entre os resultados do modelo e da referência 47. Visto que o coeficiente de temperatura do níquel e dos sensores \#2 e \#3 em silício policristalino se mostrou bastante próximo, esperase, contudo, obter resultados com o mesmo comportamento e com ordem de grandeza próxima.

Os valores das dimensões e dos demais parâmetros do modelo adotados na simulação estão mostrados na tabela 19. Vale ressaltar que nesta simulação considerou-se, com base nas imagens apresentadas na referência 47, que a largura do filamento dentro e fora do microcanal é a mesma. 
Tabela 19 - Parâmetros para validação do modelo a elementos concentrados.

\begin{tabular}{|c|c|}
\hline \multicolumn{2}{|c|}{ Dimensões do sensor } \\
\hline $\mathrm{L}=2 \mathrm{~mm}$ & $\mathrm{~L}_{\mathrm{f}}=100 \mu \mathrm{m}$ \\
\hline $\mathrm{L}_{\text {ef }}=10 \mu \mathrm{m}$ & $\mathrm{h}=2 \mu \mathrm{m}$ \\
\hline $\mathrm{w}=20 \mu \mathrm{m}$ & $a=5 \mu m$ \\
\hline$t=0,5 \mu \mathrm{m}$ & $t_{\text {PDMS }}=5 \mathrm{~mm}$ \\
\hline $\mathrm{t}_{\mathrm{v}}=1 \mathrm{~mm}$ & \\
\hline \multicolumn{2}{|c|}{ Propriedades da água } \\
\hline \multicolumn{2}{|c|}{ Densidade $=998,2 \mathrm{~kg} / \mathrm{m}^{3}$} \\
\hline \multicolumn{2}{|c|}{ Viscosidade $=1,001.10^{-35}$ Pa.s } \\
\hline \multicolumn{2}{|c|}{ Condutividade térmica $=0,5984 \mathrm{~W} /(\mathrm{m} . \mathrm{K})$} \\
\hline \multicolumn{2}{|c|}{ Calor específico a pressão constante $=4183 \mathrm{~J} /(\mathrm{kg} \cdot \mathrm{K}$} \\
\hline \multicolumn{2}{|c|}{ Fator de compressibilidade $=1$} \\
\hline \multicolumn{2}{|c|}{$\begin{array}{l}\text { Propriedades do níquel } \\
\end{array}$} \\
\hline \multicolumn{2}{|c|}{ Resistividade a $0^{\circ} \mathrm{C}=123,23 \cdot 10^{-9} \Omega . m$} \\
\hline \multicolumn{2}{|c|}{ Coeficiente de temperatura $(\mathrm{TCR})=0,0058661 / \mathrm{K}$} \\
\hline \multicolumn{2}{|c|}{ Condutividade térmica $=90,75 \mathrm{~W} /(\mathrm{m} . \mathrm{K})$} \\
\hline \multicolumn{2}{|c|}{$\begin{array}{l}\text { Propriedades do PDMS } \\
\end{array}$} \\
\hline \multicolumn{2}{|c|}{ Condutividade térmica $=0,15 \mathrm{~W} /(\mathrm{m} . \mathrm{K})$} \\
\hline \multicolumn{2}{|c|}{$\begin{array}{l}\text { Propriedades do vidro } \\
\end{array}$} \\
\hline Condutividac & n.K) \\
\hline
\end{tabular}

O circuito equivalente utilizado nessa simulação, que compreende os três domínios físicos, é mostrado na figura 51. 

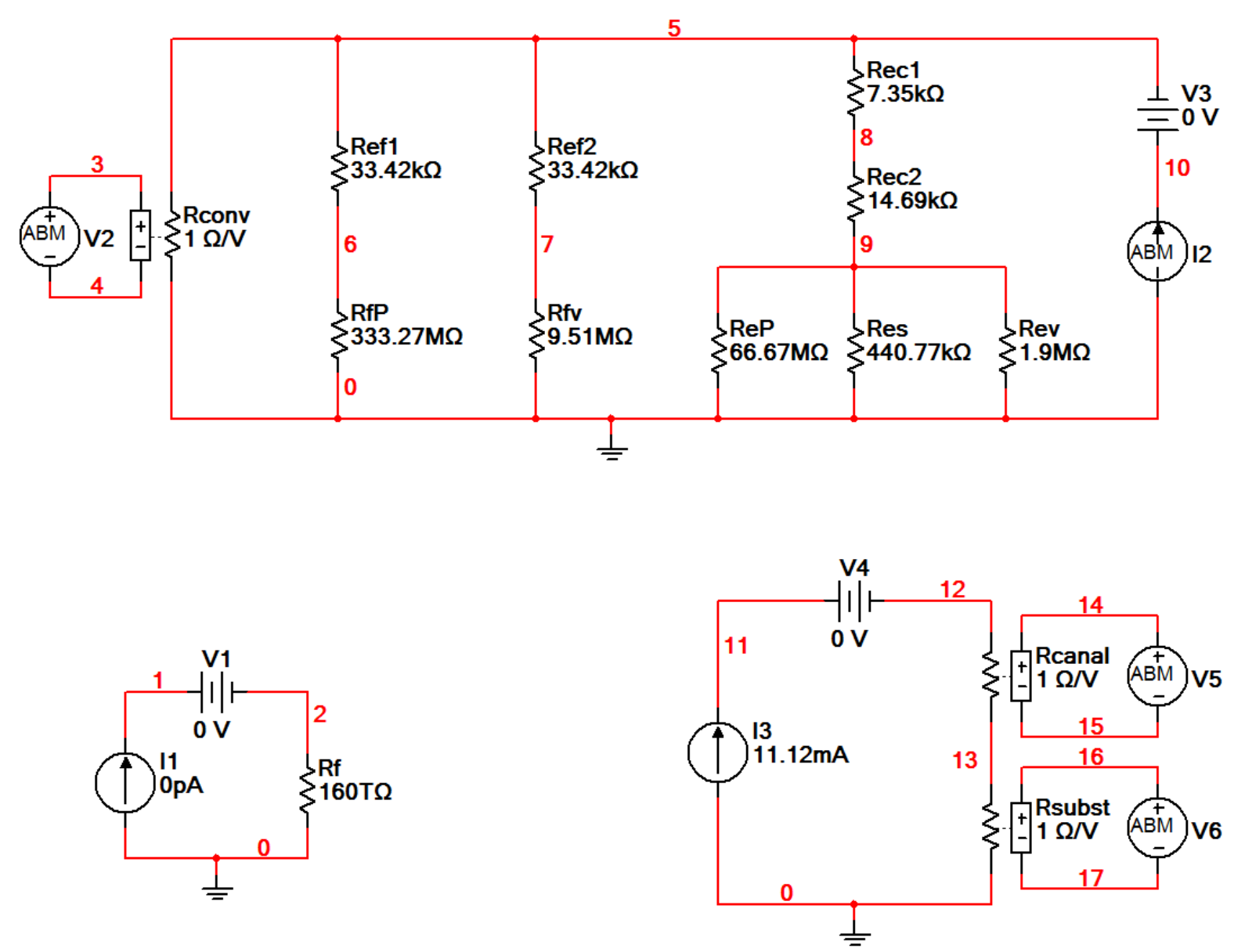

Figura 51 - Circuito equivalente utilizado para validação do modelo a parâmetros concentrados.

Para levantar a resposta estática foi empregada a simulação de varredura de parâmetros (Parameter sweep), sendo que a vazão foi o parâmetro variado. Levantou-se a resposta do dispositivo para valores de vazão que vão de 0 a 30 $\mathrm{nL} / \mathrm{min}$ (ou $5.10^{-13} \mathrm{~m}^{3} / \mathrm{s}$ ) com correntes de excitação no domínio elétrico iguais a 7,87mA, 11,12 mA e 13,61 mA. Esses valores de corrente foram escolhidos de modo que a potência total dissipada pelo filamento fosse igual a $70 \mu \mathrm{W}, 140 \mu \mathrm{W}$ e $210 \mu \mathrm{W}$, respectivamente.

Fontes do tipo ABM (Analog Behavioral Modeling) juntamente com resistores controlados por tensão fazem o acoplamento entre os domínios fluídico, térmico e elétrico. Esse tipo de fonte permite que a forma de onda seja determinada por uma expressão algébrica. As fontes de tensão CC com valor OV são um artifício para permitir que o valor da corrente na malha possa ser extraído. 
As expressões matemáticas usadas nas fontes do tipo ABM foram:

- Fonte de tensão V2:

$$
\begin{aligned}
V 2=R_{\text {conv }} & =\frac{1}{h_{c} A} \rightarrow V 2=\frac{1}{\left(\frac{8 k}{h}+\frac{16 \rho U_{\infty} a^{2} c_{p}}{h^{2}}\right) \frac{w}{2} a}=\frac{1}{\left(h_{c 0}+h_{c 1} U_{\infty}\right) \frac{w}{2} a} \rightarrow \\
& \rightarrow \quad V 2=\frac{1}{\left(2,39 \cdot 10^{6}+4,18 \cdot 10^{8} \frac{I(V 1)}{4 \cdot 10^{-11}}\right) 10 \cdot 10^{-6} \cdot 5 \cdot 10^{-6}}
\end{aligned}
$$

- Fonte de corrente I2:

$$
I 2=\frac{\dot{Q}}{2}=\frac{1}{2} R_{\text {canal }} I^{2} \rightarrow I 2=\frac{1}{2}(V(14)-V(15)) I(V 4)^{2}
$$

- Fonte de tensão V5:

$$
\begin{gathered}
V 5=R_{\text {canal }}=\frac{\varrho\left(T_{\text {canal }}\right) \ell}{A} \rightarrow V 5=\frac{\varrho_{0}(1+\alpha(\overline{\Delta T}+25)) w}{a t} \rightarrow \\
\rightarrow V 5=R_{\text {canal0 }}(1+\alpha(\overline{\Delta T}+25)) \rightarrow V 5=0,9858\left(1+5,866 \cdot 10^{-3}(V(8)+25)\right)
\end{gathered}
$$

* Supõe-se que a temperatura ambiente é igual a $25^{\circ} \mathrm{C}$ por isso se soma 25 à temperatura média do filamento $\overline{\Delta T}$.

- Fonte de tensão V6:

$$
V 6=R_{\text {substrato }}=\frac{\varrho\left(T_{\text {substrato }}\right) \ell}{A} \rightarrow V 6=\frac{\varrho_{0}\left(1+\alpha\left(\Delta T_{L}+25\right)\right) 2 L_{f}}{a t} \rightarrow
$$

$\rightarrow \quad V 6=R_{\text {substratoo }}\left(1+\alpha\left(\Delta T_{L}+25\right)\right) \rightarrow \quad V 6=2.4,93\left(1+5,866.10^{-3}(V(9)+25)\right)$

* Ao contrário do que foi assumido no item 4.2.2.1, a largura do filamento fora do microcanal neste caso é igual à largura dentro do microcanal segundo mostram as fotos da referência 47. 
Os resultados obtidos estão resumidos nas figuras 52 e 53. Para permitir a comparação dos resultados, foram definidas a diferença de temperatura $\Delta T=$ $T(\phi)-T(\phi=0)$ e a diferença de tensão $\Delta V=V(\phi)-V(\phi=0)$.

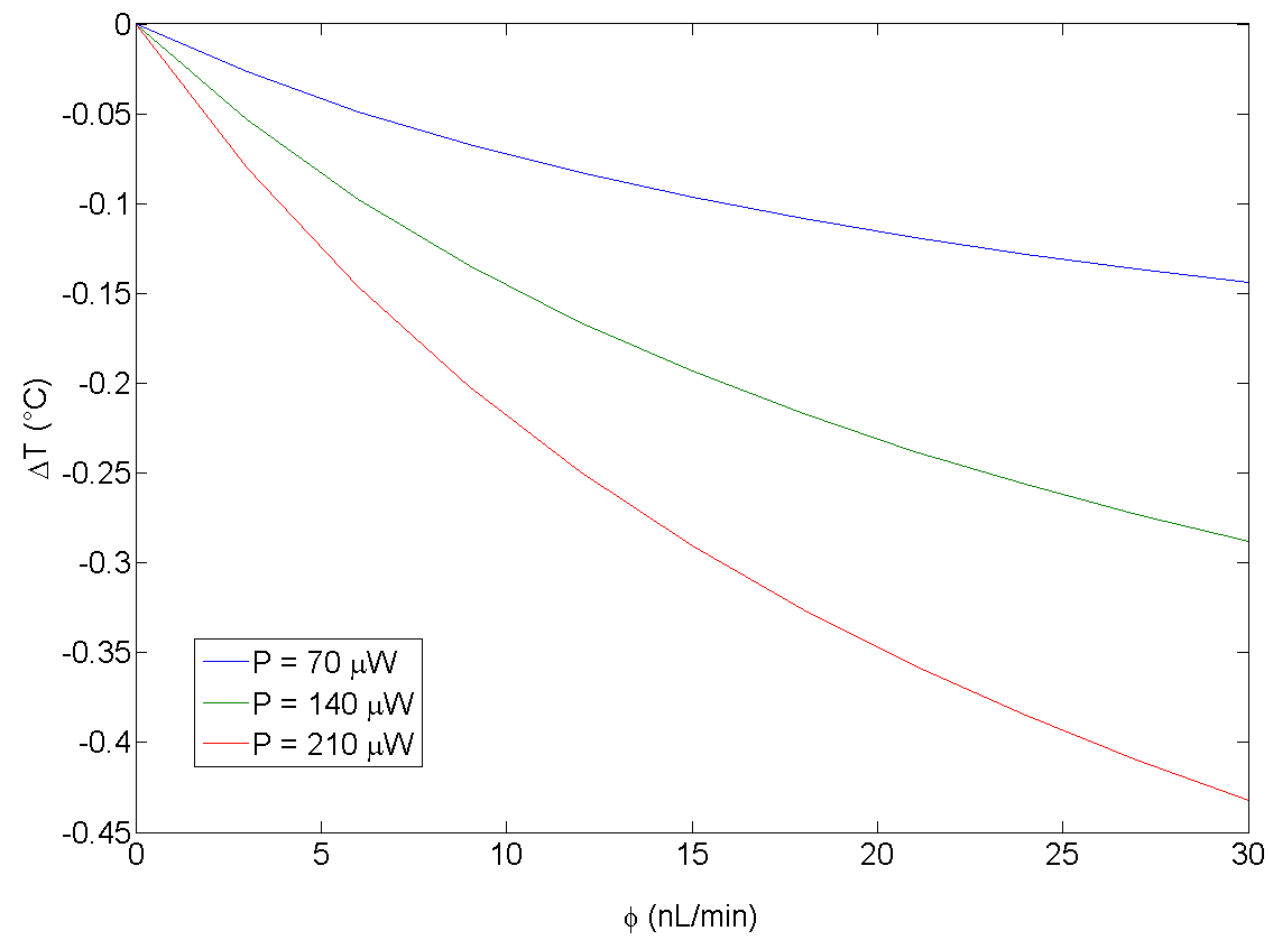

Figura 52 - Gráfico da diferença de temperatura $\Delta T$ em função da vazão $\phi$ referente à simulação para verificação do modelo a parâmetros concentrados.

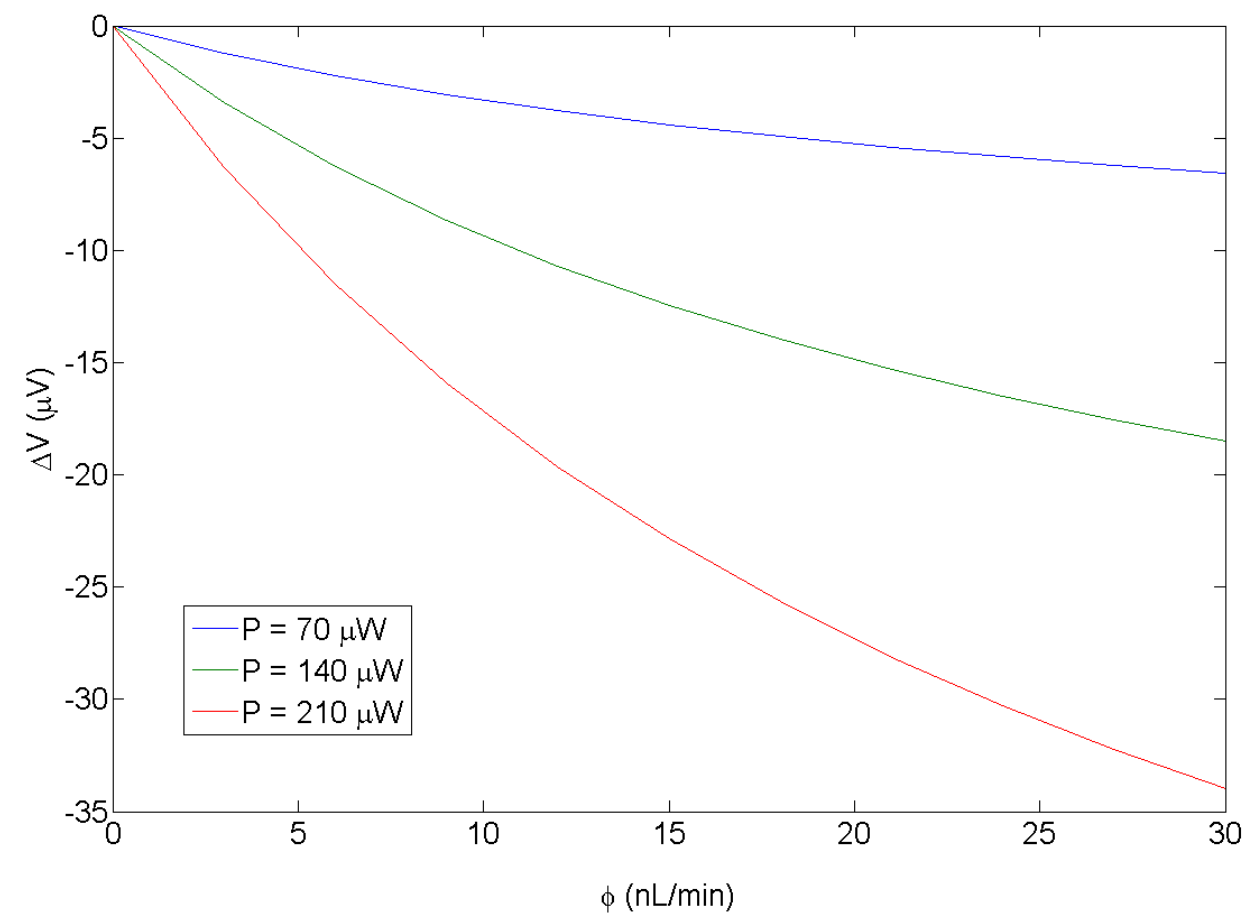

Figura 53 - Gráfico da diferença de tensão $\Delta V$ em função da vazão $\phi$ referente à simulação para verificação do modelo a parâmetros concentrados. 
Observa-se que, como esperado, a temperatura diminui com o aumento da vazão. Isso provoca uma diminuição no valor da resistência do filamento que, por ser excitado com uma corrente constante, se reflete em uma diminuição da tensão.

Os gráficos mostram que o aumento da potência dissipada no filamento, obtido através do aumento da corrente de polarização, provoca maiores diferenças de temperatura e de tensão. Conclui-se, portanto, que aumentar a corrente de excitação do sensor é uma forma de aumentar sua sensibilidade. Um aspecto negativo dessa abordagem de aumentar a sensibilidade é que a temperatura máxima do filamento também aumenta. A tabela 20 mostra o incremento de temperatura máximo e médio para cada um dos casos considerando um microcanal sem escoamento. Mesmo que o aumento de temperatura não seja significativo para os valores de potência considerados, deve-se tomar o cuidado de não aumentar demais a corrente, pois um aumento excessivo de temperatura pode limitar a aplicabilidade do sensor, principalmente nos meios biológicos e químicos. Tabela 20 - Incremento de temperatura máximo e médio em relação à potência dissipada pelo
filamento.

\begin{tabular}{|c|c|c|}
\hline$\dot{\boldsymbol{Q}}[\boldsymbol{\mu W}]$ & $\widehat{\Delta \boldsymbol{T}}\left[{ }^{\circ} \mathrm{C}\right]$ & $\overline{\Delta \boldsymbol{T}}\left[{ }^{\circ} \mathrm{C}\right]$ \\
\hline 70 & 0,29 & 0,28 \\
\hline 140 & 0,57 & 0,56 \\
\hline 210 & 0,86 & 0,84 \\
\hline
\end{tabular}

Outro resultado é que as relações $\Delta T(\phi)$ e $\Delta V(\phi)$ na faixa de interesse não são lineares. Isso provavelmente está relacionado a imperfeições no modelo da convecção. Uma das hipóteses assumidas no modelo é que o número de Reynolds e o número de Peclet são muito pequenos ( $R e \ll 1$ e $P e \ll 1)$. Como mostram os dados da tabela 21, para valores de vazão acima de $10 \mathrm{~nL} / \mathrm{min}$, ou mesmo acima de $5 \mathrm{~nL} / \mathrm{min}$, a hipótese não é verdadeira. 
Tabela 21 - Valores dos números de Reynolds e Peclet em função da vazão.

\begin{tabular}{|c|c|c|}
\hline $\boldsymbol{\phi}[\boldsymbol{n L} / \mathbf{m i n}]$ & $\boldsymbol{R e}$ & $\boldsymbol{P e}$ \\
\hline 5 & 0,0104 & 0,0727 \\
\hline 10 & 0,0208 & 0,1454 \\
\hline 15 & 0,0312 & 0,2181 \\
\hline 30 & 0,0623 & 0,4361 \\
\hline
\end{tabular}

Apesar das limitações do modelo, os resultados foram linearizados para determinar o valor numérico da sensibilidade do sensor. Assim, dois parâmetros podem ser definidos a partir dos gráficos das figuras 52 e 53:

$$
S_{T}=\frac{\Delta T}{\Delta \phi} \quad \text { (61) e } \quad S_{V}=\frac{\Delta V}{\Delta \phi} \quad(62) .
$$

O parâmetro $S_{T}$ indica a razão entre a diferença de temperatura e a vazão e o parâmetro $S_{V}$ representa a sensibilidade do sensor, que é dependente da polarização do mesmo. Um modo de eliminar essa dependência é definindo a sensibilidade normalizada:

$$
S_{V / V_{0}}=\frac{\Delta V / V_{0}}{\Delta \phi} \text { (63) , }
$$

em que $V_{0}=V(\phi=0)$.

Os valores de $S_{T}, S_{V}$ e $S_{V / V_{0}}$ para os três casos de potência dissipada estão mostrados na tabela 22. Eles demonstram que o aumento da potência dissipada melhora a sensibilidade do sensor, como havia sido dito anteriormente.

Tabela 22 - Parâmetros de sensibilidade do sensor em função da potência dissipada pelo filamento.

\begin{tabular}{|c|c|c|c|}
\hline$\dot{\boldsymbol{Q}}[\boldsymbol{\mu W}]$ & $\begin{array}{c}\boldsymbol{S}_{\boldsymbol{T}} \\
{\left[{ }^{\circ} /(\boldsymbol{n L} / \mathbf{m i n})\right]}\end{array}$ & $\begin{array}{c}\boldsymbol{S}_{\boldsymbol{V}} \\
{[\boldsymbol{\mu V} /(\boldsymbol{n L} / \mathbf{m i n})]}\end{array}$ & $\begin{array}{c}\boldsymbol{S}_{\boldsymbol{V} / \mathbf{V}_{\mathbf{0}}} \\
{[\boldsymbol{p} \boldsymbol{p m} /(\boldsymbol{n L} / \mathbf{m i n})]}\end{array}$ \\
\hline 70 & $-0,0048$ & $-0,22$ & $-24,51$ \\
\hline 140 & $-0,0096$ & $-0,62$ & $-48,95$ \\
\hline 210 & $-0,0144$ & $-1,13$ & $-73,33$ \\
\hline
\end{tabular}


Os resultados obtidos para o sensor excitado com corrente igual a $11,12 \mathrm{~mA}$ $(\dot{Q}=140 \mu W)$ foram comparados com aqueles da referência 47 , obtidos para o mesmo valor de potência. Os parâmetros de sensibilidade estão mostrados na tabela 23. É apresentado o valor absoluto de cada parâmetro já que o coeficiente de temperatura do silício policristalino é negativo.

Tabela 23 - Comparação entre os parâmetros de sensibilidade obtidos pela simulação e apresentados na referência 47.

\begin{tabular}{|c|c|c|c|}
\hline & $\begin{array}{c}\boldsymbol{S}_{\boldsymbol{T}} \\
\left.\left[{ }^{\circ} \mathrm{C} / \boldsymbol{n L} / \mathbf{m i n}\right)\right]\end{array}$ & $\begin{array}{c}\boldsymbol{S}_{\boldsymbol{V}} \\
{[\boldsymbol{\mu V} /(\boldsymbol{n L} / \mathbf{m i n})]}\end{array}$ & $\begin{array}{c}\boldsymbol{S}_{\boldsymbol{V} / \boldsymbol{V}_{\mathbf{0}}} \\
{[\boldsymbol{p p m} /(\boldsymbol{n L} / \mathbf{m i n})]}\end{array}$ \\
\hline Simulado & 0,0096 & $0,62 @ \mathrm{I}=11,12 \mathrm{~mA}$ & 48,95 \\
\hline Sensor \#1 & 0,0047 & $3,60 @ \mathrm{I}=100 \mu \mathrm{A}$ & 8,00 \\
\hline Sensor \#2 & 0,0071 & $26,20 @ \mathrm{I}=100 \mu \mathrm{A}$ & 40,00 \\
\hline Sensor \#3 & 0,0263 & $361,20 @ \mathrm{I}=70 \mu \mathrm{A}$ & 180,00 \\
\hline
\end{tabular}

Os resultados da simulação apresentam boa concordância com os resultados da referência, principalmente do sensor \#2. Esse sensor apresenta coeficiente de temperatura igual a -0,0056, praticamente idêntico, em módulo, ao usado na simulação, o que explicaria a concordância.

Observa-se, contudo, que a sensibilidade $S_{V}$ do sensor simulado é muito inferior a dos demais sensores mesmo com uma corrente de polarização muito maior. A justificativa para esse fato é que o silício policristalino apresenta condutividade elétrica muito inferior ao do níquel. Portanto, dada uma corrente de excitação, a queda de tensão sobre o filamento de silício policristalino será muito maior do que aquela sobre o filamento de níquel.

O modo mais adequado de se comparar os sensores é então usar a sensibilidade normalizada, que leva em consideração a tensão de polarização do sensor. Nesse caso, o sensor simulado mais uma vez apresenta resultado bastante semelhante ao do sensor \#2.

A comparação provou que mesmo com algumas diferenças e limitações, o modelo desenvolvido é capaz de simular o funcionamento de um sensor térmico de vazão 
microfluídico. Futuramente a validação será complementada com resultados de simulações por elementos finitos e por medidas elétricas dos sensores fabricados.

\subsubsection{Análise estática}

Tendo o modelo a parâmetros concentrados sido validado com resultados da literatura, partiu-se para a simulação do sensor de interesse neste trabalho. Foi levantada a resposta estática e dinâmica do sensor (mostrada na próxima seção) utilizando-se os mesmos parâmetros apresentados anteriormente na tabela 14 da seção 5.2 .

Novamente empregou-se a simulação de varredura de parâmetros (Parameter sweep) com variação do valor da vazão. Neste caso, porém, a vazão apresentou valores entre 0 e $300 \mathrm{~nL} / \mathrm{min}$ (ou $5.10^{-12} \mathrm{~m}^{3} / \mathrm{s}$ ), já que os números de Reynolds e Peclet no pior dos casos são $R e=0,0416$ e $P e=0,2907$.

Os valores de corrente de excitação também tiveram que ser aumentados para que a potência dissipada pelo filamento fosse igual ao dos casos anteriores. Assim, os três valores de corrente de excitação foram 11,13 mA, 15,74 mA e 19,28 mA, que correspondem a potência dissipada pelo filamento igual a 70, 140 e $210 \mu \mathrm{W}$, respectivamente.

O circuito equivalente utilizado nessa simulação é mostrado na figura 54 . 

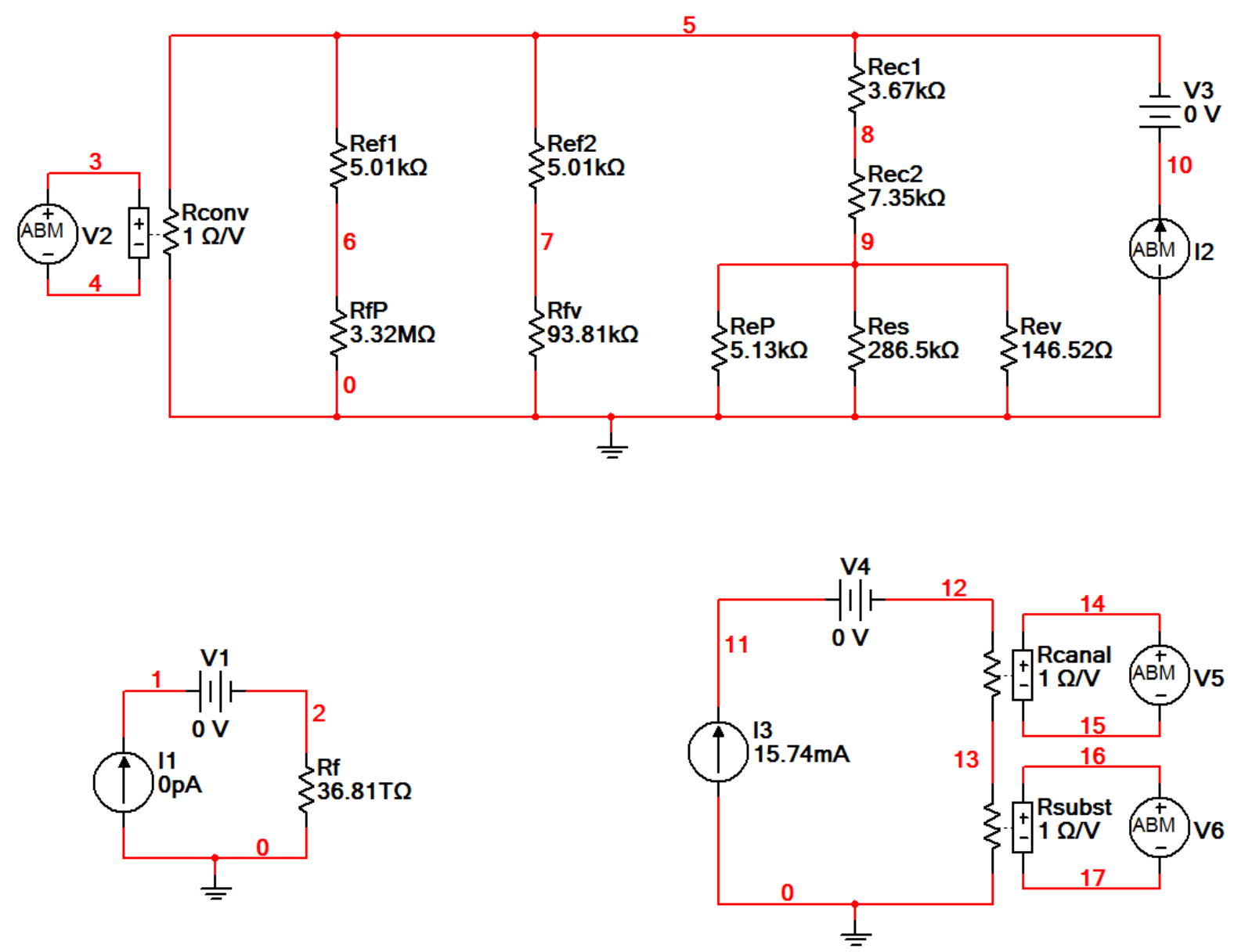

Figura 54 - Circuito equivalente utilizado para determinar a resposta estática do sensor projetado.

As fontes do tipo ABM foram ajustadas de acordo com as expressões mostradas no item 6.2.1 mas empregando agora os valores numéricos da tabela 14. Uma pequena modificação foi feita na expressão da fonte de tensão V6, na qual voltou a ser considerado que a largura do filamento fora do microcanal é dez vezes maior que a largura dentro do microcanal.

Os resultados obtidos estão apresentados nas figuras 55 e 56 . 


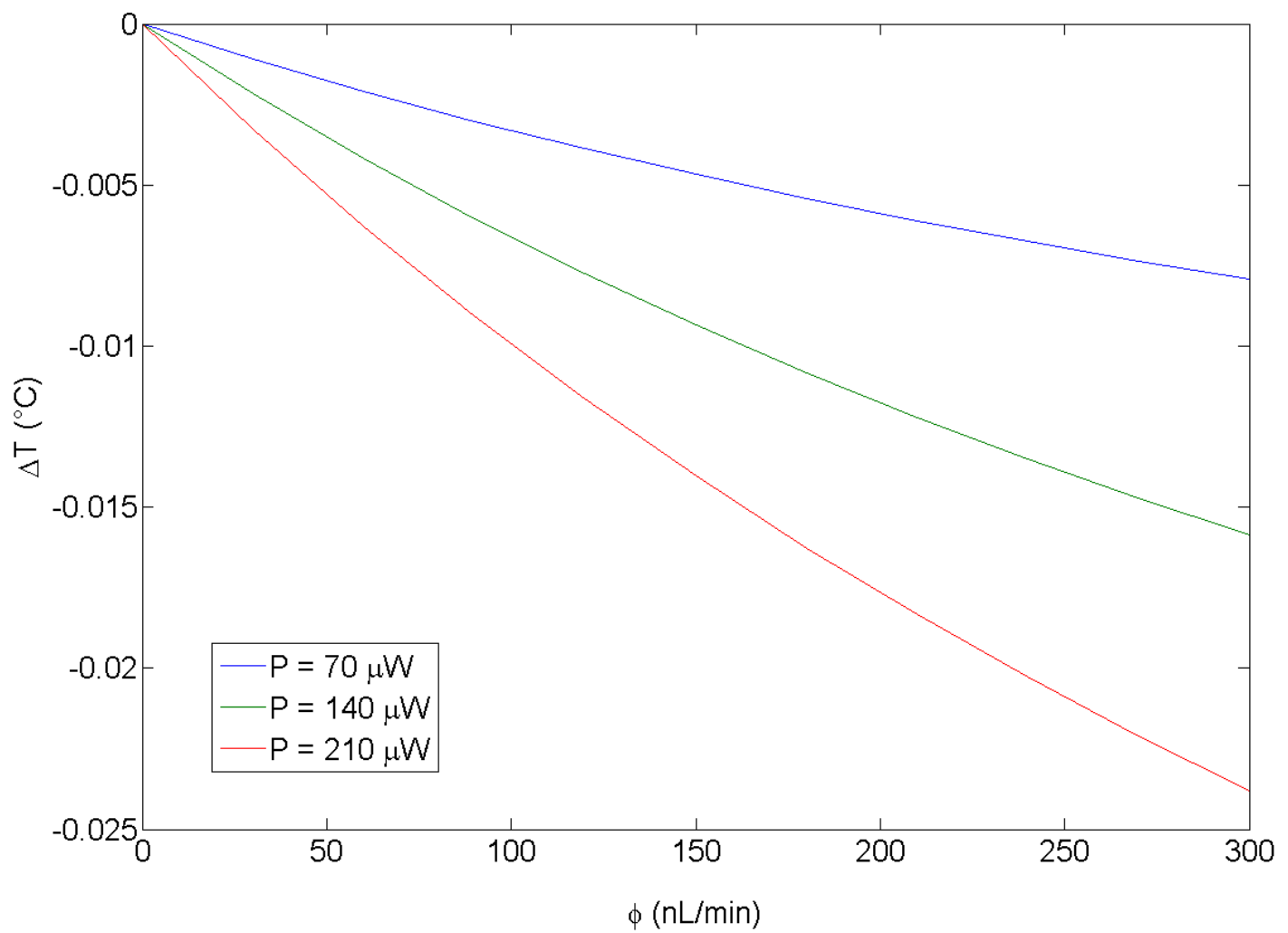

Figura 55 - Gráfico da diferença de temperatura $\Delta T$ em função da vazão $\phi$ referente ao sensor projetado.

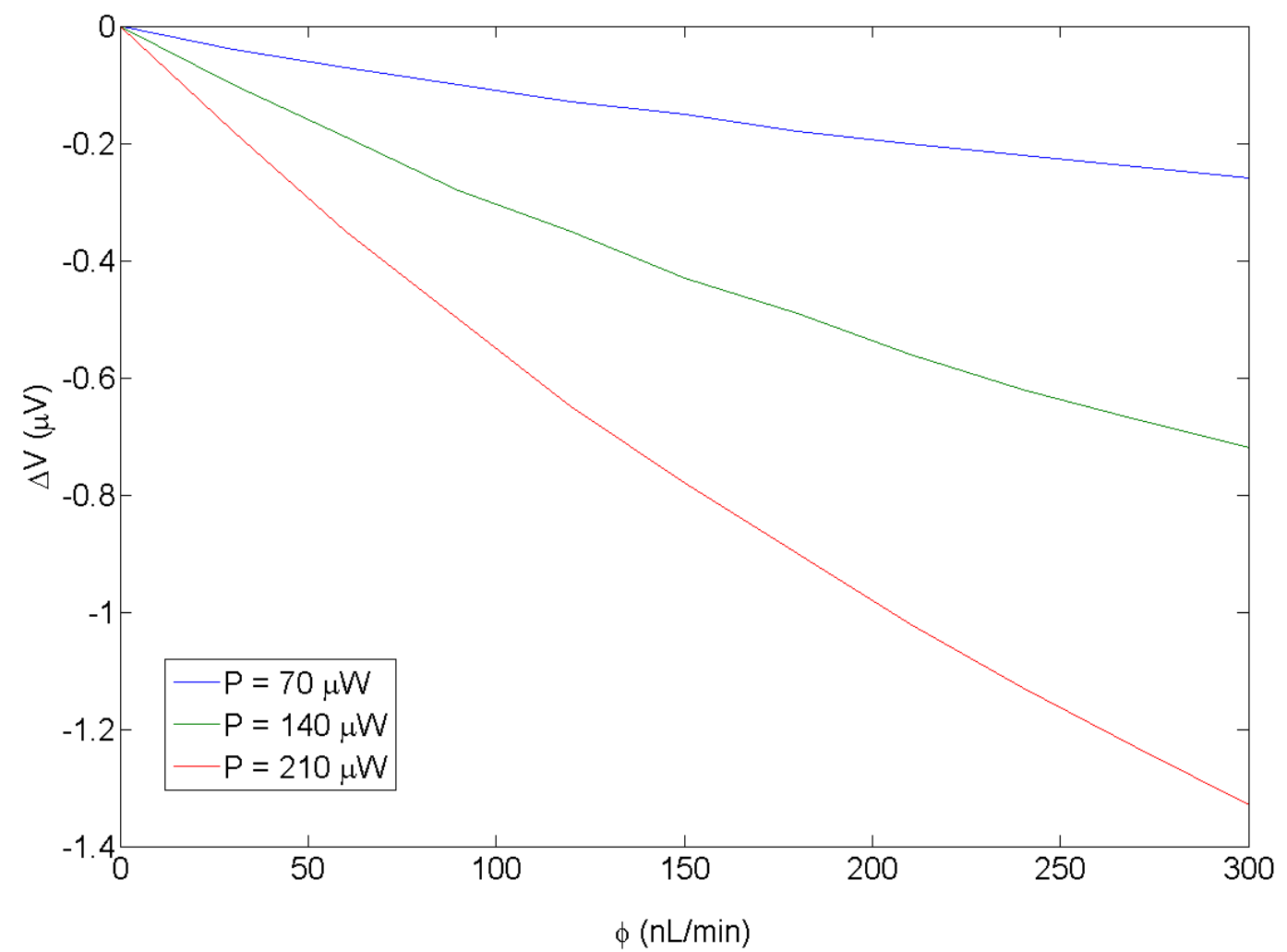

Figura 56 - Gráfico da diferença de tensão $\Delta V$ em função da vazão $\phi$ referente ao sensor projetado. 
Os gráficos apresentam o mesmo comportamento não-linear obtido anteriormente, justificado pelo descumprimento da hipótese de que $P e \ll 1$. Um aspecto bastante negativo mostrado pelos resultados da simulação é a baixa sensibilidade do sensor. De fato, considerando a potência dissipada pelo filamento igual a $140 \mu \mathrm{W}$ e a vazão no microcanal igual a $30 \mathrm{~nL} / \mathrm{min}$, a diferença de tensão $\Delta V$ é de apenas $0,1 \mu \mathrm{V}$, contra 18,51 $\mu \mathrm{V}$ medidos pelo sensor simulado no item 6.2.1 com dados da literatura. Medir tal valor na prática não é uma tarefa fácil já que ele se encontra muito próximo da amplitude do ruído eletromagnético.

A baixa sensibilidade desse sensor é confirmada pelos valores de sensibilidade mostrados na tabela 24 obtidos através da linearização das curvas.

Tabela 24 - Parâmetros de sensibilidade do sensor projetado em função da potência dissipada pelo filamento.

\begin{tabular}{|c|c|c|c|}
\hline$\dot{\boldsymbol{Q}}[\boldsymbol{\mu W}]$ & $\begin{array}{c}\boldsymbol{S}_{\boldsymbol{T}} \\
{\left[{ }^{\circ} \mathrm{C} /(\boldsymbol{n L} / \mathbf{m i n})\right]}\end{array}$ & $\begin{array}{c}\boldsymbol{S}_{\boldsymbol{V}} \\
{[\boldsymbol{\mu V} /(\boldsymbol{n L} / \mathbf{m i n})]}\end{array}$ & $\begin{array}{c}\boldsymbol{S}_{\boldsymbol{V} / \mathbf{V}_{\mathbf{0}}} \\
{[\boldsymbol{p p m} /(\boldsymbol{n L} / \mathbf{m i n})]}\end{array}$ \\
\hline 70 & $-2,64 \cdot 10^{-5}$ & $-0,0009$ & $-0,14$ \\
\hline 140 & $-5,29 \cdot 10^{-5}$ & $-0,0024$ & $-0,27$ \\
\hline 210 & $-7,94.10^{-5}$ & $-0,0044$ & $-0,40$ \\
\hline
\end{tabular}

Visto que as dimensões dos dois sensores são significativamente diferentes, uma forma mais adequada de comparar os resultados é igualar não a potência dissipada pelo filamento mas sim a densidade de potência. A área do sensor do item 6.2.1 através da qual ocorre troca de calor é igual a:

$$
A_{\text {ref }}=(w \cdot a)_{\text {ref }}=20 \mu m \cdot 5 \mu m=100 \mu m^{2}=1 \cdot 10^{-4} \mathrm{~mm}^{2},
$$

enquanto que a área do sensor projetado é de:

$$
A_{\text {projeto }}=(w \cdot a)_{\text {projeto }}=200 \mu m \cdot 50 \mu m=10000 \mu m^{2}=1 \cdot 10^{-2} \mathrm{~mm}^{2},
$$

ou seja, 100 vezes maior. Assim, a potência dissipada pelo sensor projetado deve ser 100 vezes maior que aquela do sensor de referência.

Os valores de corrente de excitação foram então ajustados para os seguintes valores: 110,55 mA, 155,33 mA e 189,01 mA, que correspondem a potência 
dissipada de $7 \mathrm{~mW}, 14 \mathrm{~mW}$ e $21 \mathrm{~mW}$, respectivamente. Os resultados para essa nova situação estão mostrados nos gráficos da figura 57 e 58.

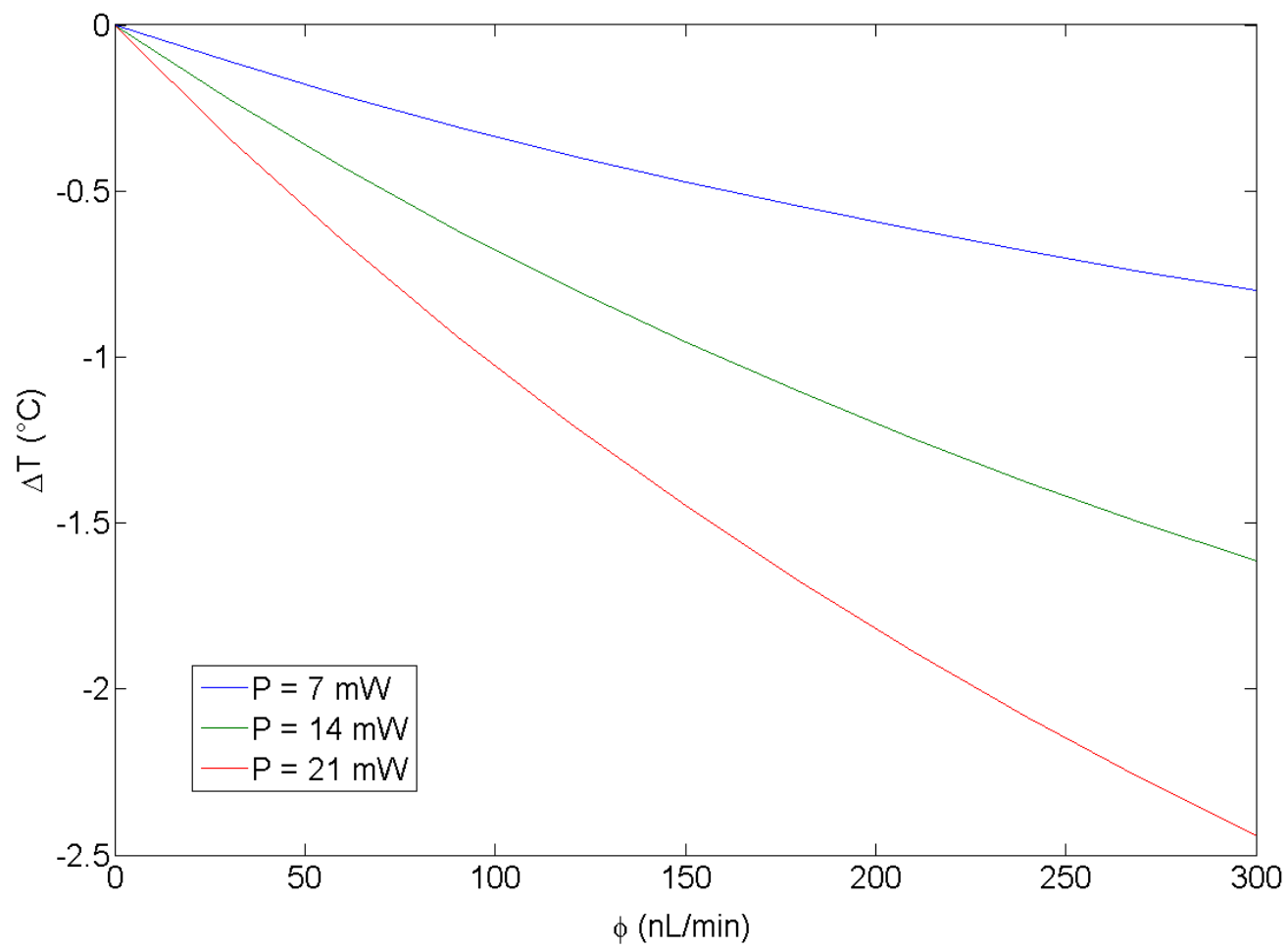

Figura 57 - Gráfico da diferença de temperatura $\Delta T$ em função da vazão $\phi$ referente ao sensor projetado polarizado para dissipar a mesma densidade de potência do sensor de referência do item 4.1.1.

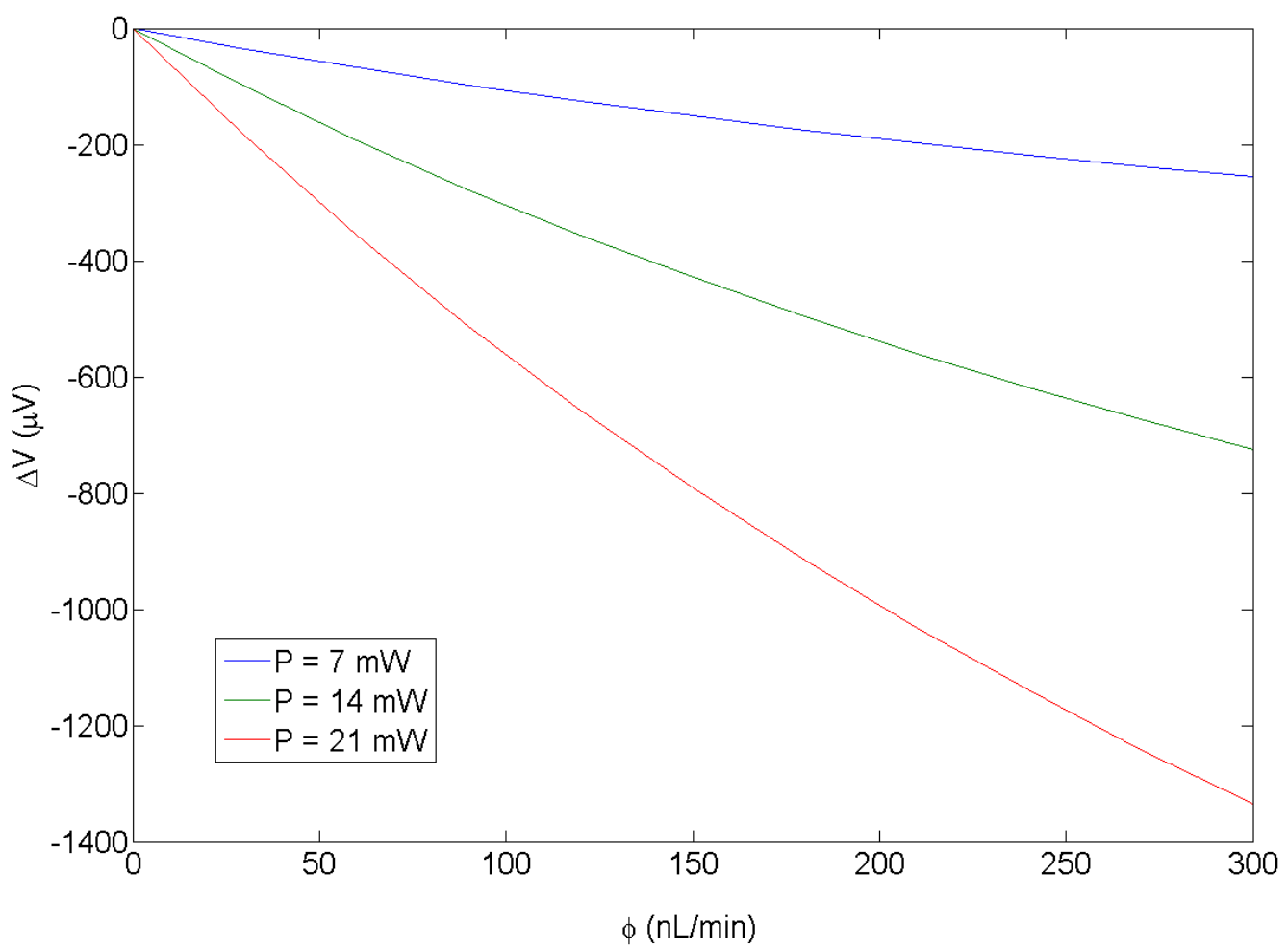

Figura 58 - Gráfico da diferença de tensão $\Delta V$ em função da vazão $\phi$ referente ao sensor projetado polarizado para dissipar a mesma densidade de potência do sensor de referência do item 4.1.1. 
O comportamento das curvas é o mesmo observado anteriormente mas existe uma diferença significativa na amplitude dos sinais, que podem passar de $1 \mathrm{mV}$. Isso acarreta em um aumento da sensibilidade do sensor, como mostram os dados da tabela 25.

Tabela 25 - Parâmetros de sensibilidade do sensor projetado em função da potência dissipada pelo filamento.

\begin{tabular}{|c|c|c|c|}
\hline$\dot{\boldsymbol{Q}}[\boldsymbol{m W}]$ & $\begin{array}{c}\boldsymbol{S}_{\boldsymbol{T}} \\
{\left[{ }^{\circ} \mathrm{C} /(\boldsymbol{n L} / \mathbf{m i n})\right]}\end{array}$ & $\begin{array}{c}\boldsymbol{S}_{\boldsymbol{V}} \\
{[\boldsymbol{\mu V} /(\boldsymbol{n L} / \mathbf{m i n})]}\end{array}$ & $\begin{array}{c}\boldsymbol{S}_{\boldsymbol{V} / \mathbf{V}_{\mathbf{0}}} \\
{[\boldsymbol{p p m} /(\boldsymbol{n L} / \mathbf{m i n})]}\end{array}$ \\
\hline 7 & $-0,0027$ & $-0,85$ & $-13,46$ \\
\hline 14 & $-0,0054$ & $-2,42$ & $-26,82$ \\
\hline 21 & $-0,0081$ & $-4,45$ & $-40,07$ \\
\hline
\end{tabular}

A comparação desses resultados com aqueles apresentados na tabela 22 mostra que apesar do aumento na sensibilidade do sensor $S_{V}$, a razão entre temperatura e vazão $S_{T}$ e a sensibilidade normalizada $S_{V / V_{0}}$ ainda estão abaixo das obtidas com um sensor de menores dimensões.

Uma conclusão à que se chega é que mesmo dissipando a mesma densidade de potência, a troca de calor entre fluido e filamento não acontece da mesma forma nos dois sensores. Isso se deve ao fato da área da seção transversal dos dois sensores ser diferente, o que faz com que, para o mesmo valor de vazão nos dois sensores, o valor da velocidade média do fluido seja diferente. O sensor de referência (item 6.2.1), por exemplo, apresenta menor seção transversal o que faz com que, para um mesmo valor de vazão, a velocidade do fluido seja maior. Com o fluido escoando a uma velocidade maior, a troca de calor por convecção é intensificada, o que explicaria a diferença entre os parâmetros de sensibilidade nos dois casos.

Além da sensibilidade abaixo da desejada, o sensor projetado provoca um aumento maior da temperatura do fluido que do que o sensor de referência, como mostram os resultados da tabela 26. 
Tabela 26 - Incremento de temperatura máximo e médio em relação à potência dissipada pelo filamento para o sensor projetado.

\begin{tabular}{|c|c|c|}
\hline$\dot{\boldsymbol{Q}}[\mathbf{m W}]$ & $\widehat{\Delta \boldsymbol{T}}\left[{ }^{\circ} \mathrm{C}\right]$ & $\overline{\Delta \boldsymbol{T}}\left[{ }^{\circ} \mathrm{C}\right]$ \\
\hline 7 & 3,89 & 2,61 \\
\hline 14 & 7,78 & 5,22 \\
\hline 21 & 11,67 & 7,83 \\
\hline
\end{tabular}

Dado o processo de fabricação e os materiais escolhidos até o momento, os parâmetros geométricos do sensor devem ser variados caso se deseje melhorar sua sensibilidade e diminuir a corrente de polarização. Sendo assim, é conveniente realizar um estudo mais detalhado da influência dos parâmetros geométricos sobre a resposta do sensor. Tal estudo, entretanto, ainda não foi realizado.

\subsubsection{Análise dinâmica}

A análise dinâmica mostra como é a resposta do sensor a uma variação temporal da vazão ou diferença de pressão no microcanal. Para esse tipo de análise é importante incluir todas as indutâncias e capacitâncias equivalentes presentes no modelo. O circuito equivalente empregado nessa simulação, projetado com as dimensões da tabela 14, está apresentado na figura 59.

Para efetuar a simulação foi empregada uma análise do tipo transiente (Transient Analysis) com duração de $80 \mathrm{~ms}$. A fonte de vazão constante utilizada na simulação estática foi substituída por uma fonte de vazão que aplica um pulso de duração de $40 \mathrm{~ms}$, amplitude de $1,667 \cdot 10^{-14} \mathrm{~m}^{3} / \mathrm{s}$ (equivalente a se obter uma vazão de $1 \mathrm{~nL} / \mathrm{min}$ ) e tempos de subida e descida de $1 \mathrm{~ns}$. A corrente de excitação do sensor foi mantida em 155,33 mA, o que corresponde a um valor de potência dissipada de $14 \mathrm{~mW}$ ou a uma densidade de potência de $1,4 \mathrm{~W} / \mathrm{mm}^{2}$. 

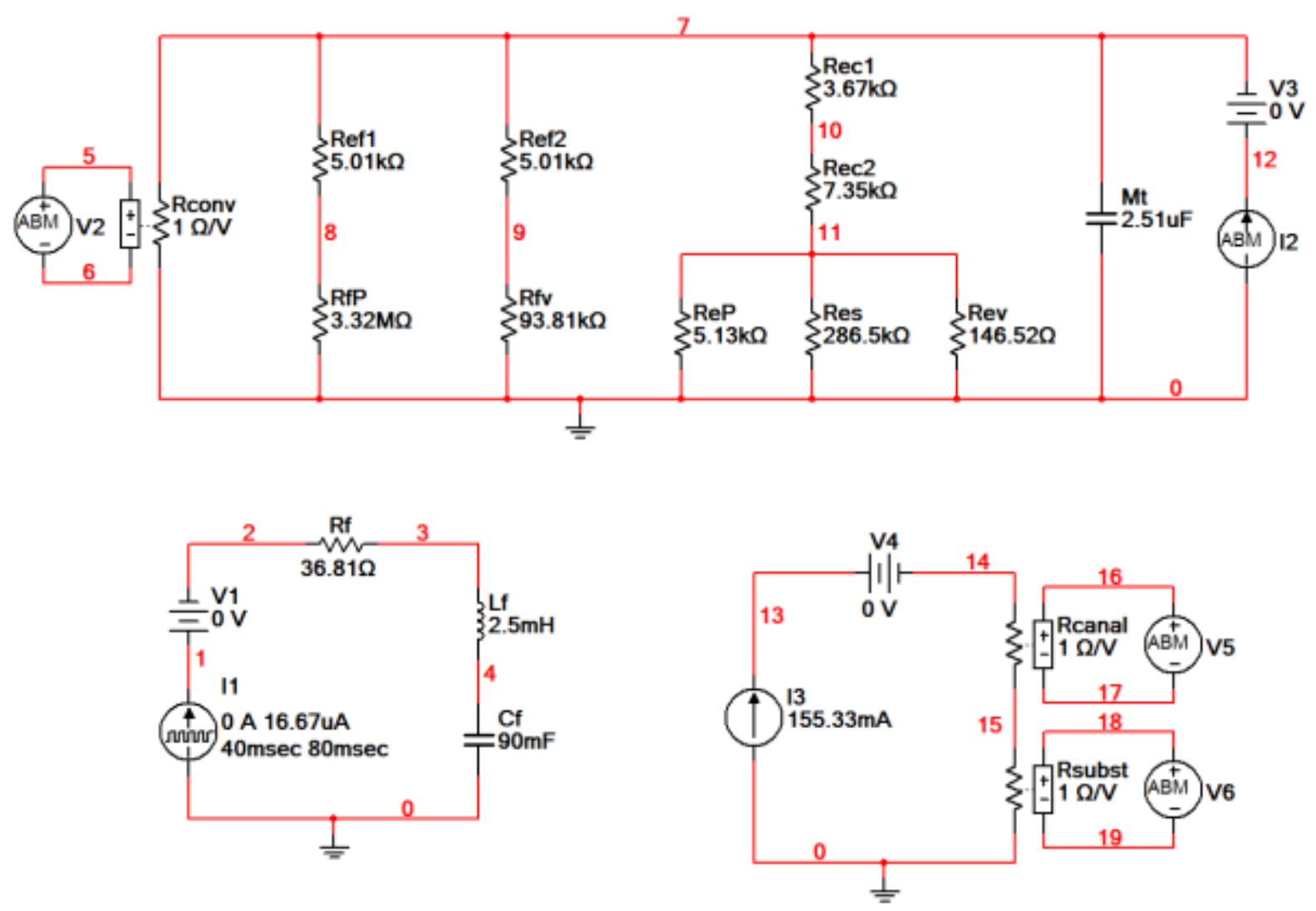

Figura 59 - Circuito equivalente utilizado para determinar a resposta dinâmica do sensor projetado.

Os componentes do domínio fluídico tiveram que ser reescalonados pois os valores encontrados para a inércia fluídica $\left(L_{f}\right)$ e para rigidez fluídica $\left(C_{f}\right)$ encontravam-se fora dos limites de simulação aceitos pelo software. Para tanto, passou-se a adotar a vazão volumétrica não mais em $\mathrm{m}^{3} / \mathrm{s}$ mas $\operatorname{sim}$ em $\mathrm{mm}^{3} / \mathrm{s}$. Isso acarretou na multiplicação dos seguintes fatores às grandezas calculadas pela rotina em Matlab (Apêndice A):

$$
\begin{gathered}
{[\phi]=\mathrm{m}^{3} / \mathrm{s}=\left(10^{3} \mathrm{~mm}\right)^{3} / \mathrm{s}=10^{9} \mathrm{~mm}^{3} / \mathrm{s} ;} \\
{\left[R_{f}\right]=\frac{P a}{\mathrm{~m}^{3} / \mathrm{s}}=\frac{N \cdot \mathrm{s}}{\mathrm{m}^{2} \cdot \mathrm{m}^{3}}=\frac{\mathrm{kg} \cdot \mathrm{m} \cdot \mathrm{s}}{\mathrm{s}^{2} \cdot \mathrm{m}^{5}}=\frac{\mathrm{kg}}{\mathrm{s} \cdot \mathrm{m}^{4}}=\frac{\mathrm{kg}}{\mathrm{s} \cdot\left(10^{3} \mathrm{~mm}\right)^{4}}=10^{-12} \frac{\mathrm{kg}}{\mathrm{s} \cdot \mathrm{mm}^{4}}} \\
{\left[L_{f}\right]=\frac{\mathrm{kg}}{\mathrm{m}^{4}}=\frac{\mathrm{kg}}{\left(10^{3} \mathrm{~mm}\right)^{4}}=10^{-12} \frac{\mathrm{kg}}{\mathrm{mm}^{4}} ;} \\
{\left[C_{f}\right]=\mathrm{m}^{3}=\left(10^{3} \mathrm{~mm}\right)^{3}=10^{9} \mathrm{~mm}^{3} .}
\end{gathered}
$$


Além dos fatores, foi necessário multiplicar o valor da vazão na expressão da fonte V2 por $1.10^{-9}$, para manter a coerência entre as unidades.

A resposta no domínio térmico à variação de vazão apresenta o comportamento mostrado na figura 60 . A resposta do circuito térmico é do tipo superamortecida e é bastante rápida, com um tempo de descida (ou de modo equivalente subida), definido como $t_{d}=t_{10 \% \phi_{\max }}-t_{90 \% \phi_{\max }}$, igual a $6,39 \mathrm{~ms}$.

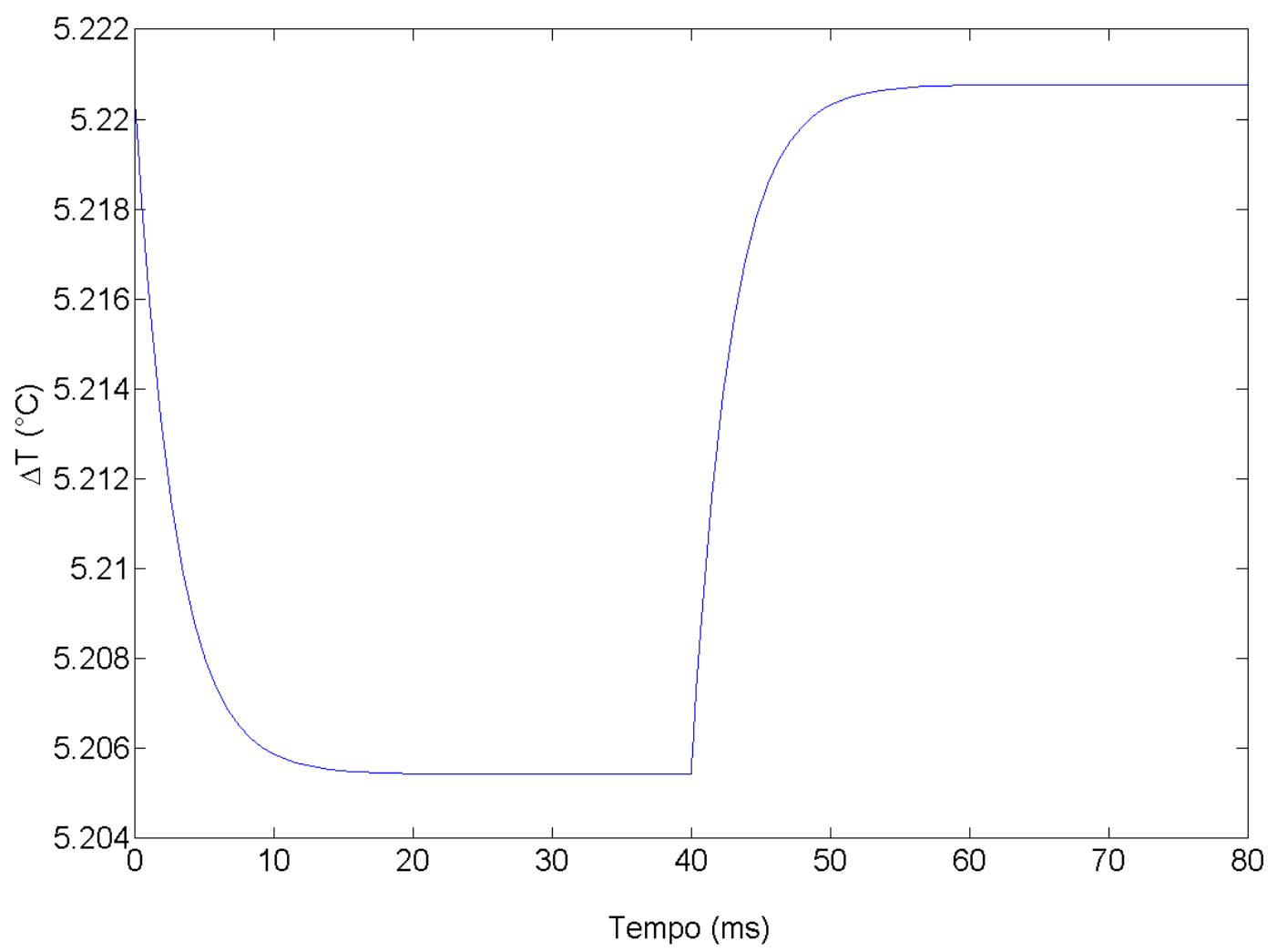

Figura 60 - Resposta temporal da diferença de temperatura $\Delta T$ à aplicação de um pulso de vazão para o sensor projetado.

A resposta no domínio elétrico, mostrada na figura 61, apresenta o mesmo comportamento superamortecido e tempo de subida praticamente idêntico ao do domínio térmico, com valor $6,17 \mathrm{~ms}$. 


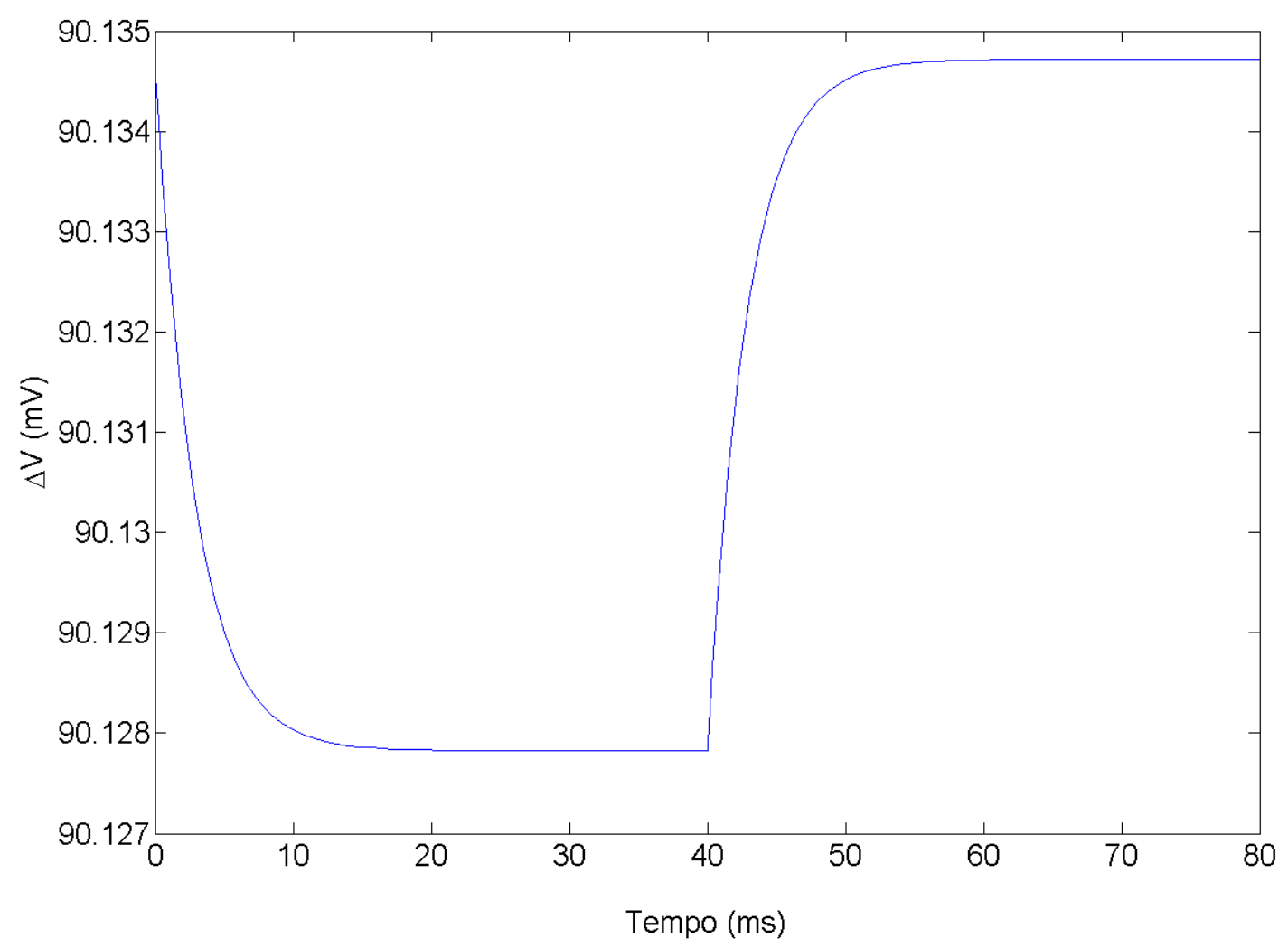

Figura 61 - Resposta temporal da diferença de tensão $\Delta V$ à aplicação de um pulso de vazão para o sensor projetado.

Uma observação com respeito aos gráficos deve ser feita. Dado que o pulso de vazão tem amplitude de $1 \mathrm{~nL} / \mathrm{min}$, era de se esperar que a variação de temperatura $\Delta T$ e a variação de tensão $\Delta V$ seguissem os valores de sensibilidade mostrados na tabela 25. Observa-se, no entanto, que as variações têm amplitude quase três vezes maior. Isso acontece porque os valores de sensibilidade expressos na tabela 25 foram obtidos a partir da linearização dos dados na faixa de vazão simulada e há, portanto, um erro associado a essa linearização.

Como forma de comparação, a resposta dinâmica do circuito de referência da seção 6.2.1 também foi levantada. O circuito utilizado para tanto está mostrado na figura 62. Assim como no caso anterior, foi necessário realizar um reescalonamento dos valores do domínio fluídico. 

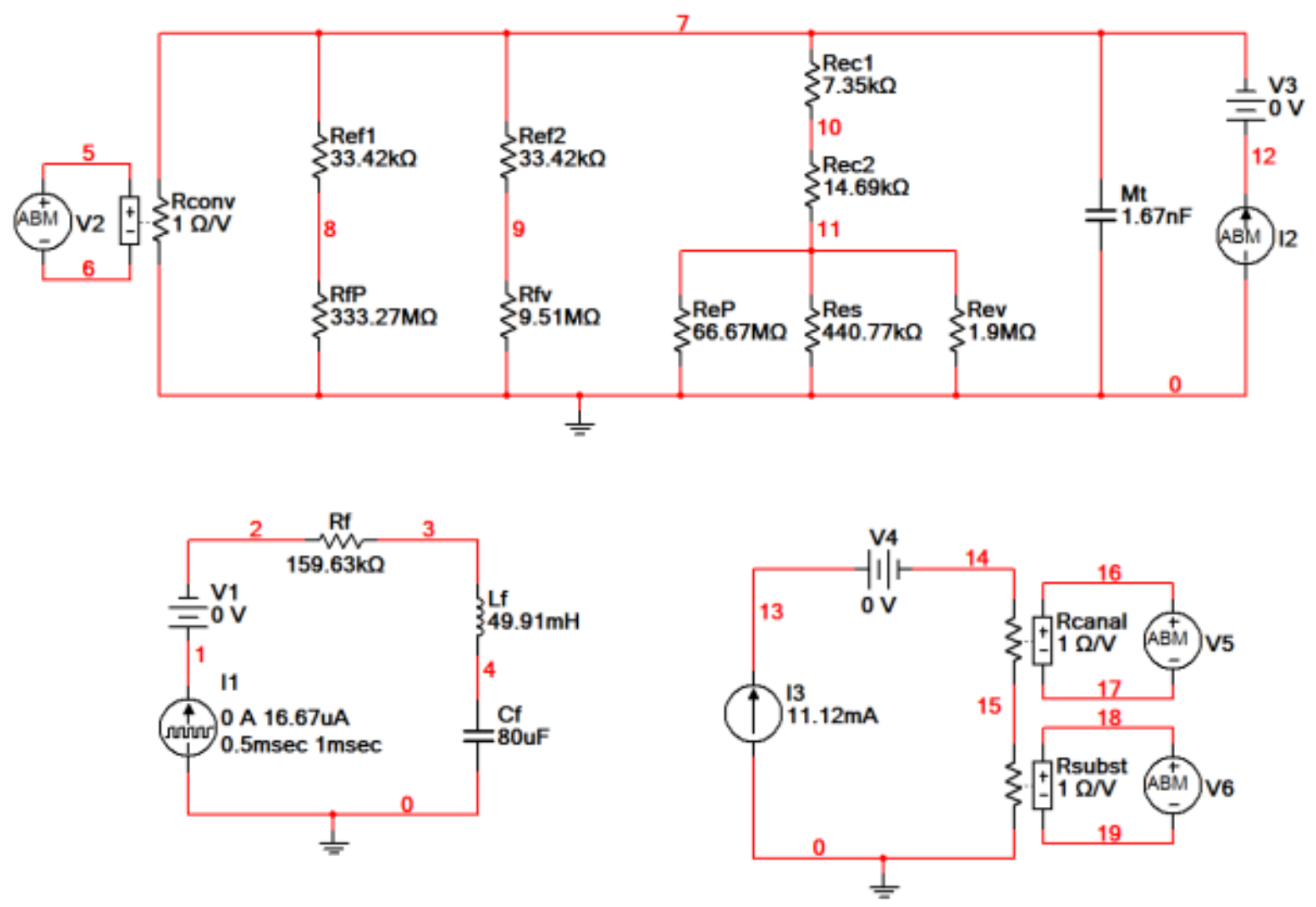

Figura 62 - Circuito equivalente utilizado para determinar a resposta dinâmica do sensor de referência.

Nesse caso, a duração da análise transiente foi diminuída para $1 \mathrm{~ms}$, bem como a duração do pulso de vazão, que passou a ser $0,5 \mathrm{~ms}$. A corrente de excitação foi mantida em 11,12 mA, o que equivale a valores de potência e densidade de potência dissipada iguais a $140 \mu \mathrm{W}$ e $1,4 \mathrm{~W} / \mathrm{mm}^{2}$, respectivamente.

A resposta temporal do domínio térmico é mostrada na figura 63. Novamente o comportamento é do tipo superamortecido mas o tempo de descida é drasticamente menor que aquele do sensor projetado, sendo igual a 27,34 $\mu \mathrm{s}$. 


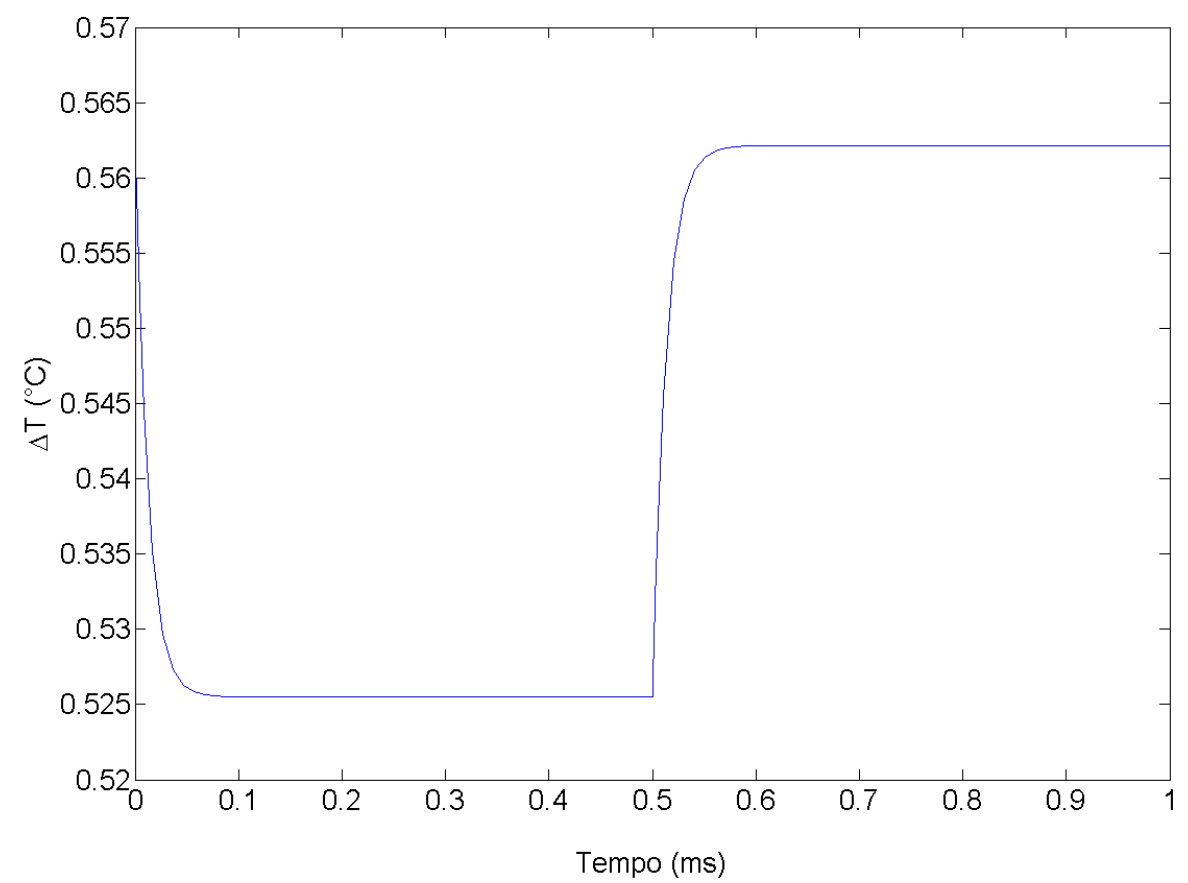

Figura 63 - Resposta temporal da diferença de temperatura $\Delta T$ à aplicação de um pulso de vazão para o sensor de referência.

A resposta no domínio elétrico, mostrada na figura 64, também apresenta comportamento superamortecido e tempo de descida muito próximo, igual à $29,51 \mu \mathrm{s}$.

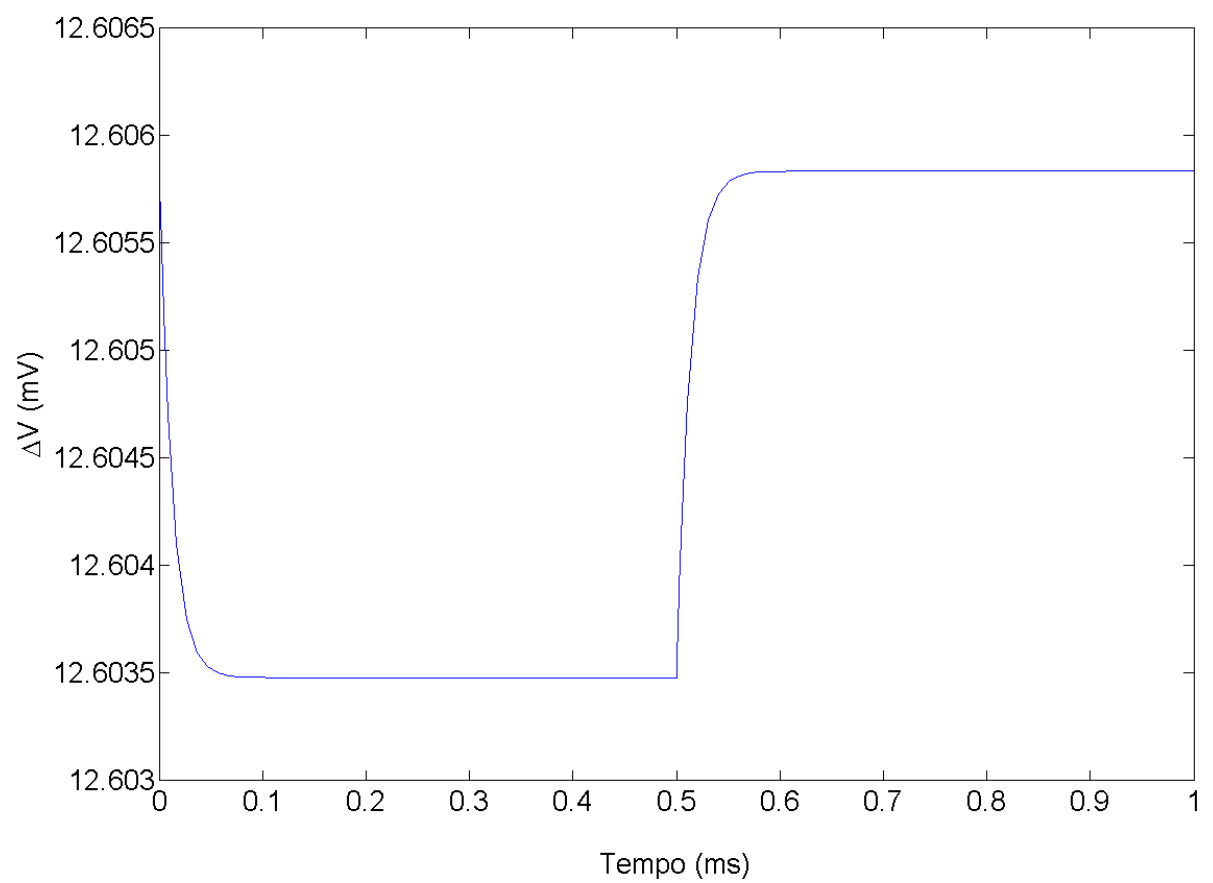

Figura 64 - Resposta temporal da diferença de tensão $\Delta V$ à aplicação de um pulso de vazão para o sensor de referência. 
Tamanha discrepância entre os tempos de resposta do sensor projetado e o de referência pode ser explicada pela velocidade com que o fluido escoa sobre o filamento. Por apresentar seção transversal muito menor, o fluido passa pelo filamento a uma velocidade maior no sensor de referência. Isso faz com que a troca de calor por convecção seja mais intensa e a resposta seja mais rápida.

\subsection{FABRICAÇÃO DOS DISPOSITIVOS}

Os três processos de fabricação alternativos propostos para otimizar a resposta do sensor de vazão foram testados. Apesar de terem se mostrado viáveis alguns problemas ainda precisam ser solucionados. Por conta disso, nenhum dispositivo passível de ser testado chegou a ser fabricado. Os resultados obtidos serão apresentados a seguir.

\subsubsection{Determinação da taxa de corrosão dos microcanais}

Para se ter um bom controle sobre a fabricação dos microcanais é fundamental conhecer alguns aspectos da corrosão do vidro Corning 7059, em especial a taxa de corrosão. Conhecendo essa taxa torna-se possível determinar por quanto tempo a lâmina deve ficar imersa na solução para se obter uma determinada espessura de microcanal ou ainda para que o filamento seja completamente liberado do substrato.

Alguns parâmetros como temperatura e agitação podem alterar a taxa de corrosão, reduzindo a reprodutibilidade do processo. Para evitar que isso aconteça, tentou-se manter os parâmetros inalterados em todos os processos. Para aumentar ainda mais o controle sobre essa etapa, a taxa de corrosão foi medida antes de cada sequência de corrosão, visto que a saturação da solução também afeta a taxa de corrosão. 
A corrosão em solução de $\mathrm{HF}, \mathrm{HCl}$ e $\mathrm{H}_{2} \mathrm{O}$ é do tipo isotrópica, portanto basta medir a taxa de corrosão em uma única direção. A direção escolhida foi a perpendicular ao substrato, visto que é muito fácil determinar qual a espessura de substrato que foi corroída.

Para realização dos testes, uma lâmina de $1 \times 1$ pol$^{2}$ de vidro Corning 7059 foi cortada em quatro partes. Cada parte teve metade de sua área recoberta com apiezon, de modo a proteger metade da lâmina da corrosão. As quatro partes foram levadas à solução e permaneceram imersas de um a quatro minutos. Após a corrosão, a camada de apiezon foi removida e a espessura de lâmina corroída foi determinada através da medida do degrau formado entre as partes corroída e não corroída da lâmina. Para realização das medidas foi empregado o perfilômetro Alpha Step 500. A figura 65 ilustra etapas de realização da medida.

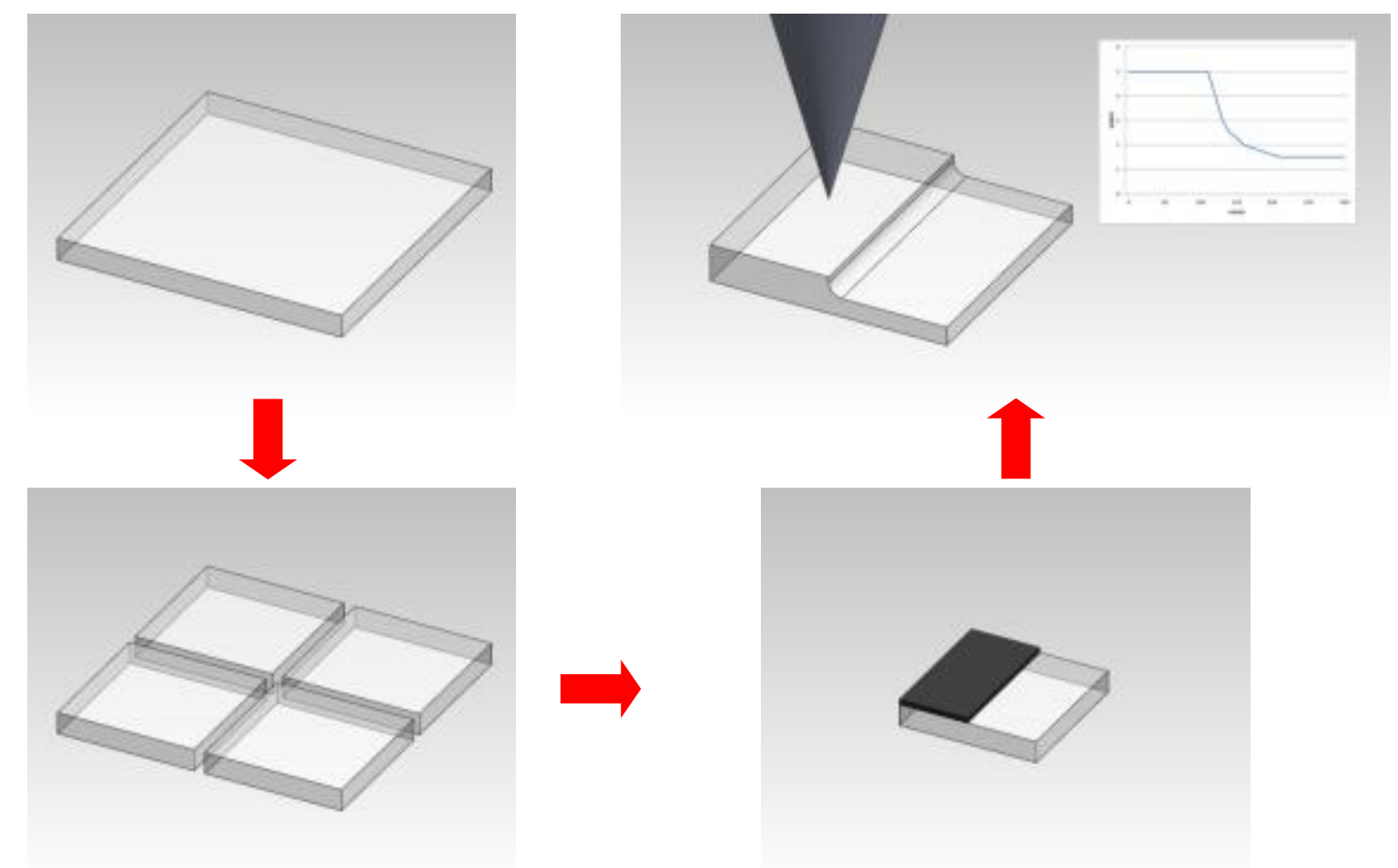

Figura 65 - Desenho esquemático mostrando o procedimento usado para determinar a taxa de corrosão do vidro Corning 7059 em solução de HF. 
O gráfico da figura 66 mostra os valores de espessura obtidos. Interpolando os dados através de uma reta, obtém-se que a taxa de corrosão é de $4,75 \mu \mathrm{m} / \mathrm{min}$. Esse valor foi utilizado como referência para os processos de corrosão, cujos resultados serão mostrados a seguir.

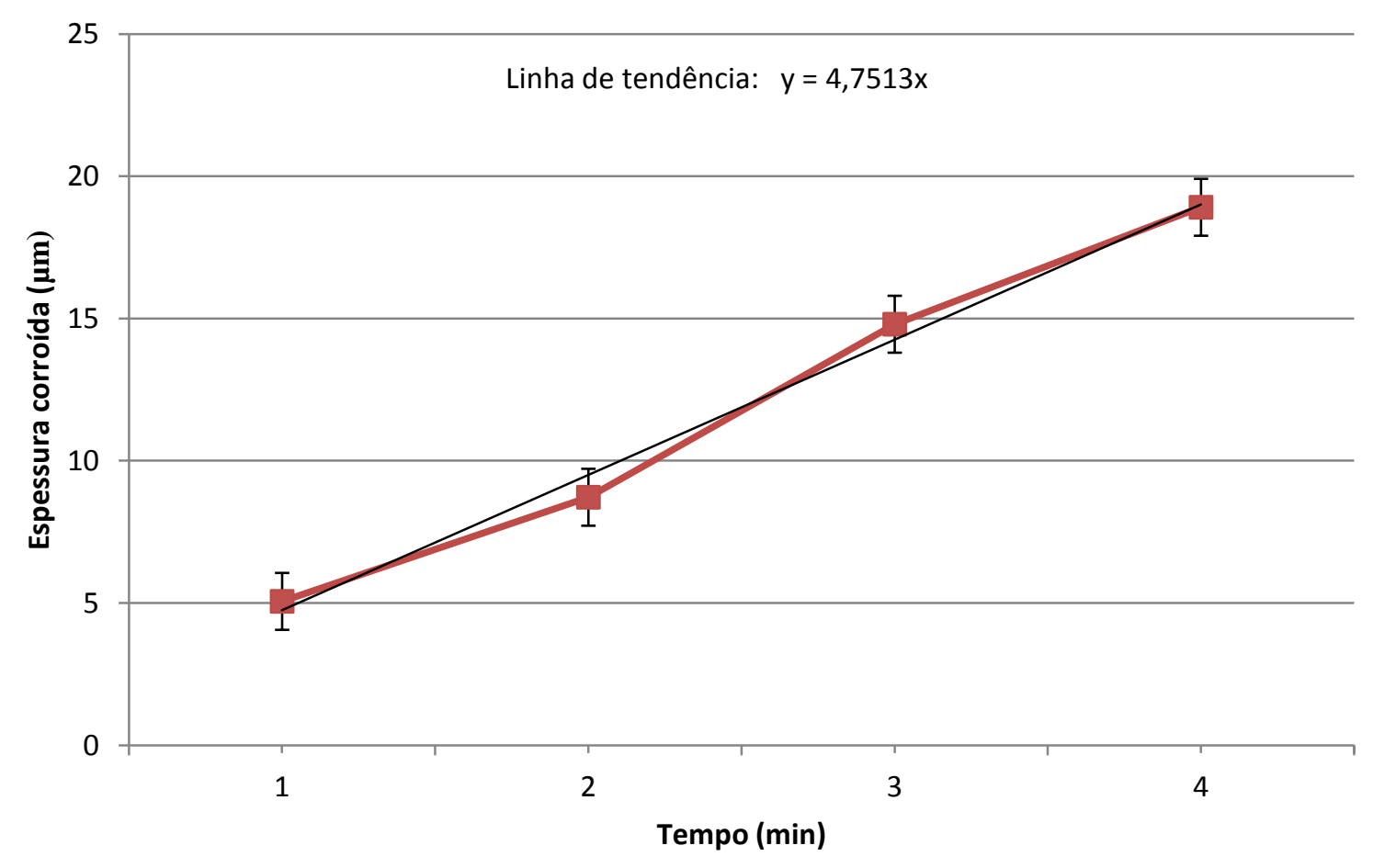

Figura 66 - Gráfico da espessura corroída em função do tempo para determinação da taxa de corrosão do vidro Corning 7059 em solução de HF.

\subsubsection{Resultados do método 1}

A figura 67 mostra fotos tiradas durante o processo de planarização do fotorresiste AZ-1518. A figura 67a mostra uma lâmina com os microcanais fabricados no substrato de vidro já preenchidos com fotorresiste. As figuras $67 \mathrm{~b}$ e $67 \mathrm{c}$ mostram o aspecto da lâmina após as etapas de lixamento manual em lixa d'água $n^{\circ} 1200 \mathrm{e}$ polimento fino sobre as pastas de polimento com grãos de 3 e $1 \mu \mathrm{m}$ de diâmetro, respectivamente. Antes de iniciar o polimento do fotorresiste, a lâmina é colada 
sobre um suporte metálico com auxílio de uma cola térmica próprio para preparo de lâminas para microscopia de tunelamento.

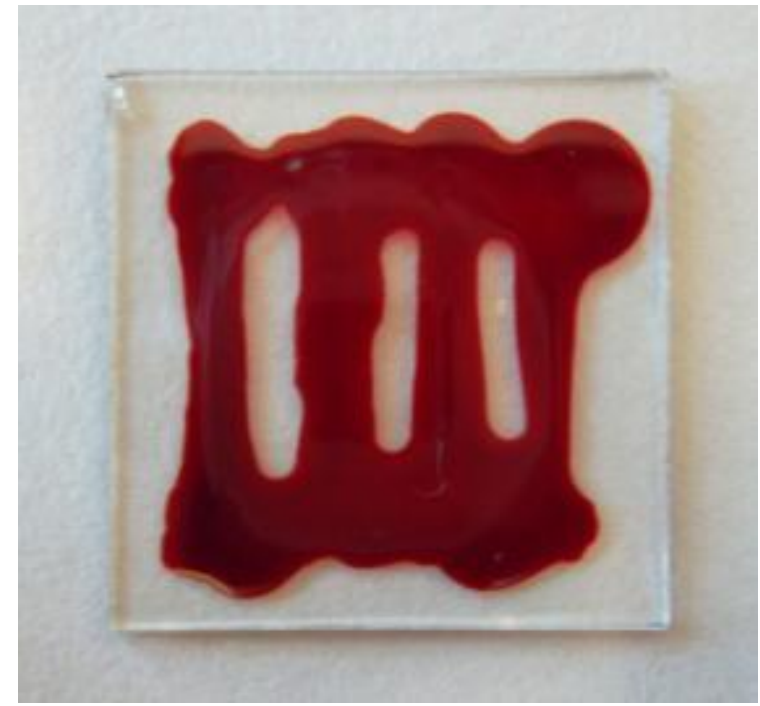

(a)

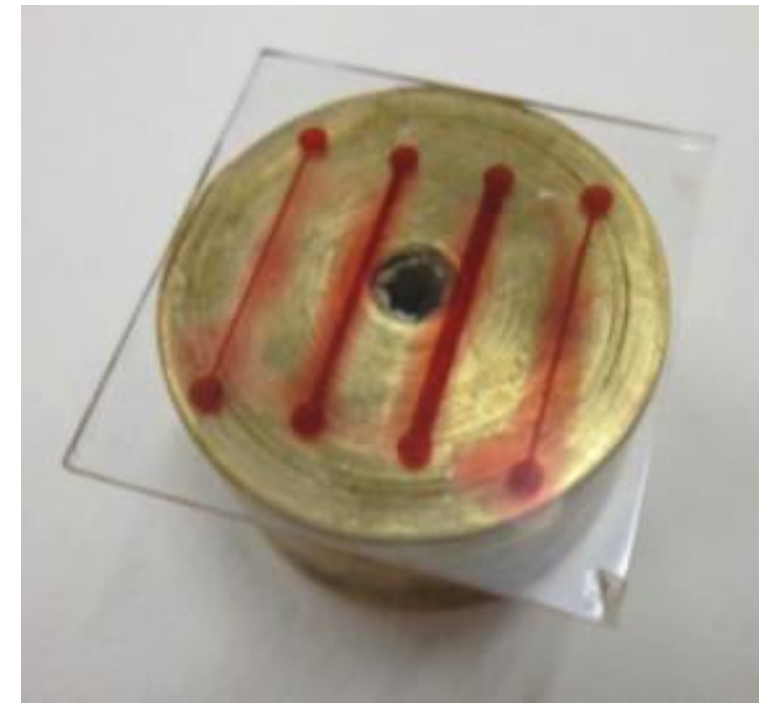

(b)

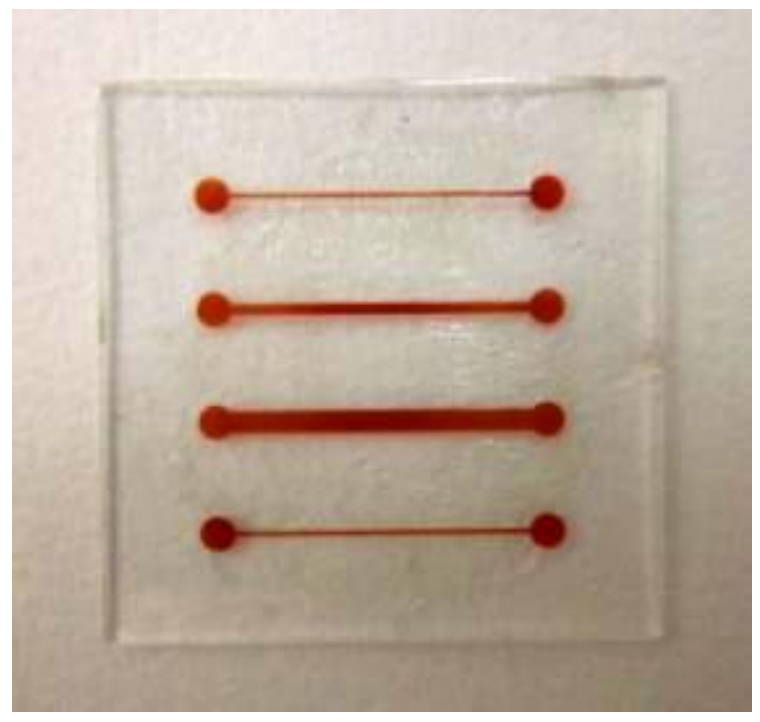

(c)

Figura 67 - Lâmina de vidro Corning 7059 com microcanais fabricados em diferentes pontos da etapa de planarização do fotorresiste. (a) Microcanais preenchidos com fotorresiste antes da planarização; (b) Aspecto da lâmina após o lixamento; (c) Aspecto da lâmina após polimento final.

A figura 67c mostra que a lâmina apresenta um bom acabamento superficial depois de concluída a etapa de polimento. A superfície do vidro não apresenta nenhuma rugosidade aparente enquanto que, mesmo não visível nas fotos, nota-se um aspecto levemente áspero no fotorresiste. 
A figura 68 mostra imagens de uma lâmina ao final do processo de fabricação, obtidas com o auxílio de um microscópio eletrônico de varredura. As figuras 68a e 68b mostram filamentos auto-sustentados sobre o microcanal de $500 \mu \mathrm{m}$ de largura. As figuras $68 \mathrm{c}$ e $68 \mathrm{~d}$ mostram uma estrutura em forma de serpentina.

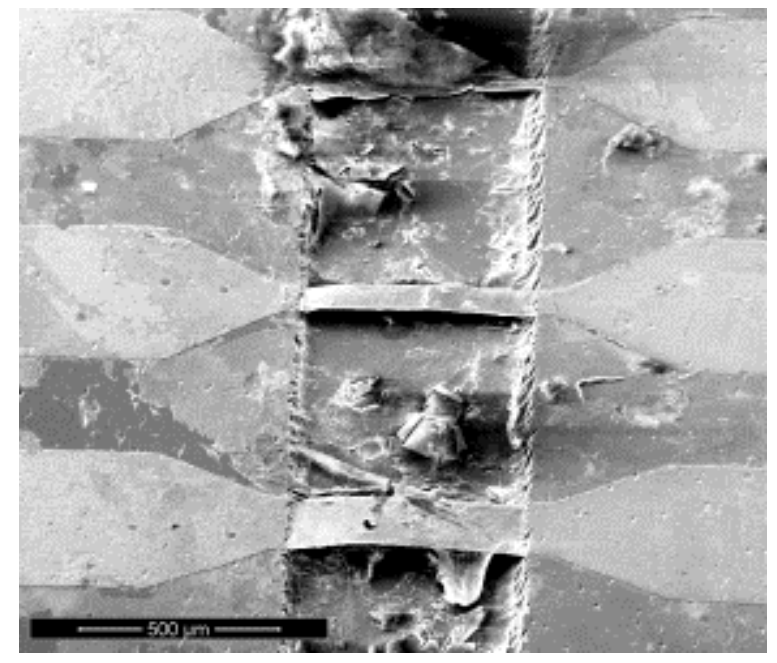

(a)

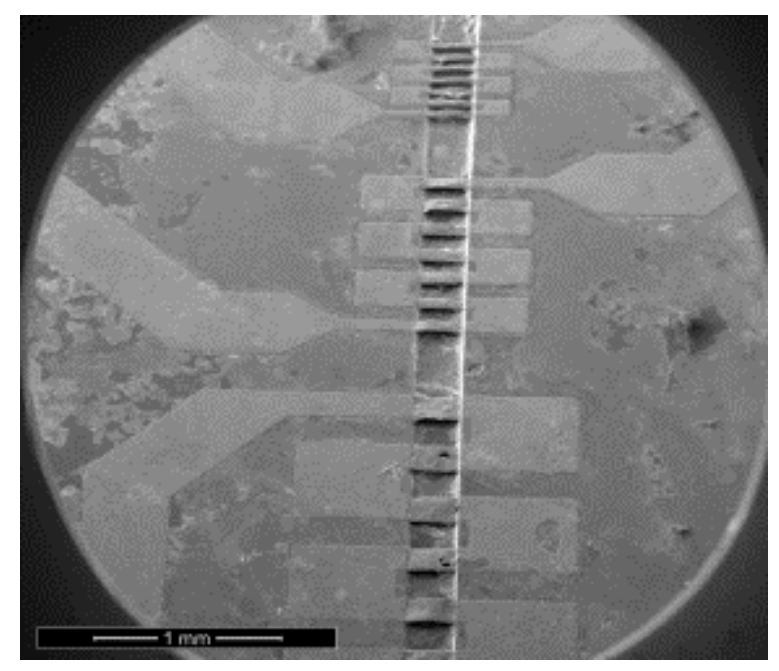

(c)

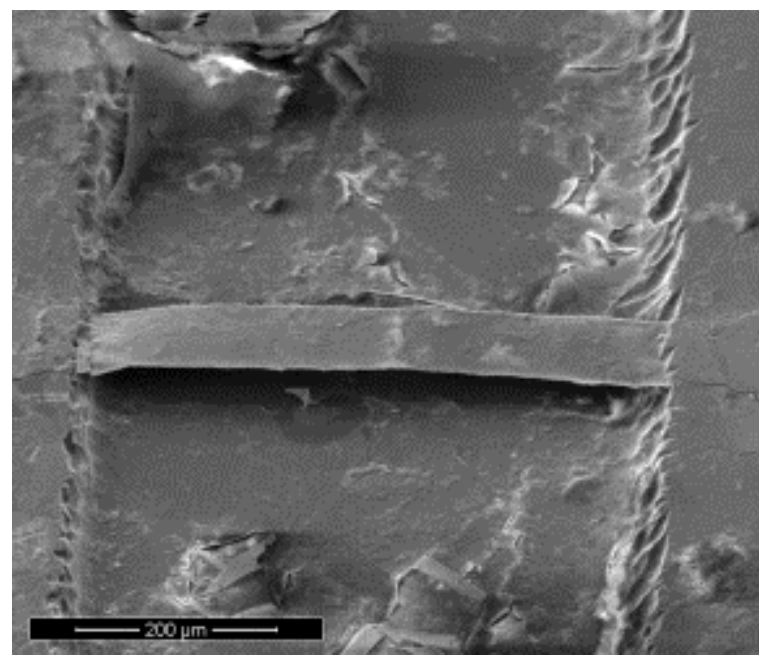

(b)

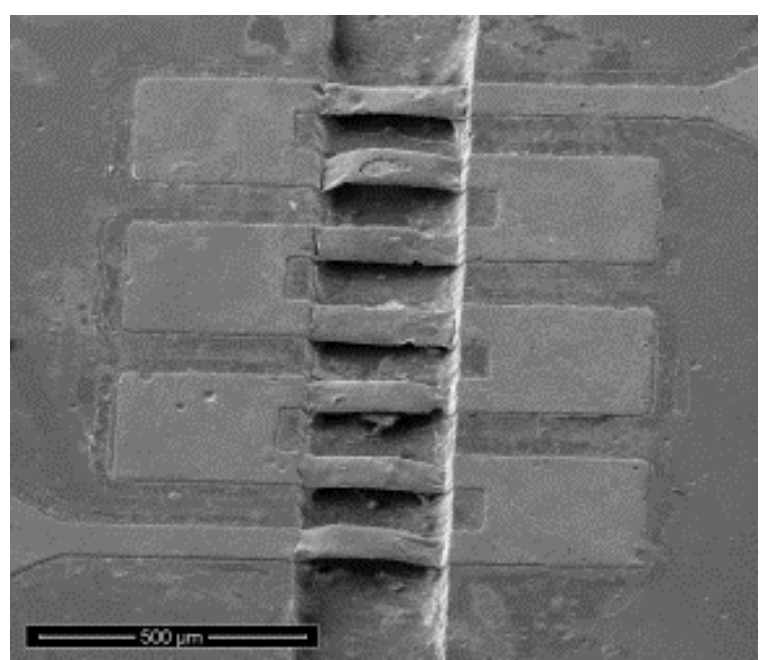

(d)

Figura 68 - Fotos dos filamentos tiradas com auxílio de um microscópio eletrônico de varredura. (a) Conjunto de filamentos sobre o microcanal de $500 \mu \mathrm{m}$; (b) Destaque do filamento de $100 \mu \mathrm{m}$ de largura; (c) Conjunto de filamentos com a forma de serpentina; (d) Destaque da estrutura de $100 \mu \mathrm{m}$ de largura. 
As fotos demonstram que é possível obter filamentos auto-sustentados através deste método de fabricação, inclusive estruturas com formato de serpentina. Isso prova que o filme de níquel apresenta baixo estresse mecânico residual, o que possibilita que ele fique suspenso sem o auxílio de outros materiais estruturais. Além disso, como os filamentos são fabricados sobre os microcanais já corroídos, não existe o problema de destruição dos filamentos na solução de $\mathrm{HF}, \mathrm{HCl}$ e $\mathrm{H}_{2} \mathrm{O}$.

As fotos mostram ainda que as etapas de deposição e fotogravação de filmes sobre o fotorresiste polido funcionaram bastante bem, produzindo filamentos com bom acabamento superficial. Apesar disso, alguns pontos da fabricação devem receber maior atenção. As figuras $68 \mathrm{a}$ e $68 \mathrm{~b}$ deixam claro que o fotorresiste não foi completamente removido do interior do microcanal. A provável causa para isso foi o pouco tempo que a amostra permaneceu imersa em acetona. Por se tratar do primeiro conjunto de dispositivos fabricados com essa abordagem, houve um excesso de cuidado na hora de remover o fotorresiste sem danificar os filamentos, o que acabou resultando na remoção incompleta do material do interior dos microcanais.

O excesso de zelo com os filamentos também fez com que os filmes de titânio e cobre que servem de camada de adesão para o níquel não fossem completamente removidos. Observam-se variações de tonalidade sobre a lâmina, principalmente na figura 68c, que indicam que esses filmes ainda estão presentes.

Devido à remoção incompleta das camadas metálicas de adesão, não foi possível verificar a continuidade elétrica dos filamentos através de medidas. Fotos obtidas com o microscópio eletrônico, mostradas na figura 69, indicam contudo que existe sim continuidade nos filmes. 


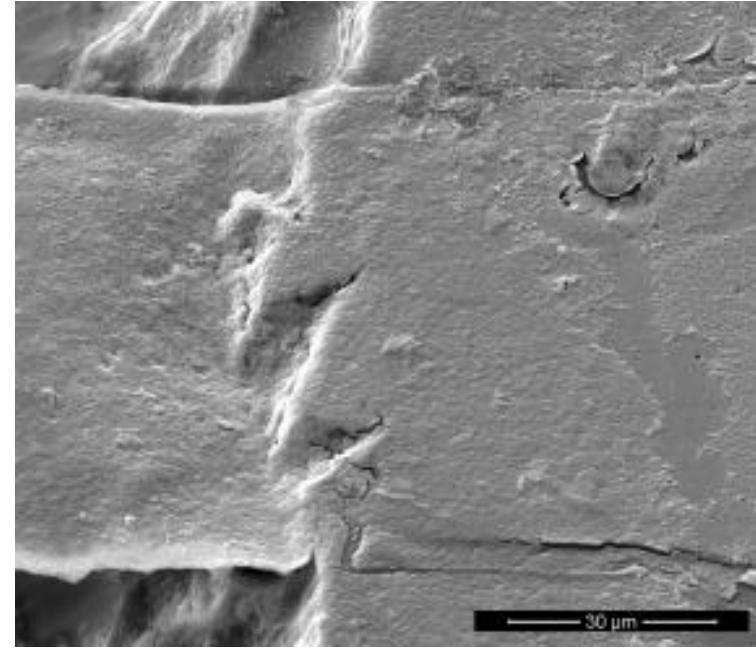

(a)

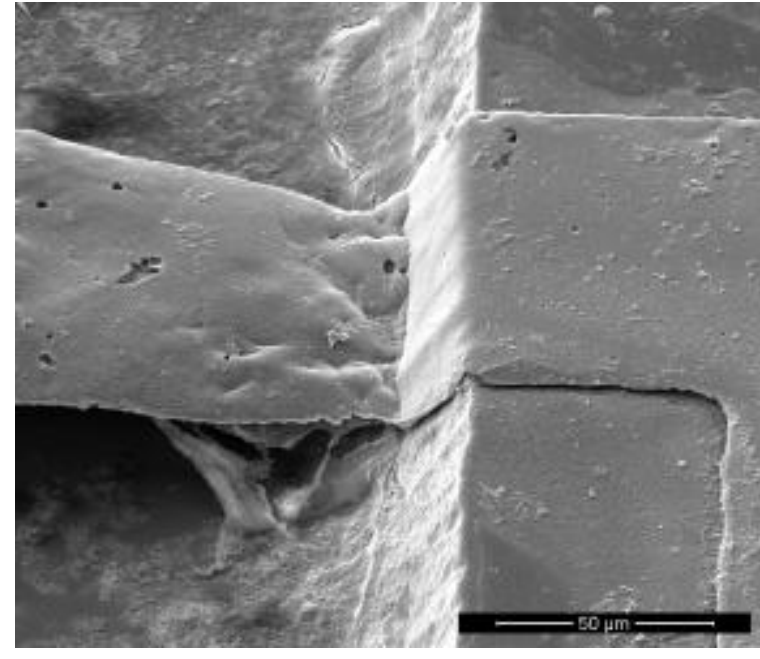

(b)

Figura 69 - Detalhe da borda do microcanal, mostrando a continuidade do filamento. (a) Microcanal com largura de $500 \mu \mathrm{m}$; (b) Microcanal de $200 \mu \mathrm{m}$ sob o filamento no formato de serpentina.

Tais imagens também dão uma ideia de qual é o aspecto do fotorresiste no interior do microcanal. A figura $69 \mathrm{~b}$ deixa claro que, em algumas regiões, o fotorresiste não estava exatamente nivelado com a superfície da lâmina de vidro. Desse modo, o filamento não estará localizado na metade da altura do microcanal quando esse for fechado com a tampa de PDMS, como supõem os modelos a elementos finitos e concentrados. Isso pode influenciar no funcionamento do sensor e indica que esta etapa do processo de fabricação deve ser melhor estudada.

O processo de fabricação foi repetido desde o início para outro conjunto de lâminas, tomando-se especial cuidado com as etapas de remoção das camadas de titânio e cobre e de remoção do material sacrificial para que os filmes fossem totalmente removidos. $\mathrm{O}$ aspecto geral das lâminas foi melhorado, como mostram os resultados da figura 70 . 


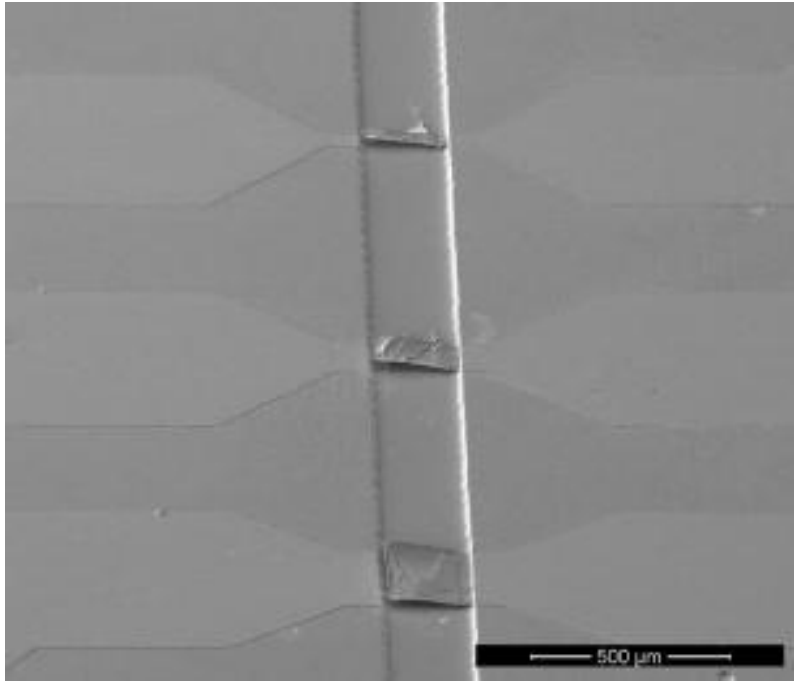

(a)

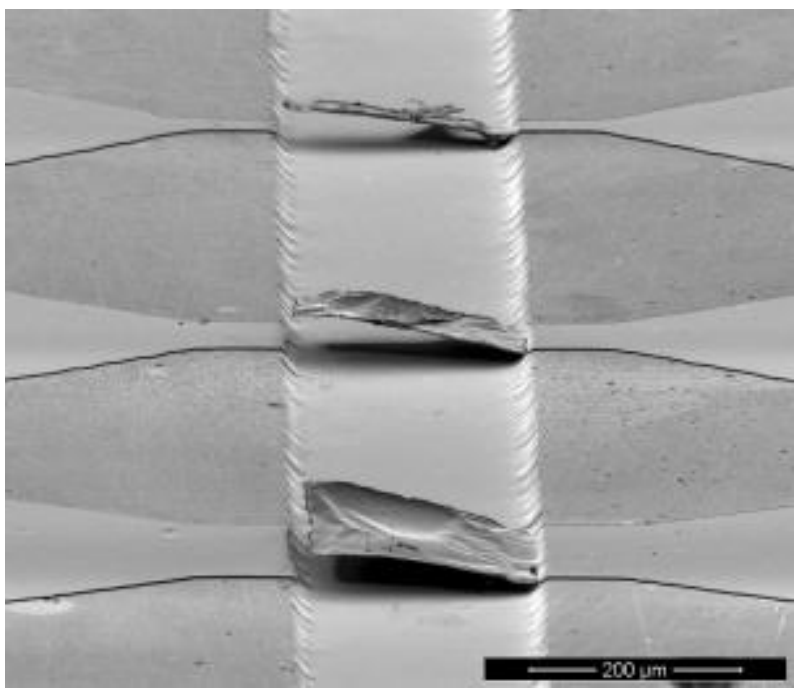

(c)

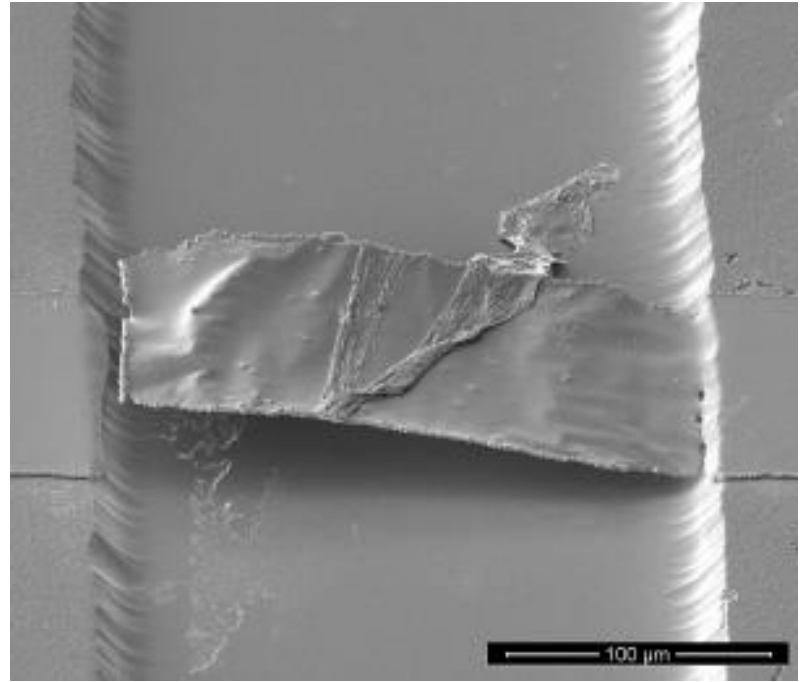

(b)

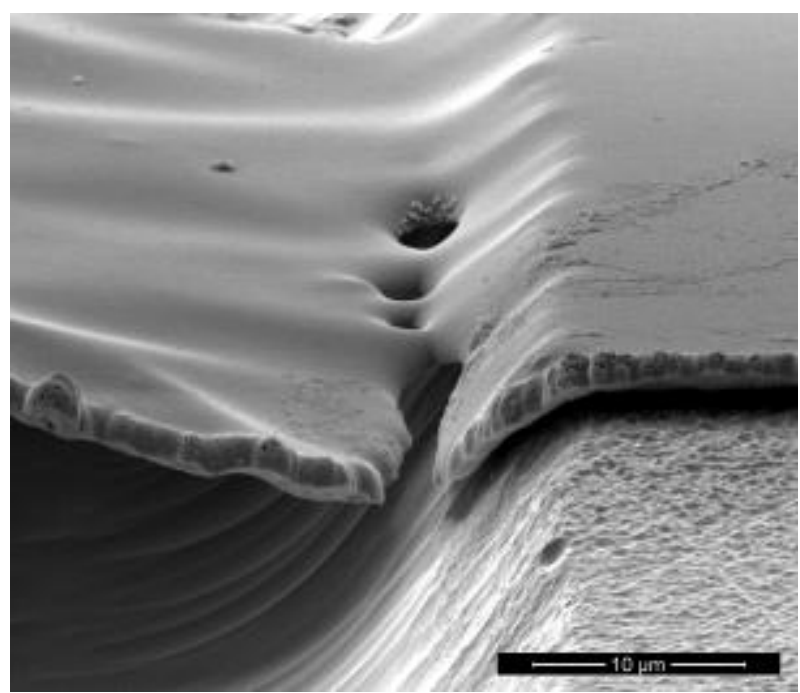

(d)

Figura 70 - Fotos dos filamentos sobre o microcanal de $200 \mu \mathrm{m}$ tiradas com auxílio de um microscópio eletrônico de varredura. (a) Visão geral do microcanal; (b) Destaque do filamento de 100 $\mu \mathrm{m}$ de largura; (c) Vista em perspectiva dos filamentos; (d) Detalhe do filamento de $200 \mu \mathrm{m}$ de largura na margem do microcanal.

Apesar das melhoras na limpeza, nota-se que não há continuidade elétrica nos filamentos já que todos eles estão presos apenas por uma extremidade do microcanal. Os filamentos se romperam exatamente na região próxima a borda do microcanal, a mesma região que, no conjunto de lâminas processadas anteriormente foi observada não estar nivelada com a superfície do vidro.

No segundo conjunto de lâminas processadas, o desnível entre o topo do fotorresiste e a superfície da lâmina de vidro na região das margens do microcanal 
foi ainda maior, tendo sido criada uma verdadeira depressão. Na maioria dos casos, dado o perfil relativamente suave dessa região, os filmes de titânio e cobre tiveram continuidade elétrica. No entanto, durante a etapa de fotogravação da geometria dos filamentos sobre o filme de cobre, houve acúmulo de fotorresiste nas margens do microcanal, como mostram as imagens da figura 71.

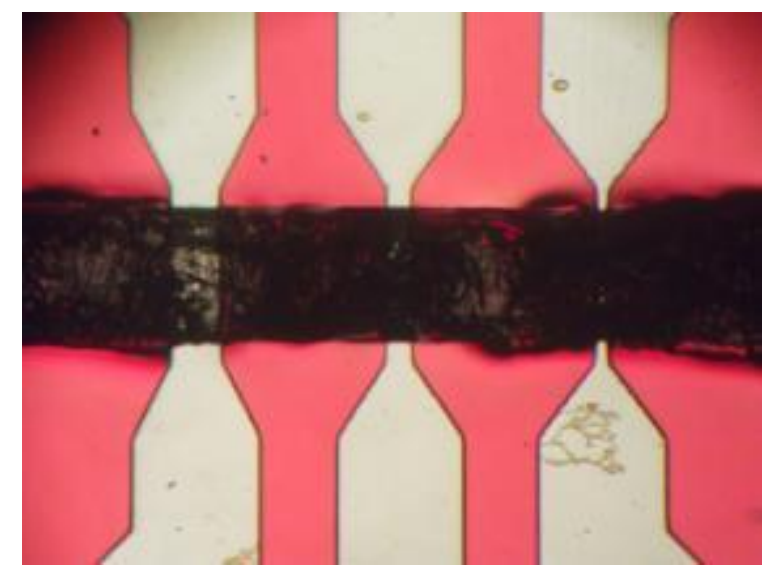

(a)

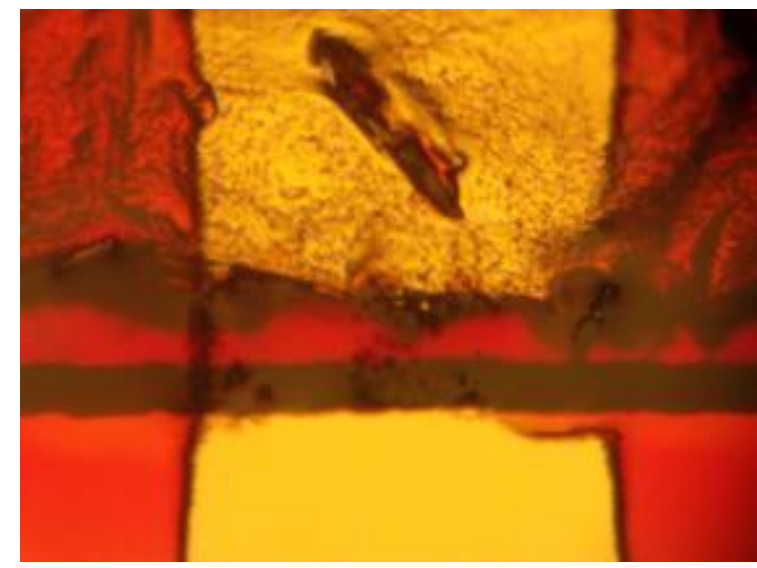

(b)

Figura 71 - Fotos dos filamentos sobre o microcanal de $500 \mu \mathrm{m}$ de largura após o crescimento do filme de níquel. (a) Visão geral; (b) Detalhe da margem do microcanal para o filamento de $100 \mu \mathrm{m}$ de largura.

Com isso, não foi possível crescer o filme de níquel nessas regiões, já que o filme de cobre que serve como semente estava encoberto pelo fotorresiste. Os filamentos ficaram então fragilizados na região das margens do microcanal, visto que os filmes de titânio e cobre são muito finos e não suportam tensões mecânicas, rompendo-se durante as etapas seguintes de corrosão e limpeza. Na realidade, na maioria das lâminas fabricadas, os filamentos se romperam em ambas as margens do microcanal e foram completamente removidos das lâminas.

Apesar de promissor esse método de fabricação ainda precisa ser otimizado. 


\subsubsection{Resultados do método 2}

A figura 72 mostra fotos de uma lâmina obtida segundo método de fabricação 2. Na foto, os microcanais aparecem em branco, o filme de SiC sobre o vidro apresenta cor alaranjada e os filamentos aparecem em tom escuro. As imagens das figuras 72b, 72c e 72d mostram detalhes dos filamentos fabricados sobre microcanais com largura de $200 \mu \mathrm{m}, 500 \mu \mathrm{m}$ e $1 \mathrm{~mm}$, respectivamente.

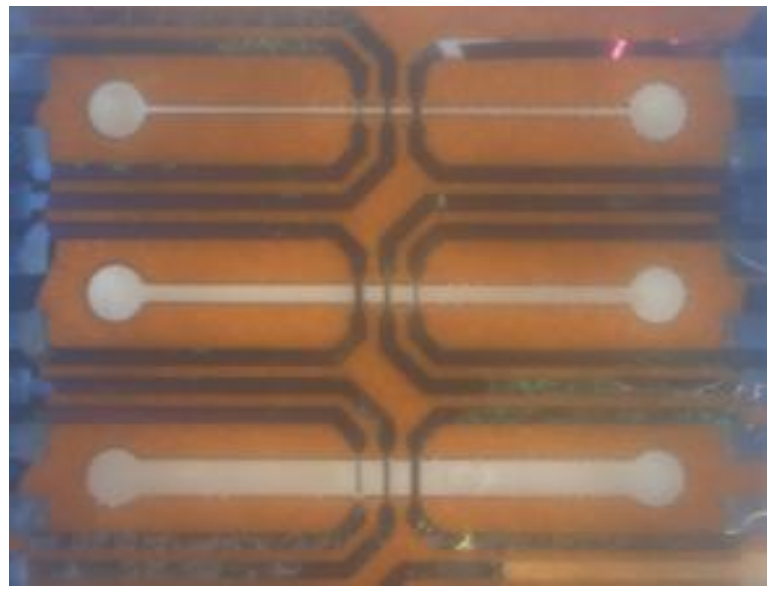

(a)

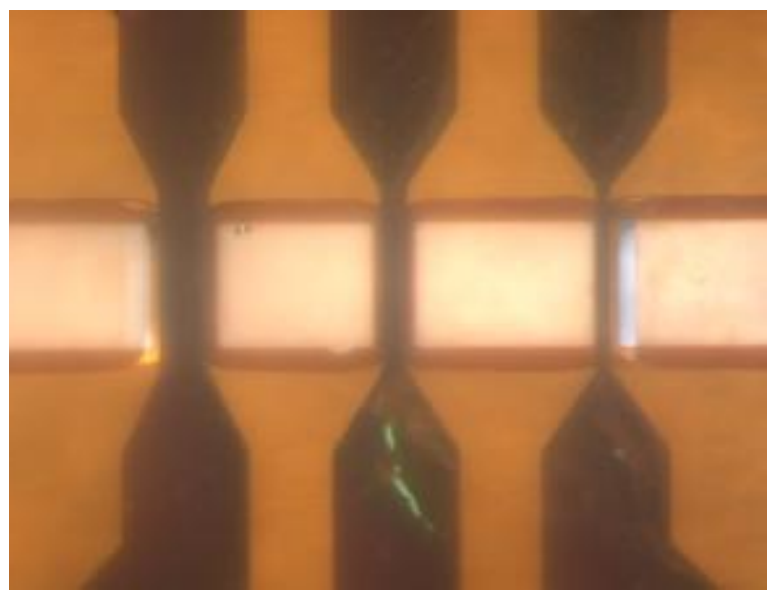

(c)

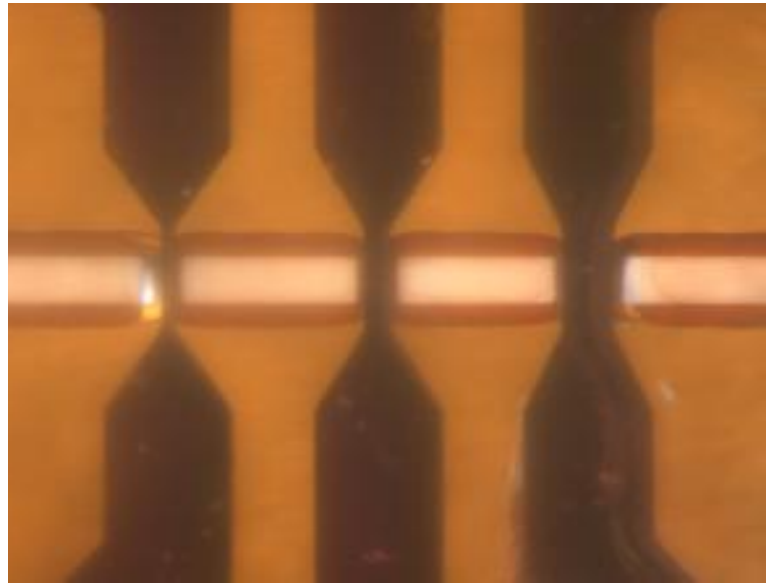

(b)

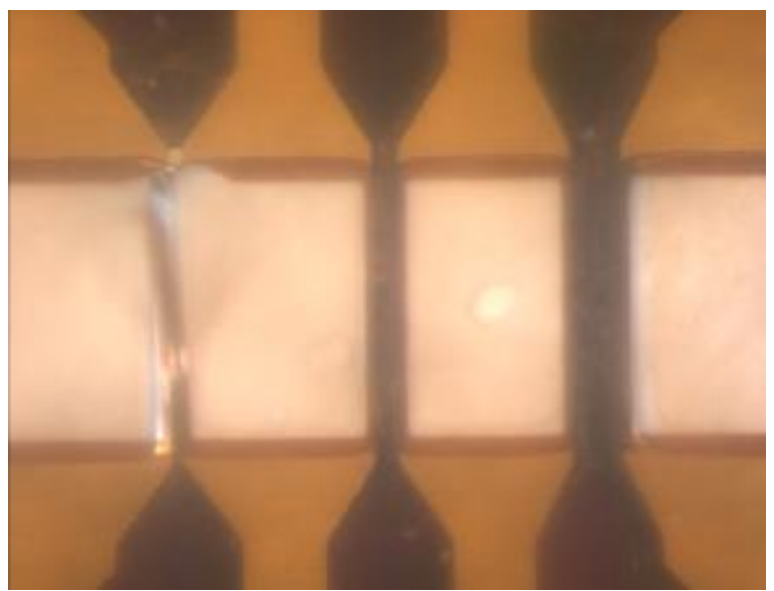

(d)

Figura 72 - Fotos de uma lâmina fabricada segundo o método 2 com tempo de corrosão de 15 minutos. (a) Visão geral das estruturas; Detalhes dos microcanais com largura de (b) $200 \mu \mathrm{m}$, (c) $500 \mu \mathrm{m}$ e (d) $1 \mathrm{~mm}$

A lâmina passou por uma etapa de corrosão de 15 minutos em solução de 1 HF : 2 $\mathrm{HCl}: 3 \mathrm{H}_{2} \mathrm{O}$. Considerando a taxa de corrosão apresentada no item 6.3.1, pode-se 
afirmar que a corrosão avançou por baixo dos filamentos, deixando aqueles com largura igual à 50 e $100 \mu \mathrm{m}$ completamente auto-sustentados.

As fotos mostram que os filamentos resistiram à etapa de corrosão e permaneceram suspensos por até $1 \mathrm{~mm}$, o que demonstra que os filmes apresentam baixo estresse mecânico. Apenas um dos filamentos se rompeu (figura $72 \mathrm{~d}$ ), mas o rompimento pode estar associado a algum incidente durante a manipulação da lâmina. Testes de condutividade elétrica foram efetuados e mostraram que há continuidade nos filmes, possibilitando que, em teoria, eles fossem caracterizados eletricamente.

É possível observar que as margens dos microcanais apresentam uma tonalidade diferente daquela do restante da lâmina (laranja escuro ao invés de laranja claro). Essa mudança de tonalidade se deve ao fato de os filmes de SiC também estarem suspensos nessas regiões, ou seja, a corrosão do microcanal avançou por baixo do filme de a-SiC:H das margens (under etch). Isso era esperado já que a corrosão é isotrópica. Medidas realizadas com auxílio do software ImageJ mostram que a corrosão avançou aproximadamente $80 \mu \mathrm{m}$ por baixo do filme de a-SiC:H das margens, o que é coerente com a taxa e o tempo de corrosão do processo.

A figura 73a mostra com mais detalhes e com outra iluminação filamentos de 50 e $100 \mu \mathrm{m}$ de largura auto-sustentados sobre o microcanal com $500 \mu \mathrm{m}$ de largura. Essa foto evidencia alguns aspectos negativos do processo de fabricação, que ainda precisam ser otimizados. É possível notar que as margens do microcanal que antes apareciam em cor laranja escuro apresentam nessa foto com outra iluminação uma alternância entre cores claras e escuras. Essa alternância de cores corresponde a ondulações nos filmes de a-SiC:H, também chamadas de "saias" ou "franjas". Uma representação de como seriam essas ondulações é mostrada na figura 73b. 


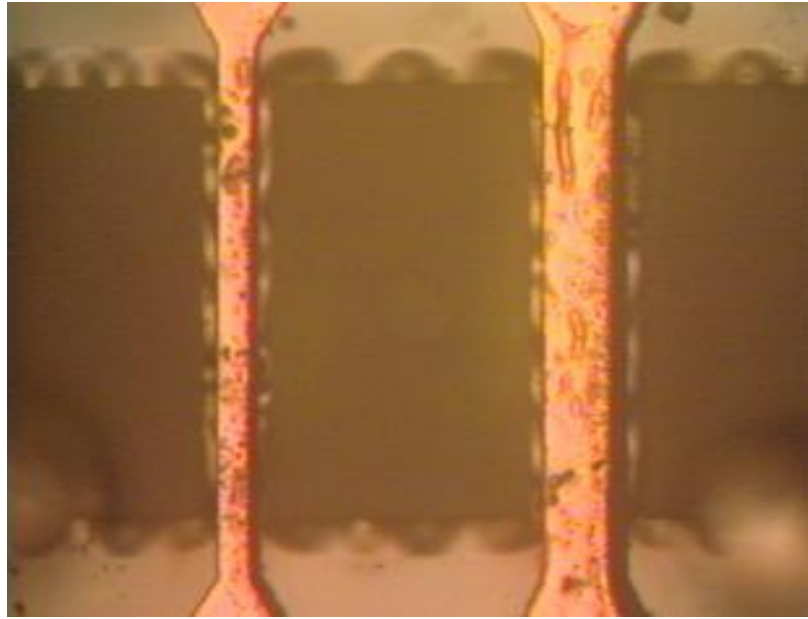

(a)

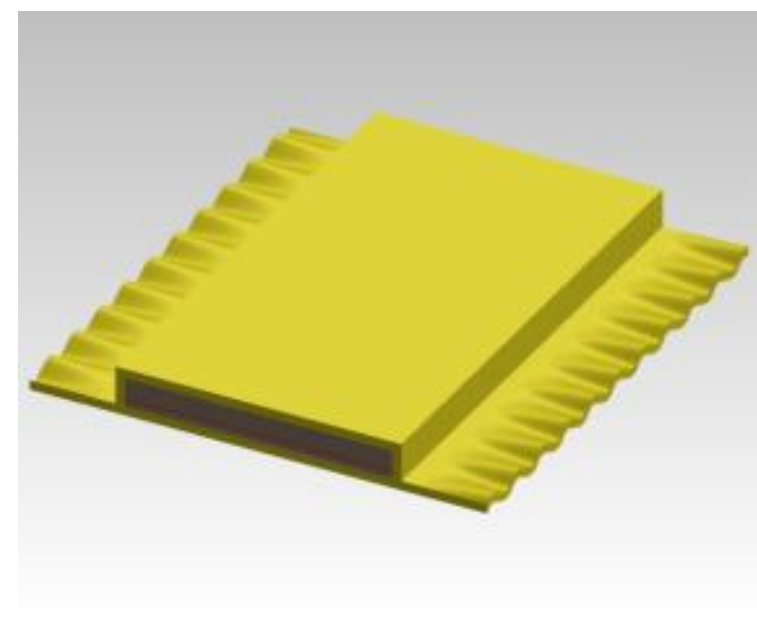

(b)

Figura 73 - (a) Foto da lâmina obtida segundo o método 2, destacando alguns pontos negativos do processo de fabricação; (b) Representação das ondulações nos filmes de SiC.

As ondulações estão associadas a tensões mecânicas residuais nos filmes de a-SiC:H e estão presentes inclusive no filme junto aos filamentos, como se observa na figura 73a. Até o momento não foi possível avaliar o impacto dessas ondulações no funcionamento do sensor, porém mesmo com elas os filamentos permanecem auto-sustentados. A formação dessas ondulações pode ser evitada realizando uma etapa de recozimento dos filmes de a-SiC:H para o alívio das tensões intrínsecas aos filmes.

Fotos obtidas posteriormente com auxílio de um microscópio eletrônico de varredura confirmaram todas as observações feitas a partir das imagens de microscópio óptico. Algumas dessas imagens estão mostradas na figura 74 . 


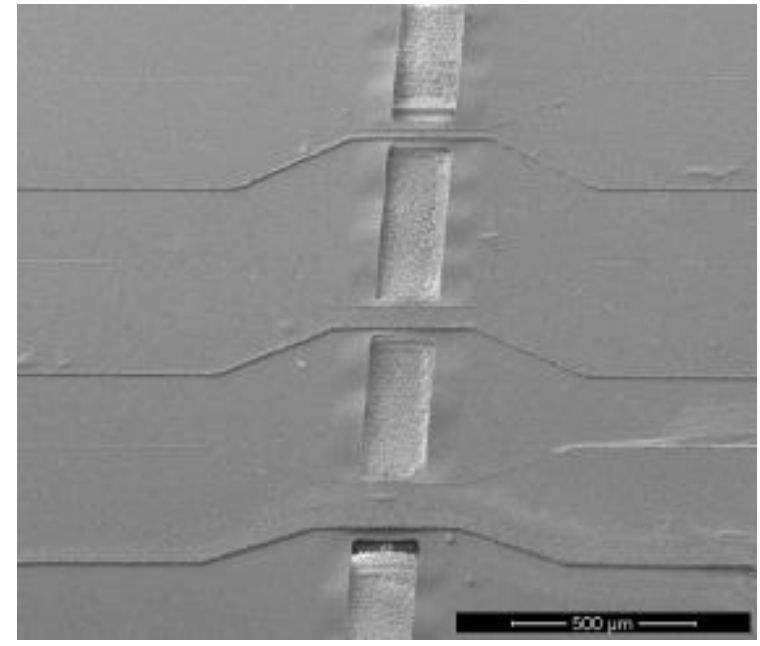

(a)

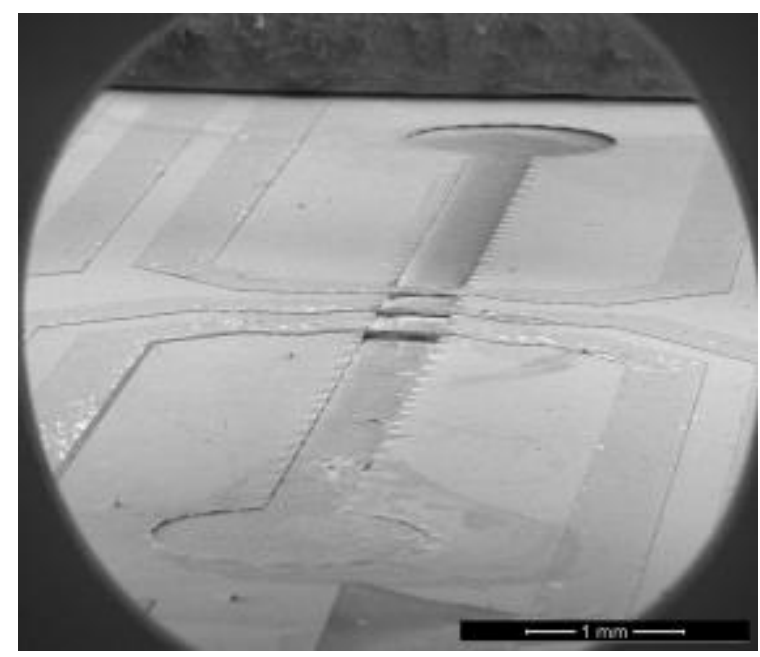

(c)

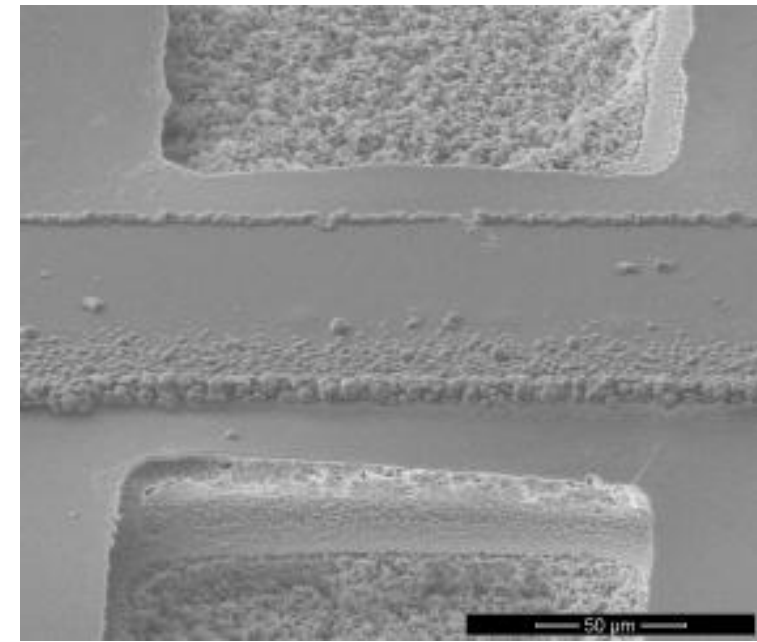

(b)

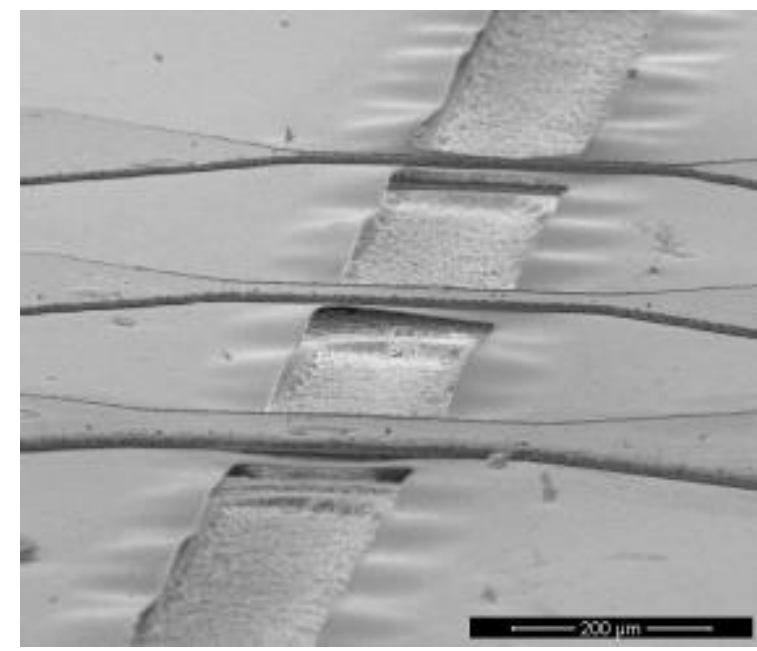

(d)

Figura 74 - Fotos dos filamentos fabricados sobre os microcanais de $200 \mu \mathrm{m}$ pelo método 2 tiradas com auxílio de um microscópio eletrônico de varredura. (a) Visão geral do microcanal; (b) Destaque do filamento de $100 \mu \mathrm{m}$ de largura; (c) Vista em perspectiva dos filamentos; (d) Detalhe dos filamentos vistos em perspectiva.

Outro aspecto a ser melhorado no processo é a etapa de eletrodeposição de níquel. O acabamento superficial do filme não é o esperado, apresentando rugosidade excessiva e pequenas cavidades. Além disso, observou-se por meio de medidas com perfilômetro que a espessura do filme é bastante desuniforme ao longo da lâmina. Assim, parâmetros como agitação da solução e corrente de polarização precisam ser melhor ajustados para otimizar a deposição.

A aderência do segundo filme de a-SiC:H sobre níquel também é um aspecto a ser revisto. A figura 75 mostra fotos, tiradas com auxílio de microscópio óptico e microscópio eletrônico de varredura, de outra lâmina obtida através deste método de 
fabricação. No caso dessa lâmina, a corrosão dos microcanais teve duração apenas de 3 minutos. Esse tempo foi suficiente para provocar a remoção de boa parte do segundo filme de a-SiC:H, embora não tenha sido possível liberar os filamentos. Nas fotos, os microcanais aparecem em tons claros, os filmes de a-SiC:H sobre o substrato de vidro aparecem em amarelo, os filamentos de níquel expostos aparecem em cinza e os filamentos cobertos com a segunda camada de a-SiC:H aparecem em tons escuros. Além dos microcanais, algumas regiões que corresponderiam aos filamentos também aparecem em tons claros. Essas são regiões onde todo o filme de níquel foi removido, restando somente a primeira camada de a-SiC:H.

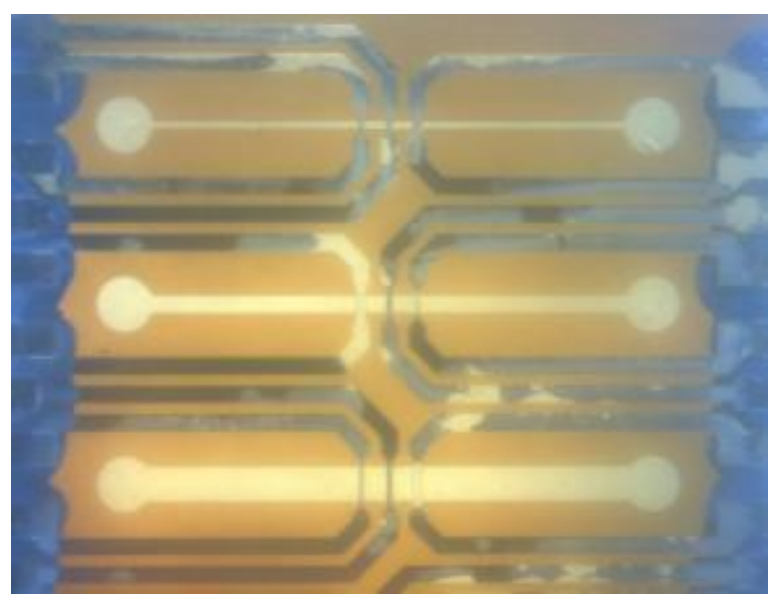

(a)

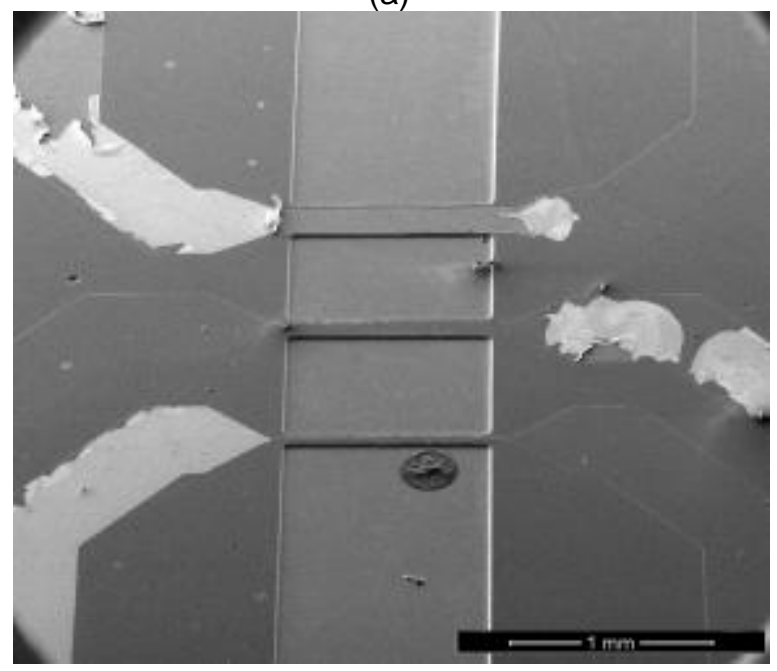

(c)

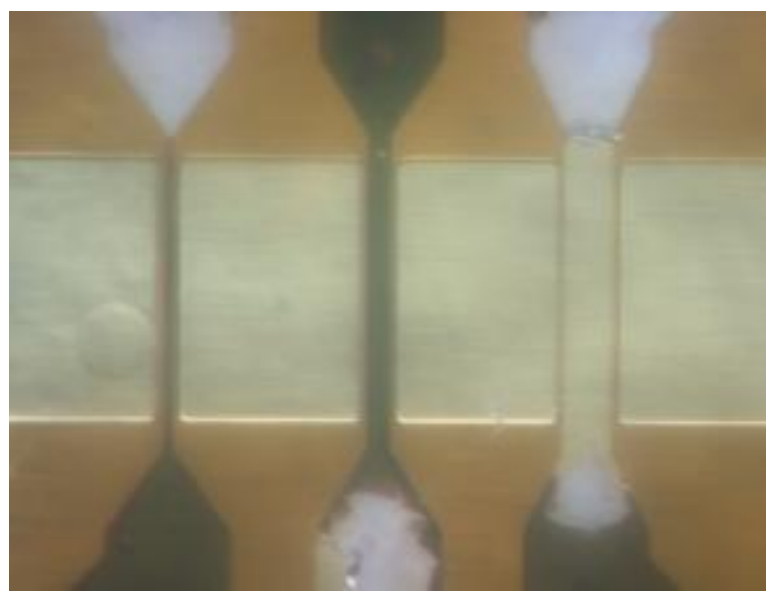

(b)

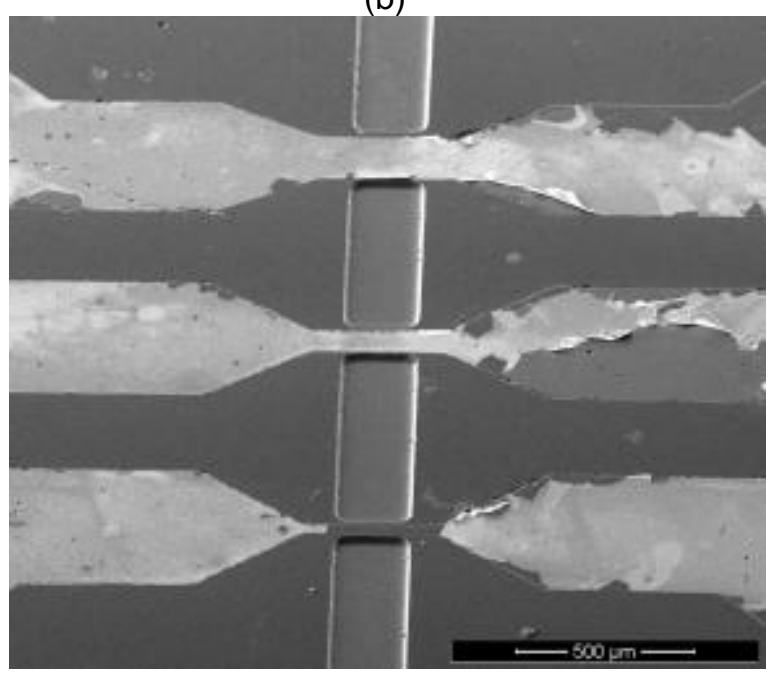

(d)

Figura 75 - Fotos obtidas por microscópio óptico e eletrônico de varredura de uma lâmina fabricada segundo o método 2 com tempo de corrosão de 3 minutos. (a) Visão geral das estruturas; Detalhe do microcanal com largura de $500 \mu \mathrm{m}$ visto (b) no microscópio óptico e (c) no MEV; (d) Detalhe do microcanal de $200 \mu \mathrm{m}$ de largura. 
As imagens deixam evidente que a proteção dos filamentos não resistiu ao processo de corrosão e foi removida. Com isso, os filmes metálicos que compõem o filamento (as camadas de aderência de titânio e cobre e o filme de níquel) ficaram expostos à solução de $\mathrm{HF}, \mathrm{HCl}$ e $\mathrm{H}_{2} \mathrm{O}$ e em algumas regiões foram completamente removidos.

A figura $75 \mathrm{~b}$ mostra com mais detalhes os filamentos sobre o microcanal de $500 \mu \mathrm{m}$ de largura. É evidente o contraste entre as três situações: regiões em tons escuros mostrando que a segunda camada de a-SiC:H está presente; regiões em cinza onde o filme de a-SiC:H se desprendeu da lâmina e expos o filme de níquel; e regiões em branco que indicam que o filamento foi completamente removido restando apenas o primeiro filme de a-SiC:H.

Os motivos para o desprendimento do filme de a-SiC:H ainda precisam ser investigados, porém existe a hipótese de que a desuniformidade na espessura do filme de níquel tenha atrapalhado a cobertura de degrau da camada de a-SiC:H. A espessura do filme de a-SiC:H a ser depositado foi determinada a partir da espessura esperada de níquel. Uma vez que a espessura do filme de níquel sofre grande variação ao longo da lâmina, é de se esperar que o filme de a-SiC:H não apresente a cobertura esperada, como esquematizado na figura 76. Nesse caso a película de a-SiC:H sobre os filamentos pode ser facilmente removida.

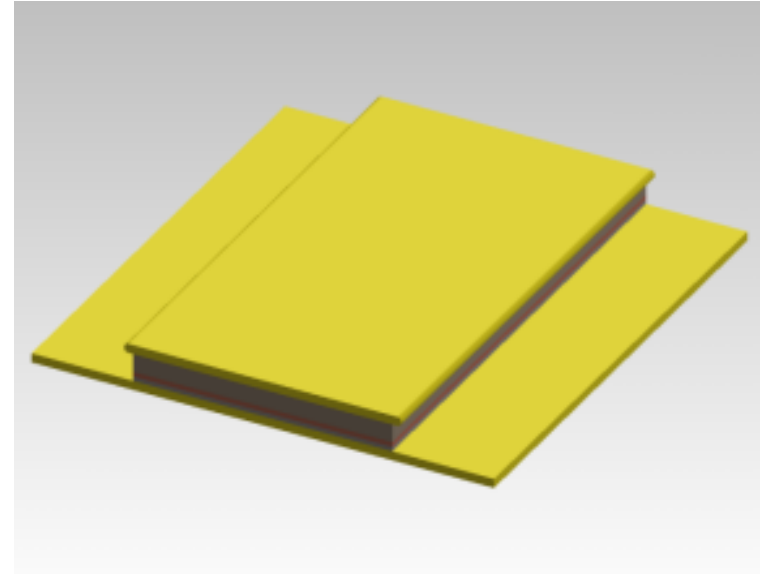

(a)

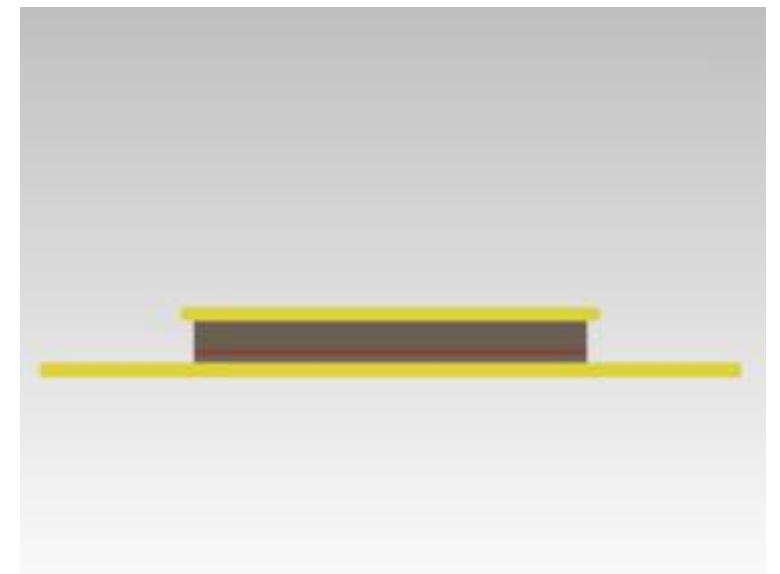

(b)

Figura 76 - Representação esquemática do possível problema de cobertura de degrau do filme de a-SiC:H. (a) Vista em perspectiva; (b) Vista frontal. 
Outra hipótese é a de que haja diferença significativa entre os coeficientes de expansão térmica dos materiais que compõem o filamento (essencialmente níquel) e do a-SiC:H. Visto que a deposição dos filmes de a-SiC:H é feita a temperatura de $320^{\circ} \mathrm{C}$, a segunda camada de a-SiC:H seria depositada sobre o filamento quente e portanto expandido. Terminado o processo de deposição, o filamento retrairia para seu comprimento original e induziria, assim, tensões mecânicas no filme de a-SiC:H que acabou de ser depositado. Neste caso, a solução seria empregar um filme intermediário (buffer) entre o níquel e o a-SiC:H que se encarregasse de minimizar os efeitos da diferença de expansão térmica dos dois materiais.

Uma terceira hipótese é a de que o filme de a-SiC:H não apresenta boa aderência sobre o filme de níquel, fato que provavelmente comprometeria essa abordagem de fabricação.

As fotos da figura 77 mostram os filamentos fabricados em forma de serpentina. A figura 77a mostra as estruturas da lâmina apresentada anteriormente na figura 72 e a figura 77b mostra aquelas da lâmina mostrada na figura 75 .

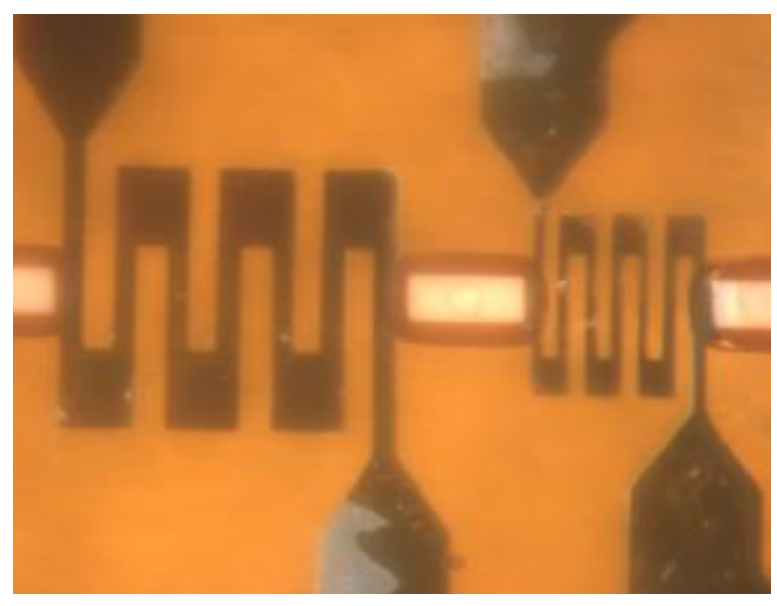

(a)

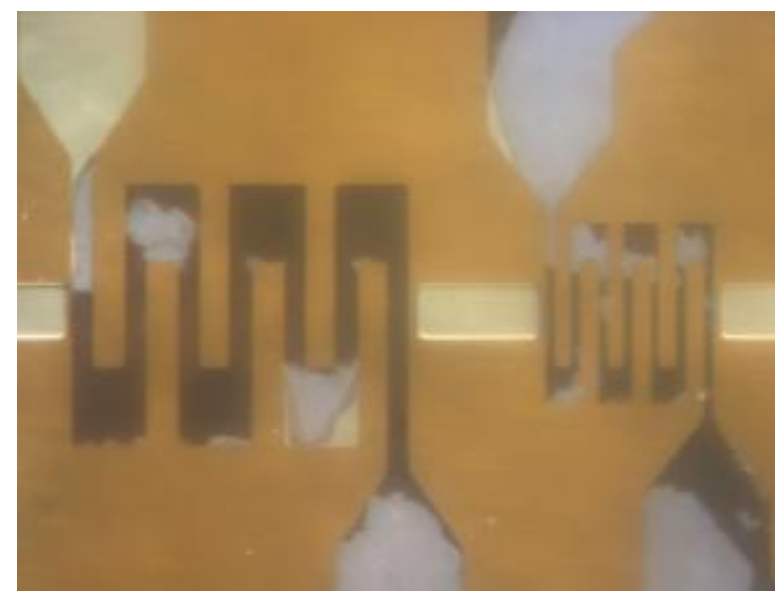

(b)

Figura 77 - Fotos das estruturas em formato de serpentina fabricadas segundo o método 2.

(a) Lâmina da figura 72; (b) Lâmina da figura 75.

Observa-se que o tempo de corrosão não foi suficiente para liberar os filamentos. $\mathrm{Na}$ realidade, da forma como foi feita a fotomáscara de cromo para corrosão dos filmes de a-SiC:H (ver figura 45 do item 5.3.2, página 121) a corrosão dos microcanais deverá se estender por horas até que o filamento seja completamente liberado. Isso 
porque a corrosão avança exclusivamente pelas duas laterais do filamento. Portanto, a fotomáscara deve ser refeita, incluindo aberturas entre os filamentos que compõem a serpentina, para facilitar a entrada de solução e a liberação das estruturas.

\subsubsection{Resultados do método 3}

As fotos da figura 78 mostram uma lâmina contendo o filme de a-SiC:H em dois momentos do processo de fabricação: após a implantação iônica (figura 78a) e após a corrosão dos microcanais (figura 78b).

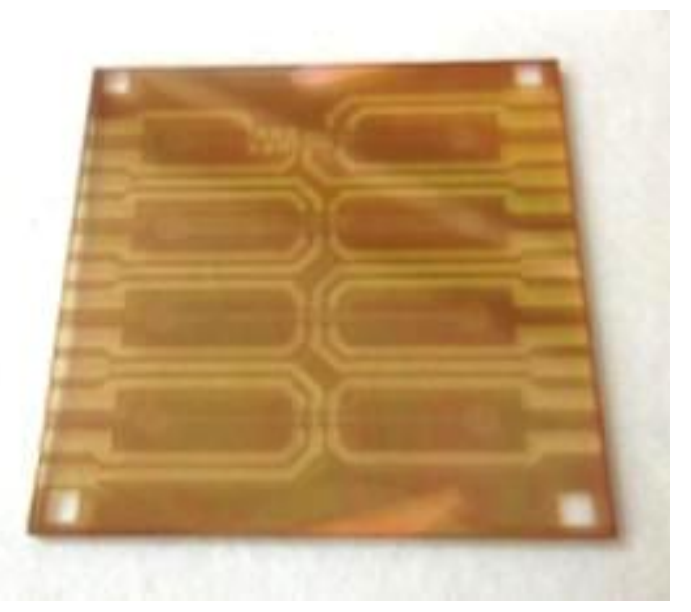

(a)

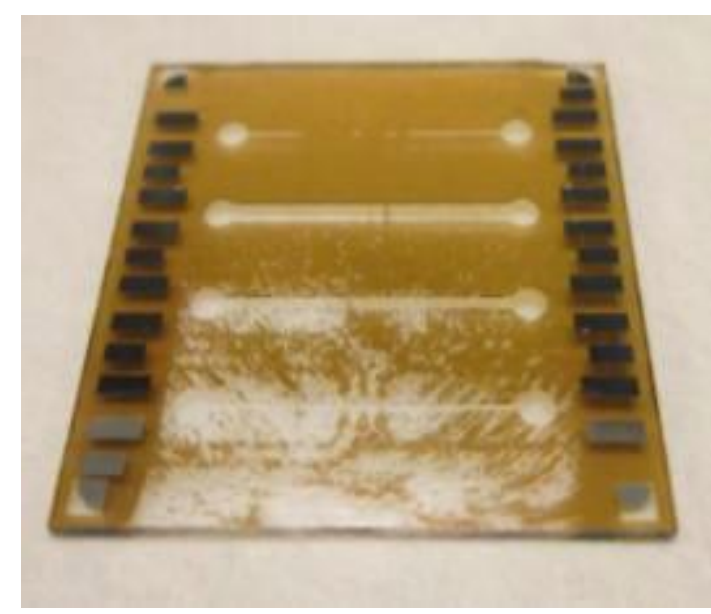

(b)

Figura 78 - Fotos de uma lâmina fabricada seguindo o método 3 após duas etapas distintas do processo de fabricação: (a) implantação iônica e (b) corrosão em solução de HF para formação dos microcanais.

As etapas de implantação iônica e deposição do filme de alumínio para os contatos elétricos tiveram bons resultados, contudo a corrosão dos microcanais destruiu significativamente o filme de a-SiC:H. As imagens da figura 79 mostram em mais detalhes a região dos filamentos, sendo as regiões em tons alaranjados as regiões cobertas com o filme de a-SiC:H. 


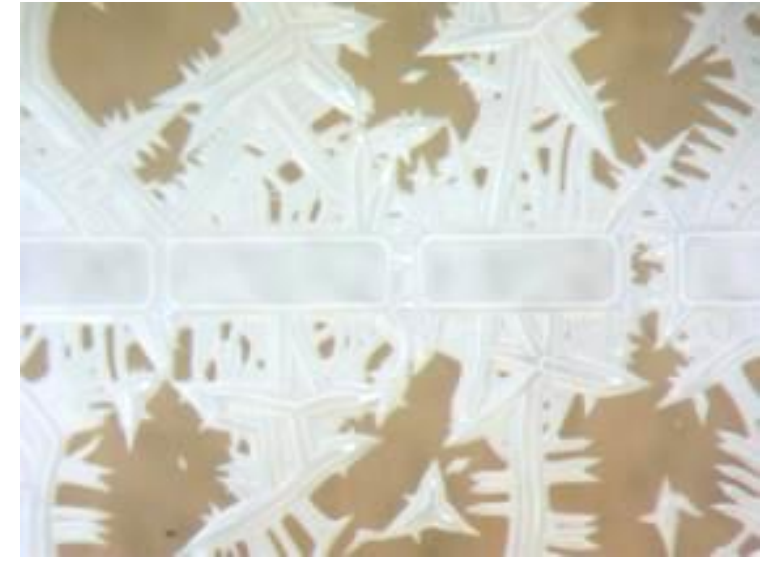

(a)

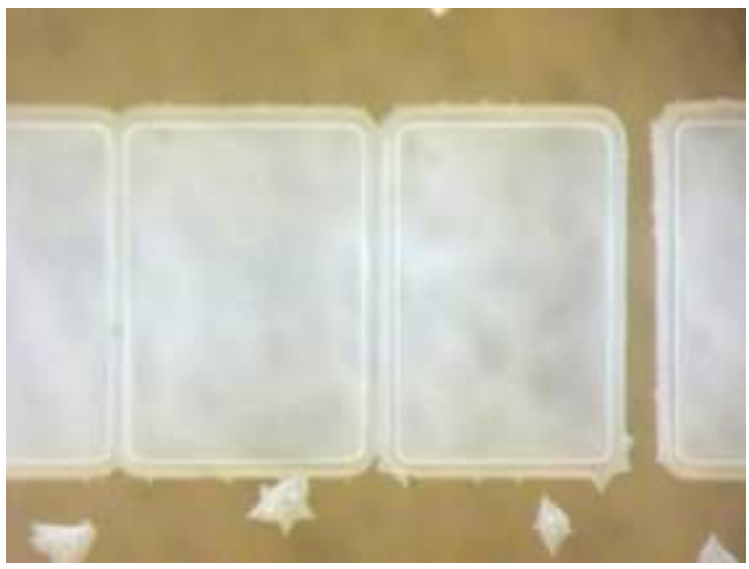

(c)

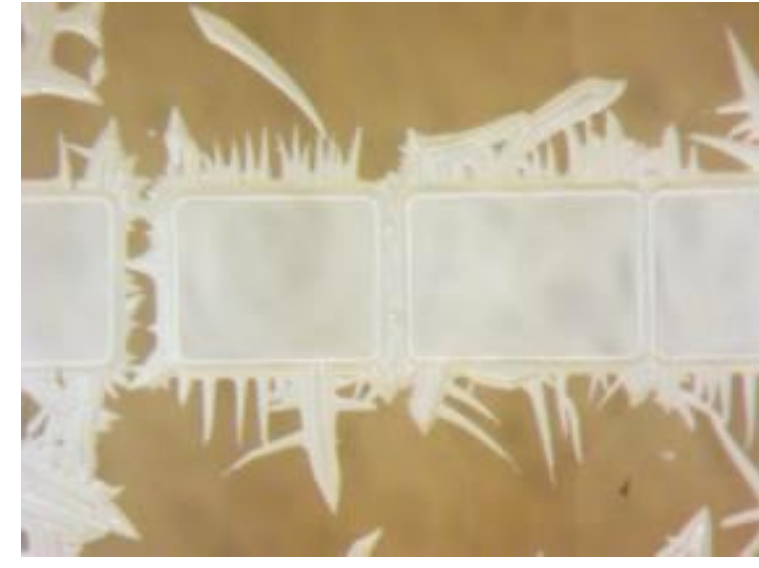

(b)

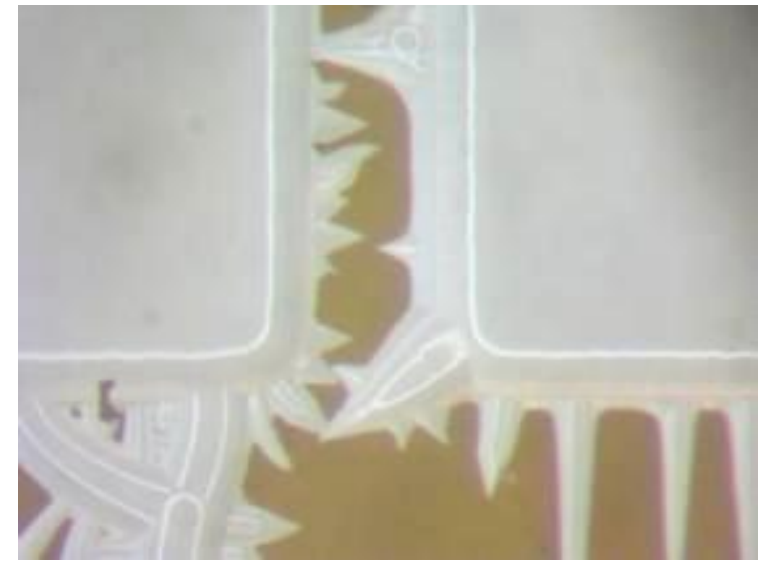

(d)

Figura 79 - Fotos mostrando em detalhe as regiões dos filamentos nos microcanais com largura de (a) $200 \mu \mathrm{m}$, (b) $500 \mu \mathrm{m}$ e (c) $1 \mathrm{~mm}$. (d) Filamento de $200 \mu \mathrm{m}$ de largura no microcanal de $500 \mu \mathrm{m}$ de largura.

É possível observar ranhuras e cavidades bastante profundas ao longo de toda a lâmina, conseqüência da ruptura do filme de a-SiC:H em estágios diversos do processo de corrosão. O tempo total de corrosão foi de 20 minutos, sendo que a cada 5 minutos o processo foi parado para limpeza das lâminas em ultrassom. As lâminas foram colocadas no ultrassom em um copo Becker com água deionizada por poucos segundos para evitar o acúmulo do particulado branco resultante do processo de corrosão.

Levando-se em conta a taxa de corrosão apresentada no item 6.3.1, o processo de corrosão com duração de 20 minutos seria suficiente para deixar auto-sustentados os filamentos com largura de 50 e $100 \mu \mathrm{m}$. Observam-se marcas no substrato de vidro na região onde estariam esses filamentos, indicando a ocorrência de under 
etch, porém todo o filme de a-SiC:H foi removido. A figura $79 \mathrm{~d}$ mostra em detalhes a região do filamento de $200 \mu \mathrm{m}$ de largura no microcanal de $500 \mu \mathrm{m}$ de largura (figura 79b). Fica claro que o filme de a-SiC:H obtido não foi capaz de permanecer autosustentado e que, além disso, a etapa de limpeza em ultrassom pode ter contribuido para a destruição do filme em alguns pontos do substrato.

Estudos mais aprofundados devem ser realizados com o intuito de solucionar essas dificuldades e viabilizar este método de fabricação. Dentre as possíveis causas para os problemas está o estresse residual intrínseco do filme, que pode estar relacionado a uma alteração em sua composição química (por exemplo, caberto de silício rico em Si ao invés de estequiométrico) ou mesmo a um aumento do estresse do filme provocado pela etapa de tratamento térmico para ativação dos dopantes. Outra hipótese levantada é a pequena espessura do filme de a-SiC:H que pode ter deixado-o frágil. A limpeza das lâminas no ultrassom, por também poder ser uma das causadoras dos problemas, deve ser evitada. 


\section{CONCLUSÕES}

Este trabalho apresentou o desenvolvimento de um sensor de vazão térmico integrado a um microcanal. Todo o ciclo de desenvolvimento foi realizado: conceito, modelagem e simulação, fabricação e caracterização.

As simulações com o modelo de elementos finitos mostraram que o sensor responde de modo diferente dependendo da faixa de vazão em que a medida está sendo feita. Assim, foram definidas três faixas de trabalho: $\phi<20 \mu \mathrm{L} / \mathrm{min}, 20<\phi<130 \mu \mathrm{L} / \mathrm{min}$ e $\phi>130 \mu \mathrm{L} / \mathrm{min}$.

Para valores de vazão menores do que $20 \mu \mathrm{L} / \mathrm{min}$, a resposta do sensor é linear e a sensibilidade do sensor é a maior se comparada com as duas outras faixas. A resposta para valores de vazão maiores do que $130 \mu \mathrm{L} / \mathrm{min}$ também é linear, mas a sensibilidade do sensor é cerca de quatro vezes menor do que da outra faixa linear. Para valores de vazão entre 20 e $130 \mu \mathrm{L} / \mathrm{min}$, o sensor encontra-se em uma faixa de transição entre os dois comportamentos lineares. A resposta do sensor nesse caso segue uma lei exponencial.

A análise do campo de temperaturas sobre o sensor, tanto na visualização bidimensional quanto tridimensional, mostrou que fenômenos distintos de transferência de calor são dominantes em cada uma das regiões lineares da resposta. Na faixa de $\phi<20 \mu \mathrm{L} / \mathrm{min}$ a troca de calor é dominada pelo fenômeno da condução entre o filamento e o fluido, tendo a convecção pouca influência sobre a resposta do sensor. Por outro lado, na faixa de $\phi>130 \mu L / \mathrm{min}$, a convecção de calor é o fenômeno de troca de calor dominante. Tais constatações puderam ser verificadas também através da análise do número de Péclet nas duas regiões.

Nas simulações, as temperaturas máxima e média do filamento mantiveram-se bastante baixas, tendo o funcionamento do sensor produzido um acréscimo de temperatura da ordem de $1,5^{\circ} \mathrm{C}$. Esse é um resultado bastante positivo já que esta era uma condição de pré-projeto pois uma das possíveis aplicações para esse sensor é na medida da vazão de fluidos biológicos ou no transporte de espécies 
químicas, as quais têm uma restrição maior com relação ao aumento de temperatura.

Os valores de sensibilidade obtidos indicam que a mínima resolução do sensor de vazão simulado é da ordem de algumas centenas de nanolitros por minuto, não atingindo a expectativa inicial de permitir que vazões da ordem de alguns nanolitros por minuto pudessem ser medidas. Uma forma encontrada de aumentar a sensibilidade do sensor sem a necessidade de reprojetá-lo, foi aumentar a corrente de polarização. A influência da corrente na sensibilidade do sensor segue uma lei exponencial, assim, ao dobrar o valor da corrente de polarização no caso simulado, de $20 \mathrm{~mA}$ para $40 \mathrm{~mA}$, a sensibilidade do sensor aumentou cerca de oito vezes. Por outro lado, a temperatura no filamento também aumenta de forma exponencial com o valor de corrente, o que limita o uso deste recurso como forma de aumentar a sensibilidade. Entretanto, observou-se que o efeito da corrente sobre a temperatura no caso simulado foi menos pronunciado do que o efeito sobre a sensibilidade, tendo o incremento de temperatura do fluido passado de $1,5^{\circ} \mathrm{C}$ para apenas $4,5^{\circ} \mathrm{C}$ (três vezes maior). Sendo assim, em situações como essa, nas quais o incremento de temperatura não é significativo, pode ser vantajoso empregar a artifício de aumentar a corrente de polarização para obter uma melhora na sensibilidade do sensor.

Com relação à fabricação do dispositivo, o método proposto inicialmente, no qual os filamentos de níquel são fabricados diretamente sobre a lâmina de vidro mostrou-se viável e permitiu a fabricação de diversos sensores, tendo como grande vantagem a simplicidade de fabricação. A eletrodeposição de níquel para formação do filamento do sensor produziu bons resultados, embora ainda deva ser otimizada. O principal problema encontrado foi a desuniformidade dos filmes de níquel, que constatou-se estar bastante relacionada com a agitação da solução. A soldagem da tampa de PDMS à lâmina de vidro contendo os filamentos também produziu excelentes resultados. Por exemplo, mesmo tendo passado por diversas etapas de processo antes de ser soldada ao PDMS, o processo de soldagem por plasma dos substratos de vidro funcionou de modo satisfatório, sendo poucos os casos em que as lâminas se soltaram. Ainda com relação a soldagem do PDMS no vidro, um ponto a ser revisto e otimizado é o alinhamento entre os microcanais da tampa de PDMS e os filamentos sobre a lâmina de vidro. Nem mesmo a introdução de margens de 
segurança nas fotomáscaras do processo impediu o desalinhamento entre os microcanais e os filamentos, já que o posicionamento dos microcanais sobre a lâmina de vidro no momento da soldagem é feito manualmente e sem auxílio de microscópio. Por conta disso, muitos dispositivos não puderam ser medidos.

Três sensores com características geométricas diferentes foram caracterizados eletricamente e neles foi possível detectar variações de vazão no interior dos microcanais da ordem de $10 \mu \mathrm{L} / \mathrm{min}$. De fato, as medidas mostraram clara diferença entre os níveis de tensão da resposta elétrica dos sensores quando não há passagem de fluido e quando a vazão no microcanal é ajustada para um dos quatro valores empregados neste estudo (45, 90, 135 e $180 \mu \mathrm{L} / \mathrm{min})$. Neste ponto é importante lembrar que o controle da vazão foi feito através de uma bomba de seringas "home made", desenvolvidas durante este trabalho mas que, por se tratar de um protótipo, não permitiu a realização de medidas em fluxos menores $20 \mu \mathrm{L} / \mathrm{min}$, ou seja, na faixa linear de maior sensibilidade dos sensores.

Os resultados obtidos na caracterização dos sensores foram confrontados com resultados da simulação por elementos finitos e houve discordância entre os valores experimentais e os previstos teoricamente. De fato, a sensibilidade medida nos sensores foi muito superior àquelas previstas nas simulações. Além disso, houve discrepância com relação ao efeito que a diminuição da espessura do filamento causa sobre a sensibilidade do sensor. Dados experimentais mostram que a sensibilidade do sensor aumenta quando a espessura do filamento diminui enquanto que a previsão teórica dizia o oposto. Apesar dessas discrepâncias, o efeito do aumento da largura do filamento sobre a sensibilidade do sensor, do ponto de vista qualitativo, foi o mesmo obtido tanto nas medidas como nas simulações. Além disso, também se constatou que o aumento da largura do filamento acarreta em um aumento na sensibilidade do sensor, o que provavelmente está relacionado à maior área de contato (entre o filamento e o fluido) em que ocorre a troca de calor. $\mathrm{Na}$ prática, é muito difícil construir um modelo que capture todos os fenômenos físicos envolvidos no problema então é natural o aparecimento de diferenças entre os resultados simulados e experimentais.

Alguns problemas foram enfrentados durante a caracterização elétrica do sensor, os quais também podem estar relacionados às discrepâncias observadas quando os 
resultados experimentais são comparados com os resultados simulados. O problema inicialmente encontrado foi a falta de qualidade nos contatos elétricos realizados para caracterizar os sensores. A principal causa desse problema foi a espessura do filme de níquel, que resultaram muito finos para permitir o uso de pontas de prova posicionadas sobre pressão contra os pads. A solução encontrada foi montar os sensores sobre placas de circuito impresso e colar fios sobre os pads utilizando uma resina epóxi condutora. Sobre as placas de circuito impresso foram soldados fios para realização dos contatos elétricos com os equipamentos, diminuindo as resistências parasitárias de contato.

Outro problema enfrentado foi a diferença do nível de offset entre as medidas realizadas num mesmo sensor. Acredita-se que esse problema esteja relacionado à massa térmica relativamente grande do sensor que faz com que cada medida tenha condições iniciais de temperatura diferentes. Outras fontes de erro nas medidas elétricas foram a variação na espessura do filme de níquel que compõe o filamento e as imprecisões nos valores de corrente de polarização e de vazão no microcanal. De fato, foi observado que a fonte de tensão empregada na caracterização elétrica dos sensores produzia pequenas variações na corrente, da ordem de dezenas de nanoampéres, mas que podem ser suficientes para influenciar na resposta do sensor. Testes realizados com a bomba de seringas e não descritos neste trabalho mostraram que, apesar de se tratar de um protótipo, na média a vazão fornecida pela bomba é constante. Outra hipótese levantada para as discrepâncias e eventuais erros nas medidas elétricas é a degradação do filamento com a passagem de valores relativamente altos de corrente por um período longo de tempo, o que se for confirmado, pode representar uma limitação deste tipo de sensor.

Um aspecto importante do trabalho desenvolvido é que foram propostas otimizações em relação ao processo de fabricação inicialmente apresentado, visando aumentar a sensibilidade do sensor através do aumento do isolamento térmico do filamento, o que seria conseguido deixando o filamento auto-sustentado no interior do microcanal. Esse estudo, porém, não foi concluído e apenas resultados preliminares foram obtidos e descritos neste trabalho.

Simulações por elementos finitos mostraram que deixar o filamento auto-sustentado pode produzir uma melhora de até $54 \%$ na sensibilidade do sensor e que o 
comportanto da temperatura do filamento em função da vazão é ligeiramente diferente daquele observado no sensor inicialmente proposto. Contudo, este estudo deve ser continuado para verificar experimentalmente estas previsões.

Ainda no âmbito da simulação numérica, o comportamento estático e dinâmico dos sensores foi estudado com mais detalhes através das simulações do modelo de elementos concentrados proposto neste trabalho.

A resposta estática do modelo mostrou que os parâmetros de sensibilidade do sensor $\left(S_{T}, S_{V}\right.$ e $\left.S_{V / V_{0}}\right)$ melhoram quando a corrente de polarização aumenta, confirmando resultados obtidos na simulação por elementos finitos no caso do sensor inicialmente proposto. O aumento da corrente, entretanto, pode provocar um aumento da temperatura do filamento de até $12^{\circ} \mathrm{C}$ acima da temperatura ambiente (no pior dos casos simulados) e consequentemente, da temperatura do fluido, o que pode eventualmente restringir o uso do sensor. Além disso, as simulações mostram que resposta do modelo é linear enquanto a hipótese de $R e \ll 1$ e $P e \ll 1$ for satisfeita.

O modelo foi validado com sucesso através da comparação com dados experimentais encontrados na literatura (47). Contudo, houve certa discrepância entre os valores de sensibilidade $\left(S_{V}\right)$ obtidos experimentalmente na referência 47 e simulados neste trabalho, os quais forneceram um valor menor que aquele da literatura mesmo com uma corrente de excitação maior. Acredita-se que essa discordância se deva ao fato de ter sido usado no modelo o níquel como material do filamento, que apresenta resistividade muito menor que o silício policristalino utilizado na referência 47.

Com o modelo ajustado para os parâmetros do projeto, a sensibilidade $S_{V}$ foi maior que a obtida pelo modelo de referência baseado nos dados da literatura (47) quando ambos foram ajustados para dissipar a mesma densidade de potência. Para isso, a corrente de excitação do sensor projetado teve que ser ajustada para valores muito elevados (maiores que $100 \mathrm{~mA}$ ) e acabaram provocando um aquecimento do fluido muito maior que aquele do sensor de referência. Desse modo, a razão entre a temperatura e a vazão $\left(S_{T}\right)$ e a sensibilidade normalizada $\left(S_{V / V_{0}}\right)$ do sensor projetado ficaram abaixo daquelas do sensor de referência. 
A análise dinâmica dos sensores mostrou que o sensor projetado tem um tempo de resposta da ordem de $6 \mathrm{~ms}$, ou seja, sua resposta é aproximadamente 200 vezes mais lenta que a do sensor de referência. Isso, bem como a menor sensibilidade normalizada $\left(S_{V / V_{0}}\right)$ apresentada pelo sensor projetado podem estar relacionados a diferenças nas interações térmicas dos dispositivos. De fato, o sensor de referência apresenta uma seção transversal do microcanal menor, o que acarreta em um aumento da velocidade do fluido em relação ao sensor projetado com maior seção. Assim, a troca de calor por convecção é maior no primeiro caso, o que explica o fato da sensibilidade ser maior mesmo com correntes de excitação menores.

Quanto aos processos alternativos de fabricação do sensor, os resultados preliminares mostraram que ao menos dois dos três métodos propostos são viáveis, tendo sido produzidos filamentos que permaneceram auto-sustentados sobre microcanais de até $1 \mathrm{~mm}$ de largura.

No método de fabricação 1, que consistia em empregar o fotorresiste AZ-1518 como material sacrificial sobre o qual os filamentos seriam fabricados, foi possível obter filamentos auto-sustentados, embora não sempre até o final de processo de fabricação. Como os microcanais foram fabricados antes dos filamentos, não houve o risco de danificá-los com a solução de HF. Em alguns casos, porém, a espessura do filme de níquel eletrodepositado foi muito pequena, o que deixou os filamentos muito frágeis a ponto de não suportarem as etapas de remoção dos filmes de titânio e cobre.

A etapa mais importante e também mais crítica nesse método de fabricação é a planarização do fotorresiste. Os resultados mostraram que na região próxima às margens dos microcanais o fotorresiste polido não fica nivelado com a superfície da lâmina de vidro, formando uma pequena depressão. Embora em alguns casos isso não tenha consequências significativas na fabricação dos dispositivos, em outros foi decisivo para o rompimento dos filamentos ainda durante o processo de fabricação. O crescimento do filme de níquel nessas regiões foi dificultado devido ao acúmulo de fotorresiste aplicado durante a fotogravação da geometria dos filamentos. Sem o filme de níquel nessas regiões, os filamentos tornaram-se mais frágeis, já que os filmes de titânio e cobre são muito finos para suportar toda a tensão mecânica 
nessas regiões, e se romperam durante as etapas posteriores de remoção dos filmes de semente e do material sacrificial.

No método de fabricação 2, que empregava duas camadas de carbeto de silício amorfo hidrogenado (a-SiC:H) para recobrir o filamento protegendo-o da corrosão em solução de HF, também foram obtidos filamentos auto-sustentados e foi possível constatar a boa aderência dos filmes metálicos sobre a camada de a-SiC:H. Entretanto, a aderência da segunda camada de a-SiC:H sobre o filamento de níquel precisa ser melhorada já que em diversos trechos das lâminas o filme foi removido durante a corrosão dos microcanais. Uma possível razão é a falta de uma boa cobertura de degrau, como ilustrado na figura 76. A espessura da segunda camada de a-SiC:H é determinada tendo-se em vista a espessura do filme de níquel. Dado que em alguns casos a variação de espessura desse filme ao longo da lâmina foi significativa, a espessura do filme de a-SiC:H depositado pode não ter sido suficiente para recobrir completamente o filamento. Outra hipótese é a diferença de expansão térmica dos filmes de níquel e carbeto. Como a deposição de a-SiC:H é feita a $320^{\circ} \mathrm{C}$, o filme de níquel poderia expandir significativamente mais do que o filme de a-SiC:H durante a deposição da segunda camada de carbeto e, uma vez que a amostra é resfriada após a deposição, surgiriam tensões capazes de romper o filme de a-SiC:H recém-depositado.

Com relação à utilização de filmes de carbeto, um aspecto que deve ser mencionado se refere às ondulações observadas nas regiões onde este filme fica autosustentado, as quais podem estar relacionadas ao estresse mecânico nos filmes. Assim, a adição de uma etapa adicional de recozimento dos filmes de a-SiC:H deve ser considerada. Embora ainda não se saiba quantificar o efeito das ondulações do a-SiC:H sobre a resposta do sensor, é possível que elas deixem o filamento mais frágil mecanicamente, comprometendo a integridade física dos dispositivos, principalmente nas etapas finais de fabricação. Além disso, um método alternativo de limpeza dos microcanais também deve ser estudado, visto que o ultrassom é muito agressivo para os filamentos auto-sustentados.

O método de fabricação 3 , em que os filamentos de níquel foram substituídos por filamentos de a-SiC:H dopado, foi o único que não produziu filamentos autosustentados até o momento. $\mathrm{O}$ estresse mecânico residual do $\mathrm{a}-\mathrm{SiC}: \mathrm{H}$ aliado à 
pequena espessura dos filmes utilizados foram os principais fatores responsáveis por esses resultados. Formas de reduzir o estresse mecânico do filme de a-SiC:H, como por exemplo o recozimento térmico antes mencionado, bem como a manutenção do filme de cromo para proteção do a-SiC:H durante a fabricação dos microcanais em vidro, devem ser estudadas de modo a viabilizar este método de fabricação. 


\section{BIBLIOGRAFIA}

1 WHITESIDES, G.M. The origins and the future of microfluidics. Nature, v. 442, n. 27, p. 368-373, 2006.

2 JANASEK, D.; FRANZKE, J.; MANZ, A. Scaling and the design of miniaturized chemical analyses systems. Nature, v. 447, n. 27, p. 374-380, 2006.

3 DE MELLO, A.J. Control and detection of chemical reactions in microfluidic systems. Nature, v. 442, n. 27, p. 394-402, 2006.

4 DITTRICH, P. S.; MANZ, A. Lab-on-a-Chip: microfluidics in drug discovery. Nature Reviews Drug Discovery, v. 5, n. 3, p. 210-218, 2006.

5 YAGER, P. et al. Microfludic diagnostic technologies for global public health. Nature, v. 442, n. 27, p. 412-418, 2006.

6 ATENCIA, J.; BEEBE, D.J. Controlled microfluidic interfaces. Nature, v. 437, n. 29, 648-655, 2005.

7 KIRBY, B.J. Micro- and Nanoscale Fluid Mechanics: Transport in Microfluidic Devices. Cambridge: Cambridge University Press, 2010. 512 p.

8 BRUUS, H. Theoretical Microfluidics. Oxford: Oxford University Press, 2008. $346 \mathrm{p}$.

9 YARIN, L.P.; MOSYAK, A.; HETSRONI, G. Fluid Flow, Heat Transfer and Boiling in Micro-channels. Berlim: Springer, 2009. 481 p.

10 DOLOMITE MICROFLUIDICS. Homepage. Disponível em: <http://www.dolomite-microfluidics.com/>. Acesso em 19 jun. 2012.

11 MICRONIT MICROFLUIDICS. Homepage. Disponível em: <http://www.micronit.com/>. Acesso em 19 jun. 2012. 
12 YOLE DEVELOPMENT MARKET ANALYSIS. Emerging Markets for Microfluidic Applications. EMMA Report 2011. 2011. Disponível em: $<$ http://www.yole.fr $>$.

13 NEXUS ASSOCIATION. NEXUS Market Analysis for MEMS and Microsystems III. 2009. Disponível em: <http://www.nexus-mems.com/taskforce.asp $>$.

14 BCC RESEARCH. Microfluidics Technology. 2006.

15 YOLE DEVELOPMENT MARKET ANALYSIS. Emerging Markets for Microfluidic Application in Life Sciences and In-Vitro Diagnostics. 2010. Disponível em: < http://mms10.mikrotechnikdortmund.de/downloads/program/29.4._16.45_France_Breussin.pdf>. Acesso em 10 jun. 2012.

16 DO LAGO, C.L. et al. A dry process for production of microfluidic devices based on the lamination of laser-printed polyester films. Analytical Chemistry, v. 75, n. 15 , p. 3853-3858, 2003.

17 MARTINEZ, A.W. et al. Programmable diagnostic devices made from paper and tape. Lab on a Chip, v. 10, n. 19, p. 2499-2504, 2010.

18 I WORKSHOP EM MICROFLUÍDICA. Campinas. Homepage. Disponível em: $<$ http://www.Innano.org.br/workshopmicrofluidica/category/i-workshop-emmicrofluidica/>. Acesso em 19 jun. 2012.

19 II WORKSHOP EM MICROFLUÍDICA. Campinas. Homepage. Disponível em: $<$ http://www.Innano.org.br/workshopmicrofluidical>. Acesso em 19 jun. 2012.

20 BEEBY, S. et al. MEMS Mechanical Sensors. Boston: Artech House Inc., 2004. $281 \mathrm{p}$.

21 TERRY, S. C.; JERMAN, J. H.; ANGELL, J. B. A gas chromatografic air analyzer fabricated on a silicon wafer. IEEE Transactions on Electron Devices, v. ED-26, n. 12, p. 1880-1886, 1979.

22 COLTRO, W. K. T. et al. Microssistemas de análises químicas. Introdução, tecnologias de fabricação, instrumentação e aplicações. Química Nova, v. 30, n. 8, p. 1986-2000, 2007. 
23 GRAVESEN, P.; BRANEBJERG, J.; JENSEN, O.S. Microfluidics - a review. Journal of Micromechanics and Microengeneering, v. 3, n. 4, p. 168-182, 1993.

24 PSALTIS, D.; QUAKE, S.R.; YANG, C. Developing optofluidic technology through the fusion of microfluidics and optics. Nature, v. 442, n. 27, p. 381-386, 2006.

25 THORSEN, T.; MAERKL, S.J.; QUAKE, S.R. Microfluidic large-scale integration. Science, v. 298, n. 5593, p. 580-584, 2002.

26 NGUYEN, N.T. Micromachined flow sensors - a review. Flow Measurement and Instrumentation, v. 8, n. 1, p. 7-16, 1997.

27 MALUF, N.; WILLIAMS, K. An Introduction to Microelectromechanical Systems Engineeging. Norwood: Artech House Inc., 2004. 282 p.

28 WHITE, F.M. Viscous Fluid Flow. Nova York: McGraw-Hill Inc., 1991. 614 p.

29 WHITE, F.M. Fluid Mechanics. Nova York: McGraw-Hill Inc., 2003. 866 p.

30 FISH, J.; BELYTSCHKO, T. A First Course in Finite Elements. Chichester: John Wiley \& Sons Ltd., 2007. 327 p.

31 ZIENKIEWICZ, O.C.; TAYLOR, R.L. The Finite Element Method: Volume 1 The Basis. Oxford: Butterworth-Heinemann, 2000. 692 p.

32 SENTURIA, S. D. Microsystem Design. Nova York: Kluwer Academic Publishers, 2002. 689 p.

33 MADOU, M. Fundamentals of Microfabrication. Nova York: CRC Press, 1997. $589 \mathrm{p}$.

34 XIA, Y.; WHITESIDES, G.M. Soft lithography. Annual Review of Materials Science, v. 28, p. 153-184, 1998. 
35 DUFFY, D. C.; MCDONALD, J. C.; SCHUELLER, O. J. A.; WHITESIDES, G. M. Rapid prototyping of microfluidic systems in poly(dimethylsiloxane). Analytical Chemistry, v. 70, n. 23, p. 4974-4984, 1998.

36 GESCHKE, O.; KLANK, H., TELLEMAN, P. Microsystem Engineering of Labon-a-chip Devices. Weinheim: WILEY-VCH, 2004. 258 p.

37 JULIANA DE NOVAIS SCHIANTI, Sistemas de microcanais em vidro para aplicações em microfluídica. Dissertação de mestrado apresentada a EPUSP, 115 p., 2008.

38 SCHIANTI, J. N.; MIELLI, M. Z.; LOPES, A. T.; CARREÑO, M. N. P. Complete microfluidic system fabricated in glass substrates. ECS Transactions, v. 14, p. 47-56, 2008.

39 JIA, Z.J.; FANG, Q.; FANG, Z.L. Bonding of glass microfluidic chips at room temperatures. Analytical Chemistry, v. 76, n. 18, p. 5597-5602, 2004.

40 SEN, M. Analytical Heat Transfer. Notre Dame: [s.n.], 2008, 222 p. Apostila para a disciplina de graduação e pós-graduação do Departamento de Engenharia Mecânica e Aeroespacial da Universidade de Notre Dame, AME60634: Intermediate Heat Transfer.

41 ROHSENOW, W.M.; HARTNETT, J.P.; CHO, Y.I. Handbook of Heat Transfer. Nova York: McGraw-Hill, 1998. 1344 p.

42 WEIGAND, B. Analytical Methods for Heat Transfer and Fluid Flow Problems. Berlim: Springer, 2004. 258 p.

43 WIKIPEDIA. Water (data page). Disponível em: $<$ http://en.wikipedia.org/wiki/Water (data page)\#cite note-7>. Acesso em: 23 jan. 2012.

44 ALL ABOUT CIRCUITS. Temperature coefficient of resistance. Disponível em: $<$ http://www.allaboutcircuits.com/vol 1/chpt 12/6.html >. Acesso em: 23 jan. 2012. 
45 MASSACHUSETTS INSTITUTE OF TECHNOLOGY. Material Property Database. Disponível em: <http://www.mit.edu/ 6.777/matprops/pdms.htm>. Acesso em: 23 jan. 2012.

46 THE ENGINEERING TOOLBOX. Thermal conductivity of some common materials and gases. Disponível em:

$<$ http://www.engineeringtoolbox.com/thermal-conductivity-d 429.html $>$. Acesso em: 23 jan. 2012.

47 WU, S. et al. MEMS flow sensors for nano-fluidic applications. Sensors and Actuators A, v. 89, n. 1-2, p. 152-158, 2001.

48 OLIVEIRA, A. R.; PEREYRA, I.; CARREÑO, M. N. P. Structural and electrical properties of low-temperature PECVD SiC/c-Si heterostructures. Materials Science and Engineering: B, v. 112, n. 2-3, p. 144-146, 2004.

49 REHDER, G.; CARREÑO, M. N. P. Thermally actuated a-SiC:H MEMS fabricated by a PECVD process. Journal of Non-Crystalline Solids, v. 352, n. 9-20, p. 1822-1828, 2006.

50 PELEGRINI, M. V.; REHDER, G. P.; PEREYRA, I. a-SiC:H films deposited by PECVD for MEMS applications. Physica Status Solidi (c), v. 7, n. 3-4, p. 786$789,2010$.

51 TODD, S. T.; XIE, H. An electrothermomechanical lumped element model of an electrothermal bimorph actuator. Journal of Microelectromechanical Systems, v. 17, n. 1, p. 213-225, 2008.

52 TODD, S. T. Electrothermomechanical modeling of a 1-D electrothermal MEMS mirror. Gainesville: University of Florida, 2005. 124 p.

53 LEAL, L. G. Advanced Transport Phenomena: Fluid Mechanics and Convective Transport Processes. New York: Cambrigde University Press, 2007. $912 \mathrm{p}$.

54 BOUROUINA, T.; GRANDCHAMP, J. P. Modeling micropumps with electrical equivalent networks. Journal of Micromechanics and Microengineering, v. 6 , n. 4, p. 398-404, 1996. 
55 BEDEKAR, A. S. et al. System-level simulation of flow-induced dispersion in labon-a-chip systems. IEEE Transactions on Computer-Aided Design of Integrated Circuits and Systems, v. 25, n. 2, p. 294-304, 2006.

56 ALESSANDRO RICARDO DE OLIVEIRA, Estudo da viabilidade de fabricação de dispositivos semicondutores baseados em filmes de carbeto de silício crescidos por PECVD. Tese de doutorado apresentada a EPUSP, 170 p., 2006. 

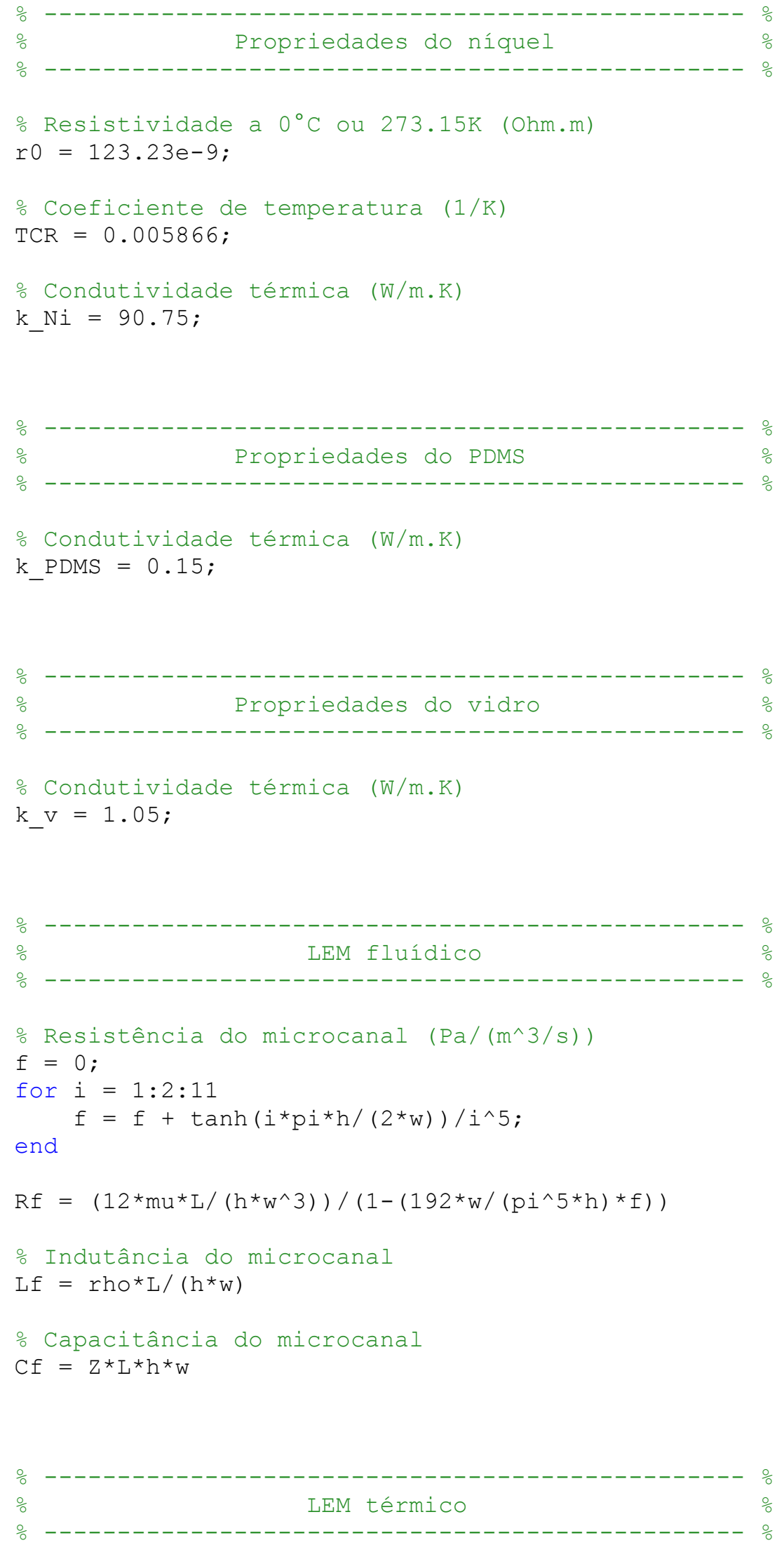

\% Condução filamento-fluido

Rcond_ef $=h /\left(k^{*} w^{\star} a\right)$ 


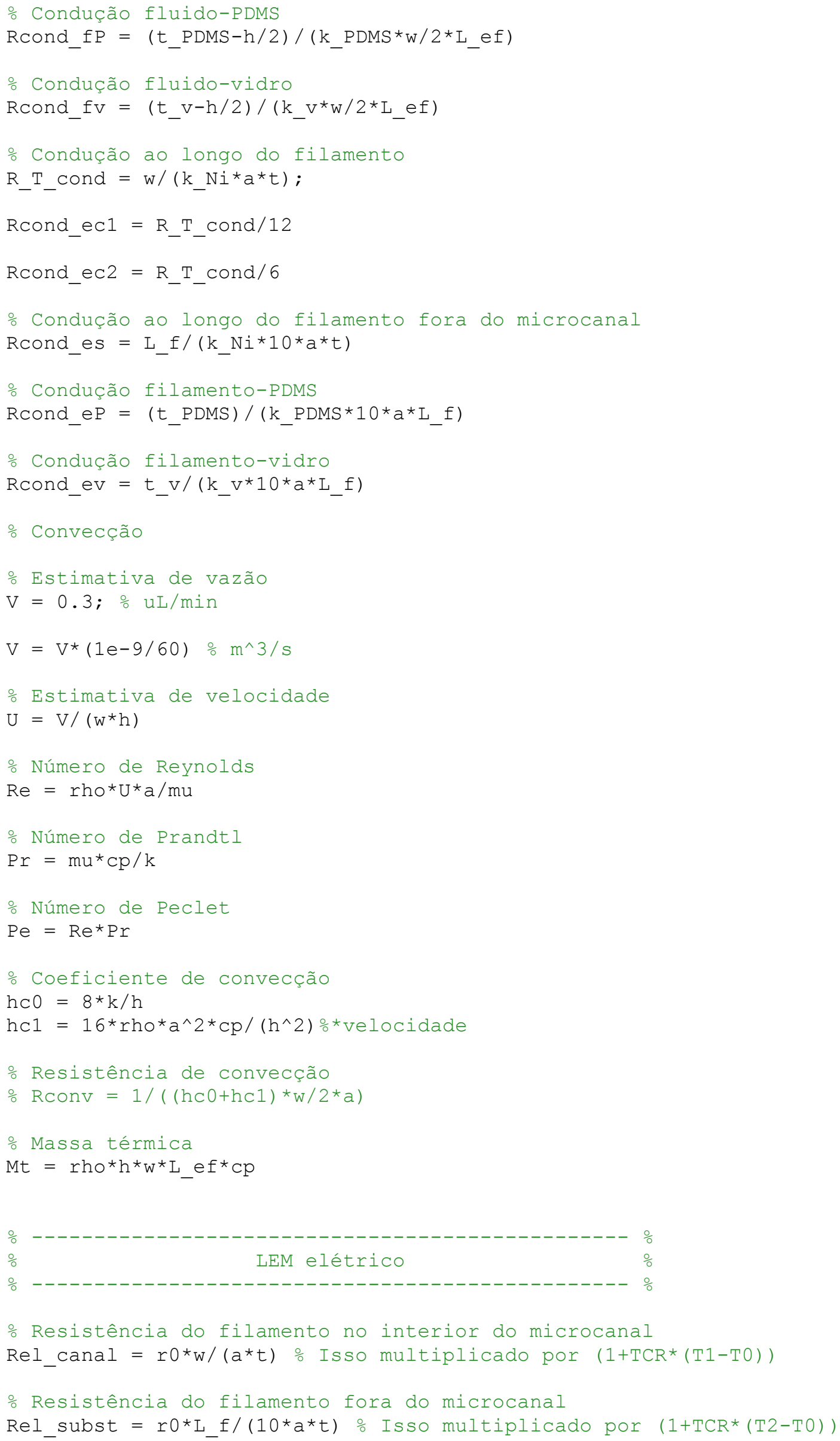

